\title{
WestVirginiaUniversity
}

THE RESEARCH REPOSITORY @ WVU

Graduate Theses, Dissertations, and Problem Reports

2006

\section{Thermal stress in concrete slabs under different constraints}

Dhananjay Rao Hejamadi

West Virginia University

Follow this and additional works at: https://researchrepository.wvu.edu/etd

\section{Recommended Citation}

Rao Hejamadi, Dhananjay, "Thermal stress in concrete slabs under different constraints" (2006). Graduate Theses, Dissertations, and Problem Reports. 4259.

https://researchrepository.wvu.edu/etd/4259

This Thesis is protected by copyright and/or related rights. It has been brought to you by the The Research Repository @ WVU with permission from the rights-holder(s). You are free to use this Thesis in any way that is permitted by the copyright and related rights legislation that applies to your use. For other uses you must obtain permission from the rights-holder(s) directly, unless additional rights are indicated by a Creative Commons license in the record and/ or on the work itself. This Thesis has been accepted for inclusion in WVU Graduate Theses, Dissertations, and Problem Reports collection by an authorized administrator of The Research Repository @ WVU. For more information, please contact researchrepository@mail.wvu.edu. 
Thermal Stress in Concrete Slabs under Different Constraints

Dhananjay Rao Hejamadi

\author{
Thesis submitted to the \\ College of Engineering and Mineral Resources \\ at West Virginia University \\ in partial fulfillment of the requirements \\ for the degree of \\ Master of Science \\ in \\ Mechanical Engineering
}

\author{
Samir Shoukry, Ph.D., Chair \\ Gergis William, Ph.D., Co-Chair \\ Jacky Prucz, Ph.D. \\ Kenneth Means, Ph.D. \\ Mourad Riad, Ph.D.
}

Department of Mechanical and Aerospace Engineering

\title{
Morgantown, West Virginia \\ 2006
}

Keywords: Dowel Bars, Shok Bars, Instrumentation, Finite Element Analysis, Temperature Variations, Environmental Conditions, Pavement Temperature Prediction. 


\title{
ABSTRACT \\ Thermal Stress in Concrete Slabs under Different Constraints
}

\author{
Dhananjay Rao-Hejamadi
}

Previous research has shown that thermal stresses developed in concrete pavements due to daily and seasonal temperature variations may be larger than those induced due to traffic loading. Dowel bars that are used for load transfer at the transverse joints of concrete pavements introduce high stresses at their interfaces with concrete leading to various forms of transverse joint distress. To solve this problem, Shoukry et al (2001) developed an alternative design of dowel bars called "Shok Bar" that was installed by Shoukry and his team in a concrete pavement section placed at the parking lot of WVDOT Maintenance Shop at Goshen Road, WV. The built section was instrumented to experimentally measure the strains developed in concrete slabs.

In the present work, the measured behavior of slabs fitted with Shok bars is studied and compared with that measured for slabs fitted with regular dowel bars. The effect of slabbase friction on the expansion and contraction of concrete slabs is studied. The thermal stresses known to cause the top-down transverse cracking at the mid-slab were investigated. The results indicate that the new dowel bar design reduces the concrete slab strains especially during the initial stages of concrete setting. The Shok bars reduce permanent residual strain in the slab, lower the axial forces in the dowels considerably and help in relieving curling stresses in the pavement. The measured data show that slabs fitted with Shok bars have symmetrical joint opening compared with those slabs that were fitted with regular dowel bars.

In this study the thermal diffusivity theory was used to develop a method to calculate the temperature and the thermally induced strain at different depths through the slab thickness given the time history of weather parameters: air temperature, solar radiation, relative humidity, and wind velocity. While previous research efforts were limited to sunny and clear days, this method is capable of calculating the slab temperature for a 24 hour period and also for a sequence of days including days with light rain and cloud cover. The effects of snow cover on the slab and heavy rainfall on the method have been discussed. Equations for the strains developed at the slab top and bottom were presented. The temperatures calculated by the method were compared with the values measured from the test slabs. The results from the proposed model were found to be in reasonable agreement with the experimentally measured data from the slabs. 


\section{ACKNOWLEDGEMENTS}

I express my sincere gratitude to my advisor, Dr. Samir Shoukry for taking me as a research assistant and providing me with the opportunity to work with him and his team. His timely advice and encouragement kept me working hard at my research. I appreciate his foresight and never ending stream of ideas. Under Dr. Shoukry's guidance I have broadened my technical knowledge by taking some interdisciplinary courses.

I also thank Dr. Gergis William and Dr. Mourad Riad for their expert guidance and patience in discussing difficult technical issues. Dr. William's expertise in Finite Element analysis and data analysis and Dr. Riad's experimental knowledge has helped me greatly in this work. Without their contribution this thesis would have been nearly impossible to complete.

I thank my office mates Praveen, Dony and Thomas for making work in office a lot of fun. The innumerable discussions I had with Praveen helped me greatly while working on the equation to predict slab temperatures from weather parameters.

I would like to thank my friends Mahesh, Shashi, Ashwin, Amar, Karthik, Bala, Deepika and Bhuvi for their constant support and encouragement.

I thank my family immensely without whose support and love, I could not have completed the research work and my Masters.

I would finally like to thank the WV Department of Transportation, Division of Highways for funding the project. 
TABLE OF CONTENTS

$\begin{array}{lr}\text { ABSTRACT } & \text { ii } \\ \text { ACKNOWLEDGEMENT } & \text { iii } \\ \text { TABLE OF CONTENTS } & \text { iv } \\ \text { LIST OF FIGURES } & \text { vi } \\ \text { LIST OF TABLES } & \text { viii }\end{array}$

CHAPTER ONE INTRODUCTION

1.1 Background 1

1.2 Problem Statement 2

1.3 Research Objectives 3

1.4 Thesis Outline $\quad 4$

CHAPTER TWO LITERATURE REVIEW

2.1 Introduction 6

2.2 Jointed Slabs with Regular Dowel Bars 8

2.3 Jointed Slabs with Shok Bars 9

2.4 Friction Between Slab and Base 11

2.5 Finite Element Modeling $\quad 11$

2.5.1 2D FE Models 11

2.5.2 3D FE Models 12

2.6 Prediction of Slab Performance from Weather Data 14

$\begin{array}{lll}2.7 & \text { Summary } & 17\end{array}$

CHAPTER THREE FIELD INSTRUMENTATION

3.1 Introduction 18

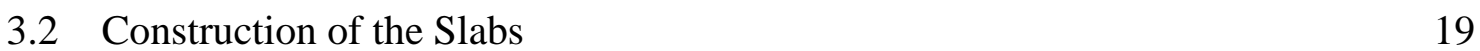

3.3 Instrumentation and Data Acquisition System 21

3.4 Data Acquisition 26

3.5 Weather Station 27

\section{CHAPTER FOUR EXPERIMENTAL DATA ANALYSIS}

$\begin{array}{lll}4.1 & \text { Introduction } & 29\end{array}$

4.2 Longitudinal Strains $\quad 29$

4.2.1 Slab Jointed with Dowel Bars $\quad 29$

4.2.2 Slabs Jointed with Shok Bars 30

4.2.3 Free Slab on Low Friction Base (Smooth Base) 34

4.2.4 Free Slab on High Friction Base (Coarse Base) 34

4.3 Contributers to Slab Volumetric Change 37

4.4 Mid Slab Stresses $\quad 41$

4.5 Bending Moment and Axial Forces in the Bars 45

4.5.1 Bending Moments 46

4.5.2 Axial Forces $\quad 47$

4.6 Axial Forces Along the Transverse Joint 49

4.7 Bending Moments along the Transverse Joint 53 


\section{CHAPTER FIVE 3D FINITE ELEMENT ANALYSIS}

5.1 Introduction $\quad 57$

5.2 Finite Element Models $\quad 57$

5.2.1 Free Slab On Smooth Base $\quad 57$

5.2.2 Free Slab On High Friction Subgrade $\quad 59$

5.2.3 Slab Fitted With Regular Dowel Bars 60

5.2.4 Slab Fitted With Shok bars 63

$\begin{array}{lll}5.3 & \text { Thermal Loading } & 63\end{array}$

5.4 Comparison Of The Concrete Strains 65

5.4.1 Thermal Stresses Estimated By 3D FE 75

$\begin{array}{lll}5.5 & \text { Summary } & 78\end{array}$

\section{CHAPTER SIX PREDICTION OF SLAB TEMPERATURES AND STRAINS} FROM ENVIRONMENTAL CONDITIONS

6.1 Introduction 79

6.2 Certain Observations made Relating Weather Conditions and Slab Response 80

6.2.1 Accumulation of Snow on Pavement 81

6.2.2 Occurrence of Non-Linear Temperature Gradients Through the Slab 81

6.2.3 Solar Radiation Through the Year 84

6.3 Pavement Temperature Calculations 85

6.3.1 Heat Transfer Model 85

6.3.2 Thermal Diffusion Theory: Barber (1957) 87

6.3.3 Thermal Diffusion Theory: Modified Barber’s Equations 88

6.3.3.1 Parametric Multipliers 89

6.3.3.2 Temperature Below Slab Surface $\quad 91$

6.4 Results and Discussion 93

6.4.1 Comparison Among the Three Models 93

6.4.2 Examples Using Modified Barber's Equation 96

6.4.3 Prediction of Slab Temperature During Extreme Weather Conditions 105

6.4.4 Effect of Fabric Sheet Between Slab and Subgrade 111

6.4.5 Error Analysis of Calculated Temperatures 112

$\begin{array}{ll}\text { 6.4.6 Calculation of Strains } & 114\end{array}$

$\begin{array}{lll}\text { 6.4.7 Error Analysis } & 118\end{array}$

\section{CHAPTER SEVEN CONCLUSIONS AND RECOMMENDATIONS}

$\begin{array}{lll}7.1 & \text { Conclusions } & 119\end{array}$

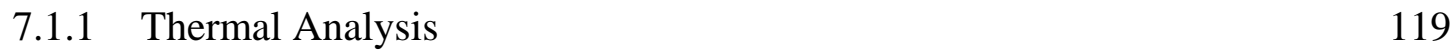

7.1.2 Slab Temperature and Strain Prediction 120

$\begin{array}{lll}7.2 & \text { Future Work } & 121\end{array}$

$\begin{array}{ll}\text { REFERENCES } & 123\end{array}$

$\begin{array}{ll}\text { APPENDIX } & 127\end{array}$ 


\section{LIST OF FIGURES}

Figure 2.1: Design of Shok bar $\quad 10$

Figure 3.1: Layout of the Test Site $\quad 20$

Figure 3.2: Stage I of Test Slabs Construction: Installing the Steel Anchors 20

Figure 3.3: Instrumentation plan of Jointed Slab $\quad 22$

Figure 3.4: Location of Sensors on Dowel Slab. 23

Figure 3.5: Instrumentation of Regular Dowels and Shok Bars 25

Figure 3.6: Calibration of Instrumented Dowel Bars. 26

Figure 3.7: Data acquisition system $\quad 27$

Figure 3.8: Weather station 28

Figure 4.1: Longitudinal Strains and Temperature Histories Measured at 1.5” from Top Surface of the Slab Fitted with Dowel Bars.

Figure 4.2: Longitudinal Strains and Temperature Histories at 1.5” from Bottom Surface of the Slab fitted with Dowel Bars. 32

Figure 4.3: Longitudinal Strain Histories in the Slab Fitted with Shok Bars. 33

Figure 4.4: Longitudinal Strain Histories Measured in the Free Slab on Smooth Base. 35

Figure 4.5: Longitudinal Strain Histories Measured in the Free Slab on Coarse Base. 36

Figure 4.6: Strain versus Temperature Change in Different Slabs 37

Figure 4.7: Strains $/{ }^{\circ} \mathrm{C}$ along the longitudinal axis of the slabs. 40

Figure 4.8: Components of temperature change (Temperature Increase). 41

Figure 4.9: Stresses Developed in Concrete During the first Three Days. 44

Figure 4.10 Time History of Mid-Slab Stresses Developed in the First 28 Days. 45

Figure 4.11: Positive and negative strains in the bars. $\quad 45$

Figure 4.12: Average Bending Moments and Axial Forces in Bars at joint 48

Figure 4.13: Average Bending Moments and Axial Forces in Bars at Wheel Path 48

Figure 4.14: Average Bending Moments and Axial Forces in Bars at Slab Corner. 49

Figure 4.15: History of the Measured Mean Slab Temperature. $\quad 50$

Figure 4.16: Axial Forces along the joint between slabs 1 and 2.

Figure 4.17: Axial Forces along the Joint between Slabs 2 and 3.

Figure 4.18: Tension in Dowel Bars due to Temperature Increase. 51

Figure 4.19: Axial Forces along the joint between slabs 3 and 4.

Figure 4.20: Bending Moments in Dowel Bars along the Joint between Slabs 1 \& $2 . \quad 54$

Figure 4.21: Bending Moments in Dowel Bars along the Joint between Slabs 2 \& $3 . \quad 54$

Figure 4.22: Bending Moments in Dowel Bars along the Joint between Slabs 3 \& $4 . \quad 55$

Figure 4.23: Joint opening plots. $\quad 56$

Figure 5.1: 3D FE Model for a Free Slab on Low Friction Subgrade 58

Figure 5.2: Uneven Mesh at the Slab - Subgrade Interface. $\quad 60$

Figure 5.3: Slab Fitted With Dowel Bars. $\quad 61$

Figure 5.4: Dowels Fitted To Slab Edge $\quad 62$

Figure 5.5: Magnified image of Shok Bars Fitted to Slab Edge. 62

Figure 5.6: Linear gradient along with uniform temperature change 63

Figure 5.7: Linear Temperature Gradient through Thickness of slab Vs Uniform

Temperature change in the slab

64

Figure 5.8: Longitudinal Strains vs Temperature Gradient Near Transverse Edge of Free

Slab on Smooth Base. 
Figure 5.9: Longitudinal Strains vs Temperature Gradient at the Center of Free Slab on Smooth Base.

Figure 5.10: Longitudinal Strains vs Temperature Gradient near Transverse Edge of Free

Slab on Coarse Base.

Figure 5.11: Longitudinal Strains vs Temperature Gradient at the Center of Free Slab on Coarse Base.

Figure 5.11a: Deformation of slab under positive temperature gradient - FE results 69

Figure 5.12: Longitudinal Strains vs Temperature Gradient near Transverse Joint of Slab Fitted with Dowel Bars.

Figure 5.13: Longitudinal Strains vs Temperature Gradient at the Center of Slab Fitted with Dowel Bars.

Figure 5.14: Longitudinal Strains vs. Temperature Gradient near Transverse Joint of Slab Fitted with Shok Bars.

Figure 5.15: Longitudinal Strains vs. Temperature Gradient at the Center of Slab Fitted with Shok Bars.

Figure 5.16: Bending Moment of Dowel Bar at Slab Wheel-Path. 74

Figure 5.17: Bending Moment of Dowel Bar at Joint Center. $\quad 74$

Figure 5.18: Bending Moment of Dowel Bar at Slab Corner. $\quad 74$

Figure 5.19: Longitudinal Stress along slab centerline - Temperature Drop of $-10^{\circ} \mathrm{C} \quad 76$

Figure 5.20: Longitudinal Stress along slab centerline - Temperature Drop of $-20^{\circ} \mathrm{C} \quad 77$

Figure 6.1: Parameters affecting slab performance

Figure 6.2: Variation of Slab surface and air temperature during snow accumulation $\quad 81$

Figure 6.3: Occurrence of nonlinearity through the day 82

Figure 6.4: Magnitude of $2^{\text {nd }}$ Coefficient during rainy days 83

Figure 6.5: Solar radiation received during a typical day of the month 84

Figure 6.6: Temperature and Solar radiation during a day 85

Figure 6.7 a: Heat transfer model $\quad 94$

Figure 6.7 b: Barber's original equation $\quad 94$

Figure 6.7 c: Modified Barber's equation 95

Figure 6.8: Measured and calculated temperatures at different depths (Feb/Mar 2004) 97

Figure 6.9: Measured and calculated temperatures at different depths (Mar/Apr 2004) 98

Figure 6.10: Measured and calculated temperatures at different depths (Apr 2004) 99

Figure 6.11: Measured and calculated temperatures at different depths (May 2005) 100

Figure 6.12: Measured and calculated temperatures at different depths (June 2005) 101

Figure 6.13: Measured and calculated temperatures at different depths (July 2005) 102

Figure 6.14: Measured and calculated temperatures at different depths (Aug 2005) 103

Figure 6.15: Measured and calculated temperatures at different depths (Sept 2005) 104

Figure 6.16: Measured and calculated temperatures at different depths (October 2005)105

Figure 6.17: Over prediction of slab temperature during heavy rains 106

Figure 6.18: Under prediction of slab temperature during rains 107

Figure 6.19: Error in prediction during snowfall 108

Figure 6.20: Gradient difference during rains 109

Figure 6.21 a-d: Conditions on March 2 and $3 \quad 110$

Figure 6.21 e: Solar radiation on March 2 and $3 \quad 110$

Figure 6.22: Probability distribution function (PDF) of error 113

Figure 6.23: Examples of calculated and measured longitudinal strains 117 


\section{LIST OF TABLES}

Table 4.1: Slope and Intercepts of the Linear fits to the Strain Versus Temperature. 39

Table 5.1: Material Properties Used for the FE Model

59

Table 6.1: Values of parameter $\mathrm{p}$ for each month

89

Table 6.2: Statistical error analysis

111

Table 6.3: Factors $\alpha_{\text {exp }}, \varepsilon_{\mathrm{r}}$ and $\varepsilon_{\mathrm{v}}$ for different slabs

114

Table 6.4: Statistical analysis of error between calculated and measured strains

118 


\section{CHAPTER ONE \\ INTRODUCTION}

\subsection{BACKGROUND}

During the course of their service, concrete pavements are subjected to various conditions of traffic loads, changes in moisture and temperature variations. Temperature and moisture gradients occurring through the slab thickness are due to daily and seasonal environmental variations and produce inevitable cracking throughout the pavement length (McGhee, 1995; NCHRP, 1973). The formations of these cracks were controlled by introducing joints along the pavement to alleviate the slab movement during contraction and expansion which relieves the stresses caused by the restrained motion of the concrete material. The transverse joints helped regulate the formation of transverse cracks but increased the deflections and bending stresses along the slab edges. To overcome the excessive stresses developed at the joint edges under traffic conditions, load transfer devices were provided to transfer the wheel loads to adjoining slabs. Epoxy coated steel dowel bars are the most commonly used load transfer devices. Dowel bars assisted in distributing the wheel load on one slab to the adjacent slab thus reducing the flexural stresses and deflections in the slab edges (Westergaard, 1929).

In addition to transferring dynamic loads, dowels are also instrumental in reducing curling of slab edges due to curing as well as temperature and moisture gradients across slab thickness. Doweled joints enhance the pavement performance; however stresses developed in rigid pavements are still attributed to joint imperfections. Dowel bars transfer a portion of the wheel load to the adjacent slab through shearing force and bending moments in the dowels as a vehicle passes over the dowel jointed pavements. During this load transfer, the dowel bar creates zones of stress concentrations around the dowel when it comes in contact with the surrounding concrete material (Shoukry et al., 1998). Besides the compressive stress zone formed at the contact portion between the dowel and the surrounding concrete, Shoukry et al. (2002) showed the formation of two tensile stress zones on either sides of the dowel. The magnitude of such 
tensile stress is high enough to initiate cracks at the concrete-dowel interface. In addition to this, looseness is created in the areas of contact between the dowel and concrete over cycles of pavement loading. This looseness or void spaces are prone to increase after a significant number of vehicles have passed over the joint. The existence of such void deteriorates the ability of dowels to transfer the load effectively. These findings led Shoukry et al to develop a new dowel design called the Shok Bar which was pending for patent in 1998. The details of the Shok bar have been discussed in other publications (Shoukry et al. 2001, 2002, 2004). The Shok bar aims at reducing the stresses that would develop between the dowel and the concrete pavement. The idea behind a new design of

the dowel was to formulate a better shape and material in the region of high tensile and compressive stresses that would provide better distribution of stresses thus eliminate their severity. The performance of the Shok bar was assessed after conducting basic laboratory experiments for static, dynamic, and fatigue loading and its proper geometrical dimensions were optimized (Shoukry et al. 2003). The promising results obtained from lab testing of simulated joints led to the field investigation of performance of Shok bars under combined axle and environmental loading configurations. Concrete test slabs were constructed and instrumented off Goshen Road, WV to access the performance of the Shok bars with respect to the regular dowel bars in field conditions.

\subsection{PROBLEM STATEMENT}

Concrete pavements respond continuously to the variations in temperature and moisture changes. These seasonal and daily variations build up thermal stresses in the concrete that result in deterioration of the slabs. Extensive research has been done to assess the performance of dowel bars in the presence of temperature variations along with traffic loads.

Westergaard (1927) suggested that the thermally induced stresses can be superimposed with those calculated due to traffic loading when designing the concrete pavements. But the effect of thermal stresses was not accounted for in the mechanistic design procedures of rigid pavements (Huang, 1993). Pavements designers preferred to 
ignore temperature induced stresses arguing that the joints provided between slabs will relieve any thermal stress developed. They believed the stress reversals due to traffic loading were of more importance than the reversals due to temperature induced slab curling. However, recent studies both experimental and analytical (Sargand 1997; William and Shoukry, 2001) have shown otherwise. Later, the AASHTO Supplement for concrete pavement design incorporated the induced flexural stresses due to temperature differential through the slab thickness in the design of concrete pavements (AASHTO, 1998).

The environmental effects on pavements can be more adverse than the traffic loading. An accurate prediction of the temperature gradients and stresses in concrete pavements is useful in the design of the slabs. When continuous monitoring of the stress

levels in the pavement are required, expensive instrumentation of the slabs may be needed. To avoid dense instrumentation and to predict the temperature gradients and strains in the slab it is helpful to be able to relate and calculate these parameters from the environment conditions in the region. The monitoring of the slabs requires the calculation of strains round the year irrespective of the weather conditions. A method to achieve this goal was attempted and reported in the present work.

\subsection{RESEARCH OBJECTIVES}

The main objective of this study is to determine the state of thermal stress developed in concrete slabs under different constraints. The constraints considered are end restraints due to regular dowel bars and Shok bars and frictional constraints presented by the friction between the slab and a coarse base. In order to accomplish this objective, test slabs were constructed and instrumented by Shoukry (2004) and his research team. The involvement of the author of this thesis is limited to collection and analysis of data obtained from the site. A number of techniques are used to extract information out of the available raw data. Finite Element Analysis is used to simulate the slabs and predict its behavior under various conditions of temperature variations. The study also attempts to bring out the operational effectiveness of Shokbars with respect to regular dowel bars. 
The second important study is the development and validation of a relation which correlates the weather elements to the temperature gradient across the slab thickness and in turn the strains in the concrete pavement. An attempt has been made to construct a generic equation which would be applicable to most weather conditions and calculate the pavement temperature and strain levels in real time or near real time. The equation presented here calculates the surface temperature which in turn is used to calculate temperatures in the slab interior by numerically solving the partial differential heat equation. Equations for the temperature related strains in the pavement are also presented.

\subsection{THESIS OUTLINE}

The following chapters in this thesis document the work done to reach the above said objectives.

Chapter Two is a literature review of the previous efforts in computing the thermal stresses in concrete pavements. The various methodologies and results obtained including finite element modeling of slabs have been presented. Reasons for the evolution of Shokbar have been discussed. Earlier research work in correlating weather conditions to performance of concrete pavement is also presented.

Chapter Three describes the construction and instrumentation of the test slabs used in this study. The stages in slab construction and the type of base/slab interface laid are discussed. The various instruments embedded in the concrete slabs along with their locations and details of the weather station have been presented.

Chapter Four details the various techniques employed to understand and evaluate the behavior of the slabs. The chapter discusses how the raw data from the site was processed to obtain meaningful data and what results obtained from these techniques. 
Chapter Five describes the 3D - finite element modeling of the slabs, their validation technique and results derived from the finite element analysis. The assumptions and approximations used while validating the FE models are described.

Chapter Six discusses the development of an equation which calculates temperatures of the pavement in near real time. The temperatures thus calculated were used to calculate the strains in the concrete. The calculated temperatures and the strains were compared with the measured values from the instrumented test slabs.

Chapter Seven summarizes the conclusions made out these studies and offers a few recommendations for future work. 


\section{CHAPTER TWO \\ LITERATURE REVIEW}

\subsection{TEMPERATURE EFFECTS ON CONCRETE PAVEMENTS}

Mahboub et al (2004) measured the pavement response under three loading conditions, under environmental loads alone, then under environmental loads plus static vehicle loads, and finally, under environmental loads plus moving vehicle loads. The study demonstrated that environmentally induced pavement responses overshadowed the traffic-induced responses. The change in strain induced by traffic load is approximately less than $20 \%$ of the change due to temperature flux for a specific day and time. They recommend the inclusion of effects due to temperature cycles in the design of concrete pavements which currently are almost exclusively based on traffic loads.

The first in-depth study of temperature related stresses in rigid concrete pavements, dates back to the early 1900's. Westergaard published two papers related to estimation of stresses in concrete pavements. The first one related wheel loads to the stresses and deflections in the pavement (Westergaard, 1926), the second is the analysis of stresses due to variations of temperature (Westergaard, 1927).

Westergaard (1927) divided the thermal stresses into two components. The first arises from a consideration of the slow seasonal changes of temperature, which he classifies and studied under the heading "Uniform Decrease of Temperature". The second one considers the quick changes of temperature, occurring, for example, by the change from a cold night to a hot day and vice versa which was treated under the heading "Curling". The curing stresses develop due to the linear thermal gradient through the thickness of the slab. It is assumed that the temperature remains normal at the middle plane of the pavement and temperature at the slab top is different from the slab bottom. These two major components of thermal stresses were combined by algebraic addition to obtain the overall stress in the slab due to temperature variations. 
For slabs constructed with transverse joints, the stress induced by uniform temperature change was suggested as due to slab-base friction arising only from the significant volume change of the slab. This stress is small according to the subgrade drag theory (Yoder and Witczack, 1975) compared to the curling stress due to temperature gradient. Thus, the stress due to uniform temperature change is generally ignored during pavement design. However, in the case of dowel jointed pavements, William and Shoukry (2001) showed that the stresses due to the uniform temperature change forms the larger part of the thermal stress in the slab. Their results showed that as the temperature gradient and the uniform temperature change take place simultaneously, the dowel bars are bent while the slab is contracting. The bent dowels act as anchors that restrict the slab from contraction. Subsequently, the restraints from the bent dowels will cause the stresses in the slab to change with every degree of uniform temperature increase or decrease.

Contrary to what Westergaard assumed in his work, the measured temperature profiles through the concrete slab are nonlinear (Teller and Sutherland, 1935). To account for the effect of the nonlinearity, Tomlinson (1940) added a new stress component to those suggested by Westergaard. Due to such nonlinearity in the temperature gradient, various fibers of the slab cross-section tend to expand (or contract) with different amounts. However, the main assumption in the elastic plate theory is that the cross-section of a plate remains plane after bending. The different fibers will exert a restraining action on each other producing additional stresses in the slab. Such stresses were assumed to be due to self-equilibrating dummy external forces, which mean the total force on any slab cross-section is zero, so that it causes neither axial deformation nor curling in the concrete slab but contributes to the maximum tensile or compressive stress acting on the top or bottom of the slab. Choubane and Tia (1995) suggested the consideration of the nonlinear temperature distribution throughout the concrete slab depth rather than the temperature differential between the extreme slab fibers and concluded that the nonlinearity can be represented fairly well by a quadratic equation. 


\subsection{JOINTED SLABS WITH REGULAR DOWEL BARS}

Westergaard (1929) proposed the design of doweled joints by computing the shearing force in each active dowel bar along the transverse joint, as well as the critical stresses that occur in the slab under edge loading. This study was based on simplifying assumptions, as to the rigidity of dowels, and assumed equal deflections on both sides of the joint. He concluded that only the first two dowel bars located at each side of a point load applied at the joint edge are active in transferring the load to the adjacent slab. This conclusion was supported by the experimental results reported by Sutherland (1940). However, Friberg (1938) put forth that the dowels that fall at a distance lesser than 1.8 times the radius of relative stiffness only take part in the load transfer.

An early attempt to determine analytically the proper diameter, length, and spacing of dowels was conducted by Bradbury (1938). In his study, Bradbury developed a formula based on Timoshenko's equation (1925) of bending of bars on elastic foundations to calculate the required dowel length. He also suggested that increasing the dowel diameter, and smaller spacing were required. Although Timoshenko's analysis was not very useful for many researchers who studied the stress condition existing in and around the dowel bars later on, it required determination of a parameter (namely Modulus of dowel support, K) that was difficult to quantify with any degree of accuracy. Additionally, it does not take into account the possibility of separation between the dowel bar and the surrounding concrete.

The introduction of finite element modeling offered great capabilities that were not available before, for in-depth studies of the behavior of dowel bars. Using finite element simulation of doweled joints, Tabatabaie (1978) concluded that only the dowels within distance of the radius of relative stiffness $(\ell)$ are effective to transfer the load. Realizing that the effectiveness of the dowels to transfer loads relied on the state of contact at the dowel-concrete interface, more research was conducted to determine the bearing stresses on top and bottom of the dowels. 
Shoukry et al. (2002) found that dowel bars at transverse joints introduce significant restraints to the slab contraction due to uniform temperature decrease. Dowel bending is the main cause of this restrain so that mid-slab stress remains high even with the presence of an initial concrete dowel clearance. They further investigated the combined effect of thermal gradient and heavy vehicle joint axle loading on dowel jointed pavements. It was reported that while axle load has a significant influence on the stress at the point of load application, its effect on the mid slab stress is small compared to the effect of temperature variations.

\subsection{JOINTED SLABS WITH SHOK BARS}

Shoukry and William (2001) studied the state and magnitude of stress concentration around dowel bars. The detailed 3DFE modeling of rigid pavements revealed the existence of tensile stress concentration zones that lay on both sides of the loaded dowel along with a zone of compressive stress concentration that lay either on top or bottom of the dowel bar. This finding agreed with the observation of Friberg (1938) who noticed the formation of fan-shape cracks around the loaded dowel bars. The 3DFE modeling study by Shoukry et al. showed that although the magnitude of this tensile stress decays significantly as the distance from the joint face increases, the tensile stress concentration reaches a high value at the joint face and causes cracks on both sides of the dowel. These findings were also verified through experimental testing on simulated doweled joint specimens subjected to static, dynamic and fatigue loading (Shoukry et al. 2001; 2004). In the same study they found that better quality of concrete, increase in the slab thickness or increase in dowel diameter did not lead to any significant reduction in the concrete contact stresses magnitudes. Thus a new dowel design "Shokbar" was developed aiming at reducing the magnitude of contact stresses, and preserve the load transfer efficiency of doweled joints through the service life of pavement.

Both closed form solutions (Friberg, 1938) and 3DFE analysis (Shoukry et al., 2002; David, 2002) showed that contact stress around the dowels decay to a minimum value within a distance of 2 inches from the joint face. It was observed that these stresses 
lay within a radial distance of 0.25 inches of the dowel (Shoukry and William, 1998, 2001; Shoukry et al. 2002). Thus to reduce these stresses the Shok bar included two 1.5 inch internal diameter, 0.25 inch thick and two inch long protective sleeves around the dowel which bond permanently to the surrounding concrete, while allowing the dowel to slide freely in them as shown in Figure 2.1. The Shokbar was designed such that each sleeve embeds itself in the jointed slabs. Sleeve material with better characteristics than regular concrete was used in order to resist the loads applied by dowel bar contact.

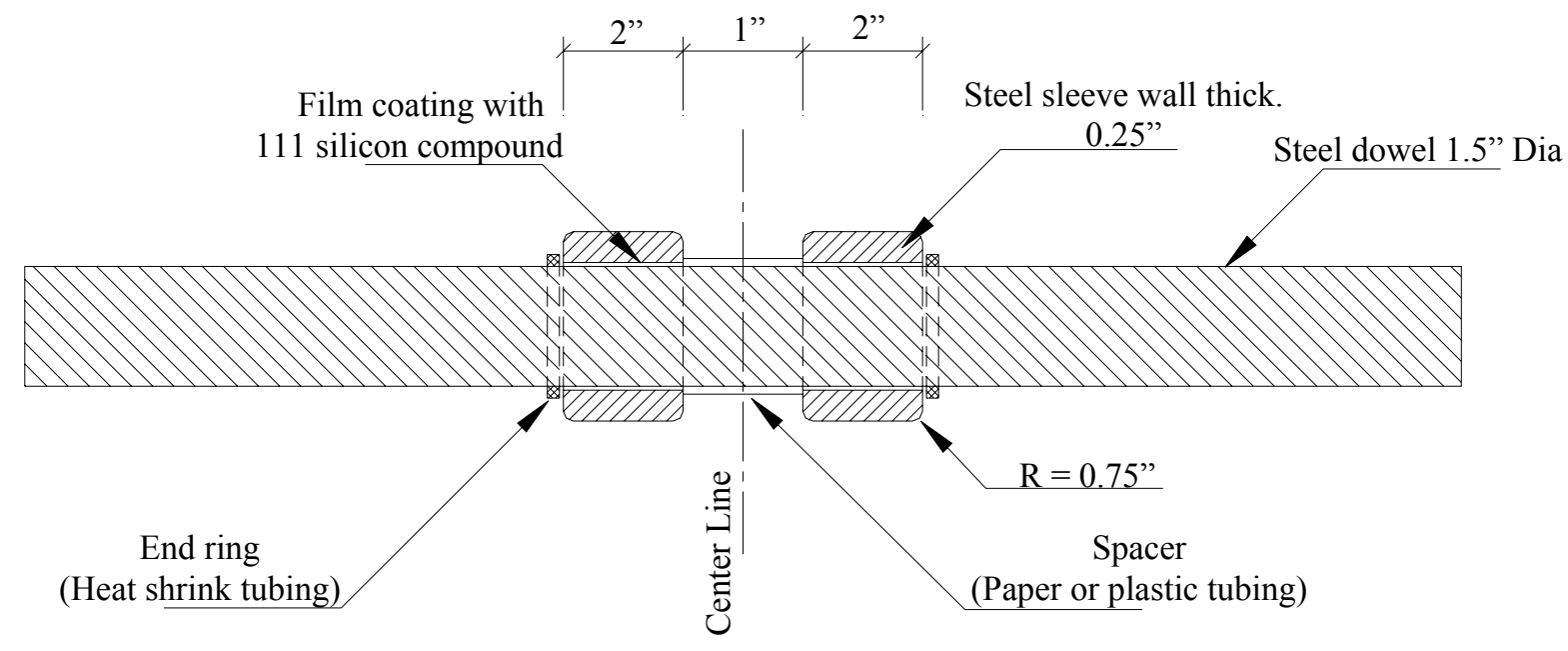

Figure 2.1: Design of Shokbar

Shoukry et al. (2004) compared the regular dowel bars with the newly designed Shok bars using finite element analysis. Tests were conducted in laboratory conditions isolating temperature and humidity effects. The test specimens were subjected to both static and dynamic loading. The study tested two designs for the shokbars, namely "Shoksteel" which used steel sleeves and "Shokpolymer" which used polymer concrete sleeves. Based on the laboratory tests along with 3DFE analysis, the researchers found that Shokpolymer and Shoksteel succeeded in reducing tensile and compressive strains at dowel/concrete interface by at least 4 to 5 times compared to regular dowel bars. Unlike the dowel/concrete interface, the Shok bar/concrete showed minimal changes in compressive and tensile strains. Shokbars also maintained steady values of load transfer efficiency across joints through 10 million cycles of fatigue loading. 
Field test of Shok bars conducted by Shoukry et al. (2004) demonstrated the effectiveness of Shok bars in allowing better joint opening as the concrete slabs shrink at the early age of concrete due to temperature variations. Joints fitted with Shokbars also showed steady values of load transfer efficiency through the 3-year pavement age. On the other hand, joints fitted with regular dowel bars, showed variations in their opening. Mostly one of every five joints opens widely while the other four showed little or no openings.

\subsection{FRICTION BETWEEN SLAB AND BASE}

It has been well documented that stresses in slab due to friction between slab and base/ subgrade occurs only when there is movement of the slab (Yoder and Witczak, 1975; Huang, 1993). Stresses are set up in pavements as a result of uniform temperature changes that cause the slab to contract or expand. It has been shown that the minimum amount of displacement required for friction to be fully developed is 0.06 inch. As contraction takes place, shearing stresses in the subgrade are developed immediately below the slab. It is seen that the rough concrete sliding over soil will have a coefficient of resistance which is dependent in part upon the shearing resistance of the soil or base course. However, in this approach the magnitude of the stress is independent of the amount of temperature decrease or increase. The magnitudes of the resulting stress were so small that this theory could not be used to explain the formation of thermal cracking in concrete slabs.

\subsection{FINITE ELEMENT MODELING}

\subsubsection{D FE models}

Finite Element modeling has made it possible for engineers to simulate and replicate the pavements and study its response to varying parameters. Calculation of curling stress was easier using the Finite element models. The last two decades saw the development of 2D and 3D FE models. For example, 2D pavement models developed are listed here: ILLI-SLAB (Tabatbaie and Barenberg, 1978; Krovosis, 1990), JSLAB 
(Tayabji and Colley, 1986), WESLAYER (Chou, 1981), KENLAYER (Huang, 1993), FEACONS IV (Tia et al., 1987; Wu and Larsen, 1993), and ISLAB2000 (Khazanovich et al., 2000, Beckemeyer et al., 2002). These programs treated traffic loads as static loads. They simulated the slab using 2D medium-thick plate elements and dowel bars as either beam elements or linear and torsion springs. The inherent drawbacks of using 2D finite element models can be summed up as:

1. The stress distribution through the depth of the slab cannot be simulated. Information about the stress concentrations around the dowel bars which cause the most common form of doweled transverse joint failure cannot be extracted. The triaxial state of stress around the dowels cannot be analyzed.

2. A nonlinear temperature gradient through the slab thickness cannot be considered directly, since the plate elements used are based on the assumption that strain distribution through the thickness is linear.

3. The use of linear springs (Chou, 1981; Huang, 1993) and a combination of linear and torsional springs (Nishizawa et al., 1989) makes it unfeasible to model the friction between the concrete and dowel bars.

\subsubsection{D FE models}

The limitations of 2D modeling of pavements along with advancements in the computer time and memory lead to the use of 3D Finite Element modeling to simulate concrete pavements. A number of researchers developed 3DFE models to study the effect of subgrade support conditions, moving traffic and temperature variations on rigid pavements. Most of the early 3D models used beam elements to simulate dowel bars and neglected the thermal effects (Sargand and Beegle, 1995; Davids 1997, 2001; Chennakeshava 1993).

Channakeshava et al. (1993) developed a static 3D FE model to study the combined effect of a linear thermal gradient and a static wheel load. They introduced nonlinearity to the model by studying the effect of different extents of loss of subgrade 
support and different dowel-concrete interface characteristics. The dowel bars were simulated as beam elements mounted on elastic springs. The study concluded that night time curling is a critical loading case since truck traffic is heaviest during the night; in addition, it causes loss of support under the joints. They also reported a large concentration of tensile stresses in the elements below the dowel bars.

The 3D FE model developed by Beegle and Sargand (1995) investigated the effect of varying the material properties on pavement response. It was shown that decreasing the subgrade modulus results in an increased contact area between the curled slab and base layer. Pavement instrumentation in Ohio Road Test indicated that deflections and stresses caused by temperature changes are more severe than those caused by traffic loading (Sargand et al., 1997).

Using a 3D FE model Masad et al. (1996) examined the effect of linear and nonlinear temperature gradient on concrete slabs. They reported that for linear temperature gradient the maximum curling stress was about $28 \%$ of the concrete modulus or rupture. They also reported that nonlinear temperature gradient caused higher tensile stresses than the linear one. The coefficient of friction at the slab base interface had minimal effect on curling stress.

The use of beam elements for modeling dowel bars was incapable of predicting the triaxial state of stress that develops in the concrete surrounding the dowel bars. Shoukry et al. (2002) used 8-noded solid brick elements for modeling the slab and the dowel bars. A fine mesh was used in the region of the dowels to capture the stress developed around dowels. Dowel- concrete and slab base interface were simulated using sliding interfaces with friction that allows for slab base separation. They examined the response of the combined effect of nonlinear thermal gradient and moving axle load. The authors reported that the combined effect of thermal gradient and axle loads were not the primary cause of premature failure of concrete slabs. Edge loading at mid slab length is the most critical loading position of a dowel jointed concrete slab. They stressed the 
importance of including uniform temperature drops as well as contact stresses in dowel concrete interfaces in pavement analysis and design procedures.

\subsection{PREDICTION OF SLAB PERFORMANCE FROM WEATHER DATA}

One of the first to correlate the temperatures of a concrete pavement to the weather conditions was Barber (1957) who proposed to calculate the maximum temperature in the concrete slab. He applied a theory of thermal diffusion to a semiinfinite mass in contact with air in which the daily solar radiation was considered by its affect on the mean effective air temperature. The equation that was developed presented a relation between pavement temperatures, wind velocity, air temperature and solar radiation involving the thermal properties of the pavement. The resulting calculations give a rough estimate of the maximum surface temperature. For more accurate temperature values the exact values of thermal properties and ambient conditions were required.

Rumney and Jimenez (1969) developed empirical nomographs to predict pavement surface temperature and at a 2 in depth as a function of air temperature and hourly solar radiation. Dempsey's (1970) heat transfer model called the climaticmaterials-structural (CMS) uses a finite difference approach to solve the heat transfer differential equation. The program can predict the variations in pavement temperature during the day for a sequence of days. Dickinson's (1978) method to predict temperature gradients in pavements on the basis of climatic information is limited to clear sunny days and low wind speed weather conditions. The conduction of heat through the pavement was treated by a finite difference procedure.

Solaimanian and Kennedy (1993) proposed a method to determine just the maximum pavement temperature. Based on the heat transfer theory, the method takes into account the latitude of the location, the air temperature, wind velocity and relative humidity. The method involved the calculation of the net heat transfer to the pavement including heat due to direct and diffused radiation, heat loss due to conduction and 
convection and long wave re-radiation. The energy absorbed from direct solar radiation was related to the pavement tilt and the zenith angle which in turn is dependent on the latitude of the site. Each of the above causes of heat transfer in the pavement was related to air and slab temperatures. The surface temperature was then calculated by equating the resulting fourth degree net heat flow equation at the pavement surface to zero assuming that there is a thermal equilibrium at the slab surface. The temperature through the depth of the pavement was approximated by a cubic equation as a function of surface temperature and depth.

Some software programs such as the Integrated model of climatic effects of pavements (Lytton et al, 1993) and the Enhanced Integrated climatic model (Larson et al, 1997) are capable of generating patterns of rainfall, solar radiation, cloud cover, wind speed and air temperature to simulate the upper boundary conditions of a pavement-soil system. The data output from the programs may include daily pore water pressures, temperature through the slab thickness at up to three times each day, frost and thaw depth, maximum and mean frost heave each day. The programs can be used for determining design parameters for a concrete pavement. But continuous monitoring is not possible by the programs.

McCullough et al (FTP 1999), modeled the early-age behavior of Portland cement concrete pavements (PCCP) and bonded concrete overlay (BCO) subjected to moisture and thermal stress. They developed a set of guidelines for the proper selection of design and construction variables to minimize early age damage to the pavement. The heat transfer model that they developed was in the form of a 2 layered finite element model with thermal boundary conditions obtained from equations for heat flux due to convection, irradiation and solar radiation absorption. The research resulted in the development of the HIPERPAV software package which helps to verify the overall effect of specific combinations of design, construction and environmental inputs on early age behavior of PCCP and BCO. 
Balbo and Severi (2001) have documented the influence of weather conditions on daily and seasonal variations in temperature differentials through the slab depths in a hot and wet tropical climate in Brazil. Fifteen concrete pavements were instrumented to experimentally examine the response of the slabs to weather conditions. It was found that the night time temperature differentials were not as extreme as the daytime differentials. The effect of rainfall on the sudden cooling of the slab surface and its subsequent effect on the temperature at the slab bottom was presented. They also provide different equations to predict the slab temperatures for the four different yearly seasons based on air temperature, relative humidity and solar radiation.

Zollinger and Jeong (2005) have investigated and reported the temperature and moisture effects on the behavior of jointed concrete pavements. The variations of temperature and moisture through the slab thickness were fitted to a third degree polynomial function and from the regression coefficients equivalent linear temperature and moisture difference were generated. The effective linear temperature and humidity differences were used to calculate total strains at the slab surface as a summation of moisture strains and thermal strains.

Most of the previous efforts in pavement temperature prediction could determine the temperature of the slab on clear sunny days that is usually during late spring and summer times. Days with high relative humidity and rainfall were neglected. Also, the comparisons between the calculated and measured values of temperature by the heat transfer model are not well documented for night times when negative gradients are present. This was acceptable since the purpose of the prediction was basically for pavement design where the interest was in the maximum temperature and gradient reached in the slab. When a continuous temperature prediction and pavement performance monitoring is desirable the inclusion of cloudy and rainy days in the calculations is inevitable. The present research effort attempts at near real time prediction and monitoring of the slab temperatures and performance of the pavement. The equation proposed by Barber (1957) was modified to include the effects of relative humidity and a 
few empirical parameters were introduced to obtain a good match with the measured data.

\subsection{SUMMARY}

Despite the significant amount of research work accumulated over the past eight decades in the area of concrete pavements, the response of such pavements to environmental conditions still need to be investigated. The usefulness of Shok bars in reducing mid-slab stresses and dowel-concrete contact stresses need to be verified from multiple sets of data from different locations. Extensive use of 3D finite element models helped develop better understanding to the slab response to temperature variations and the role of concrete-dowel interaction in constraining the slab movement due to contraction and expansion. Also the need for a relatively less expensive system of continuous monitoring of pavements is needed. The best way of doing this is to relate the response (slab temperatures and strains) to the input variables (environmental conditions) through a function in a no traffic condition. 


\section{CHAPTER THREE FIELD INSTRUMENTATION}

\subsection{INTRODUCTION}

The construction and instrumentation of the slabs described below was done by Dr. Shoukry and his team of researchers. The author of this thesis was not involved in the construction and instrumentation but only used the data collected from the site with permission from Dr. Shoukry. Further details about instrumentation and calibration of dowel and Shok bars can be obtained from the report Shoukry et al (2005).

Test concrete slabs were cast for experimental study in the designated open area at the parking lot of the WVDOT Maintenance Shop on Goshen road, West Virginia. The slabs were instrumented with a variety of sensors for long-term monitoring of the slab response to various loading conditions including seasonal and daily temperature changes. The sensory system was designed to provide continuous data from key-performance parameters that formulate the behavior of the slabs such as the distribution of strains along and across the slab centerlines, joint openings, temperature profiles through the slab thickness, dowel bending moments, dynamic shear and normal forces, strains at the concrete-dowel interface along with a continuous record of weather conditions.

Seven full scale slabs (15 ft $\times 12 \mathrm{ft} \times 10$ inches) were constructed. Three of the seven slabs were not instrumented and act as support or joint slabs. The support slabs were laid in September 2002. The remaining four slabs are instrumented and were poured in October 2003. Data collection began in October 2003 at 12:20 pm when the first of the four instrumented slabs was poured. Figure 3.1 shows the layout of the test site prior to concrete pouring. Figure 3.1(a) indicates the space between the wooden forms where the slabs fitted with regular dowels and Shokbars were poured and allowed to set. Figure 3.1(b) points to the area where the free slabs; slab on smooth base (low slab/base friction) and slab on coarse base (high slab/base friction). Thus the site has a total of seven slabs; five jointed slabs with their joints fitted with either regular dowels or Shokbars and two free slabs. The detailed construction of the slabs is described below. 


\subsection{CONSTRUCTION OF THE SLABS}

The test site was excavated to a depth of 15 inches and $15 \mathrm{ft}$ wide to accommodate the slabs. Due to the clayey nature of the soil in the site, it was necessary to design a drainage system so that water does not remain underneath the slabs. A 4-inch thick uniformly graded base layer was laid down at the excavation bottom. To allow for draining the water from the base layers, three 18-in. wide bleeders were constructed along the $120 \mathrm{ft}$ long base for rain water drainage. The base layer was extended 12 inches from the edges of the slab to provide uniform distribution to the slab support. The top surface of the base layer was carefully treated in order to provide minimum amount of the slab-base friction. A 1-inch thick layer of cement paste was spread on the top surface of the base layer, finished to a smooth surface and set to cure for 15 days. Holes of $1 / 2$-inch diameter were then drilled throughout this cement layer at staggered spacing of about 12 inch to allow better water drainage. 


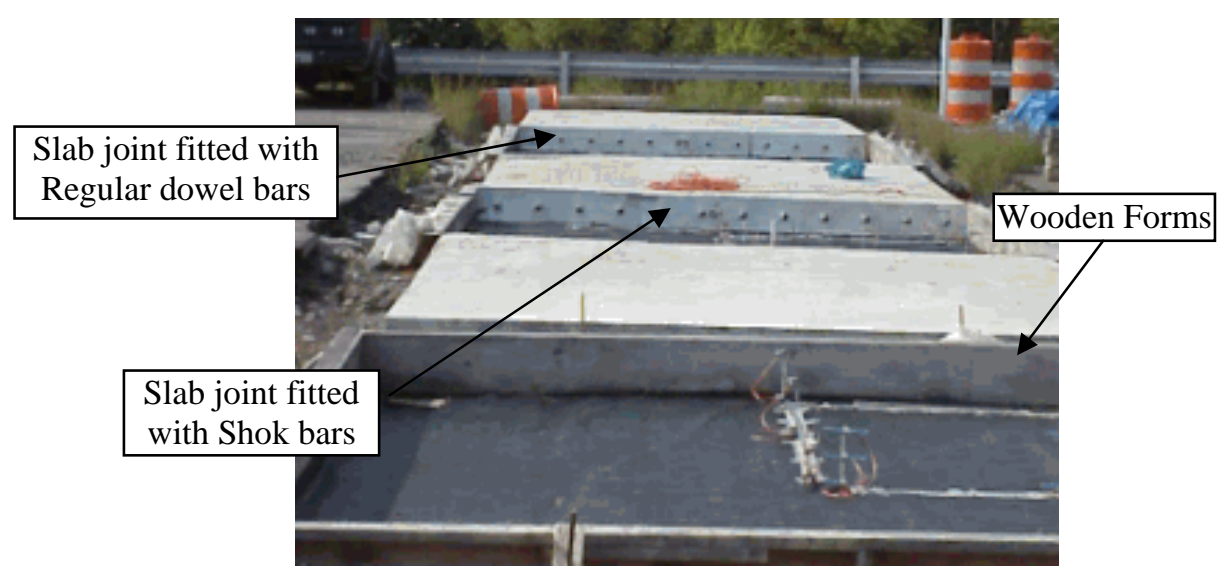

(a): Locations of jointed slabs

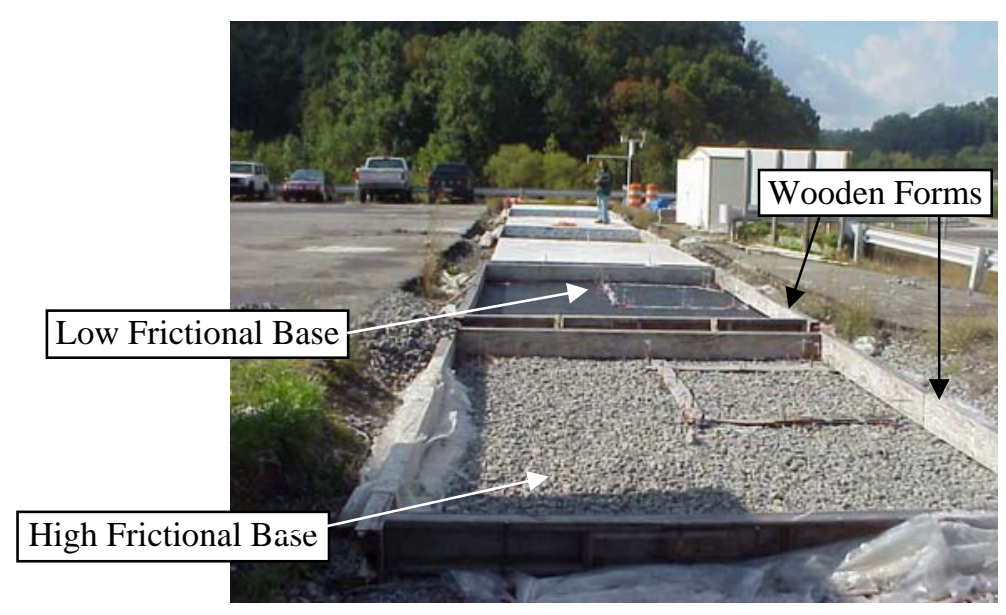

(b): Location of Free slabs

Figure 3.1: Layout of the Test Site

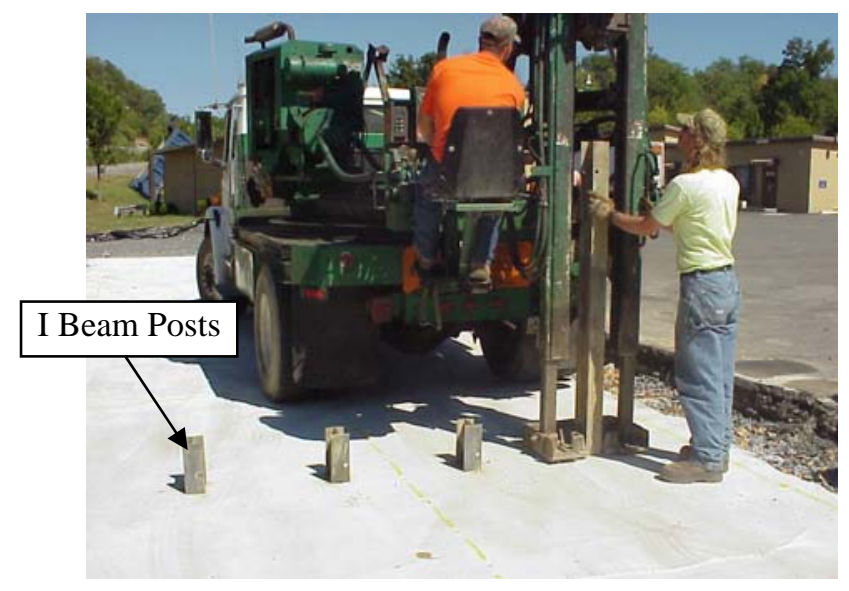

Figure 3.2: Stage I of Test Slabs Construction: Installing the Steel Anchors 
A thick fabric sheet was placed on top of the finished surface and concrete slabs were cast on top of the fabric sheets within wooden frames. In contrast, one free slab was placed directly on the crushed stones base layer for the purpose of studying the effect of slab-base friction.

The construction of the slabs took place in two stages. Stage I was the pouring of three fixed or support slabs that served to provide joints to the instrumented slabs. These slabs were placed alternately at a distance of $4.57 \mathrm{~m}$ (15 ft) from each other to accommodate the instrumented slabs which were to be cast later. Each slab is $4.57 \mathrm{~m}$ (15

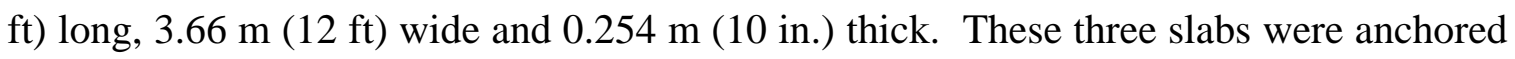
to the ground in order to simulate the extended continuity of pavements, i.e. maximum resistance to movement. In each of the fixed slabs, four steel "I" beam section posts 1.8 meters (6 ft) long, as illustrated in Figure 3.2, were driven along the transverse centerline of the slab. The ends of the posts were made flush with the slab top surface. Figure 3.2 shows the process of driving the anchor posts. Twelve equally spaced dowel bars and Shokbars were placed along the edges of the slabs in such a manner that the instrumented slabs would be jointed at both slab edges with the same type of load transfer device. Hence, there are two instrumented jointed slabs; one slab with regular dowel bars in both its transverse joints and the other with Shokbars in both its joints.

The second stage was the construction of the four instrumented slabs: slab fitted with dowel bars, slab fitted with Shok bars, free slab constructed over a low frictional base, and free slab on a high frictional base.

\subsection{INSTRUMENTATION AND DATA ACQUISITION SYSTEM}

A typical instrumentation plan of a jointed slab for long term strain measurements is shown in Figure 3.3. The figure shows a complete slab and two half slabs adjacent to the full slab for the purpose of indicating the locations of the instruments. Each instrumented slab contains sixteen vibrating wire embedment strain gages, one 
deformation meter along the slab centerline at both the transverse joints of the slab and three instrumented load transfer bars among the twelve bars.

Vibrating wire embedment strain gages (Model VCE-4200) measure the accumulated strains due to various factors inclusive of drying shrinkage of concrete, temperature and moisture variations. A thermal or mechanical strain changes the tension of the internal wire of the gage and in doing so changes the natural frequency of the wire. This change in natural frequency is calibrated to a measurement of strain. The strain gages are integrated with thermistors that measure the temperature of the concrete at the location of the gages. The temperature of the concrete is necessary to apply a correction factor to the sensor readings to compensate for the difference in coefficient of thermal expansion of the sensor material and concrete. An embedment strain gage tree consists of two strain gages at $2.54 \mathrm{~cm}$ (1 in.) and $21.59 \mathrm{~cm}$ (8.5 in.) from the slab top surface. The strain trees located along the slab centerline at distances of $0.2286 \mathrm{~m}$ (9 in.), 1.1684 m (46 in.) and $2.1844 \mathrm{~m}$ (86 in.) from the transverse edge collect the longitudinal slab strains. The transverse slab top and bottom strains are measured by the strain trees located at distances of $0.2286 \mathrm{~m}$ (9 in.), $0.9398 \mathrm{~m}$ (37 in.) and $1.7526 \mathrm{~m}$ (69 in.) from the longitudinal edge. The two strain trees at the mid-slab section contain an additional strain

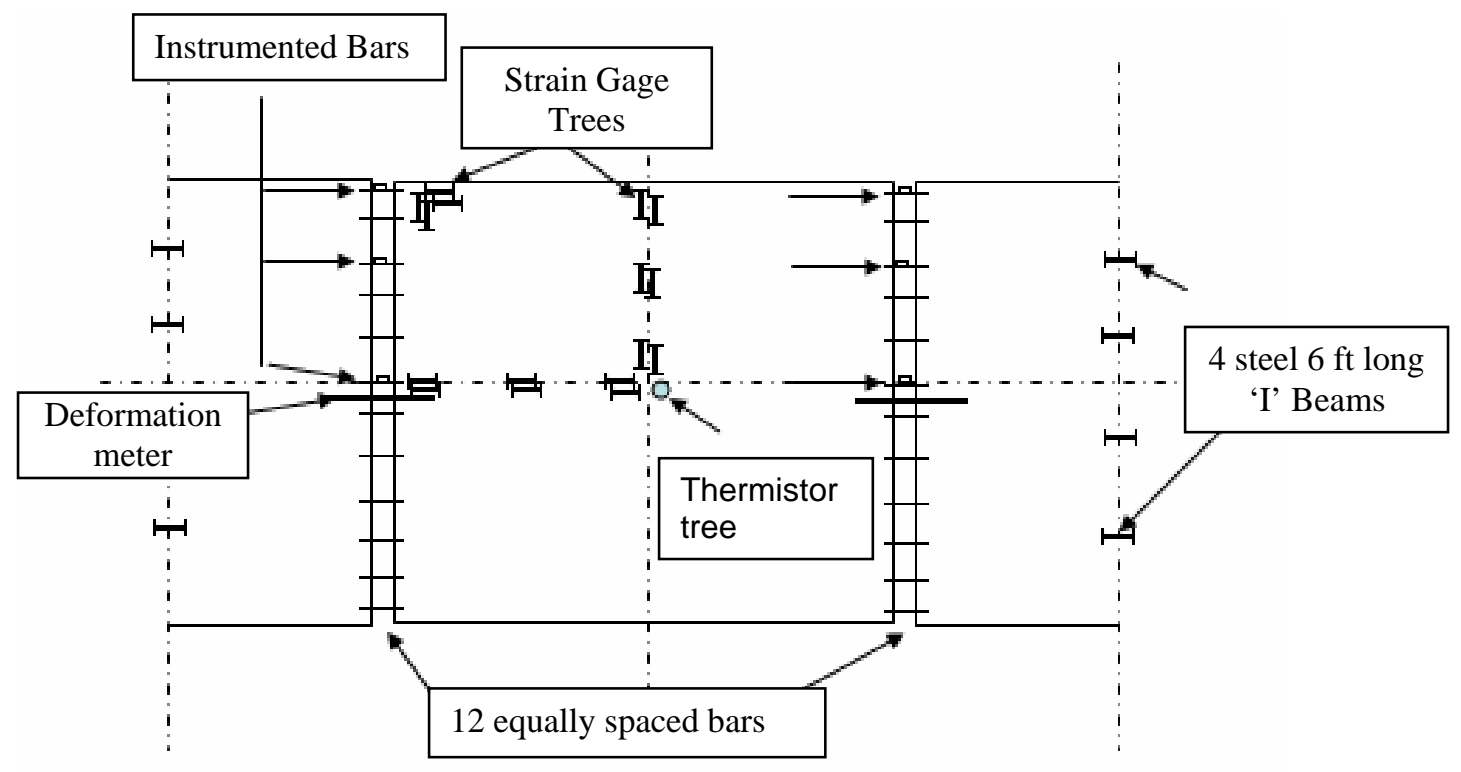

Figure 3.3: Instrumentation plan of jointed slab 
gage at $13.33 \mathrm{~cm}$ (5.25 in.) from the slab top to coincide with the neutral surface of the slab. Figure 3.4 shows the position of the sensors in the slab fitted with dowel bars.

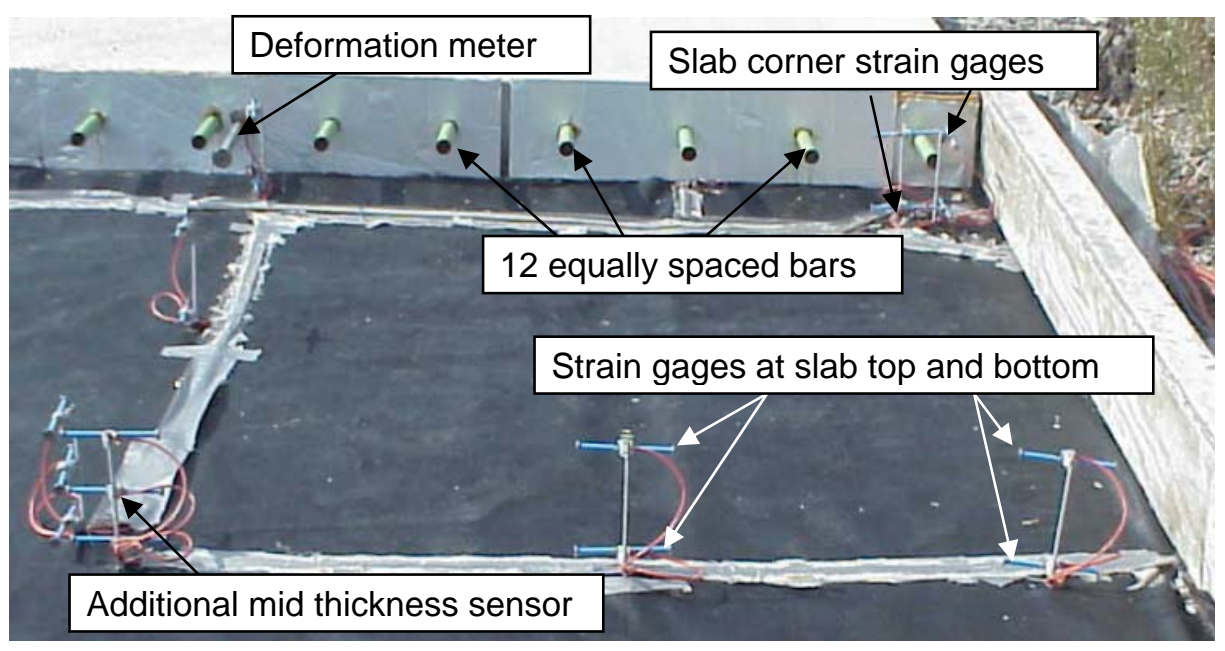

Figure 3.4: Location of Sensors on Dowel Slab.

In addition to the thermistors attached to the strain gages, two thermistor trees containing 19 thermistors record the detailed temperature profile through the thickness of the jointed slabs. The thermistor tree collects temperature values at intervals of $2.54 \mathrm{~cm}$ (1 in.) starting from the top of the base layer and at every $3 \mathrm{~mm}$ (1/8 in.) at the top 2.54 cm (1 in.) from the slab top surface. The selected thermistors are model YSI 44005.

Three of the twelve load transferring devices in each transverse joint are instrumented; one at the slab corner, the wheel path and at the joint center as shown in Figure 3.3. The strain gages were precisely mounted in each instrumented dowel to maintain the characteristics and surface texture of the dowel. For collecting bending strains, two miniature vibrating wire strain gages were mounted on the top and bottom of the dowel at its center. Geokon Inc. manufactured an innovative design of vibrating wire strain gages that was specially designed to fit this purpose. The design was made as a modification to the strain gage model VK-4150 so that it could be embedded in the dowel bar. Each gage was embedded in a $62 \mathrm{~mm}$ (2.5 in.) long and $6 \mathrm{~mm}$ (1/4 in.) deep key-slot machined at mid-length of the $38 \mathrm{~mm}$ (1.5 in.) diameter, $(460 \mathrm{~mm}) 18 \mathrm{in}$. long dowel bar. Figure 3.5 (a) and (b) show the instrumented dowel bar and Shokbar respectively in their final form. The readings from these strain gages are post-processed to calculate the 
bending moments, axial forces in regular dowel bars and Shokbars. Shear strains are collected on the bar using a ninety-degree rosette model CEA-06-187UV-120 manufactured by Micro-Measurements group. The instrumentation work has been thoroughly documented in the report submitted to the WV Department of Transportation (Shoukry 2005).

All instrumented dowels were calibrated in the laboratory by applying pure bending moments and shearing forces of known magnitudes and verifying the response of the bars against theoretical calculations. A sample of the calibration plots is shown in Figure 3.6. Along with the instrumented dowels, the uni-axial dynamic strains at the joint face on both sides of the dowel and the compressive strains below the dowel bar are being measured. Micro-Measurements strain gages model CEA-06500UW-120 were bonded at these locations. In addition to the embedment strain gages in the concrete, four Geokon 4430 vibrating wire deformation meters measure the axial displacement between the slabs caused due to drying shrinkage and the seasonal and daily variations in moisture content and temperature of the slabs. Each joint between the doweled slabs has one displacement meter placed longitudinally along the slab centerline as illustrated in Figures 3.3 and Figure 3.4. As the joint meters are present on both sides of the slabs the symmetry of slab deformation can be analyzed. 


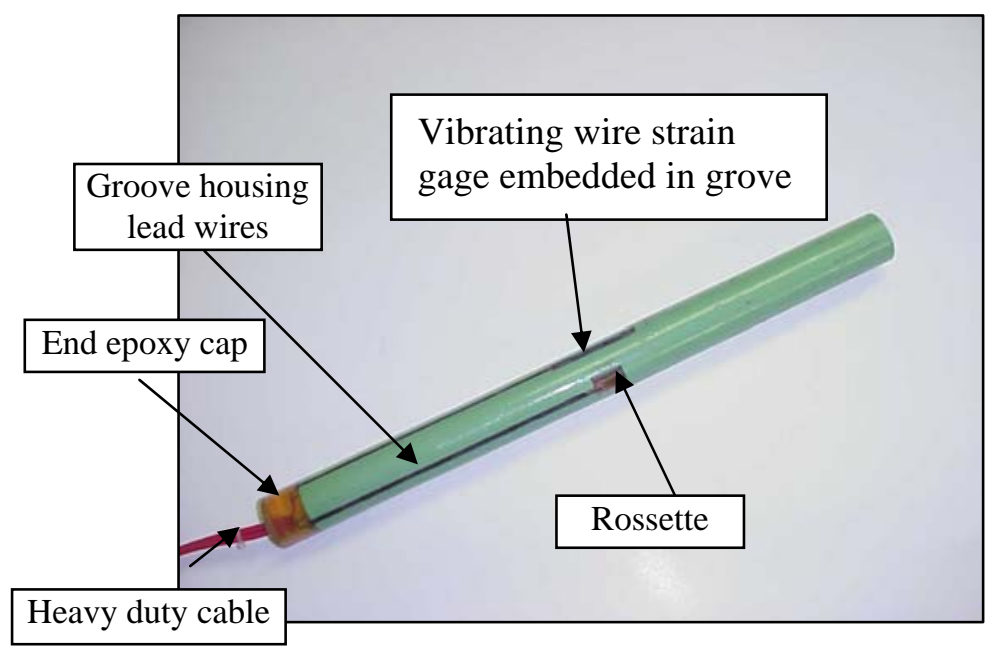

(a): Regular Dowel Bar.

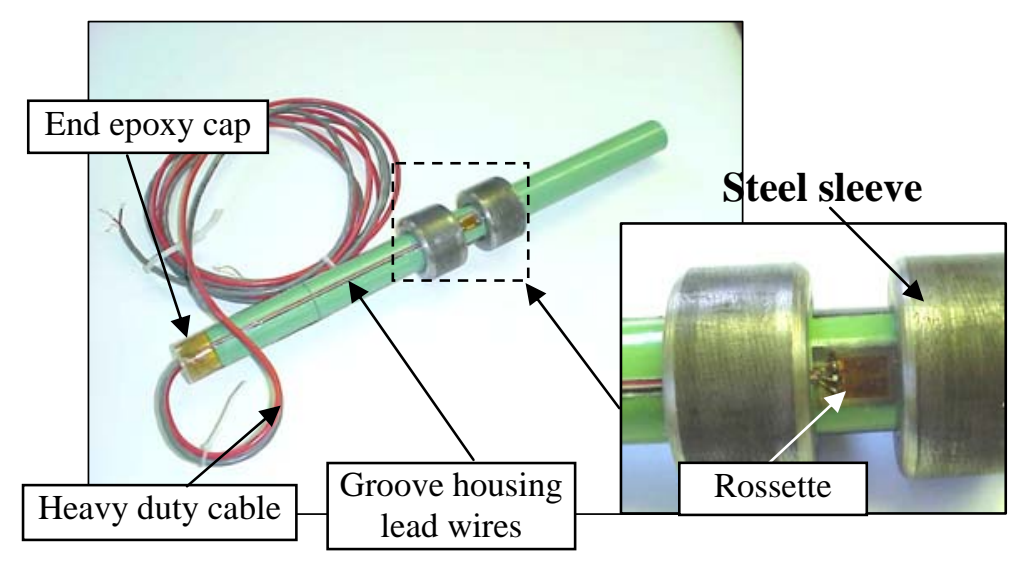

(b): Shok Bar.

Figure 3.5: Instrumentation of Regular Dowels and Shok Bars. (Courtesy: Shoukry et al 2004) 


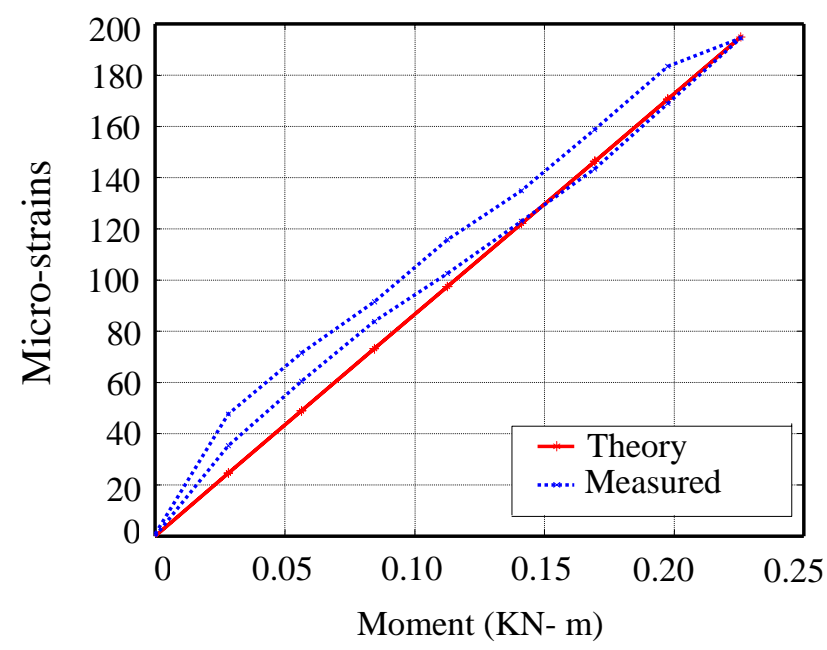

(a) Calibration for Bending

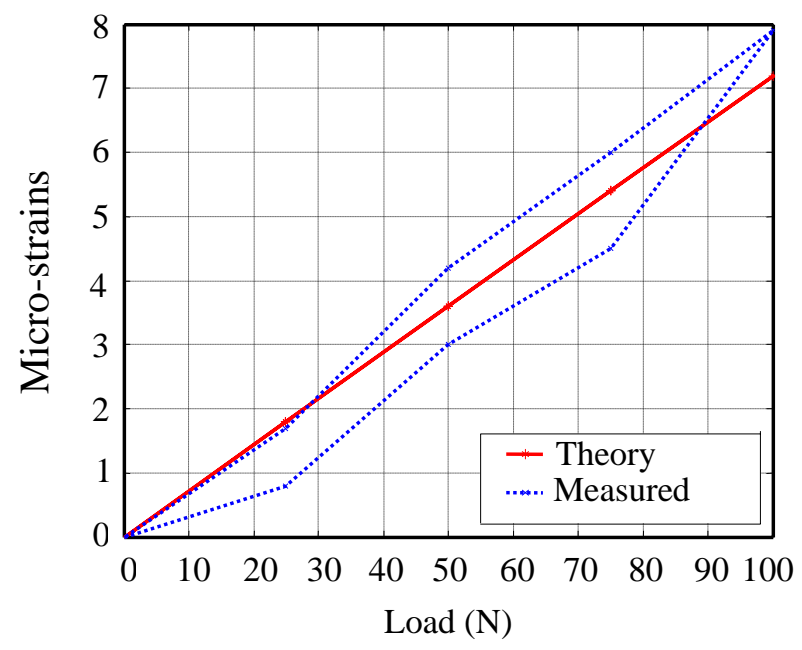

(b) Calibration for Shear

Figure 3.6: Calibration of Instrumented Dowel Bars (Courtesy: Shoukry et al 2003)

\subsection{DATA ACQUISITION}

The data acquisition system used to collect and store the data from the instrumented slab consists of seven multiplexers and a Campbell Scientific CR10X data logger as illustrated in Figure 3.7. The system has been collecting and storing data every 20 minutes continuously 24 hours a day since October 2003 till the time of writing. The acquisition system and the wires/cables from the sensors were well protected from environmental conditions. The cables were encased in duct tape to form a flat conduit and drawn on top of the finished base layer so that they do not provide any resistance to the free movement of the cured concrete. Though a direct power supply was available, a twelve-volt battery charged by the supply was used to power the data acquisition system. This was done to avoid any data loss in case of a power outage in which case a continuous power supply is ensured by the battery. The AC power supply from the grid keeps the battery at full charge. 


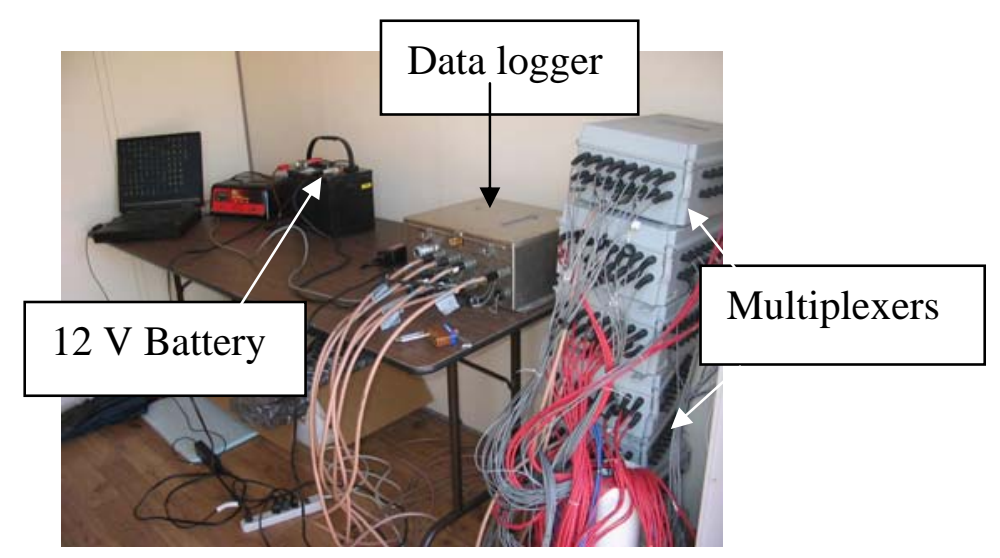

Figure 3.7: Data acquisition system

\subsection{WEATHER STATION}

The ET106 weather station from Campbell Scientific, Inc. was installed at the test site, as illustrated in Figure 3.8, to monitor the local weather conditions that affect the concrete pavement. The station consisted of electronics housed in an environmental enclosure, a 2 $\mathrm{m}$ aluminum mounting pole, and meteorological sensors. The station was powered with a 7 Ah sealed-rechargeable battery that was being float charged with AC power. The enclosure includes electronics for measuring sensors, processing and storing data, and communicating with a central computer. The weather station had an independent data acquisition system where data was sampled and stored locally every 15 minutes. Data collection from this station started around 2 weeks after the main data acquisition system. The ET106 was configured in minutes using Visual Weather software. Visual Weather software supports programming, manual and scheduled data retrieval, and report generation. The weather station measures: Solar Radiation, Air Temperature, Relative Humidity, Rainfall, Wind Speed, Wind Direction and an additional sensor, the SR50-LC Snow Depth Sensor placed at a height of $1.78 \mathrm{~m}$ from the slab measures the depth of snow accumulated on the slab. 


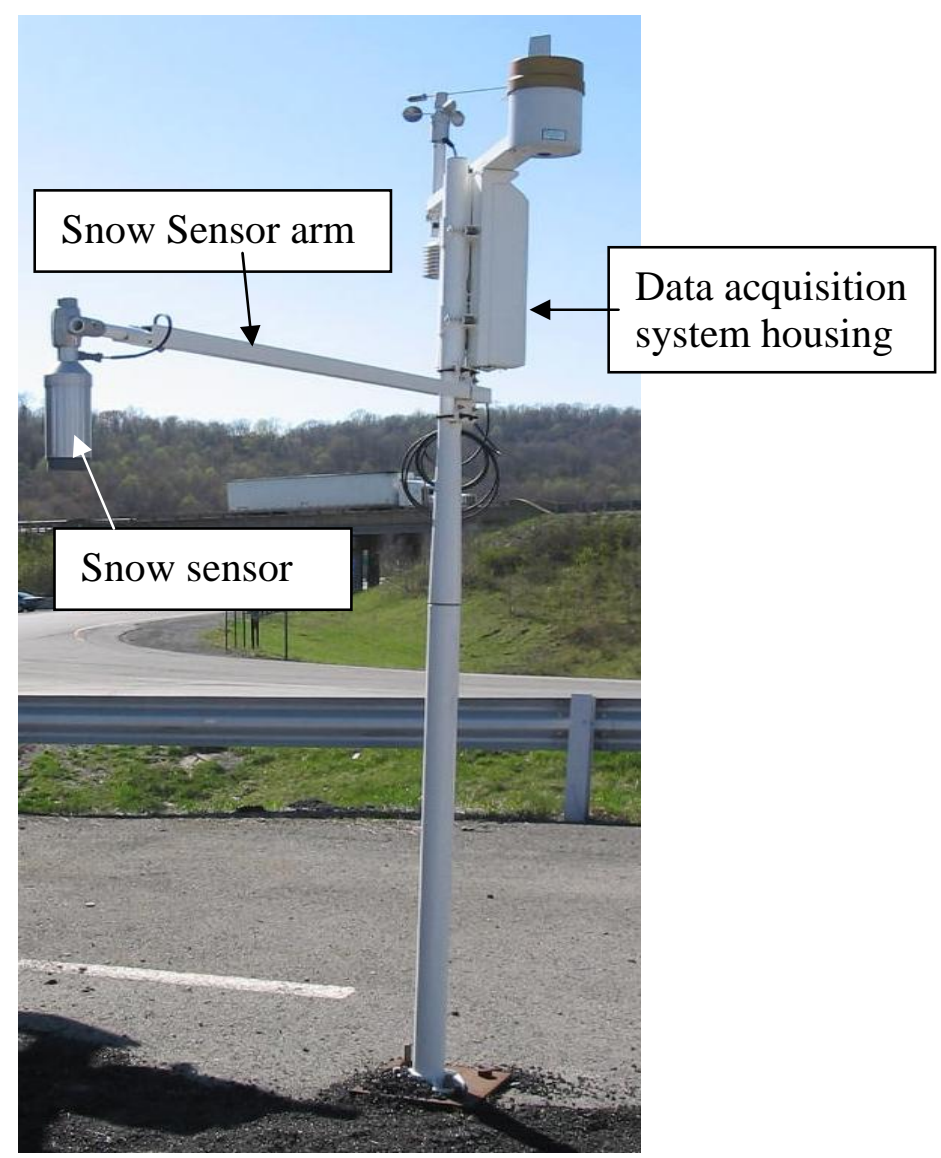

Figure 3.8: Weather station 


\section{CHAPTER FOUR \\ EXPERIMENTAL DATA ANALYSIS}

\subsection{INTRODUCTION}

The data collected from the instrumented slabs at the Goshen Road site was analyzed and the results are discussed in this chapter. Some plots presented in this report show a few missing data between days 45 and 90 from the time of concrete pour and again for a few days around the $250^{\text {th }}$ day and 304 day mark. This was due to a technical setback in data collection at the site. But the lost data did not hinder the processing and analysis of the remaining sets of data.

\subsection{LONGITUDINAL STRAINS}

Data collection from all the sensors was started simultaneously. But the slabs were poured one after the other hence the time of pour for the various slabs was different. This lead to the presence of a few data points before the concrete was actually poured. Thus, the initial reference values have been individually noted for each slab. This initial time was identified by observing the rise in the temperature of the concrete i.e. when the temperature of the slab increased with the emission of the heat of hydration. Figures 4.1 through 4.5 illustrate the time-histories of the longitudinal strains measured near the slab transverse joint and at the mid-slab region in different slabs together with the corresponding measured temperatures.

\subsubsection{Slab jointed with Dowel bars}

Figure 4.1 shows the longitudinal strains at the slab top at the slab edge and mid slab. During the first 150 days, the slab mid section had slightly higher compressive strains than at the edge. In the initial stages when the concrete was curing, the drying shrinkage and the decrease in ambient temperature induced compressive strains in the slab. The contraction of the slab edge at the joint is restricted by the bond or friction at 
the concrete-dowel interface. The mid slab was relatively more influenced by the shrinkage and decrease in temperature. The same observation could be made from the longitudinal strain histories at the slab bottom shown in Figure 4.2.

\subsubsection{Slabs jointed with Shok Bars}

The strains at the edge of the slab with Shok bars were under higher compression strains than at mid-slab unlike the ones at the edge of the slab with the dowel bars (refer Figure 4.3 (a) and (b)). Considering that the variation in temperature in the two slabs was almost the same, this phenomenon was credited to the lower constraints offered by the Shok bars providing higher freedom of movement at the joint edge. The concrete griped the sleeves of the Shok bars and they both slid over the bars. The clearance between the sleeves and the dowels was filled with high viscosity lubricant. This facilitates breaking any bond that may have existed at the concrete-dowel interface behind the sleeves, which was not the case with the traditional dowel bars. 


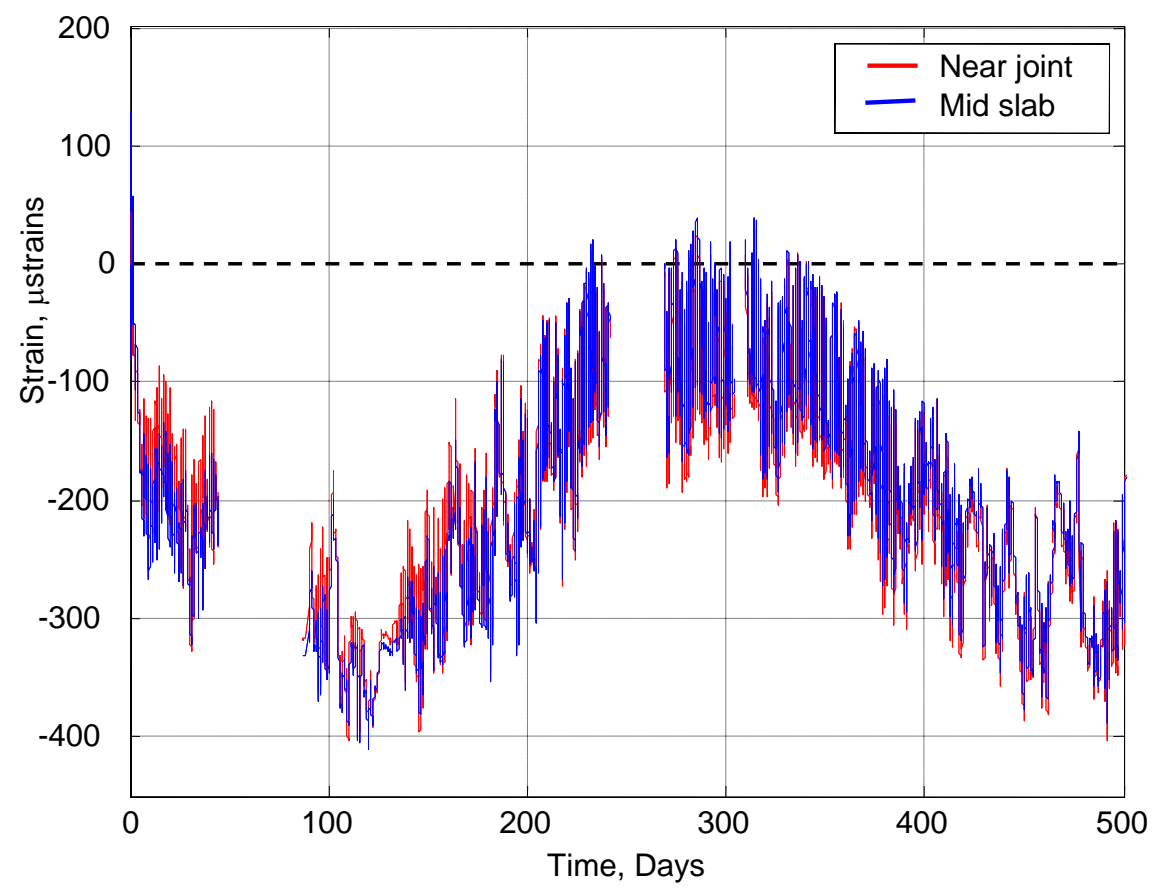

(a) Longitudinal Strain

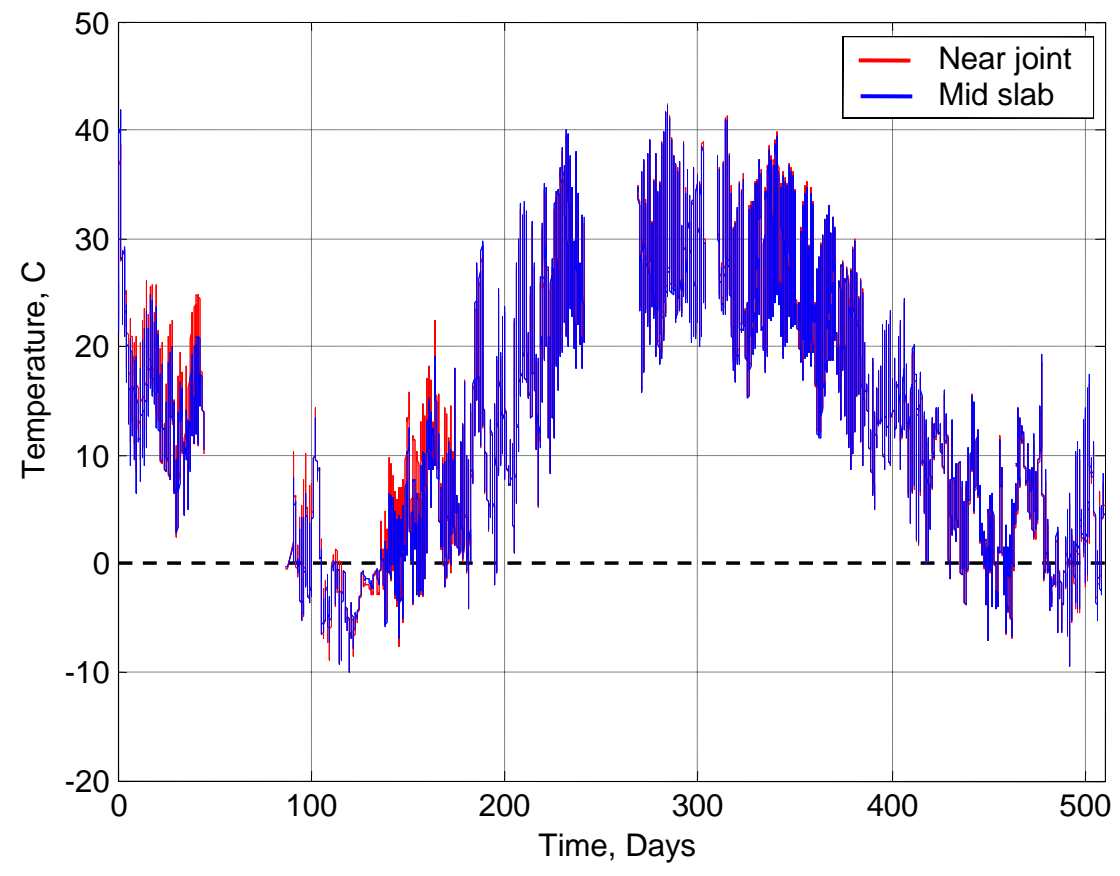

(b) Temperature

Figure 4.1: Longitudinal Strains and Temperature Histories Measured at 1" from Top Surface of the Slab Fitted with Dowel Bars. 


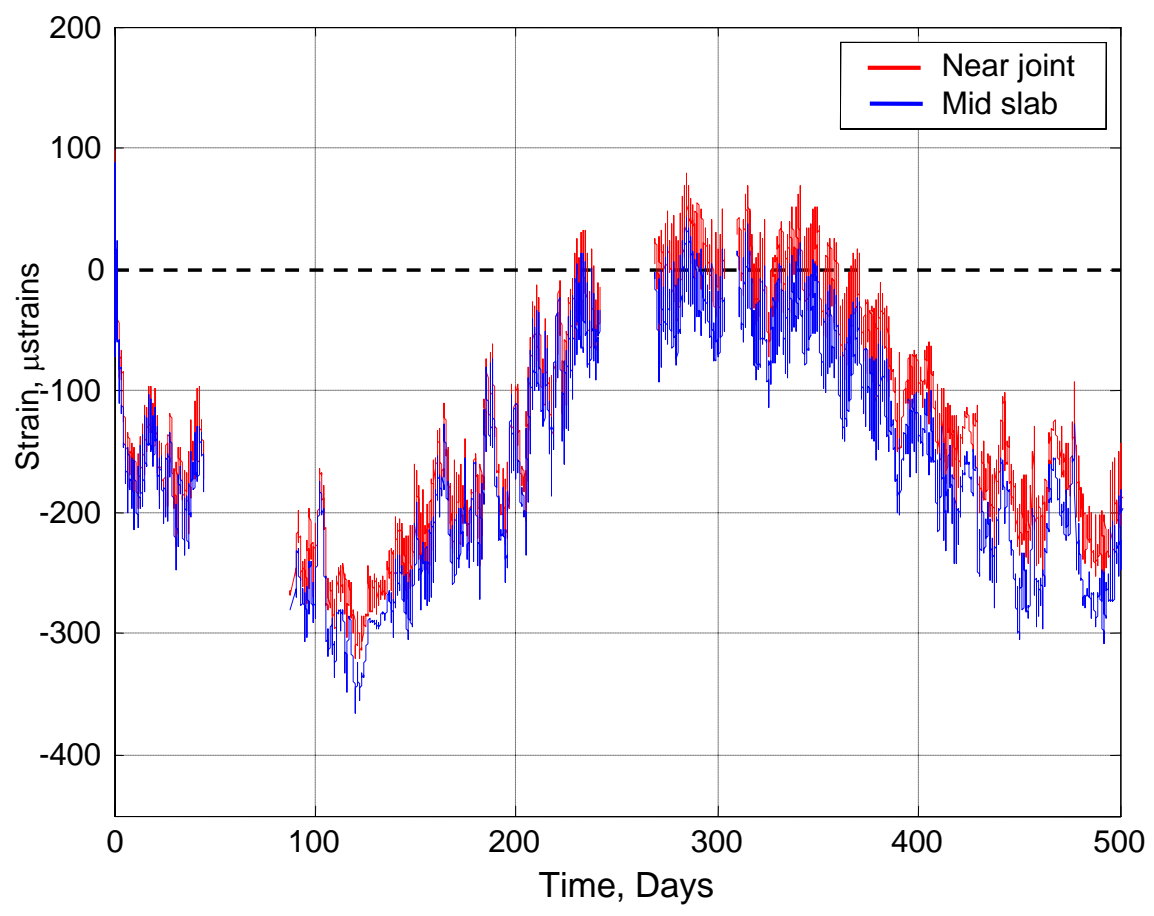

(a) Longitudinal Strain

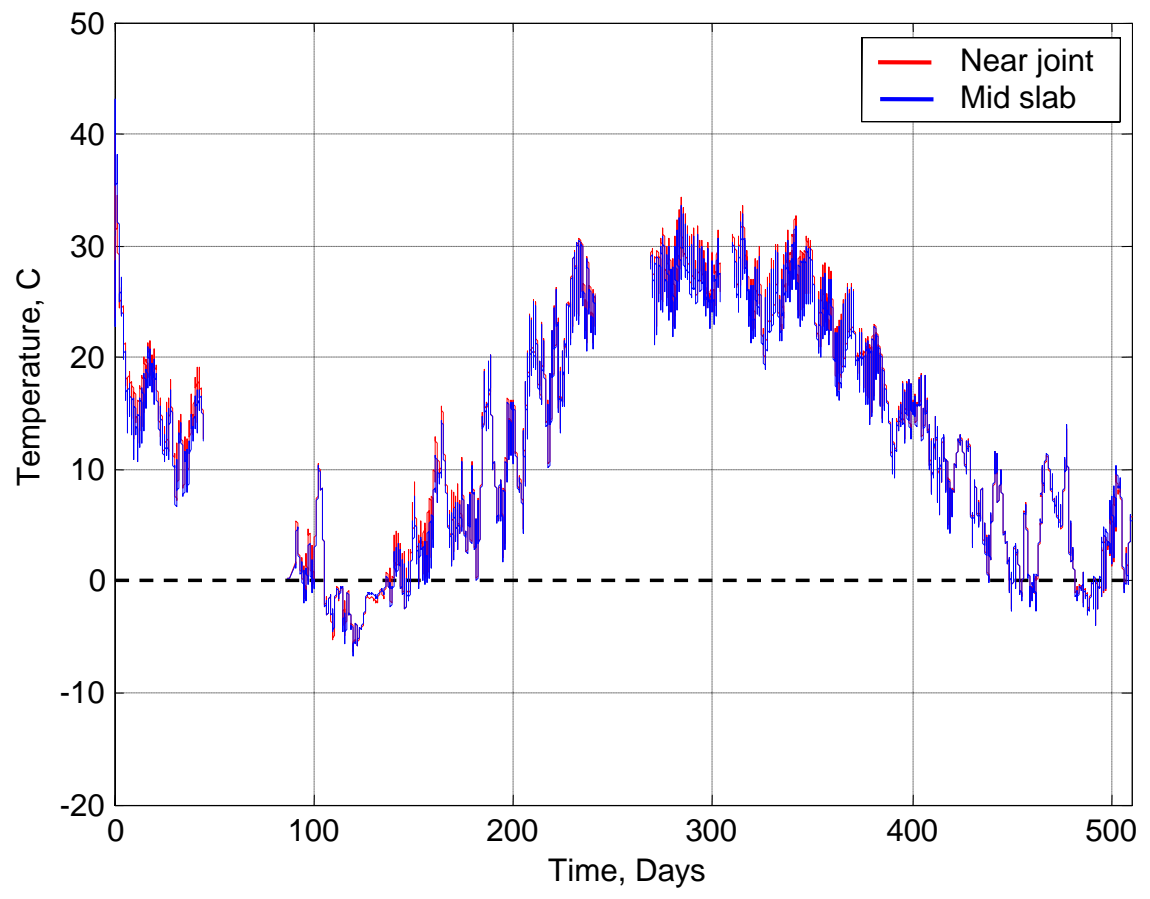

(b) Temperature

Figure 4.2: Longitudinal Strains and Temperature Histories at 1.5” from Bottom Surface of the Slab fitted with Dowel Bars. 


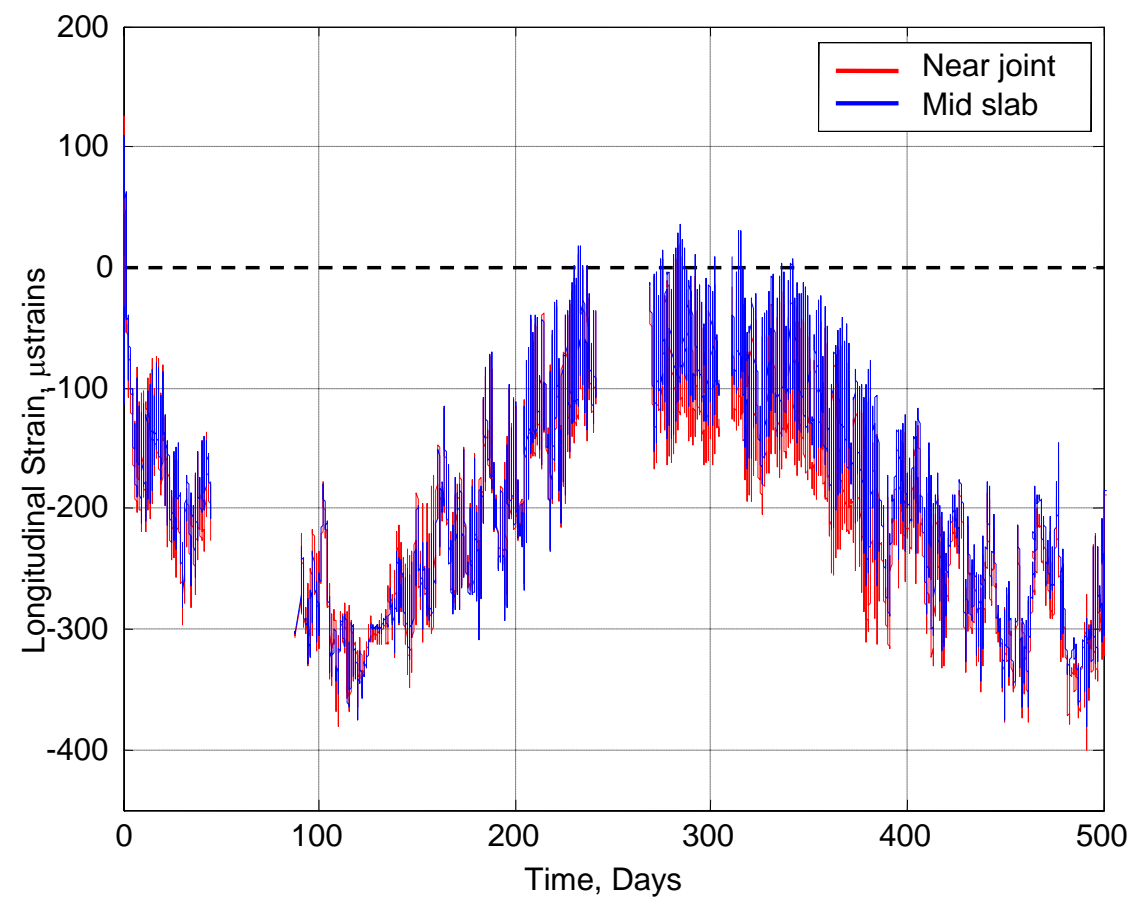

(a) Slab Top

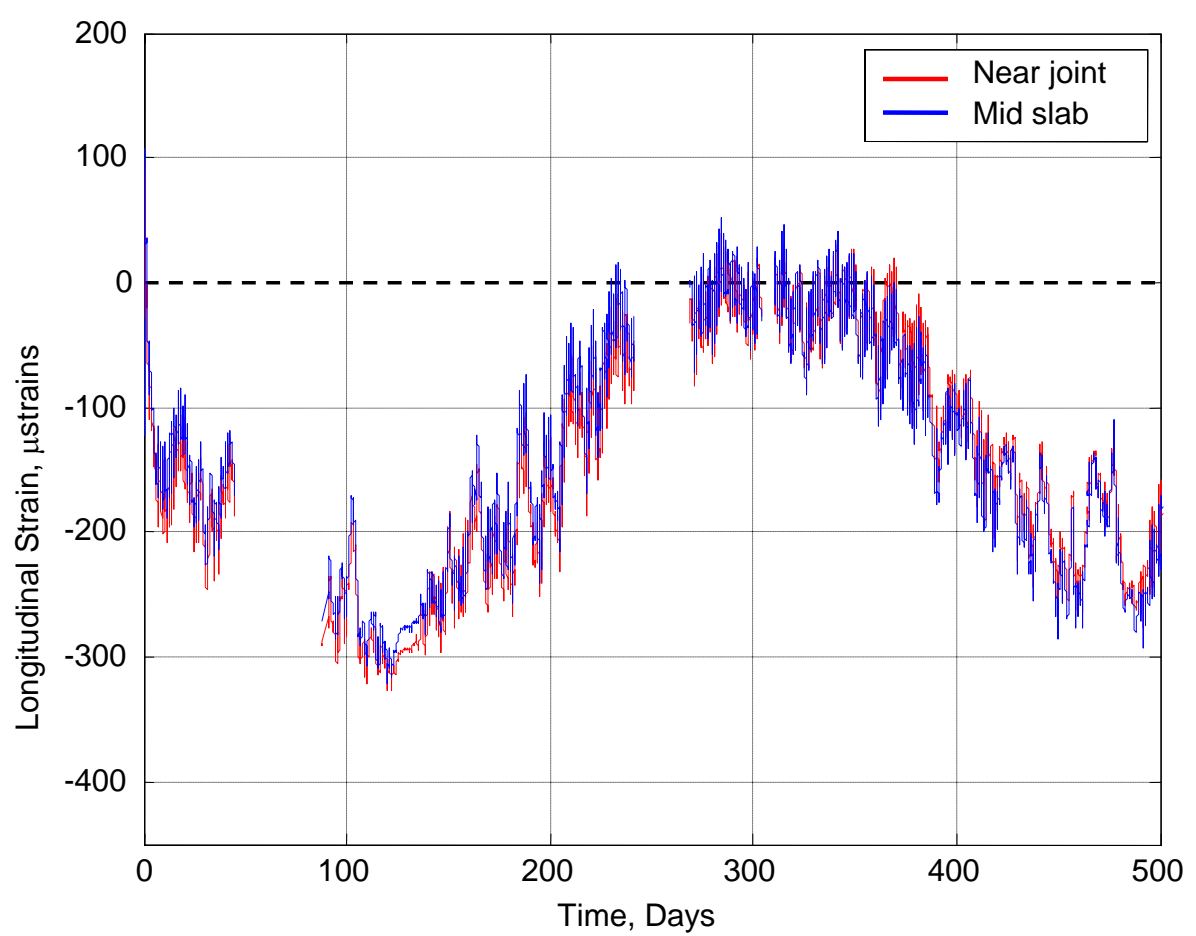

(b) Slab Bottom

Figure 4.3: Longitudinal Strain Histories in the Slab Fitted with Shok Bars. 


\subsubsection{Free slab on low friction base (Smooth base)}

In Figure 4.4 (a) and (b), the strains and temperature show a large amount of variation in one day near the slab edge. There were no constraints for the movement of the free slab except for slab/base friction which was negligible. The higher compressive strains at the slab top near the transverse edge and lower compressive strains at the slab bottom indicate that the slab curls upwards. The freedom to curl is restricted in the slabs fitted with load transferring devices, where stresses would develop around the devices and throughout the slab when the slab tends to curl due to temperature gradient through the thickness of the slab. The temperature history of the slab was identical to the slab fitted with dowel bars, hence was not plotted in this section.

\subsubsection{Free slab on high friction base (Coarse base)}

As can be seen from Figure 4.5 (a) and (b), the edge shows higher compressive strains than the center at the top of the slab which is similar to the slab with low friction subgrade. 


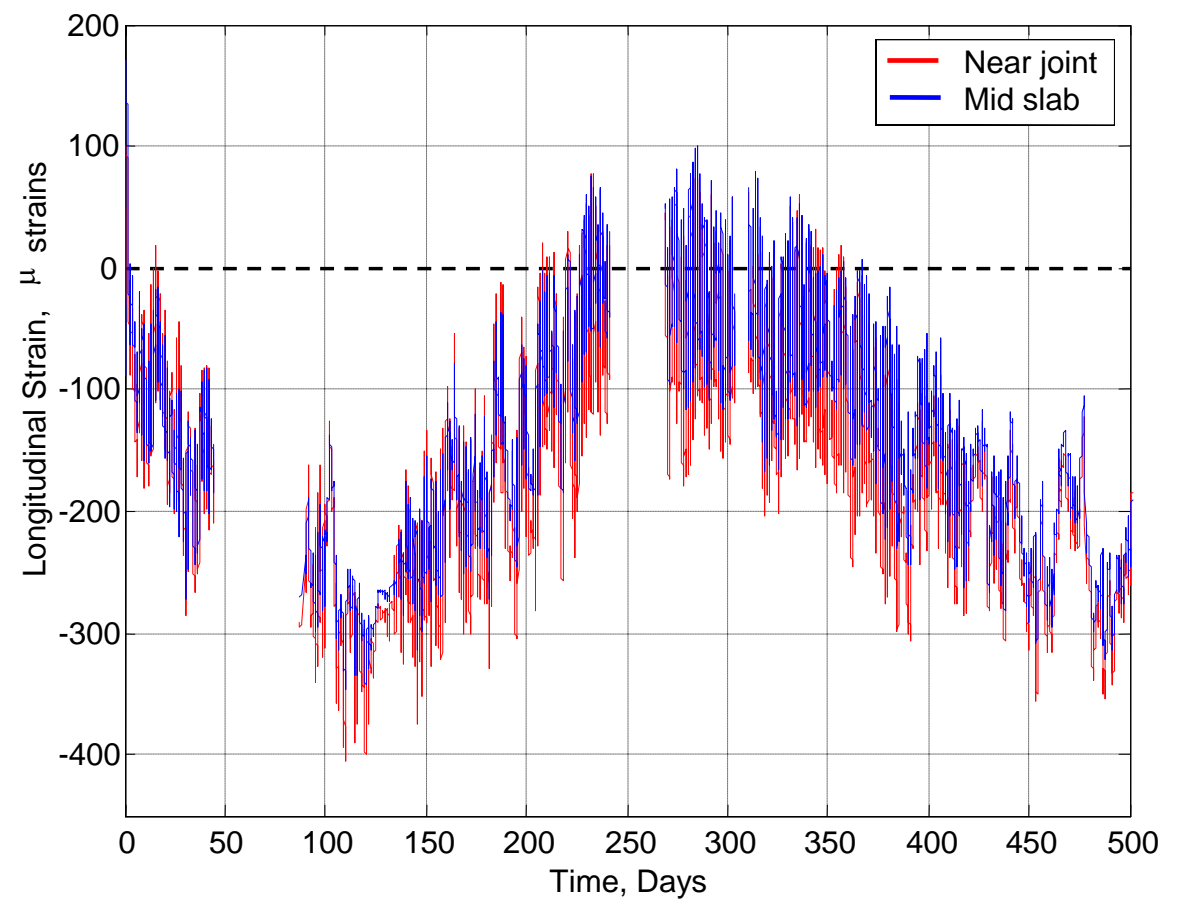

(a) Slab Top

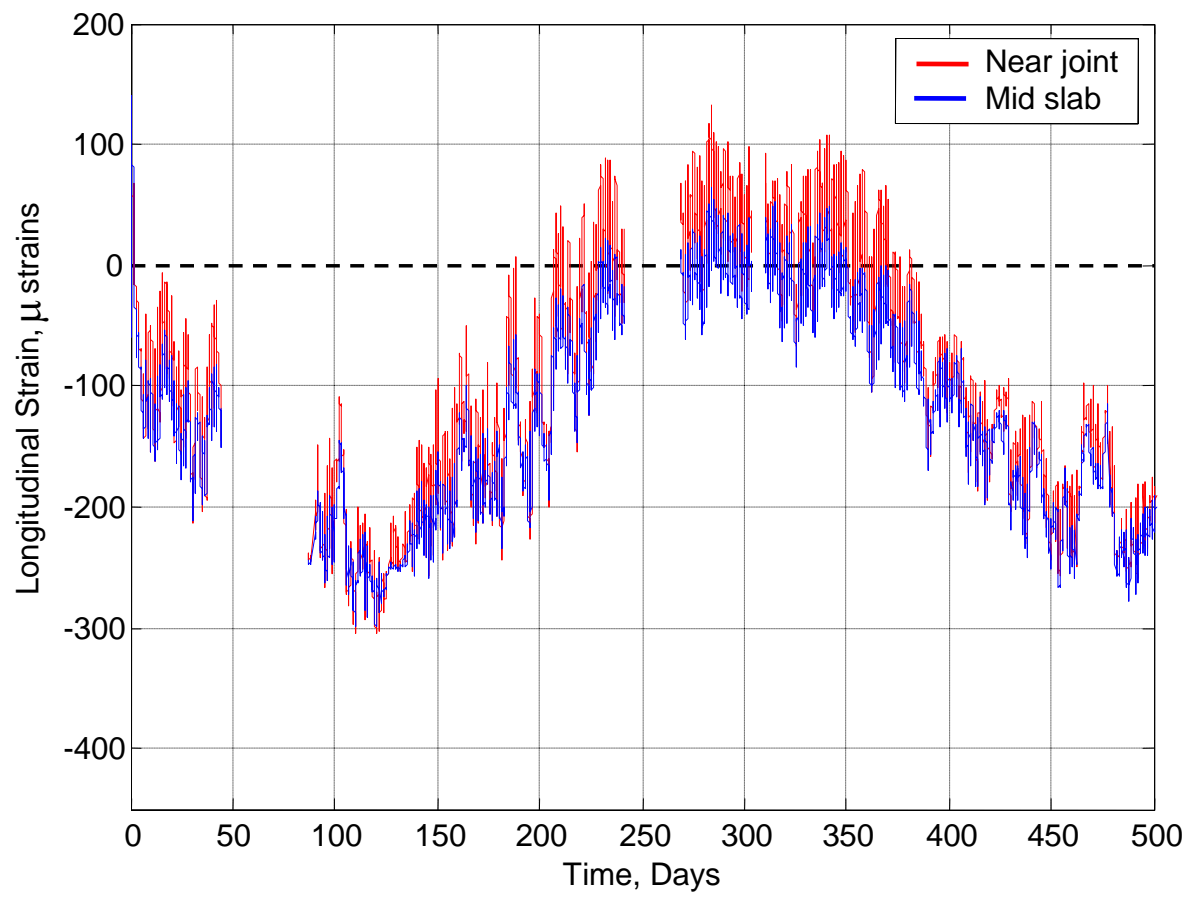

(b) Slab Bottom

Figure 4.4: Longitudinal Strain Histories Measured in the Free Slab on Smooth Base. 


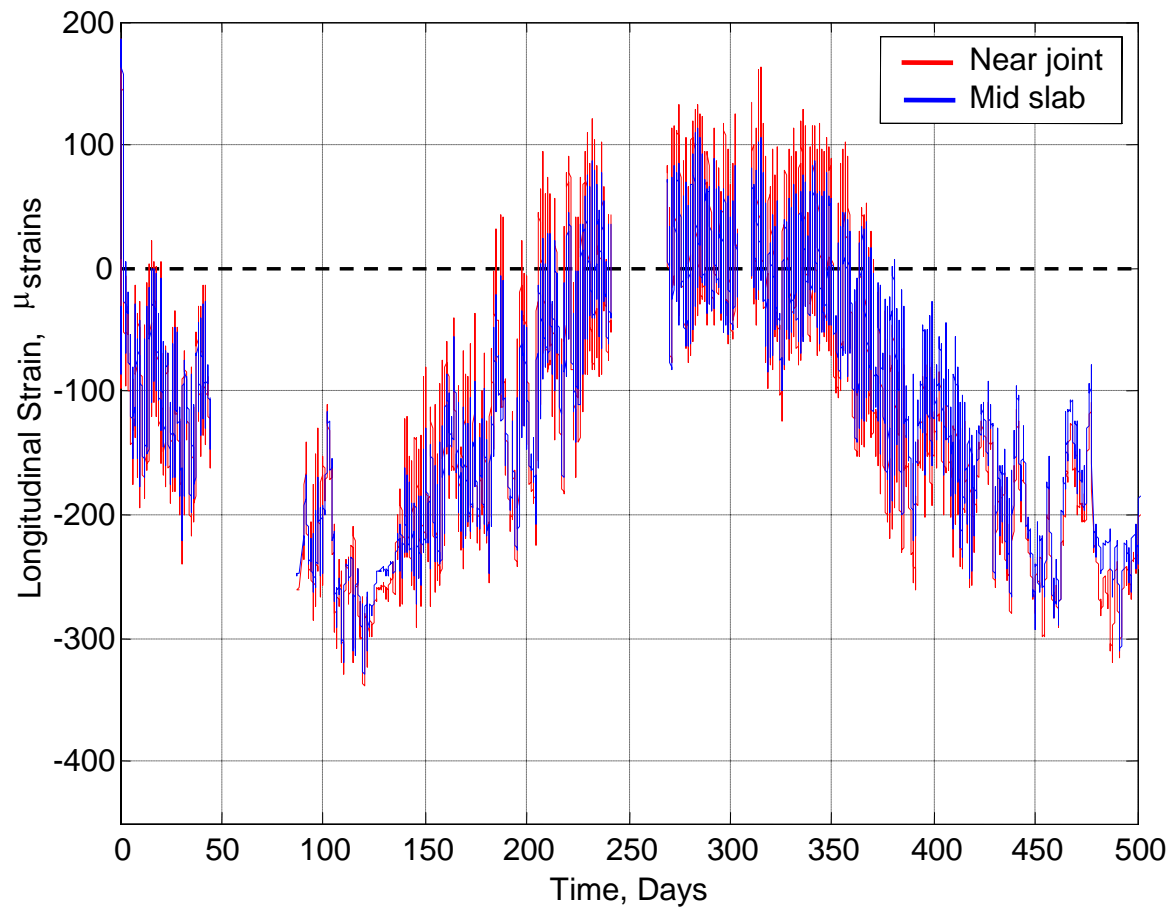

(a) Slab Top

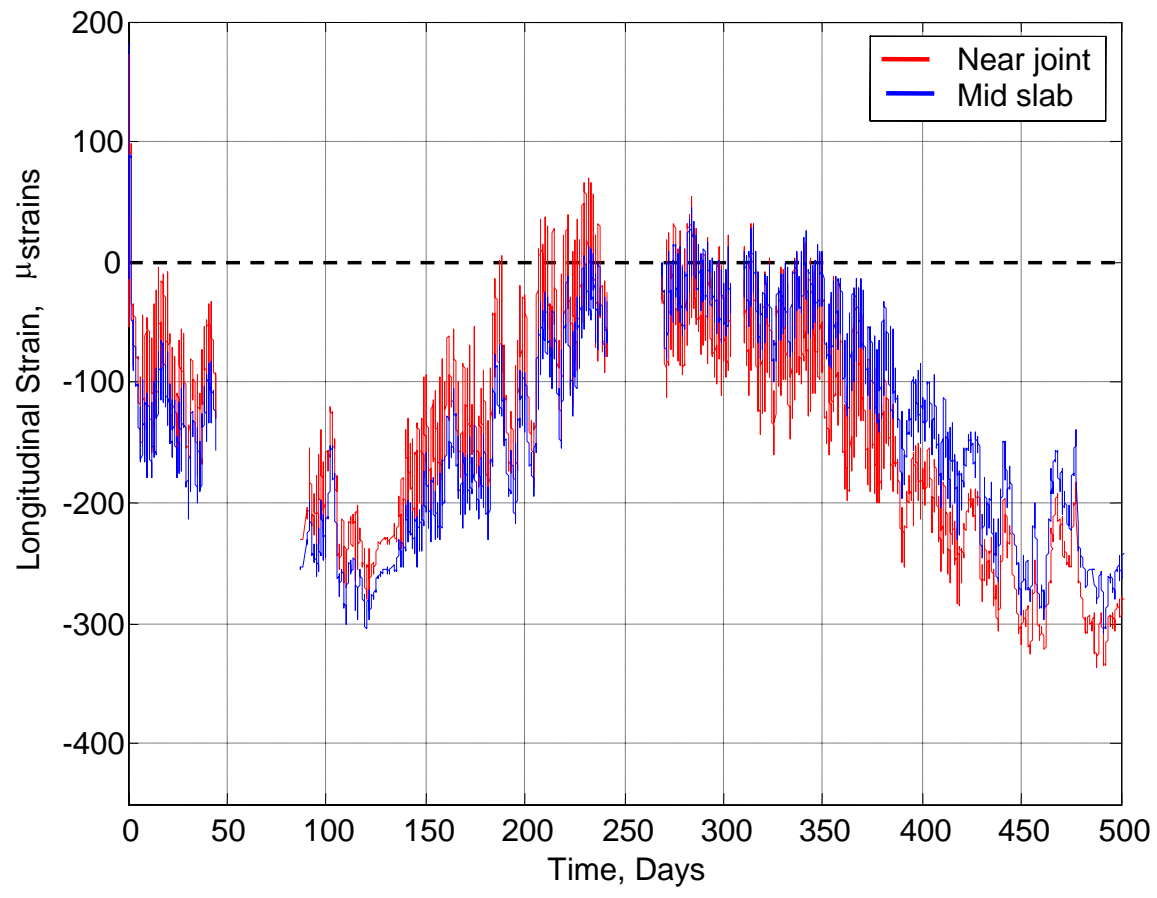

(b) Slab Bottom

Figure 4.5: Longitudinal Strain Histories Measured in the Free Slab on Coarse Base. 


\subsection{CONTRIBUTERS TO SLAB VOLUMETRIC CHANGE}

The longitudinal strain histories presented in Figures 4.1 through 4.5 indicate that concrete slabs undergo volumetric changes during their service life. The strain measured at any instant of time is sum of strains due to drying shrinkage, construction curling, and temperature variations. The longitudinal strain due to temperature variation can be expressed in terms of the coefficient of thermal expansion $\alpha$ (about $10.8 \mu$ strains $/{ }^{\circ} \mathrm{C}$ ) and the amount of temperature variation $(\Delta \mathrm{T})$ assuming one dimensional model as:

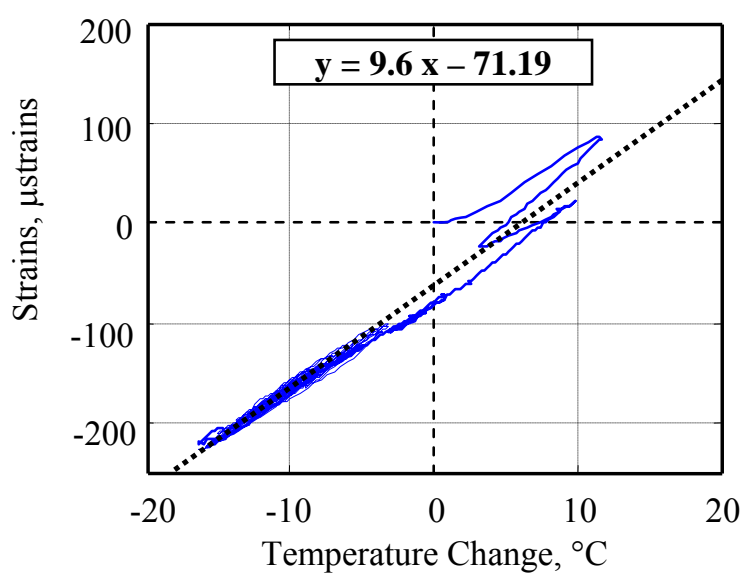

(a) Slab with Regular Dowel Bars.

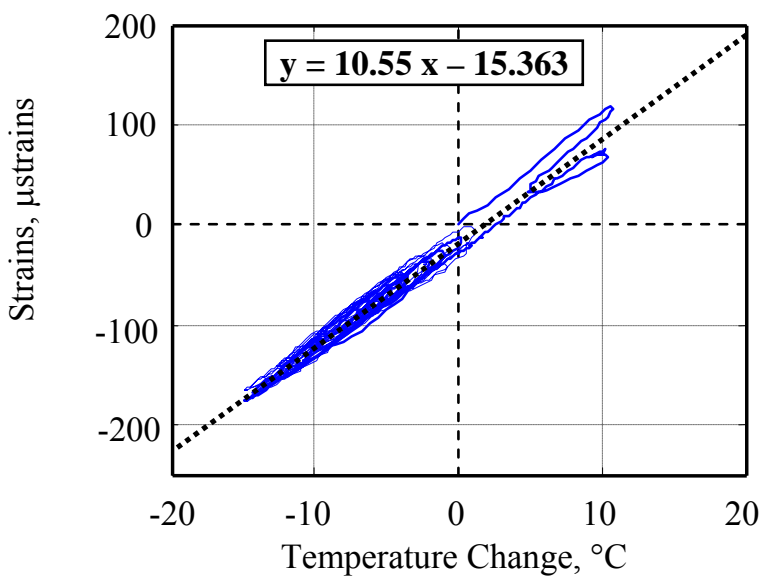

(c) Free Slab on Smooth Base.

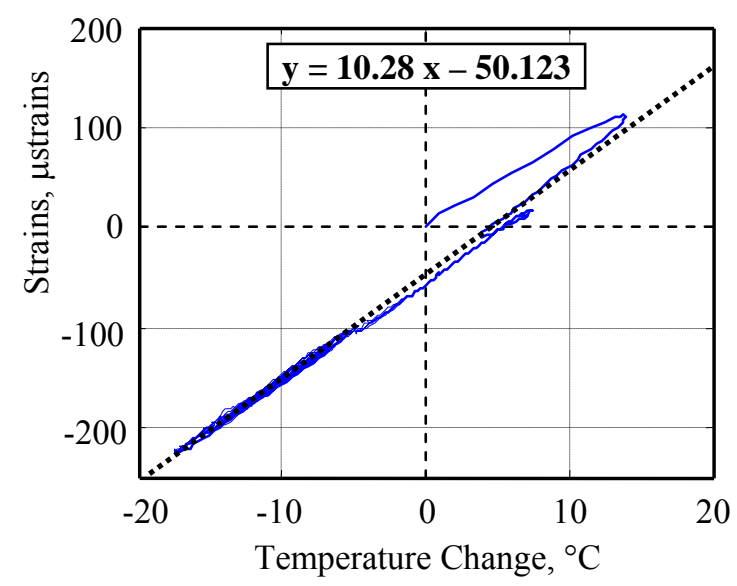

(b) Slab with Shok Bars.

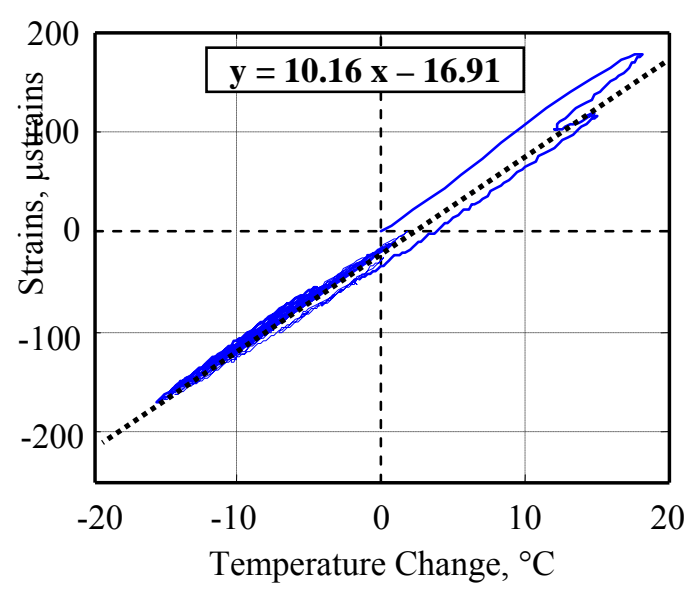

(d) Free Slab on Coarse Base.

Figure 4.6: Strain versus Temperature Change in Different Slabs 
where $\mathrm{C}$ is a constant which depends on the constraints, $\mathrm{C}=0$ for a fully constrained slab and $\mathrm{C}=1$ for a free slab.

If a concrete slab undergoes a cyclic temperature change only, so that the end temperature is the same as the initial temperature $\left(\Delta \mathrm{T}=0^{\circ}\right)$, the residual strain induced in the slab at the end of such a cycle should be zero. However, due to other volumetric changes and slab end constraints, slab would develop strains when $\Delta \mathrm{T}=0^{\circ}$. Also if a slab is free to contract and expand due to temperature variations, the constant $\mathrm{C}$ in Equation 4.1 should be equal to one and the temperature-induced strain will be equal to the product of the coefficient of thermal expansion and amount of temperature change. However, due to the effect of the constraints due to dowel bars and slab-base friction, the value of $\mathrm{C}$ will vary depending upon the degree of constraints offered by such external forces.

The following assumptions were made for the discussions that follow:

a) Friction at the slab/base interface is minimal for the slabs fitted with Regular dowels and Shok Bars and the free slab laid on the smooth base. This assumption is justified due to the careful preparation of the base below these three slabs as described in Chapter Three - Field Instrumentation.

b) The composition of concrete is the same in all four slabs. This implies that the material properties such as Modulus of elasticity and Poisson's ratio of the slabs are equal.

c) The effect of change in moisture/ humidity is identical in all slabs.

In order to quantify the contribution of drying shrinkage, construction curling, and temperature variations to the measured built-up strain in concrete slabs under different external constraints, the longitudinal strains measured near the transverse edge were plotted versus temperature change as in Figure 4.6. The plots in temperature-strain plots were made using the data collected during the first 28 days after concrete pouring. The plots in Figure 4.6 (a) through (d) indicate that in the four slabs under examination, the 
strain change linearly with the change in temperature. Table 4.1 summarizes the values of the slope and the intercepts of the straight line relation that best fits the measured data.

Table 4.1: Slope and Intercepts of the Linear fits to the Strain versus Temperature.

\begin{tabular}{|c|c|c|c|c|}
\hline $\begin{array}{c}\text { Considering the } \\
\text { First 28 days }\end{array}$ & $\begin{array}{c}\text { Slab with } \\
\text { dowel bars }\end{array}$ & $\begin{array}{c}\text { Slab with Shok } \\
\text { bars }\end{array}$ & $\begin{array}{c}\text { Free slab on } \\
\text { smooth base }\end{array}$ & $\begin{array}{c}\text { Free slab on } \\
\text { coarse base }\end{array}$ \\
\hline Slope & 9.61 & 10.28 & 10.55 & 10.16 \\
\hline $\begin{array}{c}\text { Residual } \\
\text { Strain/Intercept }\end{array}$ & -71.19 & -50.12 & -15.64 & -16.91 \\
\hline
\end{tabular}

\section{Interpretation of the slope:}

The slope of the straight line represents the quantity $(C \alpha)$ in Equation 4.1. As expected, the free slab on smooth base has the highest slope signifying maximum freedom of movement at the slab free edge $(C=0.98)$. The slab fitted with regular dowel bars has the smallest slope indicating that the edge is restricted to move due to the constraints introduced by the dowel bars $(\mathrm{C}=0.88)$. The relative higher slope of the slab with Shok Bars implies lesser constraints presented by the Shok Bars $(C=0.95)$. The friction due to the coarse base under the fourth slab decreases the movement of the slab edge $(C=0.94)$.

\section{Interpretation of the intercept:}

The slab undergoes compression in the early age due to various reasons such as drying shrinkage, decrease in ambient temperature resulting in uniform change in slab temperature and also due to variations in concrete moisture contents. When the concrete is poured, it is in an unstressed state. The strains build up with time as the concrete dries and with changes in the environmental conditions.

The intercept values indicate the amount of permanent strain induced in the slab due to shrinkage, temperature and moisture changes. It can be seen that the slab with dowel bars developed the maximum amount of permanent strain. Since the four slabs differ only in the manner of their constraints the additional strains recorded can be 
attributed to these constraints. The presence of dowel bars acts as an external constraint to the contraction and expansion of the slab. The adhesion between the bars and the surrounding concrete and the bar bending due to slab curling are the causes of such constraints on the slabs. The slab with Shok Bars has a lower intercept since a part of the strain is allowed to recover assisted by the movement of the sleeve of the Shok Bar along the bar. The slab on coarse gravel (crushed base) too builds up strains and does not recover from the initial contraction. It can be noted that the permanent strain develops in each slab during the first 24 hours, and then it varies about that value with changes in time and temperature (refer Figure 4.6).

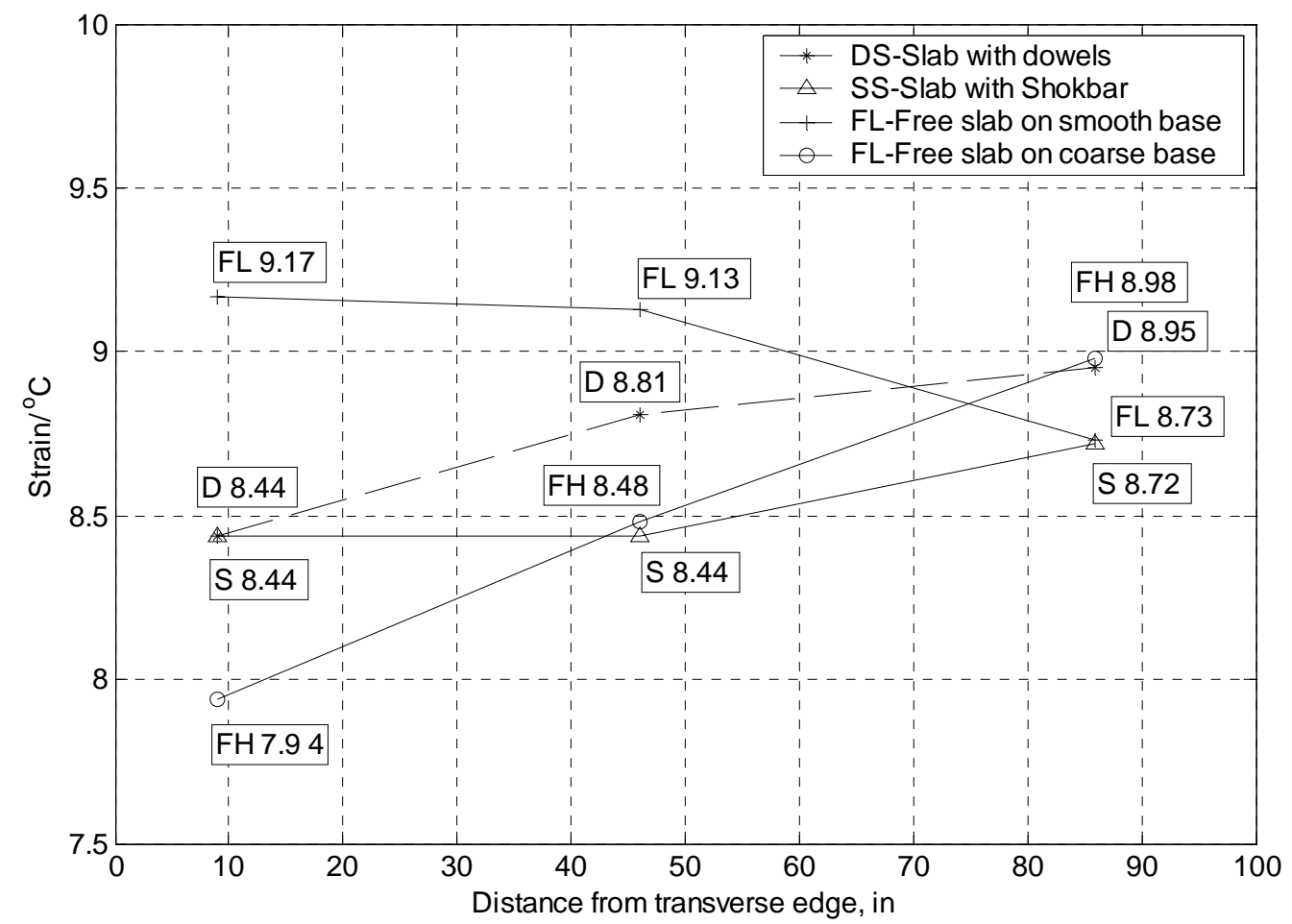

Figure 4.7: Strains $/{ }^{\circ} \mathrm{C}$ along the longitudinal axis of the slabs.

The response of the slabs to uniform change in temperature across the slab thickness was also analyzed by evaluating the strain at the neutral surface of the slab. The Figure 4.7 shows the variation of the slope values of strain-temperature relations along the longitudinal direction of the slabs i.e. in the direction of vehicular travel. 
Referring to Figure 4.7, the slope of the strain-temperature relation in the free slab reduces from the edge of the slab to the slab center. Both the slabs with dowel bars and Shok Bars in the joints have lesser edge movement due to the constraints and the resulting strain moves towards the slab center. Though the trend of the curve for the slabs with external constraints is the same, the slab with Shok Bars has a lower value at the mid slab closer to the behavior of the free slab. The higher strain $/{ }^{\circ} \mathrm{C}$ difference between the slab edge and its center is an indication of the slabs susceptibility to mid slab cracking which is higher in the case of the slab with regular dowels. The variation in the strain $/{ }^{\circ} \mathrm{C}$ values at the slab edge of the slab on coarse subgrade shows the effect of nonuniform slab/base friction across the slab compared to the smooth base.

\subsection{MID SLAB STRESSES}

In 1926, Westergaard identified two components of thermal stresses in concrete slabs arising from the two components of temperature change. The first component was named "uniform change in temperature" and the second "linear or nonlinear change in temperature". Figure 4.8 illustrates an example of the components of a temperature increase.

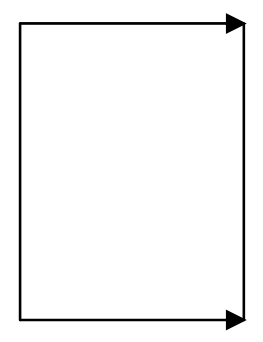

Uniform Temperature Increase

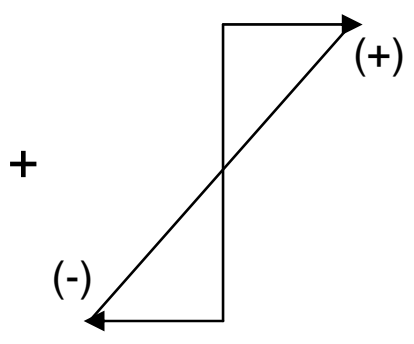

Positive Linear Temperature Gradient

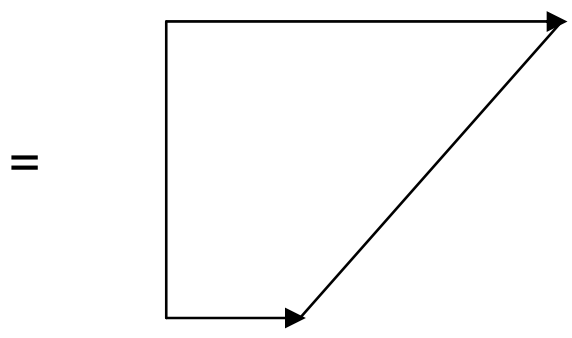

Total Temperature Increase

Figure 4.8: Components of temperature change (Temperature Increase).

Westergaard stated that the stresses resulting from these two major components should be combined by algebraic addition to produce the overall thermal stress distribution in the slab. The stresses due to uniform change in temperature have been 
greatly neglected by the earlier researchers justifying that the uniform change will generate a uniform change in strain all over the slab thus stress developed is zero. However, laws of thermo-elasticity described by Boley and Weiner (1985) state that stresses due to uniform temperature change will develop if one or more of the following conditions exist:

1. High friction between the slab and base

2. End constraints from bent dowel bars introduce stresses due to restriction to slab expansion and contraction (William and Shoukry, 2001).

3. The slab contains any geometrical discontinuity such as the holes that contain the dowel bars in a finite length slab.

Considering the slab to be in a plane stress condition, the temperature-induced stresses in the slab can be calculated as follows:

$$
\begin{gathered}
\text { Longitudinal stress: } \sigma_{x x}=\frac{E}{\left(1-v^{2}\right)}\left[\varepsilon_{x}+v \varepsilon_{y}-\alpha(1+v) \Delta T\right] \\
\text { Transverse stress: } \sigma_{y y}=\frac{E}{\left(1-v^{2}\right)}\left[\varepsilon_{y}+v \varepsilon_{x}-\alpha(1+v) \Delta T\right]
\end{gathered}
$$

Where $v=$ poisons ratio

$\varepsilon_{\mathrm{x}}$ and $\varepsilon_{\mathrm{y}}$ longitudinal and transverse strains measured at the site

$\alpha=$ thermal expansion of concrete $=10.8 \mu$ strains $/{ }^{\circ} \mathrm{C}$

$\Delta \mathrm{T}=$ temperature change.

As seen in Figure 4.9 (a), compressive stresses develop in the slab during the initial period of concrete curing at the mid-slab. Though the temperatures of the four slabs are comparable after around two days as in Figure 4.9 (b), the stress developed initially in the slab fitted with dowel bars and Shok Bars remain in the slabs and do not recover. This residual stress remains largely unrelieved in the case of the slab with dowels bars unlike the slab fitted with Shok Bars. This behavior can also be observed in Figure 4.10 which shows the time-histories of the stresses developed in the slabs over the first 28 days. The effect of the dowel bars resulting in the compressed state of the slab is noticed in the stresses even after over a year. The existence of compressive stresses in the 
slab is good, as concrete is weak in tension, and any decrease in temperature will result in the stress levels below the modulus of rupture of concrete. However, these slabs developed compressive stresses due to the volumetric growth associated with the temperature increase during the first two days after concrete casting as indicated in Figure 4.9 (b). If the slab was poured during a hotter day that was followed by a temperature decrease at night as it is the most common case, then they would have developed tensile stresses in the initial stages of curing. This residual tensile stress would have aggravated with a considerable increase in temperature.

The behavior of the slab with Shok Bars is closer to the reference free slab on low slab/base friction than is the slab with regular dowels. Although, the changes in the temperature are the same in both slabs, magnitude of residual stresses in the slab fitted with Shok Bars is lower. Apparently, the relative larger freedom for movement at the slab edges offered by the moveable sleeves on the Shok Bars enables the slab to relieve some of the accumulated stress at the slab center. 


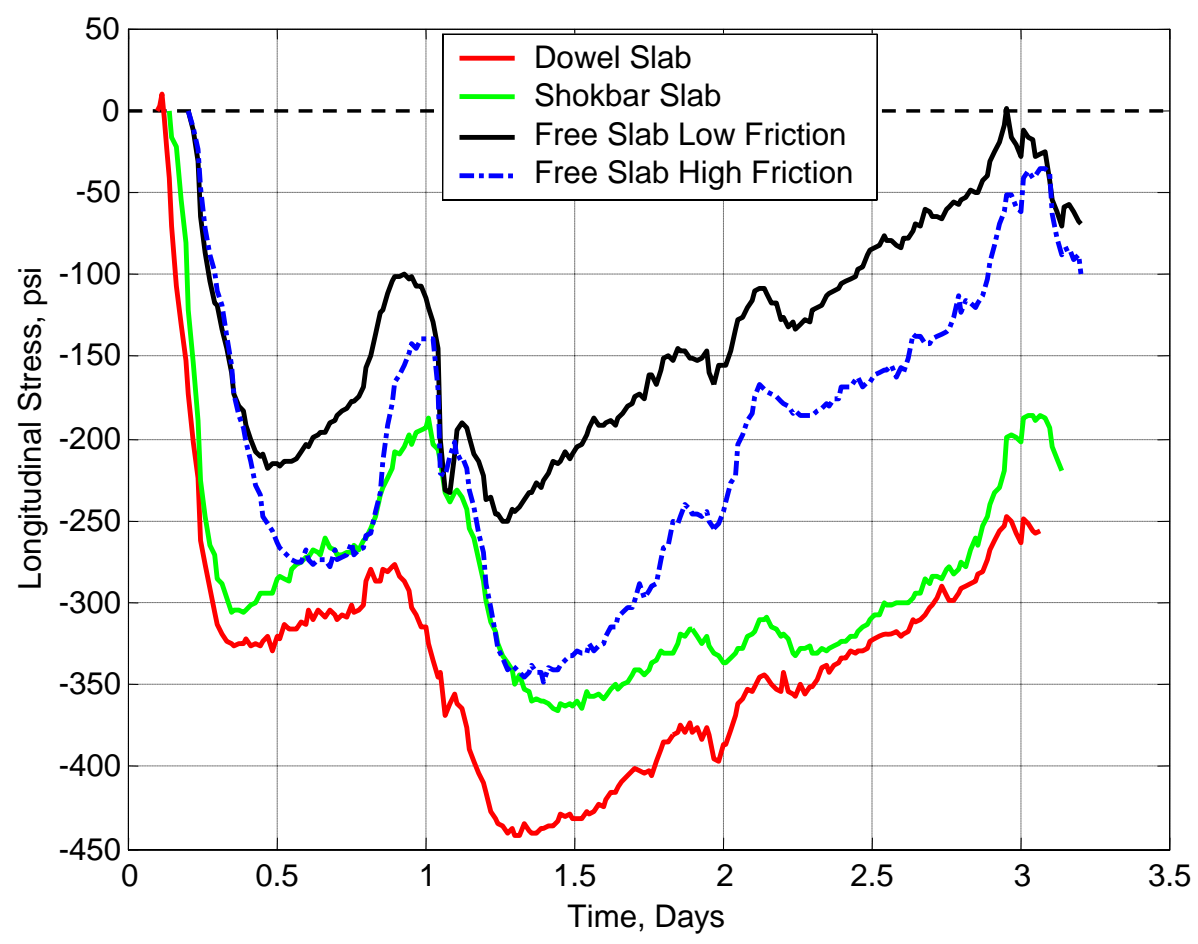

(a) Longitudinal Strains

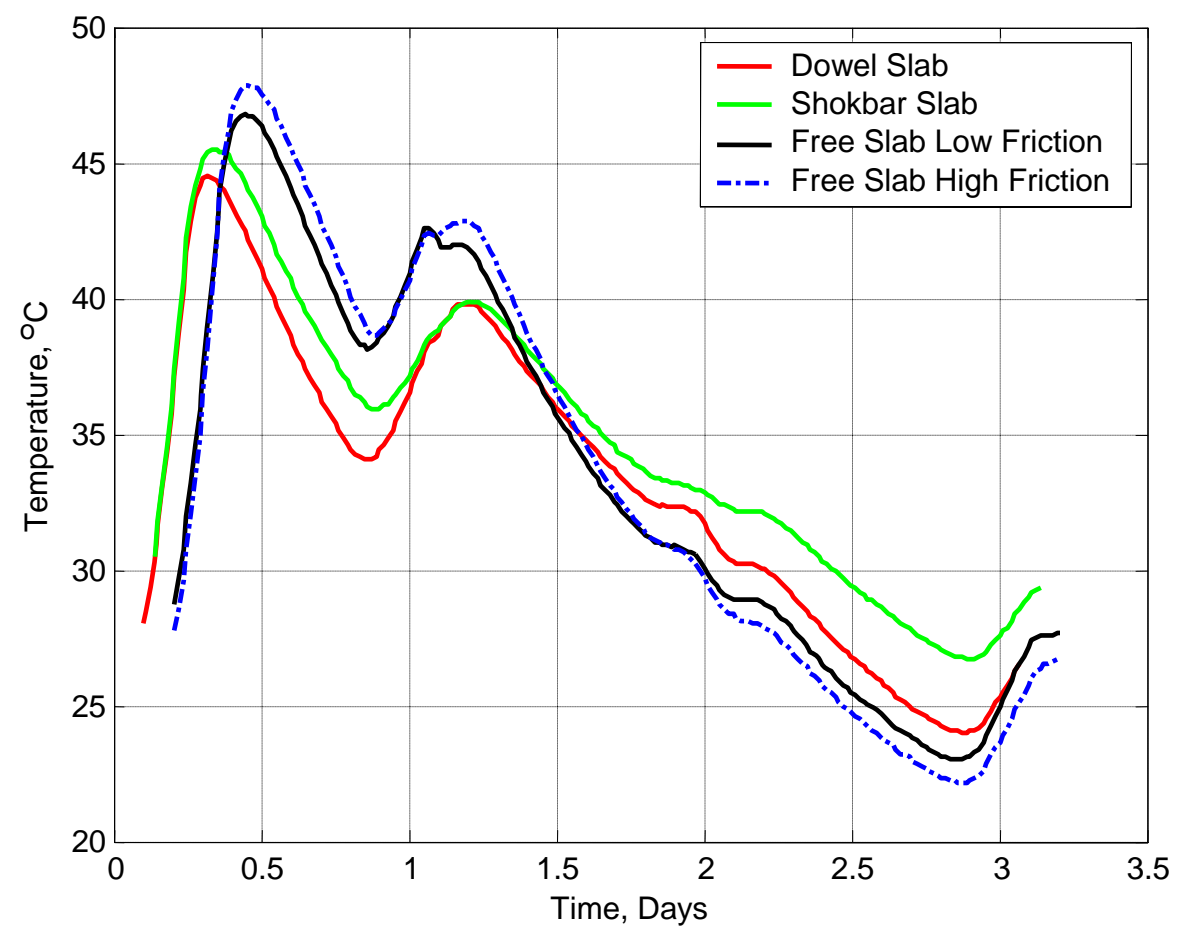

(b) Temperature History

Figure 4.9: Stresses Developed in Concrete during the First Three Days 


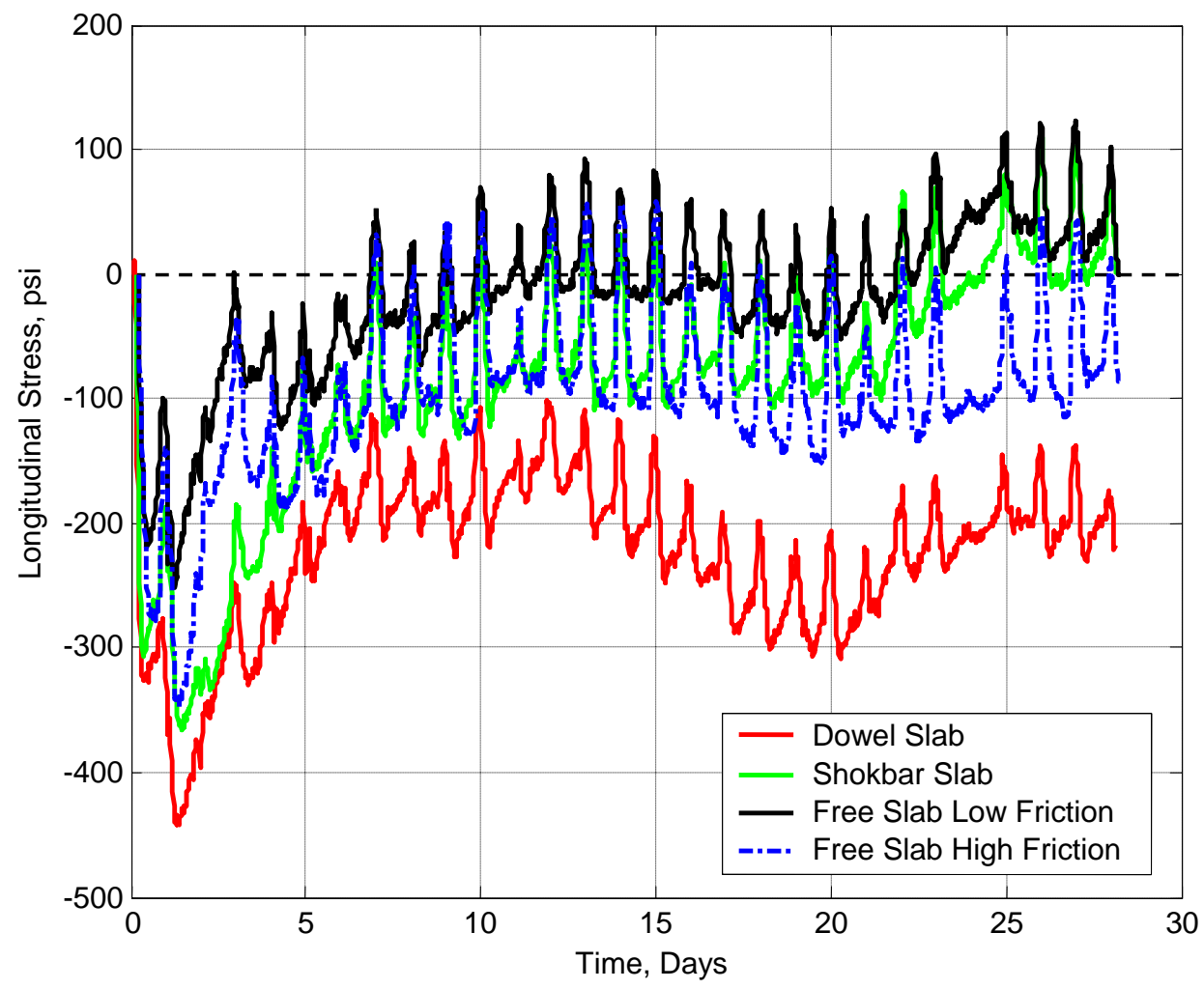

Figure 4.10 Time History of Mid-Slab Stresses Developed in the First 28 Days.

\subsection{BENDING MOMENT AND AXIAL FORCES IN THE BARS}

The bending moment and axial forces developed in the Shok bars and dowel bars were examined. The strain gages embedded at the top and bottom of the load transfer bars were used to evaluate these parameters.

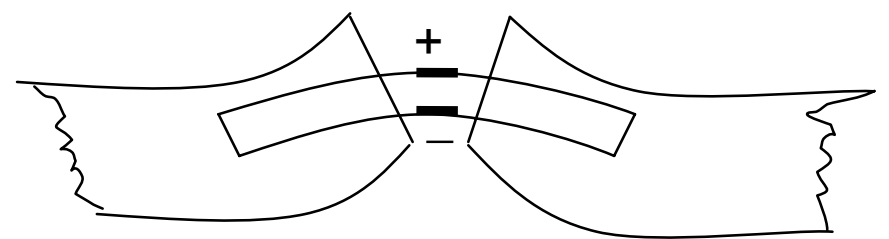

Figure 4.11: Positive and negative strains in the bars.

Figure 4.11 illustrates the bending of a load transfer device due to slab curling in response to a negative temperature gradient through the slab thickness. The negative temperature gradient is defined as when the temperature of the slab top is lower than the slab bottom. A positive gradient is said to be present when the temperature at the slab top 
is higher compared to the slab bottom. As the slabs curl they bend the bars along with them, thus creating a difference in the strains at the top and bottom of the bars. The dowel and Shok Bars bend as shown in Figure 4.11 with the bar top in tension and bottom in compression when a negative temperature gradient exists. This bending is defined as positive bending of the bar and results in a positive bending moment. The reverse is true during a positive temperature gradient; a negative bending moment results. Axial force is the force exerted along the axis of the bar due to contraction or expansion of the slab. The bending moments were calculated by taking the difference in the readings of the top and bottom strain gages and the axial forces are estimated using the average of the two strains using the equations:

$$
\begin{gathered}
\text { Bending moment: } B M=\frac{\left(\varepsilon_{\text {top }}-\varepsilon_{\text {bottom }}\right) E I}{2 y} \\
\text { Axial Force: } A F=\frac{\left(\varepsilon_{\text {top }}+\varepsilon_{\text {bottom }}\right)}{2} E A
\end{gathered}
$$

Where $\varepsilon_{\text {top }}$ and $\varepsilon_{\text {bottom }}$ are strains at the top and bottom of the bar respectively

$\mathrm{E}=$ Modulus of Elasticity of steel

$\mathrm{I}=$ Moment of Inertia of bar

$\mathrm{y}=$ distance from the neutral axis to the location of the strain gages

$\mathrm{A}=$ Cross-sectional Area of bar

As mentioned in Chapter 3, there are five jointed slabs. Slabs1-2 and slabs 2-3 are jointed with regular dowel bars. The joints between slabs 3-4 and slabs 4-5 are fitted with Shok Bars of which the bars between slabs 3-4 are instrumented.

\subsubsection{Bending moments}

The bending moment and axial forces in the bars located at the joint center, averaged over the first 500 days was calculated and is reported in Figure 4.12.

A higher positive bending moment is observed in the Shok Bars. The large value of bending moment is due to the initial large edge curling of the slab with Shok Bars. Dowel bars developed less bending moments indicating more constraints on slab curling. 
The Shok Bars provide better bending capabilities to the edge and do not constrain it as much as the regular dowel bars do. This helps in relieving some of the stresses that might arise due to slab edge bending. Also, it can be noticed that there is about $50 \%$ difference in the magnitude of the dowel bending recorded at the corner dowel in the slabs fitted with regular dowels and along the wheel path in the slab fitted with Shok Bars (Figure 4.14). This indicates that an asymmetry in the behavior of the load transferring devices along the pavement length can be expected.

During a positive temperature gradient i.e. when the temperature at the slab top is higher compared to the slab bottom the slab tends to curl downwards. This bends the bars in the opposite direction giving rise to negative bending moments. As can be seen in Figure 4.12 the Shok Bars show lesser negative bending moments. The average of negative bending moment in the Shok Bars indicates the slab with Shok Bars does not undergo much reversal of curling and has a permanent curling. This would reduce the reversals of stress thus increasing the fatigue life of the slabs.

\subsubsection{Axial forces}

The axial force experienced by the Shok Bars and dowel bars gives the degree of the constraints that the bars offer to uniform change in slab temperature. The bars are subjected to positive axial forces when the slabs contract due to temperature decrease i.e. when the bars are pulled at either end. As seen in Figure 4.12, the axial forces in the Shok Bars are less compared to dowel bars indicating that the slabs are able to move/slide more freely on the Shok Bars; thus building up lesser stresses in the Shok Bars. The dowel bars offer more resistance to the slab contraction and expansion, which could arise due to their bent position and the higher friction or adhesion between the bars and the concrete. Similar conclusions about the bending moments and axial forces can be made from the data of the bars along the wheel path and slab corner as shown in Figure 4.13 and Figure 4.14. 


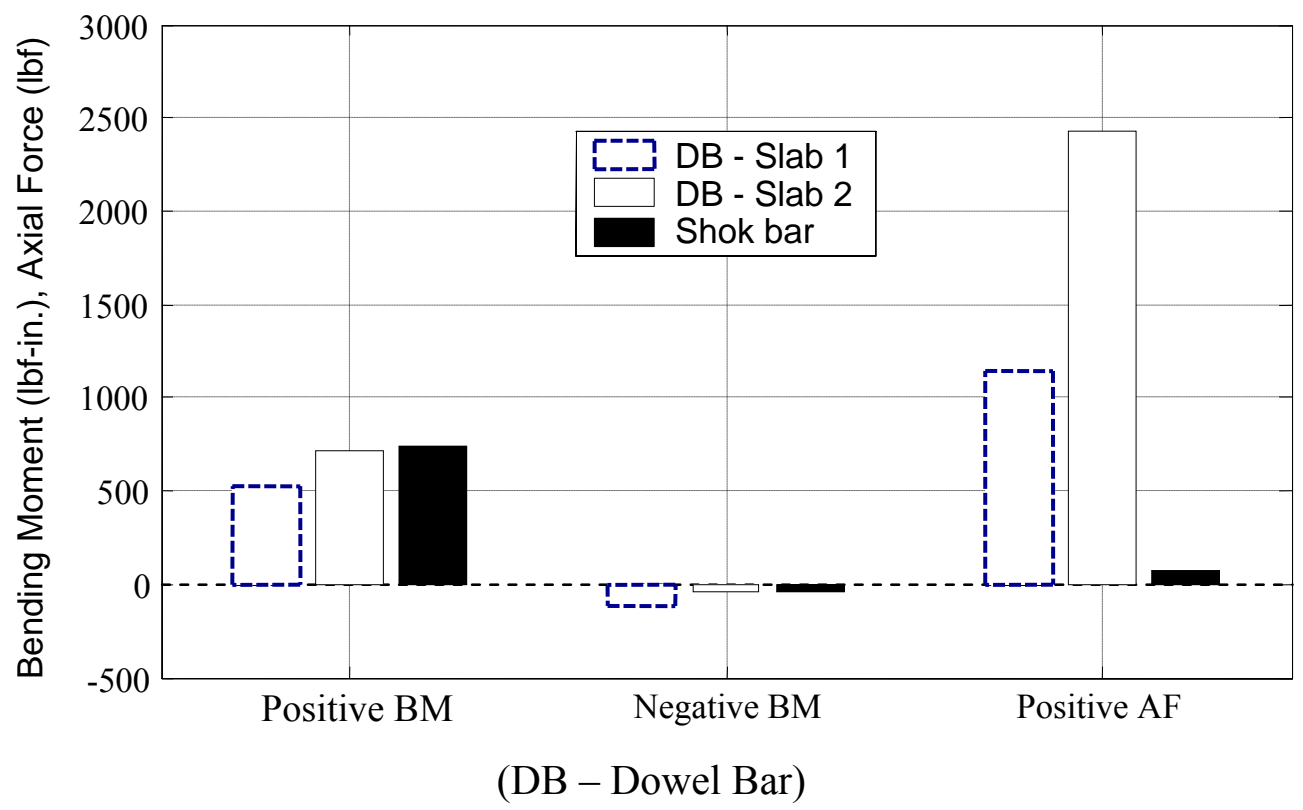

Figure 4.12: Average Bending Moments and Axial Forces in Bars at joint center.

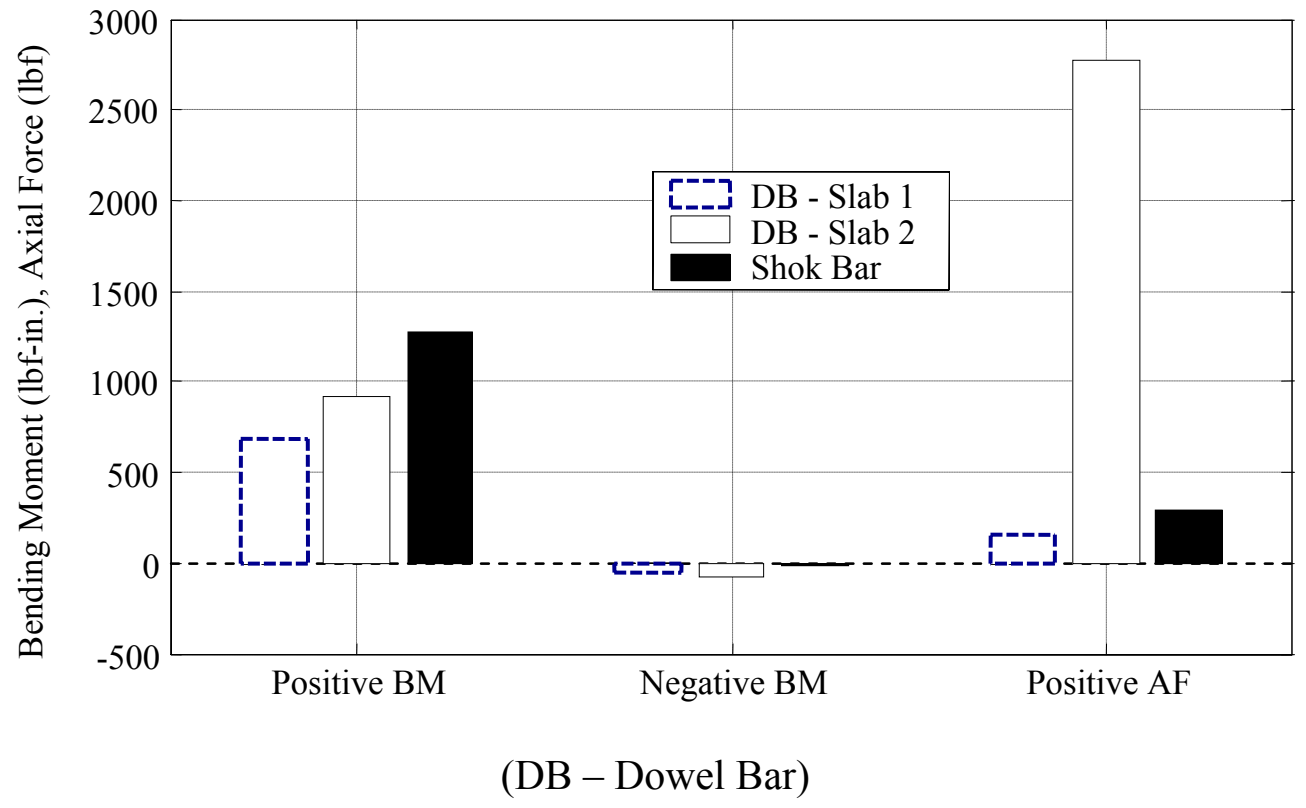

Figure 4.13: Average Bending Moments and Axial Forces in Bars at Wheel Path. 


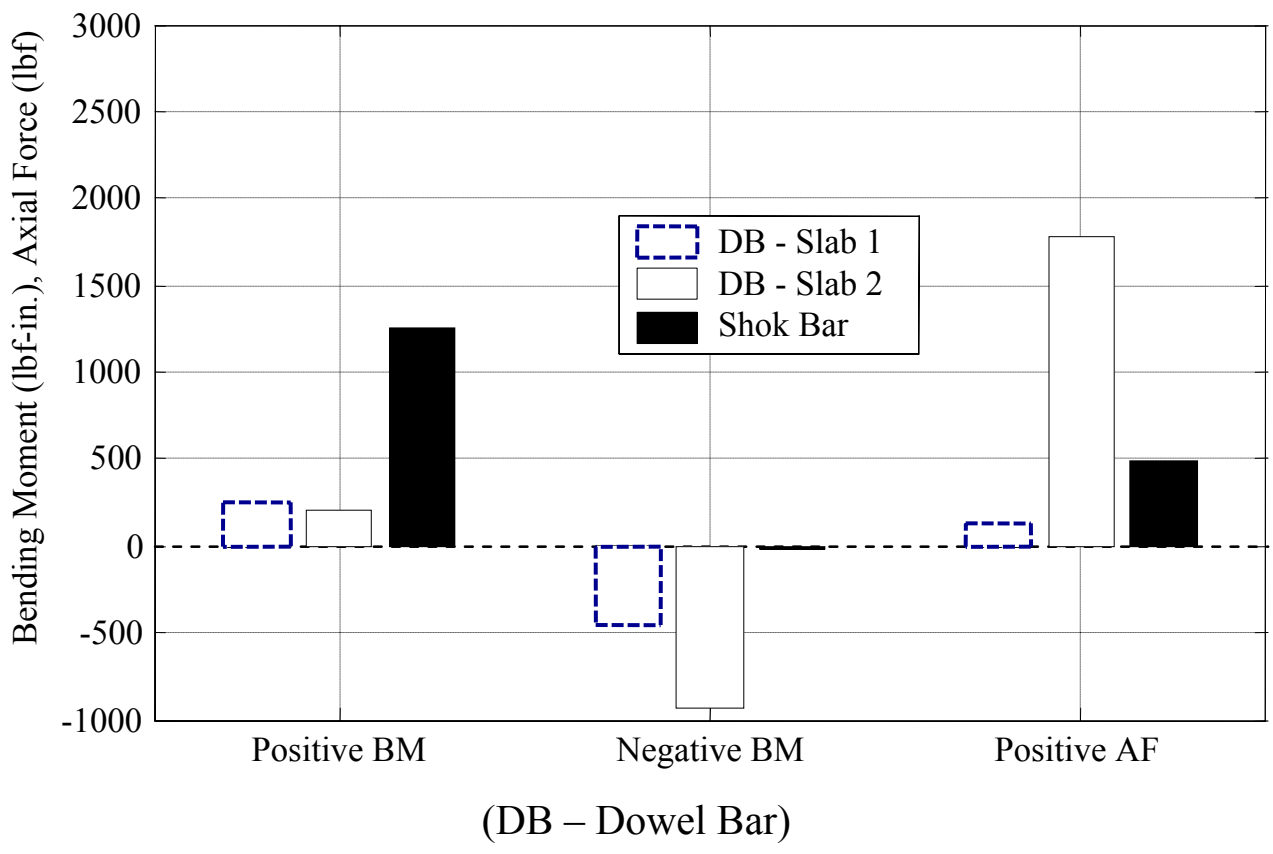

Figure 4.14: Average Bending Moments and Axial Forces in Bars at Slab Corner.

\subsection{AXIAL FORCES ALONG THE TRANSVERSE JOINT}

This section presents a detailed study of the axial forces the regular dowel bars and the Shok Bars. As seen in Figures 4.12 to 4.14, the axial forces developed in dowel bars at the joint center, wheel path and slab corner differ a lot from each other. This indicates that the amount of contraction or expansion of the slab varies along the transverse joint, the corner experiencing maximum movement.

Figure 4.15 shows the history of the measured mean slab temperature at the slab joint. Ideally, as the temperature increases, the slab expands resulting in the bars experiencing compressive forces. But as seen in Figure 4.16 and 4.17 the dowels experience tensile forces (positive axial force - pulling of the dowel) during the temperature increase after 200 days expect in the corner dowel of the first joint. This phenomenon could have occurred due to development of looseness between the dowels and the surrounding concrete. 


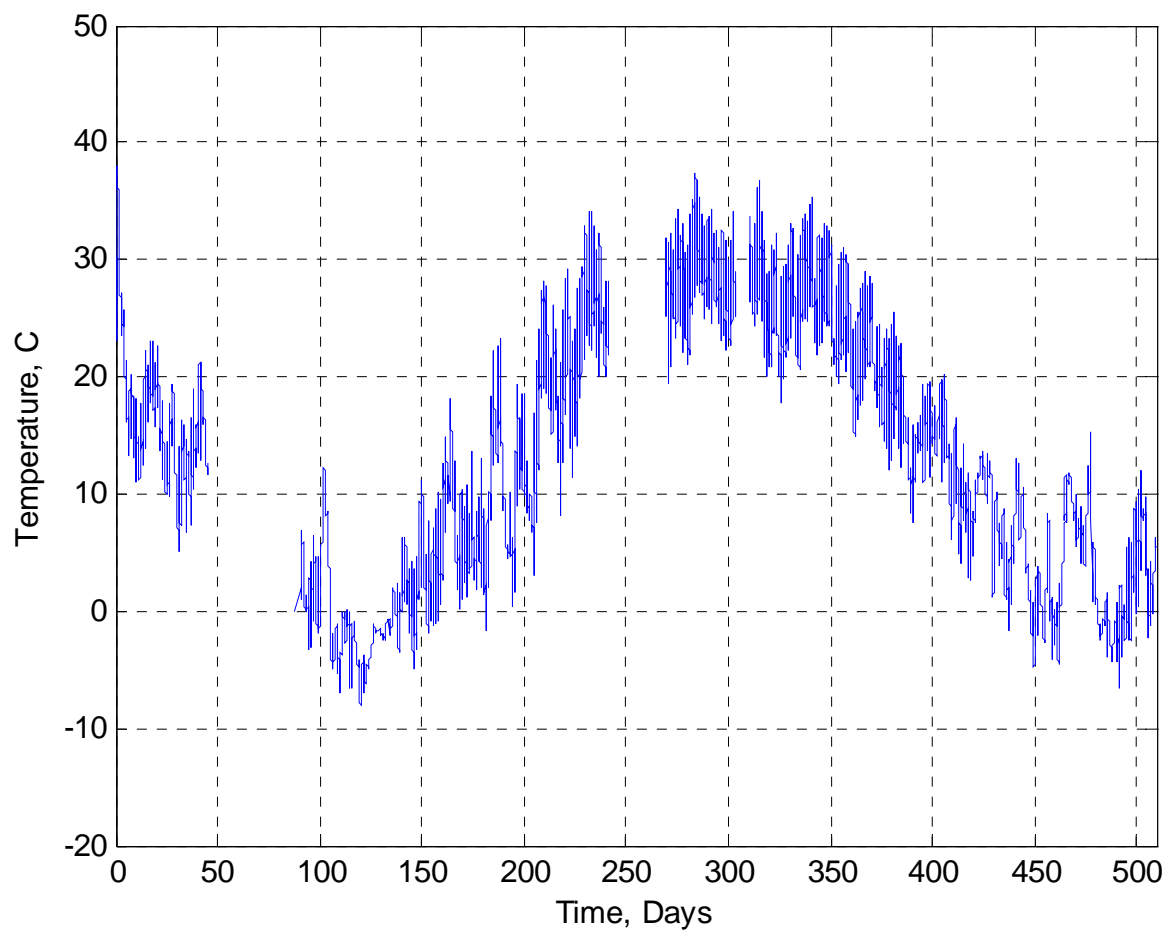

Figure 4.15: History of the Measured Mean Slab Temperature

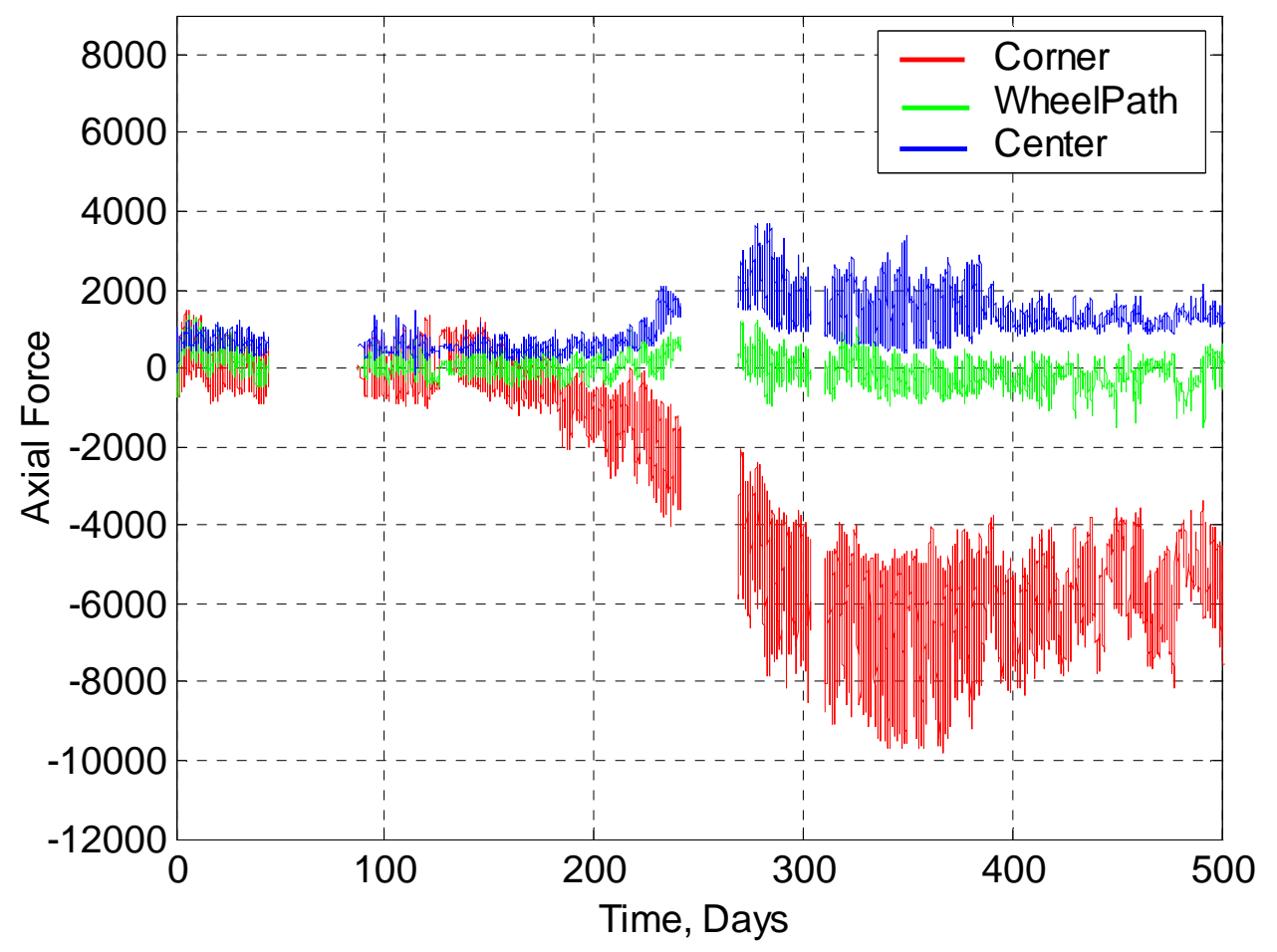

Figure 4.16: Axial Forces along the Joint between Slabs 1 and 2 (Dowel bars) 


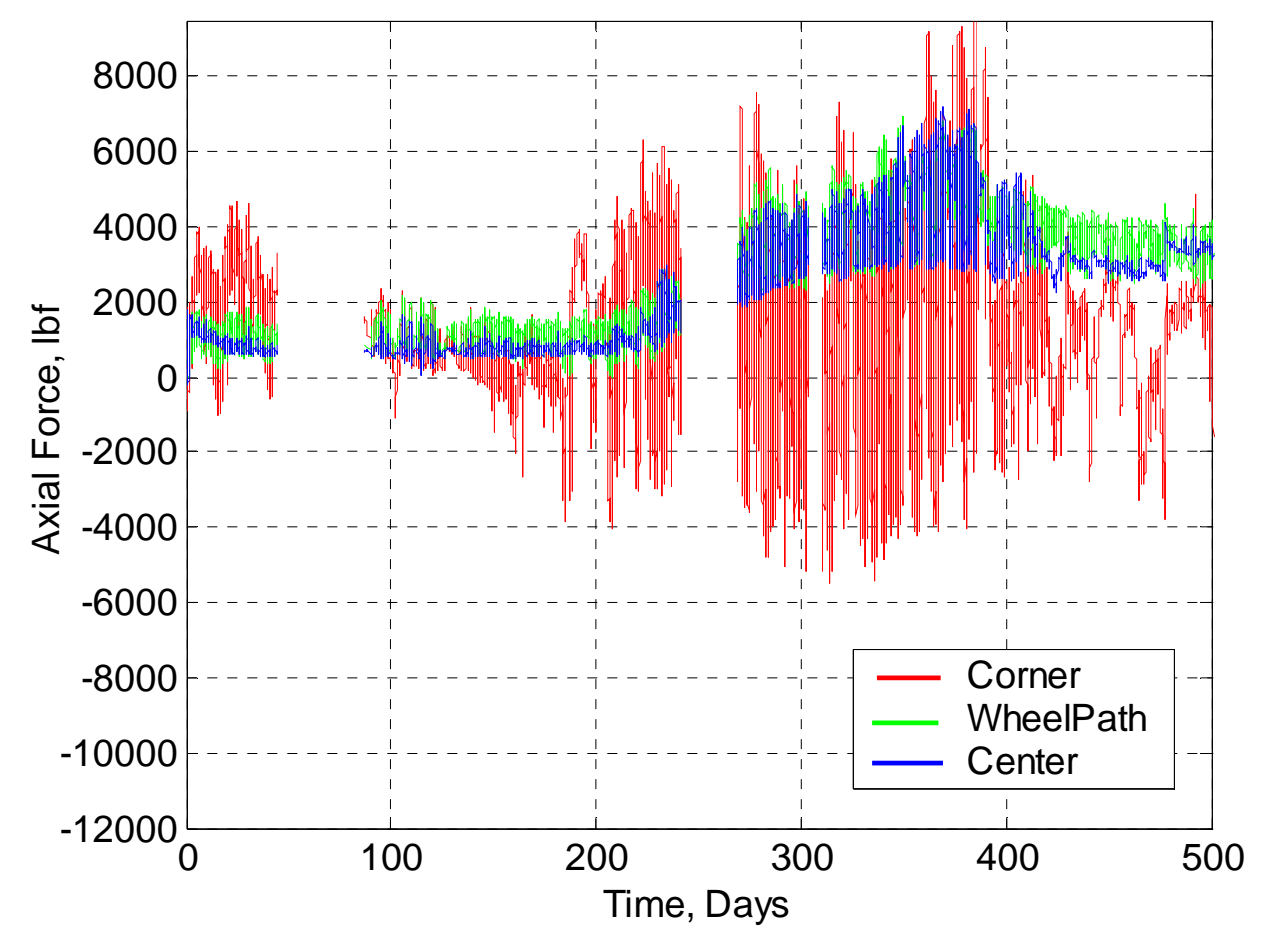

Figure 4.17: Axial Forces along the Joint between Slabs 2 and 3 (Dowel bars)

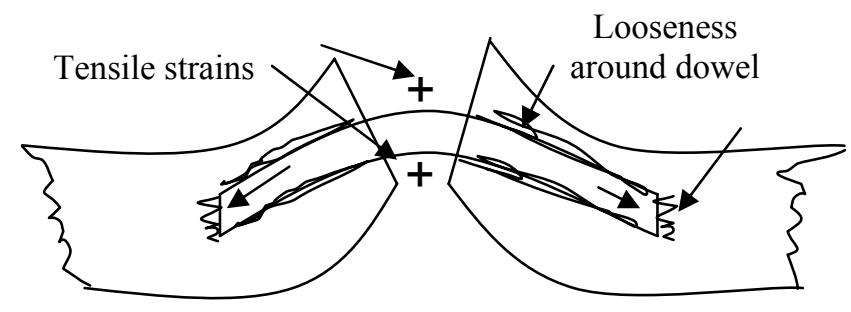

Figure 4.18: Tension in Dowel Bars due to Temperature Increase

Figure 4.18 illustrates the section ends of the two slabs and the dowel bar in between. Due to drying concrete shrinkage along with the daily cycle of expansion and contraction of the slabs, the dowels developed looseness around them. A gap developed between the dowel end and the concrete. This gap allowed the expansion of the dowel due to increase in temperature (expansion of material with increase in temperature). As there is no concrete at the dowel ends to resist the dowel's thermal expansion, no compressive forces were felt on the dowel. 
The development of looseness decreases the load transfer efficiency of the bars. This can be tested by performing the FWD tests on the slabs where the slabs are tested for simulated traffic loads.

As observed from Figure 4.19 the Shok Bars show more consistent behavior compared to dowel bars. The axial force is compressive as the temperature increases as the slab tends to expand and in turn create compressive stress in the bars. The magnitude of axial force was higher in the slab corner due to higher curling of the corner resulting in stronger gripping of the bar by the concrete.

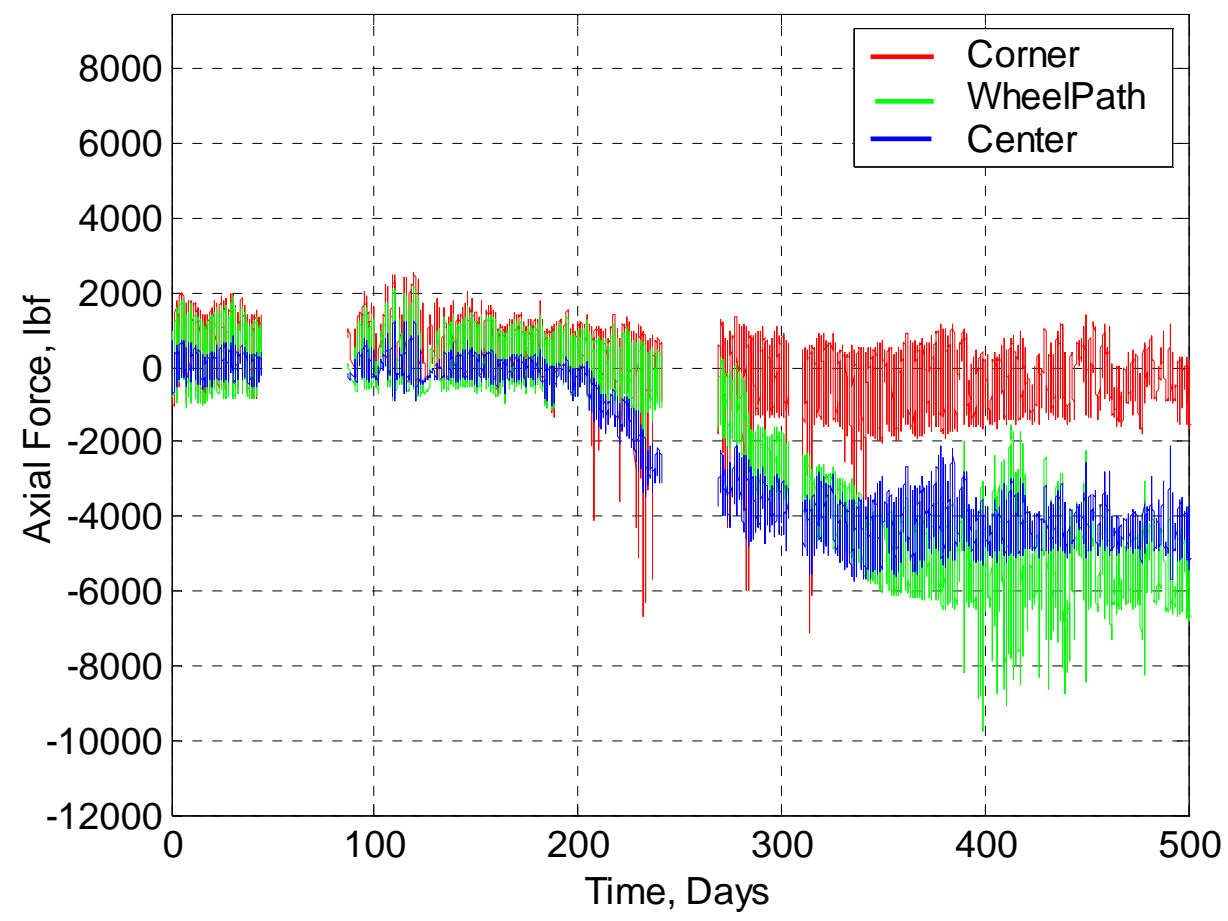

Figure 4.19: Axial Forces along the joint between slabs 3 and 4 (Shok Bars) 


\subsection{BENDING MOMENTS ALONG THE TRANSVERSE JOINT}

The time-histories of the bending moments recorded in the instrumented regular dowel bars installed at the joints between slabs 1 and 2 and those between slabs 2 and 3 are plotted in Figures 14.20 and 14.21 respectively. It can be noticed that the bending moments were more or less constant till around the 200 day mark. Thereafter, the value of bending moment changes with the change in ambient temperature. The values of the average bending moments recorded at the center and wheel-path dowels were close to each other, however higher values were recorded at the corner dowel as can be seen in Figures 14.20 and 14.21. This can be expected since the dowel bending moment was directly dependant upon the slab curling, which was maximum at the corner and less fluctuating as one move towards the joint center. Therefore, the dowel bending moment in the corner dowel is greater compared to the joint center and the wheel-path.

Figure 14.22 illustrates the time-histories of the bending moment recorded in the three instrumented Shok Bars installed at the joint between slabs 3 and 4. The average bending moment in Shok Bars has remained positive since the time of concrete pouring. In the curing stage of concrete, the Shok Bars provided the freedom for the slab to set in the curled form. Although a similar flexibility was provided by the dowel bars, over the annual change in the temperature the slab curled but did not exert the same pressure in the bars as in the case of dowel bars. Shok Bars allowed the slab to curl without the bar itself undergoing cycles of daily bending reversals. The sleeves on the Shok Bars allow the slab to slide and the bars bend thereby reducing the stress in the slab. By these results we can also deduce that Shok Bars have better resistance to thermal fatigue loads than dowel bars thus will have longer fatigue life. The variation in bending moment and in turn the curling of the slab along the transverse joint is lower when compared to the slabs with dowel bars for the same temperature variations. This implies a more uniform joint opening in the slabs fitted with Shok Bars. 


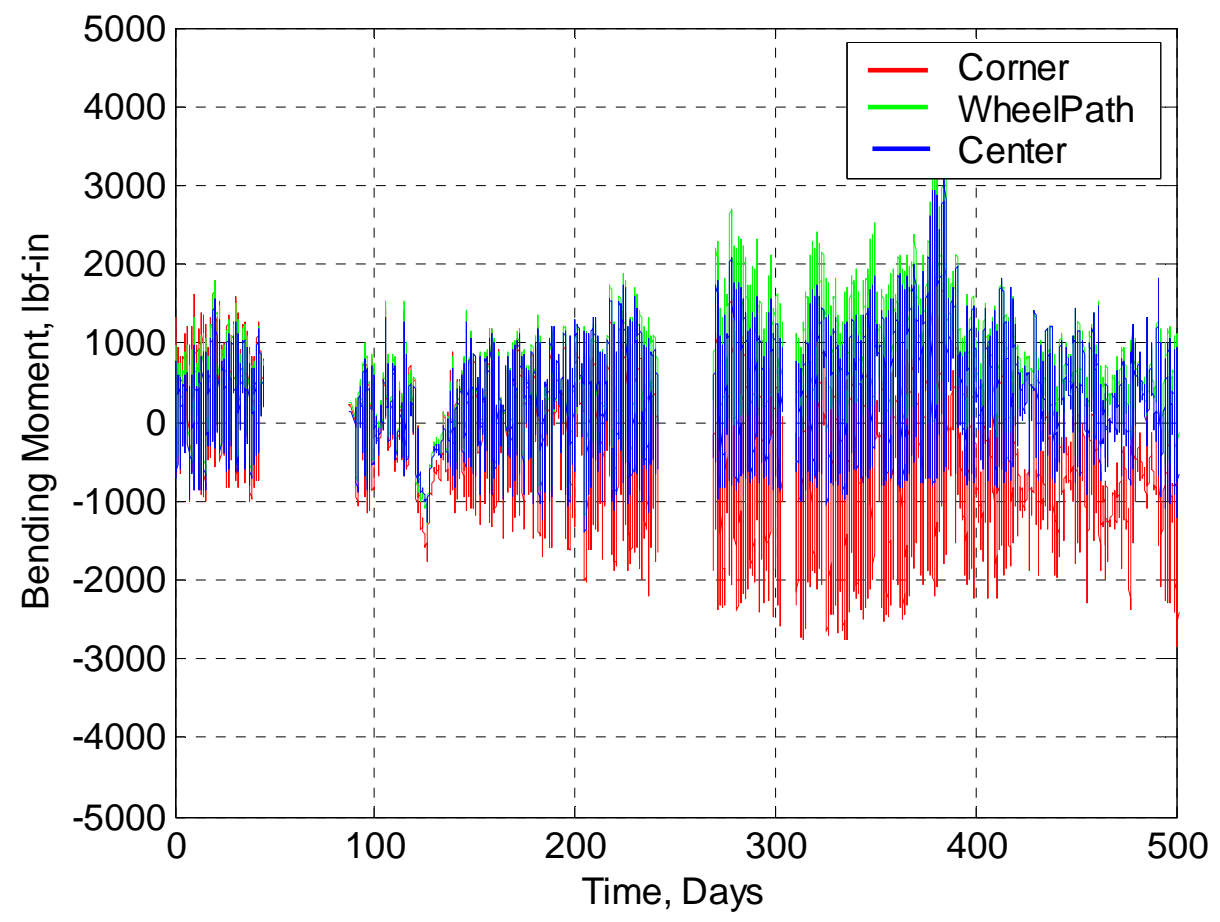

Figure 4.20: Bending Moments in Dowel Bars along the Joint between Slabs 1 \& 2

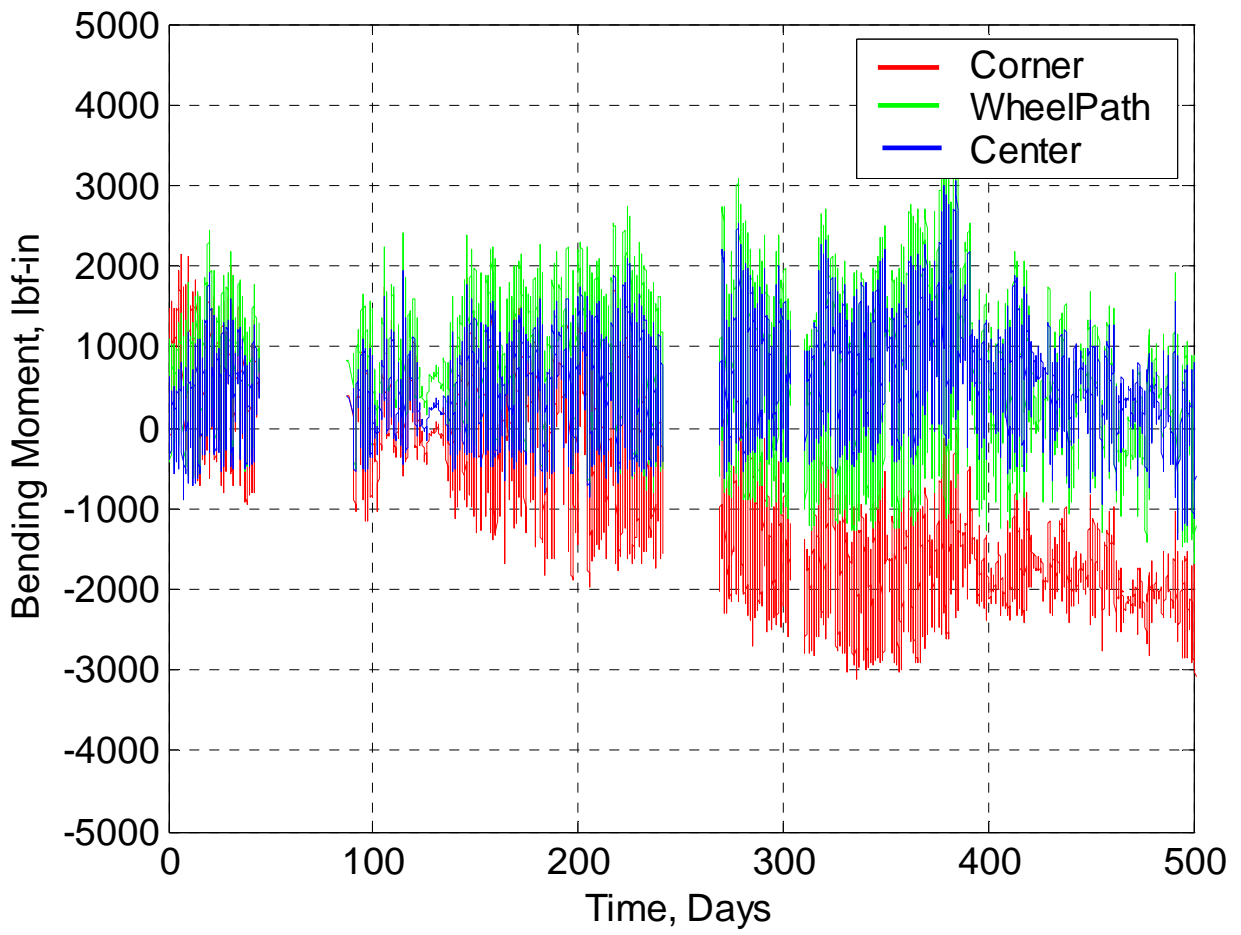

Figure 4.21: Bending Moments in Dowel Bars along the Joint between Slabs 2 \& 3 


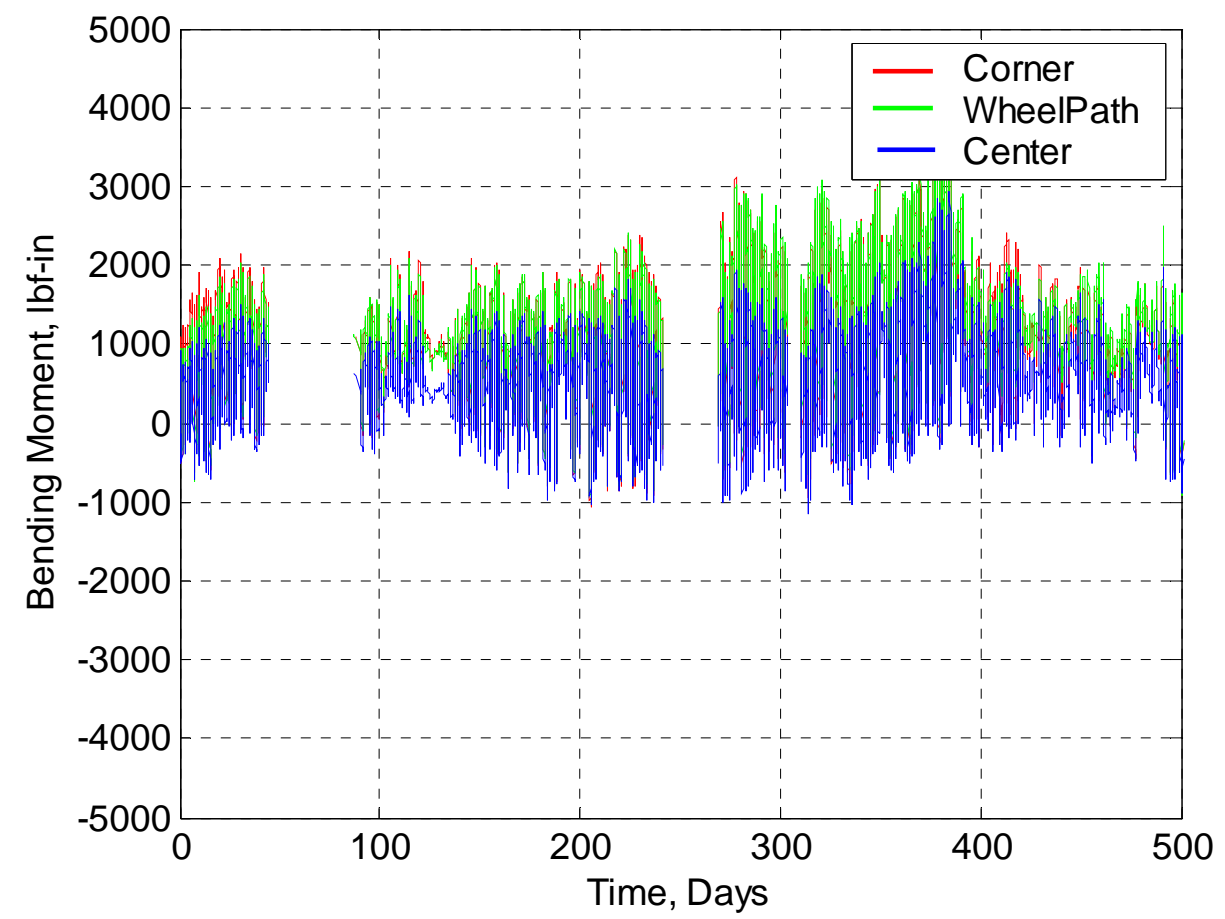

Figure 4.22: Bending Moments in Shok Bars along the Joint between Slabs 3 \& 4

\subsection{TRANSVERSE JOINT OPENING}

Joint meters placed in between the slabs jointed with Shok Bars and Dowel bars measure the continuous joint openings with daily variations of temperature. Figure 4.23 (a) and (b) plot the axial displacements recorded by the joint meters over the period of 477 days in slab fitted with regular dowel bars and Shok Bars respectively. The amount of joint opening varies with the type of end constraints in the slabs i.e. regular dowels and Shok Bars. Joint 1 and 2 belong to the 2 edges of the slab fitted with dowel bars and Joint 3 and 4 to the slab with Shok Bars. The mean gap openings for the first 500 days have been plotted in Figure 4.23 (a) and (b) in thick solid lines. The two joints fitted with dowel bars showed approximately $85 \%$ difference in their average openings, meanwhile $20 \%$ difference was observed between the joints fitted with Shok Bars. This indicates that the use of Shok Bars resulted in more symmetric joint openings than the dowel bars. Such a finding was confirmed from field observation from the instrumented pavement site in Elkins, West Virginia (Shoukry et al, 2004). All joints fitted with Shok Bars 
opened after the first day, while only one joint out five of those fitted with dowel bars showed large opening. Shok Bars provide more controlled opening of the joints.

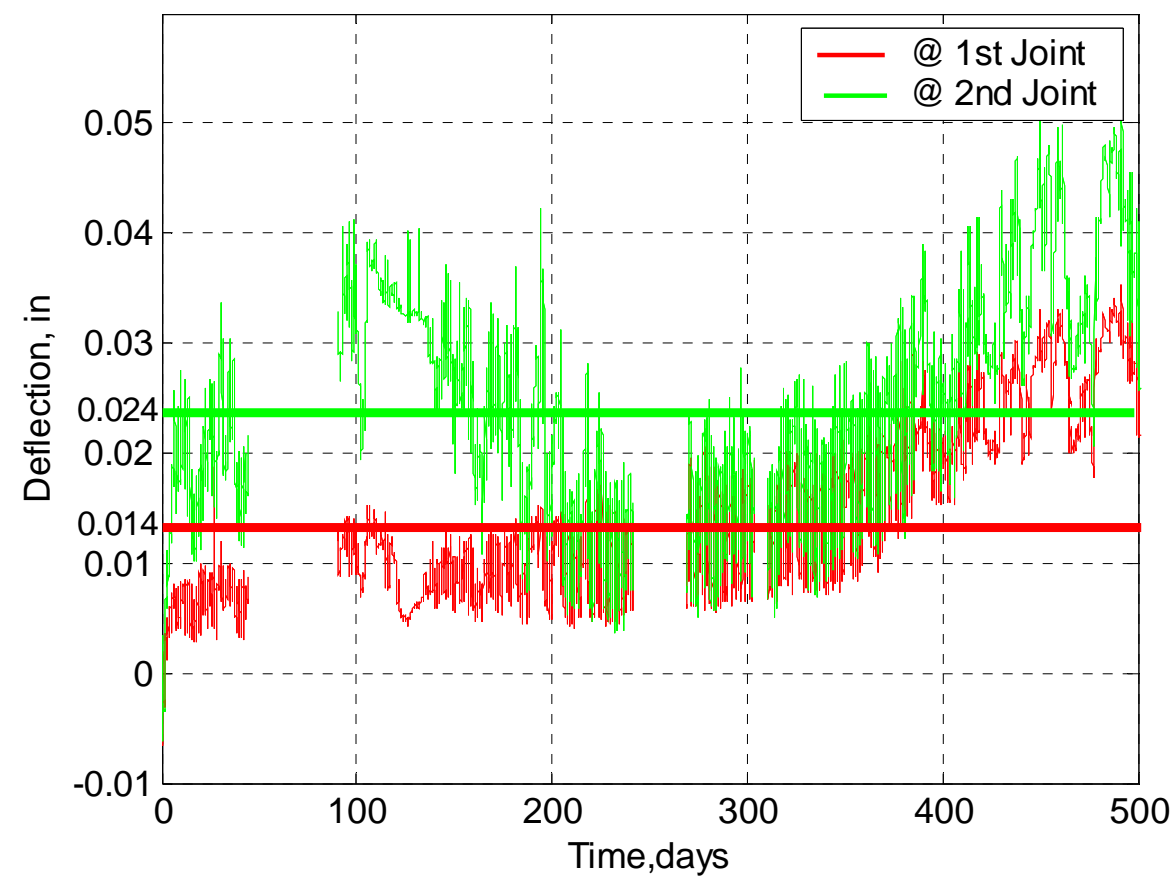

(a) Slab fitted with regular dowels.

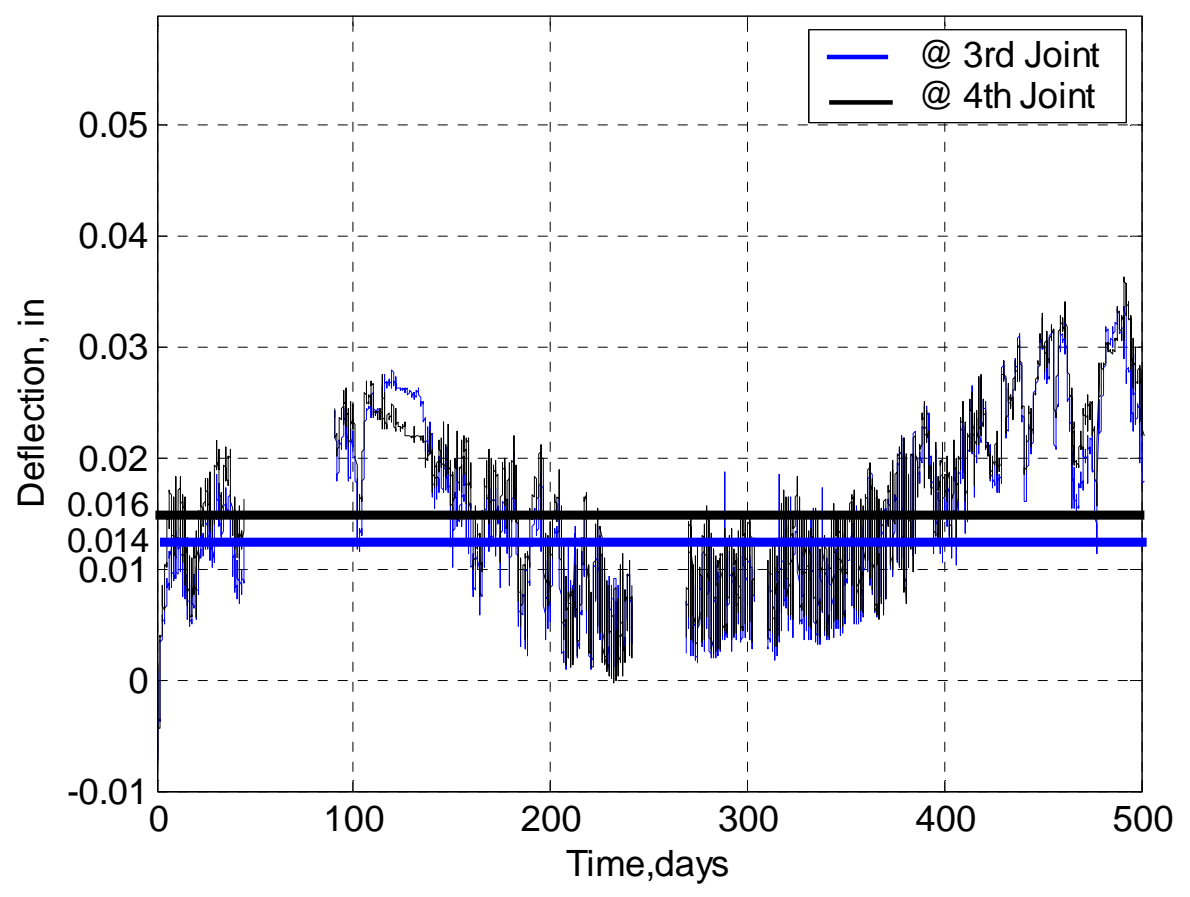

(b) Slab fitted with Shok Bars.

Figure 4.23: Joint opening plots. 


\section{CHAPTER FIVE \\ 3D FINITE ELEMENT ANALYSIS}

\subsection{INTRODUCTION}

Shoukry et.al. (2003) reported that the mid slab stresses were higher than the stresses near the edge of the slab and the effect of nonlinearity in the thermal gradient through the slab thickness is negligible. Thus only a linear temperature gradient through the thickness was considered for the finite element analysis.

It is difficult to incorporate the effects of changes in moisture content in slabs in the finite element model. The moisture can be assumed constant during a period of 4 to 6 hrs during a day i.e. the changes in their quantities is negligible. The window period of 6 hours was taken from 8 am to $2 \mathrm{pm}$, when the slab temperature gradually increases and from $9 \mathrm{pm}$ to $3 \mathrm{am}$ when the slab gradually cools down. It was noticed that during this window period of 6 hours the temperature gradient through the slab thickness can be approximated as linear. Thus, the effect of temperature variations alone can be studied using the finite element models.

\subsection{FINITE ELEMENT MODELS}

\subsubsection{Free Slab on smooth base}

The 3D finite element model used in this study consists of the free slab supported by the base and the subgrade. It was assumed that the temperature in every layer through the concrete thickness was constant. The concrete slab was modeled at its full length and width and the base and the subgrade were widened to 6 inches on all four sides of the concrete slab. The only force acting on the slab is body force (self weight). Vertical constraints at the bottom of the subgrade make up the boundary conditions. 
A fine finite element mesh of 8-noded solid brick elements was used to model the slabs and the sub-layers. A finer mesh was used for a depth of 1 inch from the top surface of the slab to capture the temperature in the region (thermocouples have been placed at every 0.1 inch in the top 1 inch of the slab).

Sliding interface with frictional contact was assumed between slab and base layer. The coefficient of friction of $\mu=1.5$ was assumed between the slab and base. Contact stiffness of $4000 \mathrm{lbs} /$ in is given to the interface, which equals zero when the surfaces lose contact. The material properties used for concrete, granular base and subgrade are listed in Table 5.1.

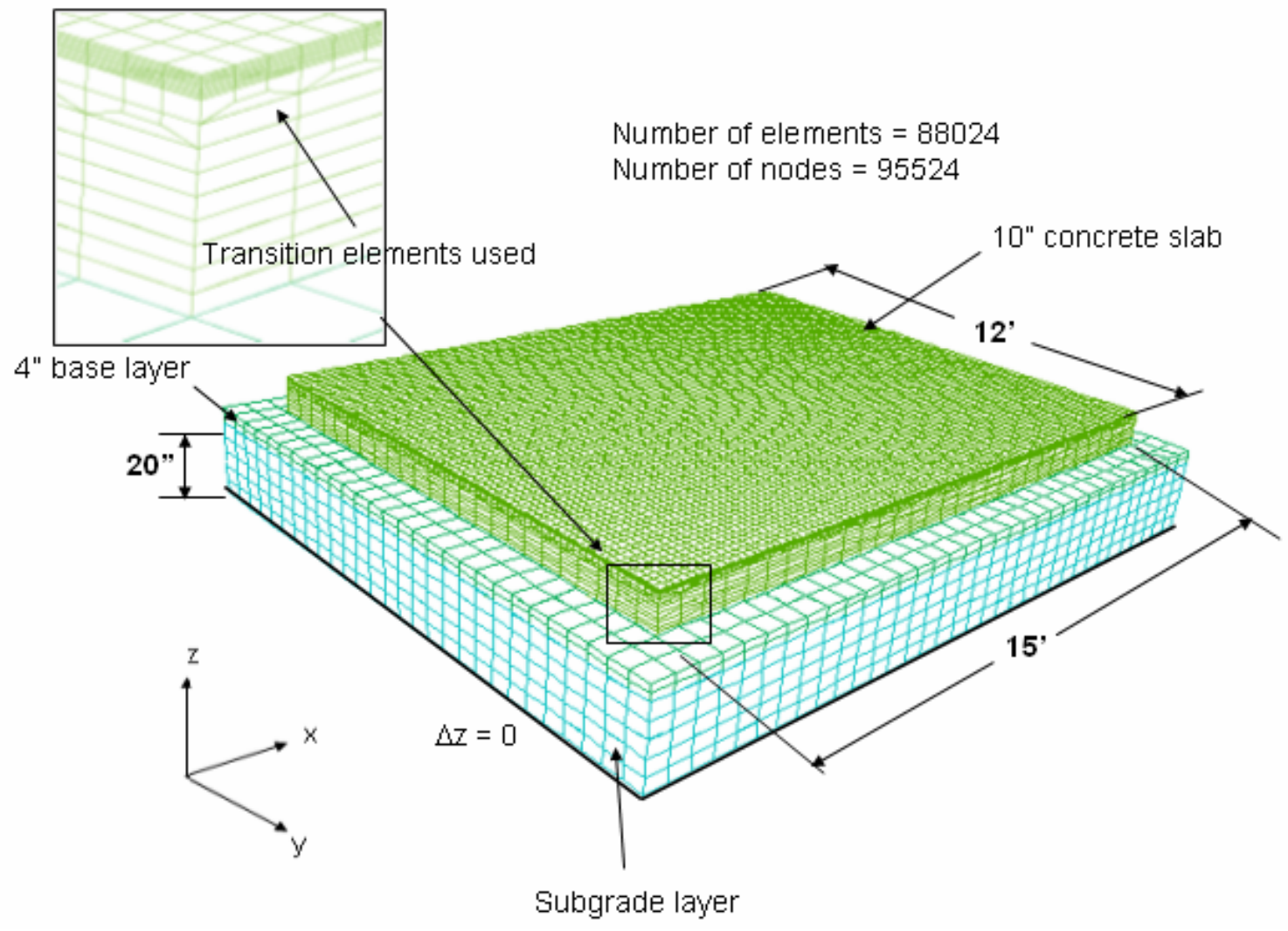

Figure 5.1: 3D FE Model for a Free Slab on Low Friction Subgrade 
Table 5.1: Material Properties Used for the FE Model

\begin{tabular}{|c|c|c|c|}
\hline Layer & Material model & Property & Value \\
\hline Concrete & $\begin{array}{l}\text { Thermo-Elastic- } \\
\text { Plastic }\end{array}$ & $\begin{array}{l}\text { Unit Weight }\left(\mathrm{lb} / \mathrm{ft}^{3}\right) \\
\text { Modulus of elasticity }(\mathrm{psi}) \\
\text { Poisson's ratio } \\
\text { Coefficient of thermal expansion }\left(/{ }^{\circ} \mathrm{C}\right)\end{array}$ & $\begin{array}{l}149.5 \\
4.5 \times 10^{6} \\
0.18 \\
10.8\end{array}$ \\
\hline Base & Linear Elastic & $\begin{array}{l}\text { Unit Weight }\left(\mathrm{lb} / \mathrm{ft}^{3}\right) \\
\text { Modulus of elasticity (psi) } \\
\text { Poisson's ratio }\end{array}$ & $\begin{array}{l}145 \\
45,000 \\
0.30\end{array}$ \\
\hline Subgrade & Linear Elastic & $\begin{array}{l}\text { Unit Weight }\left(\mathrm{lb} / \mathrm{ft}^{3}\right) \\
\text { Modulus of elasticity (psi) } \\
\text { Poisson's ratio }\end{array}$ & $\begin{array}{l}125 \\
4,000 \\
0.40\end{array}$ \\
\hline $\begin{array}{l}\text { Steel } \\
\text { Dowels/ } \\
\text { Shok bars }\end{array}$ & $\begin{array}{l}\text { Thermo-Elastic- } \\
\text { Plastic }\end{array}$ & $\begin{array}{l}\text { Unit Weight }\left(\mathrm{lb} / \mathrm{ft}^{3}\right) \\
\text { Modulus of elasticity }(\mathrm{psi}) \\
\text { Poisson's ratio } \\
\text { Coefficient of thermal expansion }\left(/{ }^{\circ} \mathrm{C}\right)\end{array}$ & $\begin{array}{l}490 \\
29.0 \times 10^{6} \\
0.3 \\
11.8 \times 10^{-6}\end{array}$ \\
\hline
\end{tabular}

\subsubsection{Free slab on high friction subgrade}

As described in Chapter 3, the slab on high friction subgrade was cast directly on the rough surface of the base coarse layer. Therefore, concrete penetrated through the voids between the gravel particles, which provide high resistance to the slab movement along the slab-base interface. Assuming a high value for the coefficient of friction between the slab and base will not produce an accurate solution for this simulation problem since frictional forces are fully mobilized only if a certain amount of relative displacement (approximately 0.1 inch) occurs between the slab and base (Yoder and Witzack, 1975). However, in this case, the resistance exists due to the interlock between the concrete slab and the base top surface. Therefore, simulation of this problem was made by creating a random uneven mesh on the bottom surface of the slab and a corresponding uneven mesh on the top surface of the subgrade as shown in Figure 5.2. A 
frictional coefficient $\mu=1.5$ was assumed at the slab-base interface. The material properties used for all pavement layers are listed in Table 5.1.

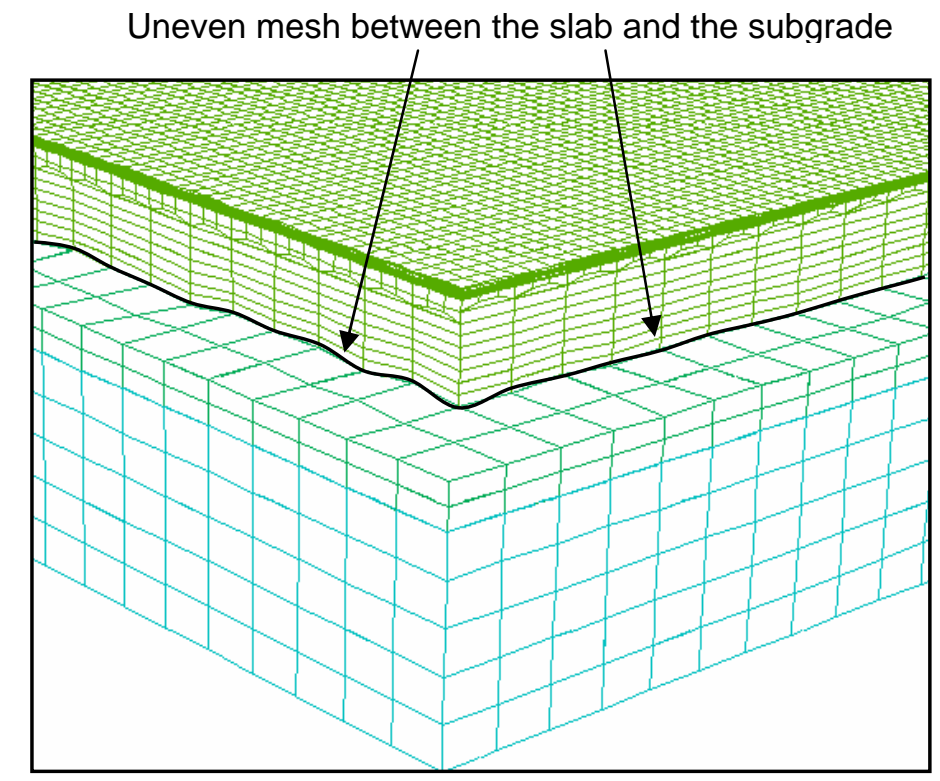

Figure 5.2: Uneven Mesh at the Slab - Subgrade Interface.

\subsubsection{Slab fitted with Regular Dowel bars}

Figure 5.3 shows the Finite Element model of the slab fitted with dowel bars. The model consists of one complete slab with two half slabs on either side of the central slab. Each transverse joint was fitted with twelve 1.5-inch diameter, 18-inch long dowel bars as illustrated in Figure 5.4. The transverse joint faces were separated by a 3/8 inch wide gap, which simulate the foam layer installed between the two slabs in the site. Concretedowel interaction is essential in determining the concrete slab response to temperature variations (William and Shoukry, 2001; Shoukry et al., 2002). Thus, accurate modeling of the dowel bars and their interfaces with the surrounding concrete was a must when studying this problem. The dowel bars were simulated to their approximate circular shape using 8-node solid brick elements as illustrated in Figure 5.4. The slab mesh was refined in the dowels vicinity to account for the circular shape of the dowel and for the accurate simulation of the dowel-concrete interface. Sliding interfaces with friction were used between the dowel bars and the surrounding concrete. Based on the pullout test 
results conducted by Shoukry et al. (2003), the dowel-concrete coefficient of friction was taken 0.05 . This general purpose interface is suitable for simulating different possibilities of the dowel-concrete contact. Dowel-contact possibilities range from localized contact that can form at two or more locations due to dowel bending and concrete surface deformation to full contact along the cylindrical interfaces. In either case, the contacting surfaces may slide against each other when the dowel pulling force exceeds the frictional shear stresses along the interface. This approach enables studying the slab contraction and expansion due to temperature variations.

Similar to the models of the free slabs, sliding interfaces with frictional contact was assumed between slab and base layer and a coefficient of friction $\mu=1.5$ was assumed. Contact stiffness of $4000 \mathrm{lbs} /$ in was given to the interface, which equals zero when the surfaces lose contact. The material properties of the slab, base, subgrade, and steel dowel bars were the same as in Table 5.1.

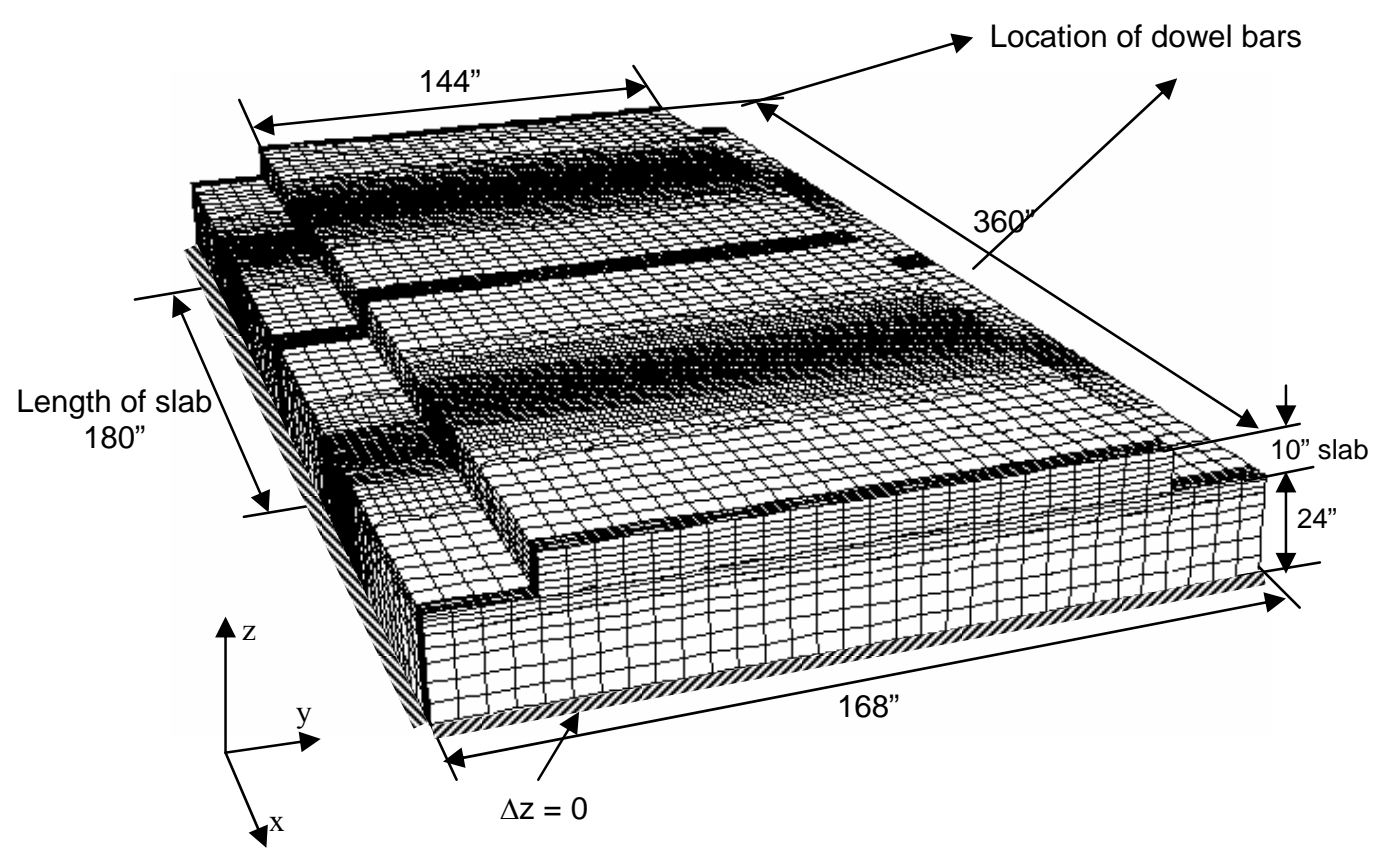

Figure 5.3: Slab Fitted With Dowel Bars. 


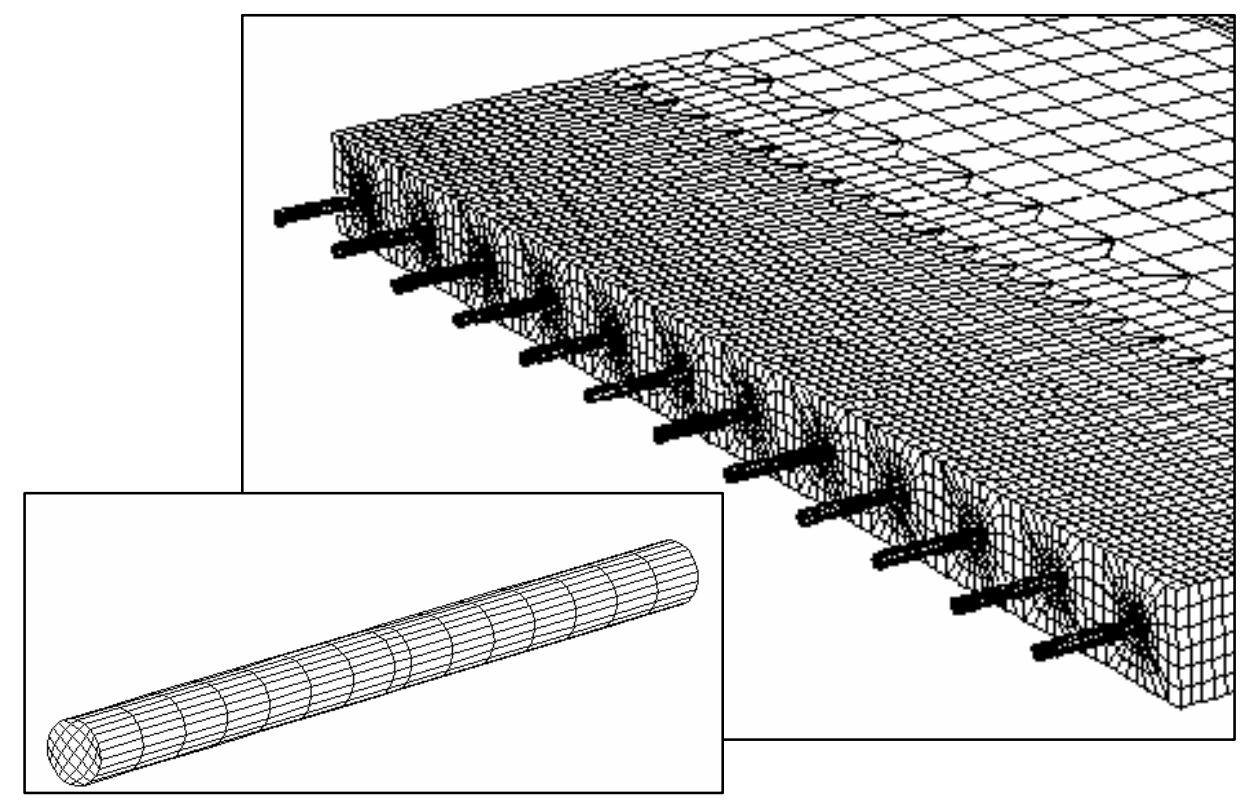

Figure 5.4: Dowels Fitted To Slab Edge

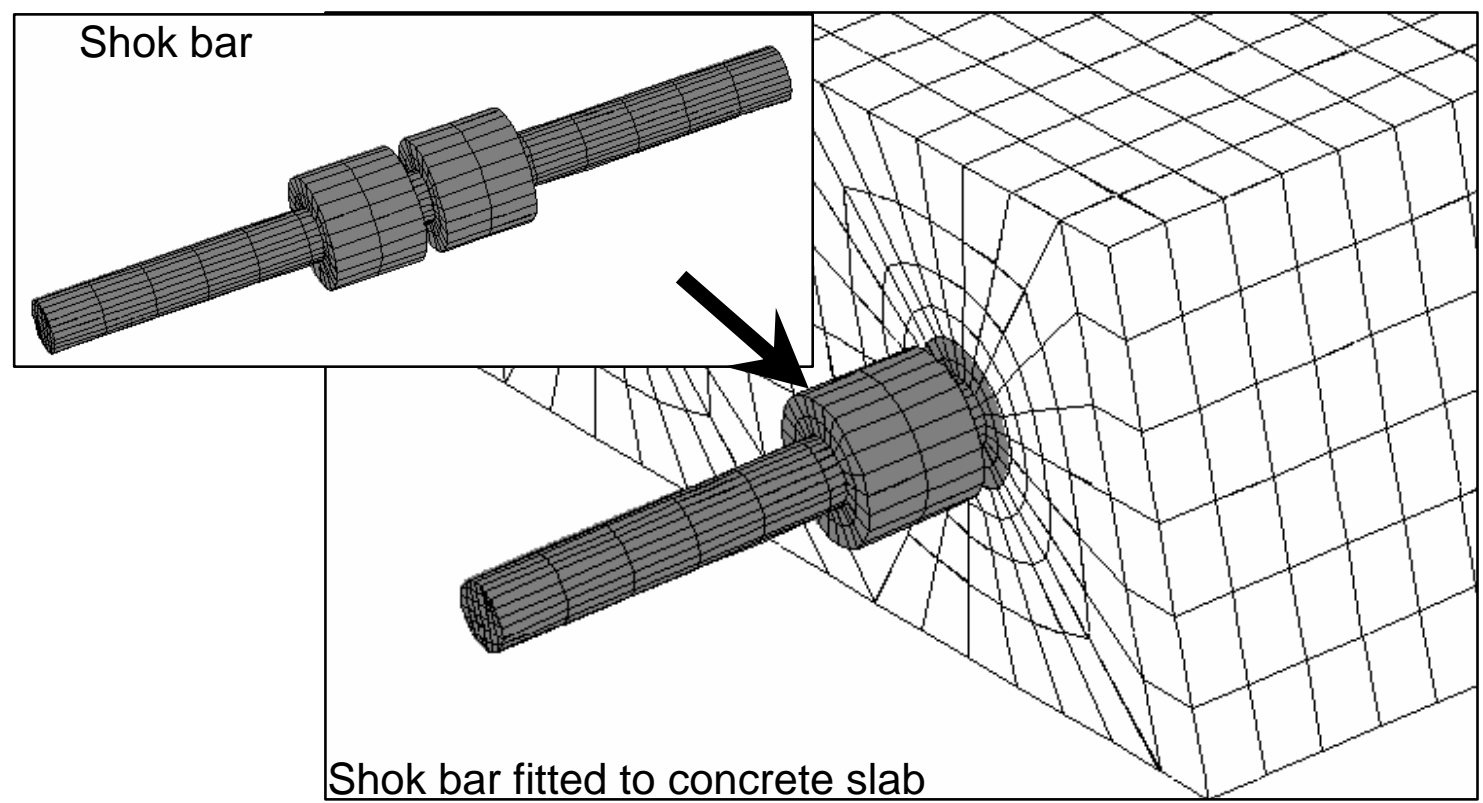

Figure 5.5: Magnified image of Shok Bars Fitted to Slab Edge. 


\subsubsection{Slab fitted with Shokbars}

The construction of the slab fitted with Shokbars is similar to that of the slabs with regular dowel bars (Figure 5.5). The only difference being the shape of the bar and a coefficient of friction $\mu=0.03$ between the Shokbar and concrete obtained from laboratory tests conducted by Shoukry et al (2003). Figure 5.5 shows the model of the Shokbar made up of a steel rod and two steel sleeves placed half and inch apart at the center of the rod. A gap of 25 microns was introduced between the steel rod and the sleeve of the Shokbar to account for the looseness of the sleeve over the bar.

\subsection{THERMAL LOADING}

In the present work, the effect of environmental changes on dowel jointed pavements and free slabs were considered. Among the various environmental factors, the temperature changes in the slab are predominant. A linear temperature gradient across the thickness of the slab was used for the finite element analysis. In a temperature cycle of a day, a time period of 6 hours of temperature increase and $6 \mathrm{hrs}$ of temperature decrease was considered. The difference in temperatures at the start and end of this time window near the top ( 1 inch into the slab from the surface top) and from the bottom (one inch into the slab from the bottom of the slab) of the slab were noted and fit to a straight line. A positive temperature gradient of $+8{ }^{\circ} \mathrm{C}$ corresponds to the top surface being at $4{ }^{\circ} \mathrm{C}$ higher than the temperature midway through the slab thickness and the slab bottom $4{ }^{\circ} \mathrm{C}$ lower than the mid slab temperature.

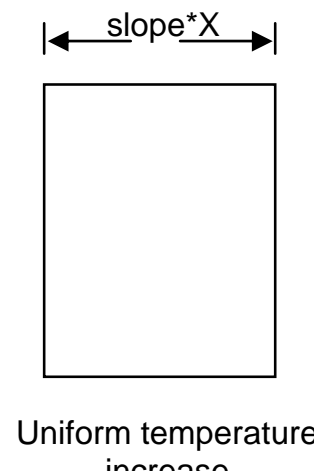

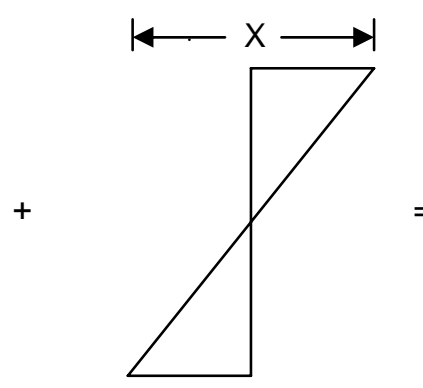

Positive temperature gradient

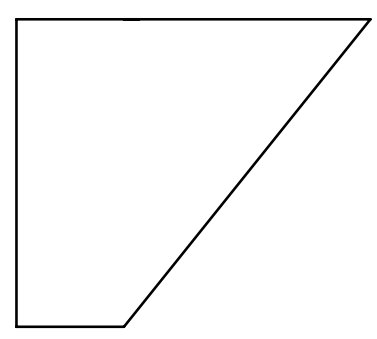

Total temperature increase

Figure 5.6: Linear gradient along with uniform temperature change 
The slab is said to have a negative temperature gradient when the slab top is at a lower temperature than the slab bottom. The above assumption about the temperature profile across the slab thickness follows the experiment temperature variation patterns.

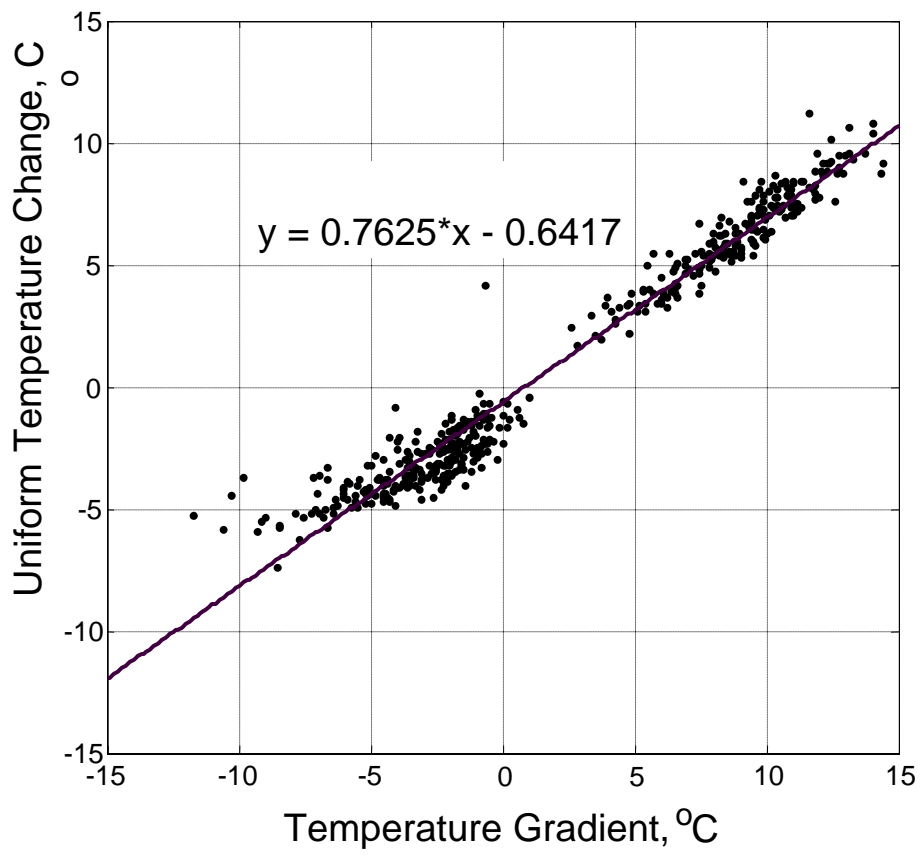

\section{Figure 5.7: Linear Temperature Gradient through Thickness of slab Vs Uniform Temperature change in the slab}

Figure 5.7 plots the magnitude of the temperature gradient through the slab thickness against the uniform change in slab temperature of the slab fitted with dowel bars. The $\mathrm{x}$-axis is the difference in temperature gradient through the thickness of the slab taken in an interval of 6 hours when a positive or a negative gradient exists as mentioned earlier. The y-axis is the difference in temperature values at the mid thickness of the slab. Equations 5.1 and 5.2 were used to calculate the temperature gradient and the uniform temperature change.

$$
\begin{aligned}
& \text { Temperature gradient }=\left(\mathrm{T}_{\text {top2 }}-\mathrm{T}_{\text {bottom2 }}\right)-\left(\mathrm{T}_{\text {top1 }}-\mathrm{T}_{\text {bottom1 } 1}\right) \\
& \text { Uniform temperature change }=\frac{\left(\mathrm{T}_{\text {top2 }}+\mathrm{T}_{\text {bottom2 } 2}\right)}{2}-\frac{\left(\mathrm{T}_{\text {top1 }}+\mathrm{T}_{\text {bottom1 }}\right)}{2}
\end{aligned}
$$

Where the subscript 1 and 2 correspond to time extremes of the $6 \mathrm{hr}$ period. 
A linear relation with an $\mathrm{R}^{2}$ value of 0.92 could fit the data as shown in Figure 5.7 and can be expressed by the equation:

$$
M=0.7625 G
$$

Where: $\quad M$ is the temperature change at mid-plane of slab thickness

$\mathrm{G}$ is the corresponding temperature gradient

The slopes in the case of the free slab over smooth base, free slab on coarse base and the slab fitted with Shokbars were found to be $0.87,0.82$ and 0.70 respectively. This factor was considered while simulating the pavement models using 3D Finite element analysis.

In all the 3DFE models, it was assumed that the temperature of all points at the same depth throughout the slab top is constant. The temperature ' $T_{z}$ ' at a depth ' $z$ ' from the slab top was calculated by the equation 5.4:

$$
T_{z}=\left[z * \frac{G}{10}+\frac{G}{2}\right]+\text { slope } * G
$$

where $G=$ Measured temperature difference between top and bottom slab surface

slope $=$ slope of plot between temperature gradient and uniform temperature change.

The $3 \mathrm{D}$ finite element models were processed for $\pm 2^{\circ} \mathrm{C}, \pm 4^{\circ} \mathrm{C}, \pm 6^{\circ} \mathrm{C}$ and $\pm 8^{\circ} \mathrm{C}$ values of temperature gradient $(G)$. The temperature at each node of the slab was assigned according to the Equation 5.4. The temperature of the slab base and subgrade were not considered.

\subsection{COMPARISON OF THE CONCRETE STRAINS}

The experimentally measured longitudinal strains near top and bottom of the concrete slab were compared with the 3DFE-calculated ones at the same locations of the strain gages for different temperature gradients. Two locations along the slab centerlines were selected for such a comparison: 1) 9-inches from transverse joint edge and 2) at the slab center. 


\section{Free Slab on a Smooth Base}

Figures 5.8 and 5.9 illustrate a comparison of the 3DFE-calculated strains and those experimentally measured in the free slab on a smooth base. A linear relation could be observed between the strain and temperature gradient. A close agreement was observed between measured and calculated strains at the slab top but at the slab bottom the strain values seem to be spread out. The discrepancy of the results at the slab bottom can be attributed to any irregularities in the finishing of the top surface of the base layer, which is not accounted for in the 3DFE model. Different values of coefficient of friction between 1.5 and 2.2 were tested. The irregularities between the slab and the base gives rise to an unreasonably high coefficient of friction. A similar mismatch at the slab bottom is found in the case of other slab models too and the same reasoning applies to them. Hence another more reliable technique of comparing the bending moments developed in the bars was used to validate the FE model of the jointed slabs.

\section{Free Slab on a Coarse Base}

Figures 5.10 and 5.11 illustrate a comparison of the 3DFE-calculated strains and those measured experimentally in the free slab on a coarse base. Similar to the free slab on free base, the strains vary linearly with the change in temperature gradient. A close agreement can be observed between the 3DFE-computed strains and the experimentally measured values at the two selected locations: near the slab edge and at the center. 

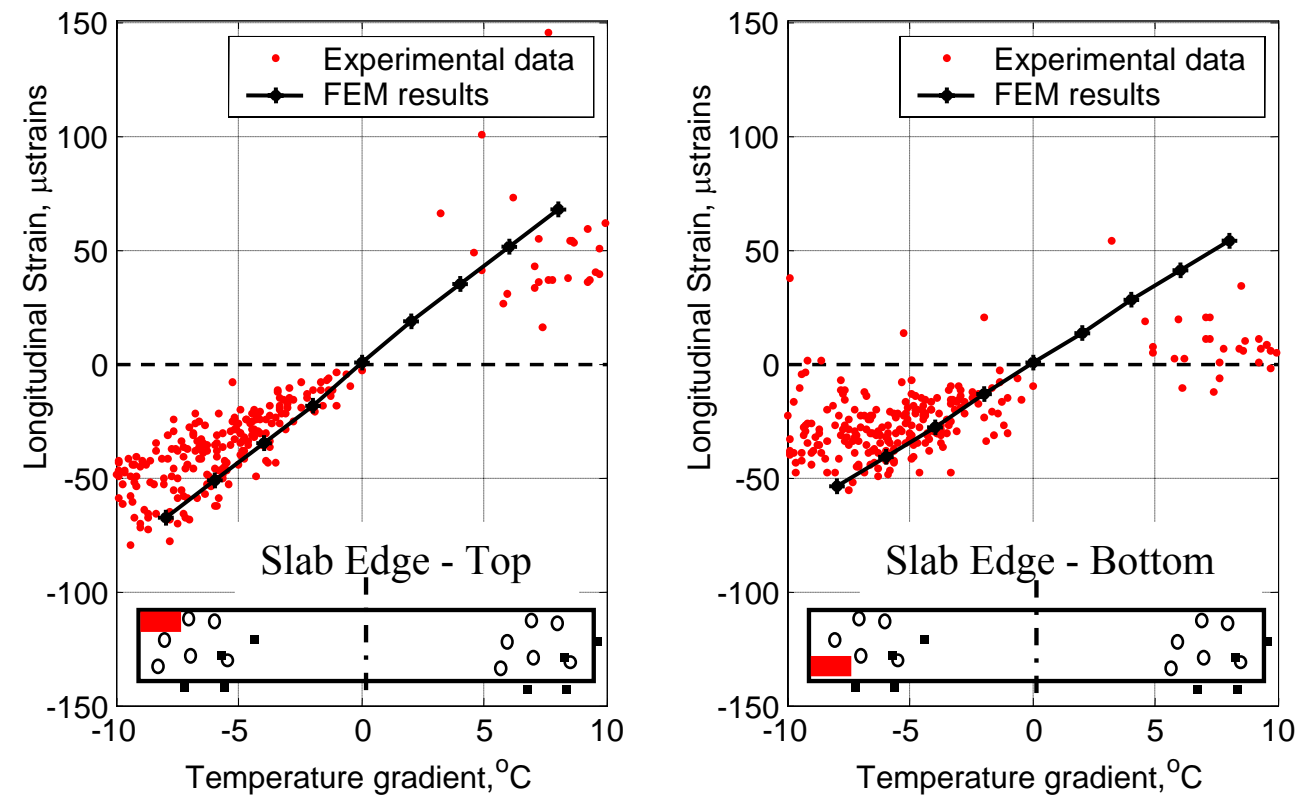

Figure 5.8: Longitudinal Strains vs Temperature Gradient near the Transverse Edge of Free Slab on Smooth Base
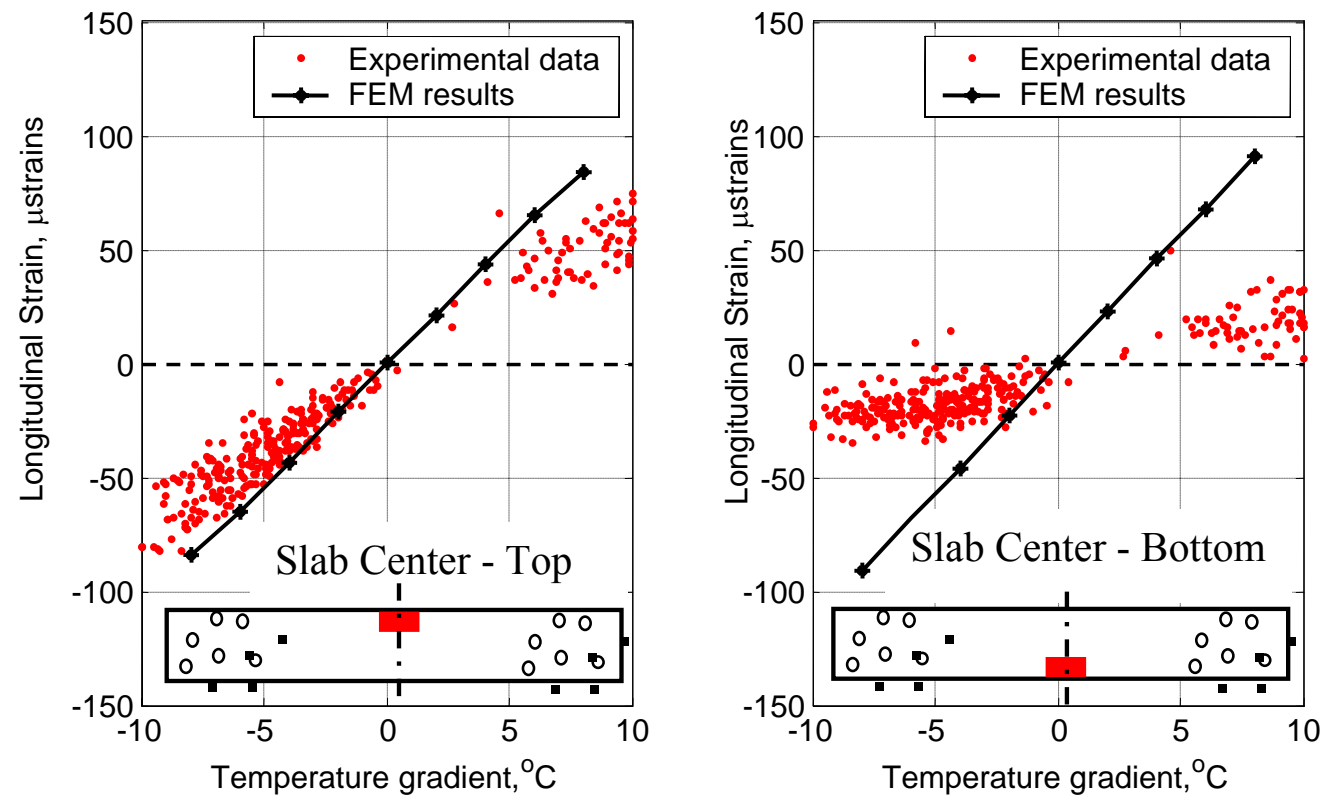

Figure 5.9: Longitudinal Strains vs Temperature Gradient at the Center of Free Slab on Smooth Base. 

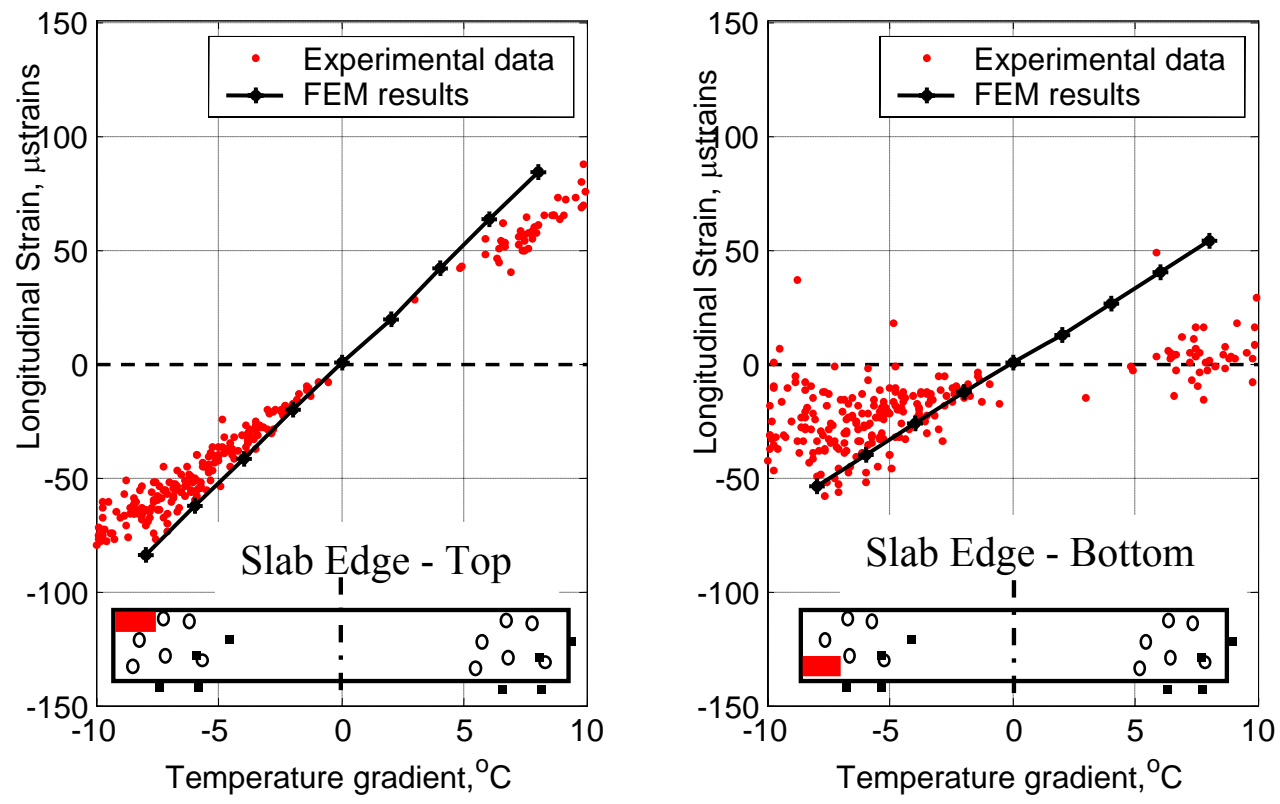

Figure 5.10: Longitudinal Strains vs Temperature Gradient near the Transverse Edge of Free Slab on Coarse Base.
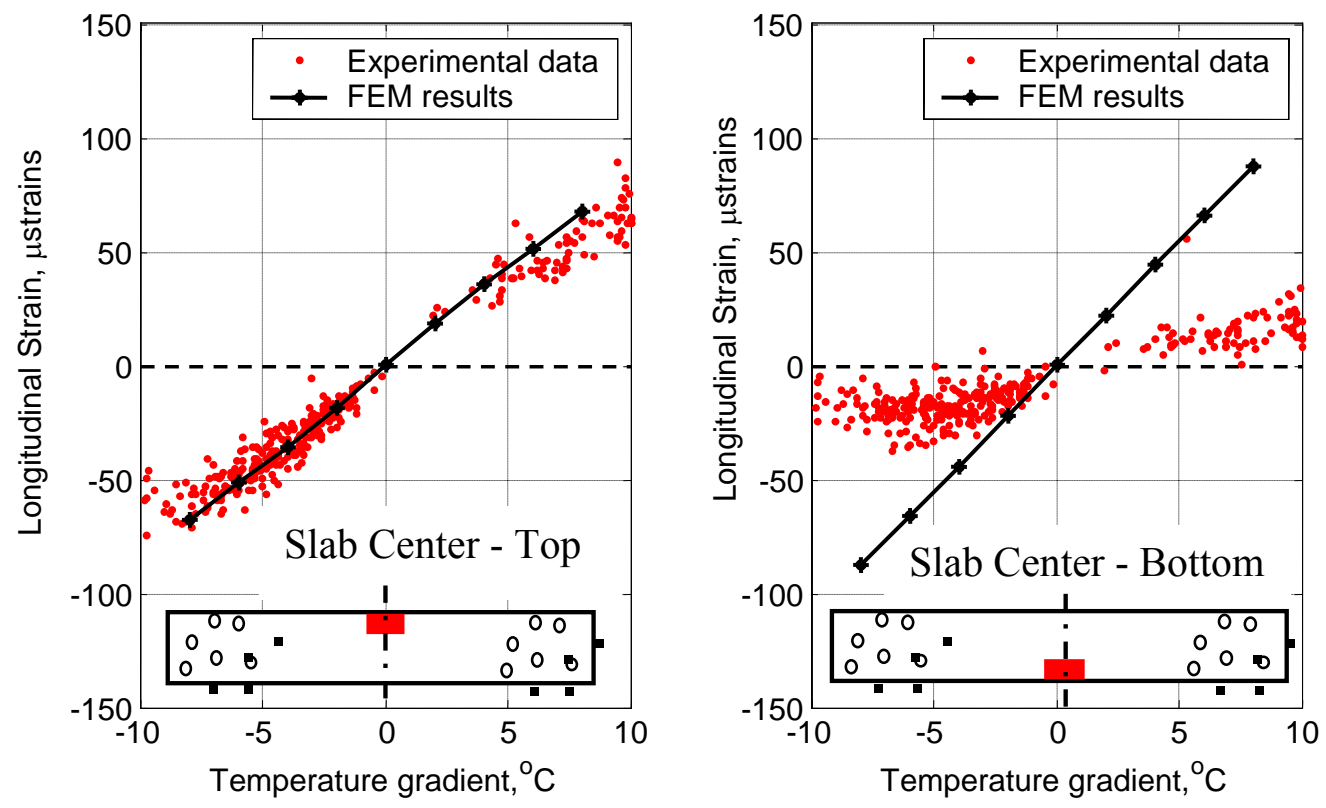

Figure 5.11: Longitudinal Strains vs Temperature Gradient at the Center of Free Slab on Coarse Base. 
The strains calculated by the finite element analysis of the free slabs shows higher strains at the bottom mid-slab than at the slab top mid-slab whereas the measured strains show higher strains at the slab top. This mismatch is higher in the case of the slab on coarse subgrade compared to the free slab on smooth base. As seen in Figure 5.11 the longitudinal strains due to $\mathrm{a}+8^{\circ} \mathrm{C}$ are around $15 \mu$ strains higher at the slab bottom than at the top mid-slab. This arises from the shape of the slab caused by a positive temperature gradient across the slab thickness estimated by the FE analysis as seen in Figure 5.11a. The profile of this deformation has been published in other FE analysis reports. (William and Shoukry 2001; 2003).

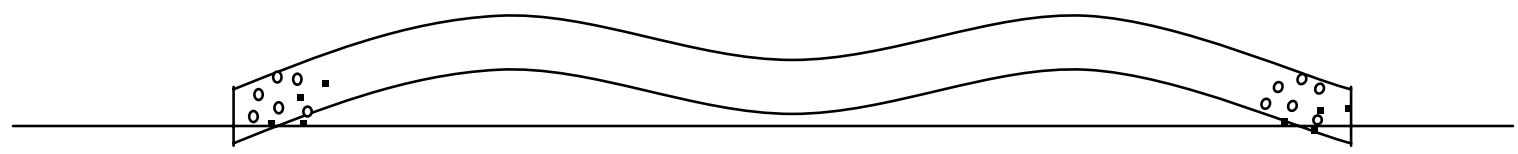

Figure 5.11a: Deformation of slab under positive temperature gradient - FE results

Figure 5.11a shows the deformation of a slab under positive temperature gradient obtained from finite element analysis. The center of the slab separates from the subgrade and develops larger tensile strains at the slab bottom than at the slab top due to the shape. Since the coarse slab/subgrade interface was modeled using uneven mesh, there could be greater constrains at the slab edge causing the higher strains when compared to the strains calculated for the free slab on smooth subgrade.

\section{Slab Fitted with Dowel Bars}

The 3DFE-calculated longitudinal strains and the experimentally measured strains near the transverse joints and at the slab center are compared in Figures 5.12 and 5.13 respectively. The success of the 3DFE model developed in this study with the detailed modeling of the dowel bars and their interfaces with the surrounding concrete is presented by the excellent agreement between calculated and measured strains at the slab top and bottom. 


\section{Slab Fitted with Shok Bars}

Figure 5.14 and Figure 5.15 plot the top and bottom strains near the slab transverse joint and slab center respectively for the slab fitted with Shok Bars. It can be noticed that the 3DFE-calculated strains are either matching or greater than the experimentally measured ones. This can be attributed to the built-in curling in this slab that formed at the early age as discussed in detail in Chapter 4, which made its joints curl upward permanently. Thus, the large differences observed were in the bottom strains and the top strain near joint as can be seen in Figures 5.14 and 5.15.

The comparison of the 3DFE-calculated strains and the experimentally measured strains in the four concrete slabs presented in this study shows a good agreement between the strains measured and calculated at the slab top. However, some discrepancies were observed when comparing the strain at the slab bottom. Such differences could be attributed to:

- The built-in slab curling at the early age distorted the slab from its original shape and may result in partial contact between the slab and the underlying base. This is not accounted for in the 3DFE models.

- The values of frictional coefficient assumed in the 3DFE model may differ from the actual one in the field.

- For the slabs fitted with dowel bars or Shok bars, the amount of looseness and characteristics of the concrete-dowel interface may have some effects that cause these differences. 

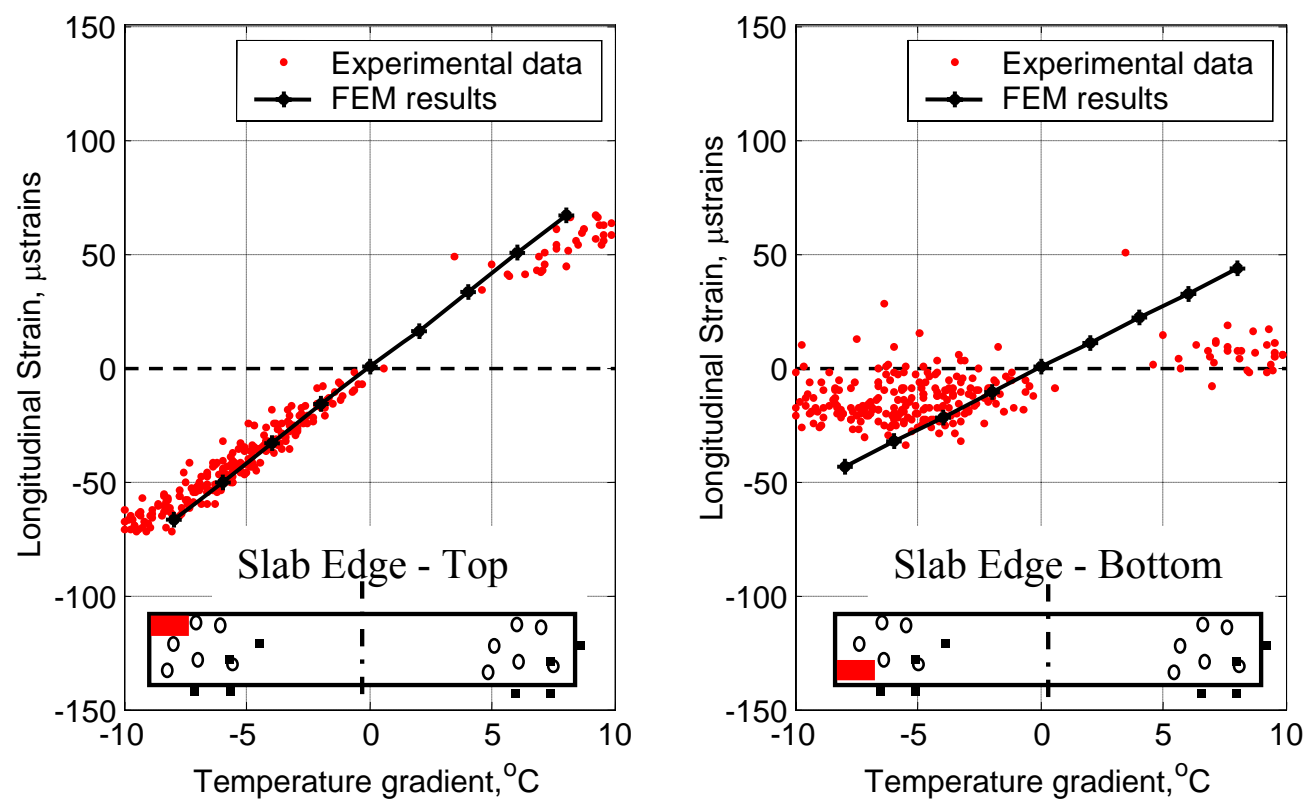

Figure 5.12: Longitudinal Strains vs. Temperature Gradient near Transverse edge of Slab Fitted with Regular Dowel Bars.
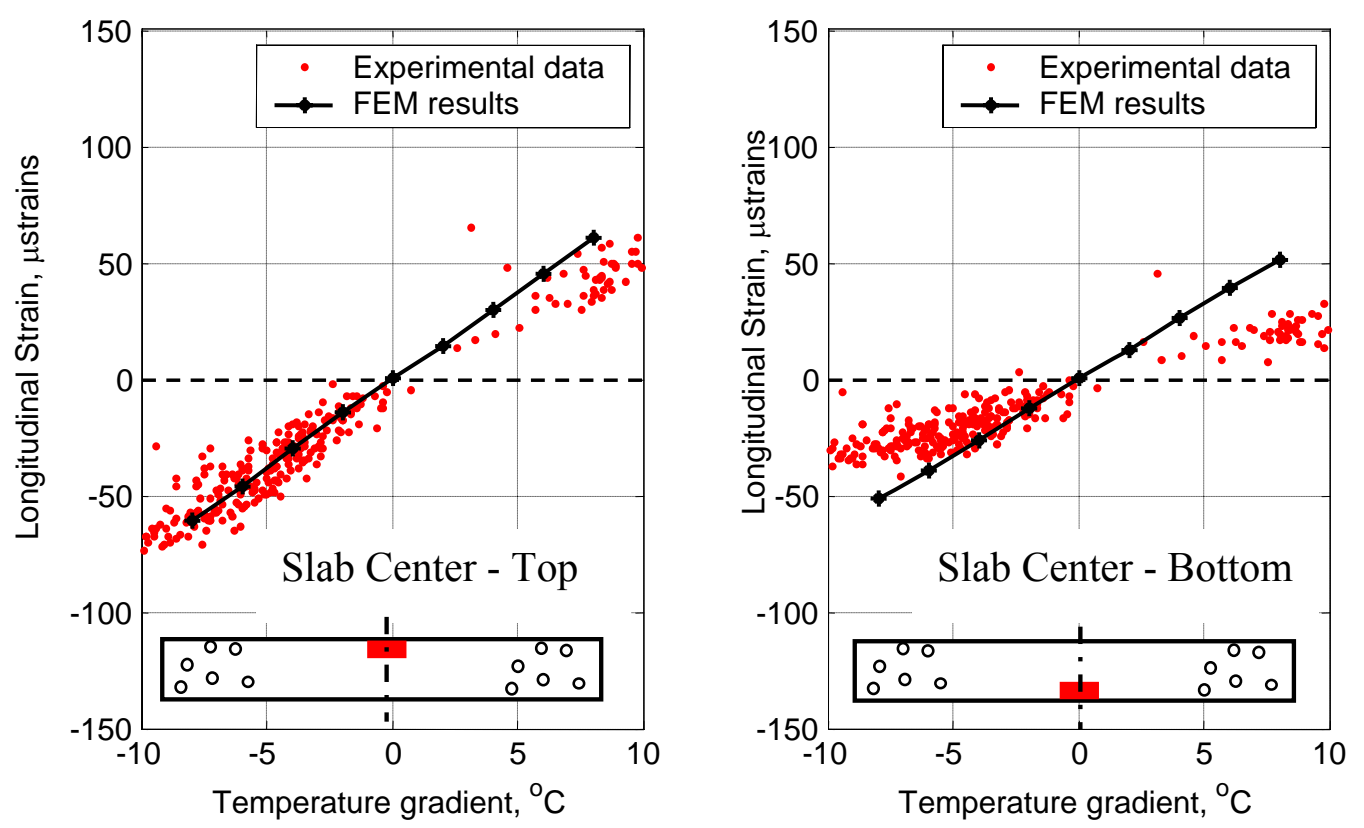

Figure 5.13: Longitudinal Strains vs. Temperature Gradient at the Center of Slab Fitted with Regular Dowel Bars. 

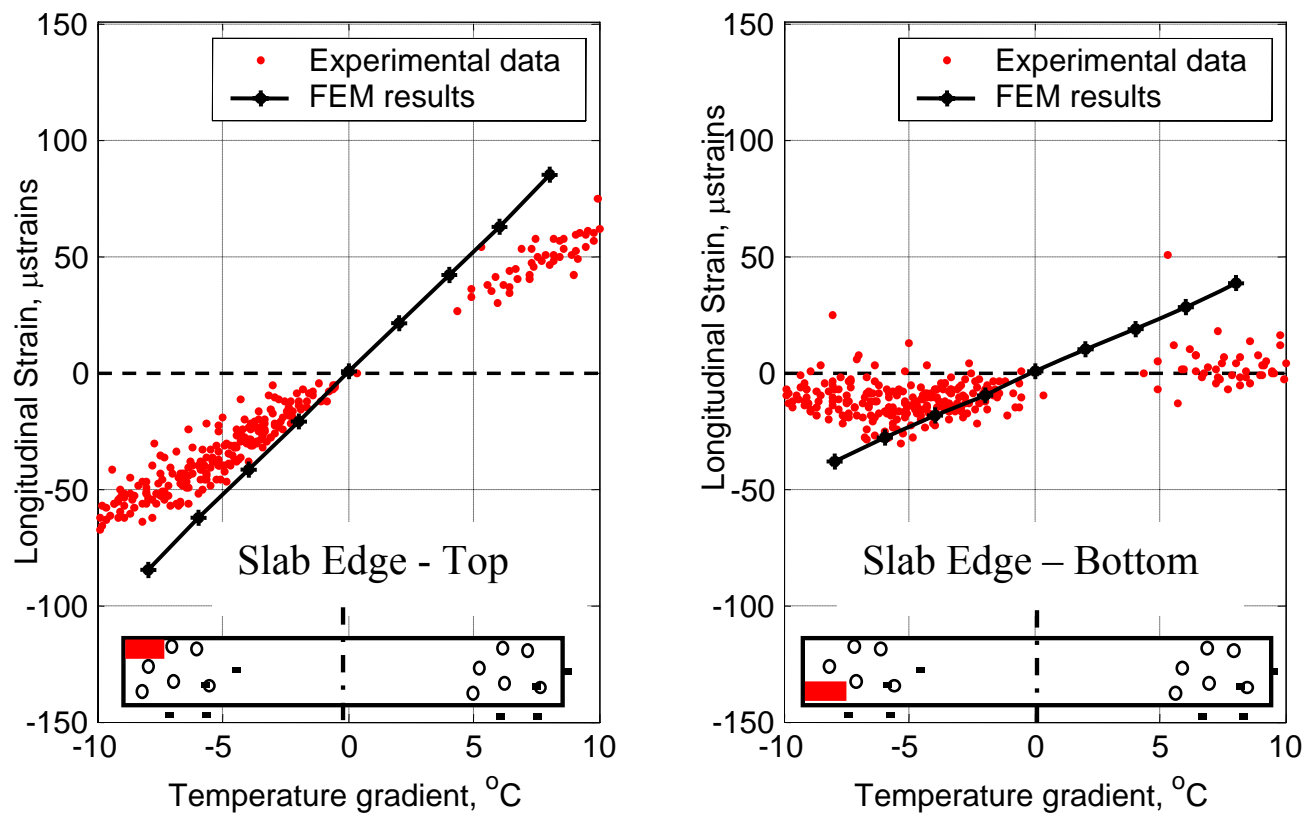

Figure 5.14: Longitudinal Strains vs. Temperature Gradient near Transverse edge of Slab Fitted with Shok Bars
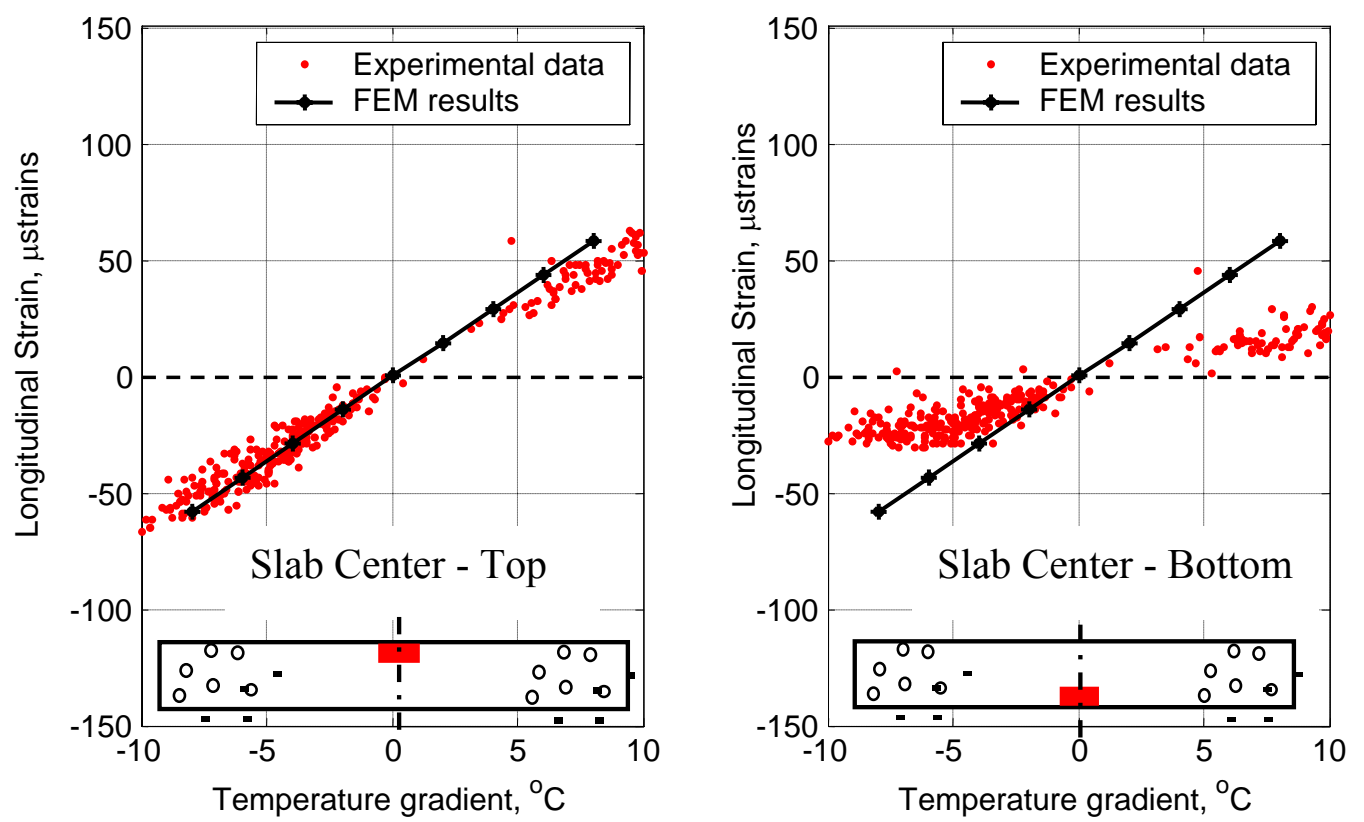

Figure 5.15: Longitudinal Strains vs. Temperature Gradient at the Center of Slab Fitted with Shok Bars 
As the slab curls due to the temperature gradient through its thickness, the dowel bars and the Shokbars are subjected to bending moments. Due to the linear elastic behavior of the steel and its independency on shrinkage and moisture, comparing the 3DFE-calculated bending moments with the experimentally measured ones offers a good technique for checking the accuracy of the 3DFE models. The dowel bars and Shokbars were modeled using 8-node solid brick elements which made it possible to represent the bars more accurately. The strains from the top and bottom of the bar mid region were noted for each temperature gradient case. The location of the elements matches the position of the vibrating wire strain gage at the top and bottom of the instrumented dowels and Shokbars. The experimental and 3DFE bending moments at the bar center were evaluated using the Equation:

$$
B M=\frac{\left(\varepsilon_{\text {top }}-\varepsilon_{\text {bottom }}\right) E I}{2 y}
$$

where $\mathrm{BM}=$ bending moment

$\varepsilon_{\text {top }}$ and $\varepsilon_{\text {bottom }}=$ strains from top and bottom elements at the bar mid region

$\mathrm{E}=$ Modulus of elasticity of Steel

$\mathrm{I}=$ Moment of Inertia of bar

$\mathrm{y}=$ Distance of element from neutral axis of bar

Figure 5.16 through Figure 5.18 plot the experimental and 3DFE results for the bending moment of dowel bars at the slab corner, slab wheel-path and transverse joint centerline against the temperature gradient through the slab thickness. Similar plots were obtained for the slab with Shokbars and hence were not presented here. It can be seen that the 3DFE model is able to satisfactorily predict the slab bending at the transverse joint. A correction factor was applied to the results obtained from the 3DFE model to match it to the measured values. The correction factors for slabs with regular dowel bars were found to be 2.1, 1.3 and 1.4 and for the slab with Shok bars were 2.9, 1.8, and 1.3 for the slab corner, slab wheel path and joint center respectively. The high values correction factors result from the facts that the temperatures at different points in the same layer below the slab surface are not same as assumed in the FE model; there could be some looseness around the dowel and concrete due to wear and tear which could not be simulated in the FE model. Considering the limitations of the FE model the CF values seem acceptable. 


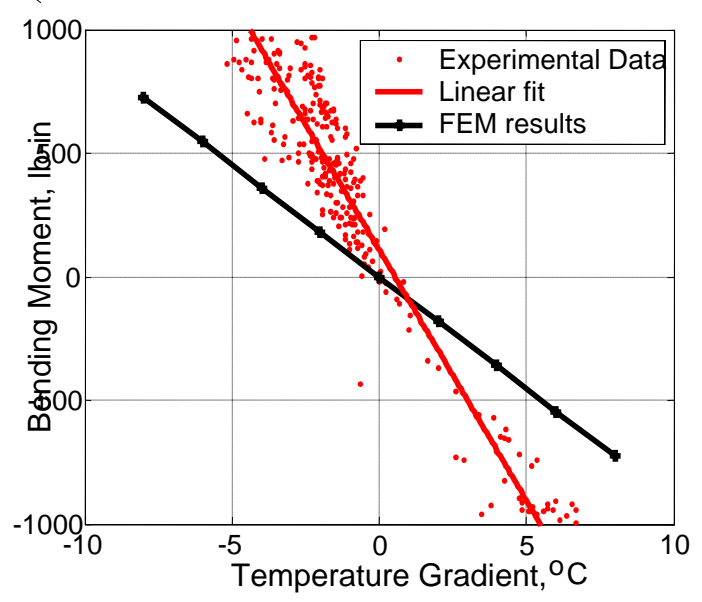

Figure 5.16: Bending Moment of Dowel Bar at Slab Corner.

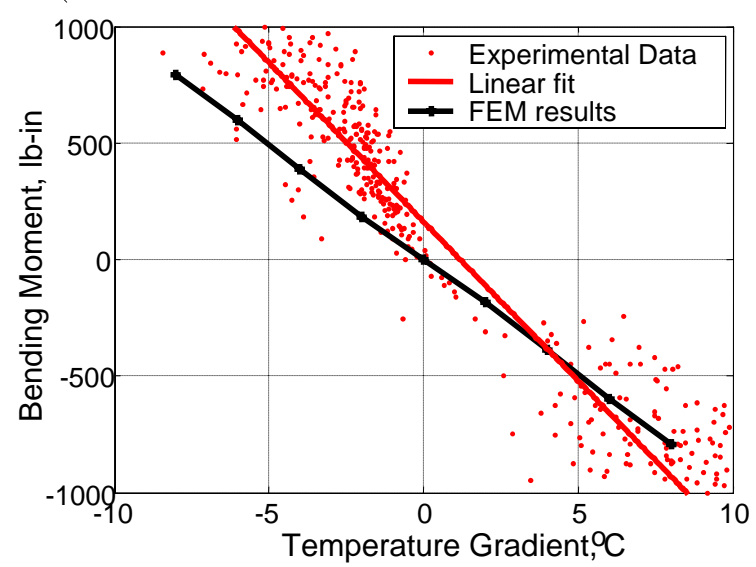

Figure 5.17: Bending Moment of Dowel Bar at Slab Wheel-path.

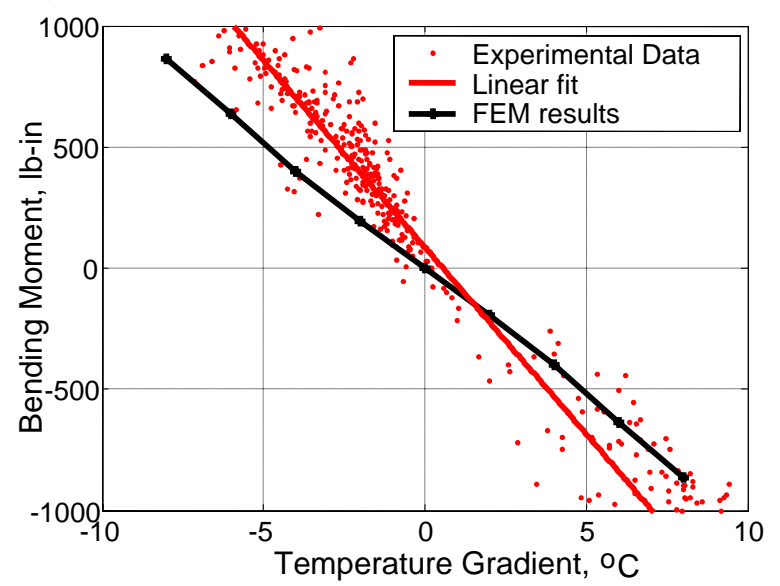

Figure 5.18: Bending Moment of Dowel Bar at Transverse Joint Centerline 


\subsubsection{Thermal stresses estimated by 3DFE}

To examine the thermal stress fields developed in concrete slabs under different constraints, the 3DFE models were subjected to uniform temperature decreases of -10 and $-20{ }^{\circ} \mathrm{C}$. The longitudinal stress profiles along the longitudinal slab centerlines due to each temperature decrease were compared as shown in Figures 5.19 and 5.20.

As expected the free slab developed the least stresses since its edges have the freedom to contract as its temperature decreases. The low compressive stresses developed in such a slab could be due to the non-uniform strain distribution developed along the slab centerline; the mid-slab strain was observed to be $2 \mu$ strain higher than that at the edge in the case of $-20^{\circ} \mathrm{C}$.

The effect of slab-base friction was manifested by the higher longitudinal stress at mid-slab as shown in Figures 5.19 and 5.20. The irregular surface of the slab bottom and the free slab top created a non-uniformity in the stress profile at the slab bottom as shown in Figures 5.19 (b) and 5.20 (b). Thus, the maximum stress was observed to be approximately at a distance 30 inches from slab edge. However, the magnitude of stress due to slab-base friction as surface irregularity of the slab bottom is still very well below the concrete modulus of rupture. The plots in Figures 5.19 and 5.20 illustrate that dowel bars and shokbars have the most constraining effect on the slab contraction, hence higher longitudinal thermal stresses. The stresses developed in the slab fitted with dowel bars are slightly higher than those developed in the Shokbar slab.

The bending of dowel bars or shokbars is the main cause of the slab constraint to contraction and expansion. Therefore, it is not expected that adopting Shokbar design to reduce thermal stresses due to seasonal and diurnal temperature changes as shown from 3DFE results presented here. However, the success of the Shokbar design is in reducing the stresses developed in concrete slab due to drying shrinkage at the early age as discussed in Chapter Four, hence reducing the built-up stresses due to shrinkage and 
temperature variations during the entire age of the concrete pavements, in addition to reducing the contact stresses developed at the concrete dowel interfaces and preserving the load transfer efficiency.

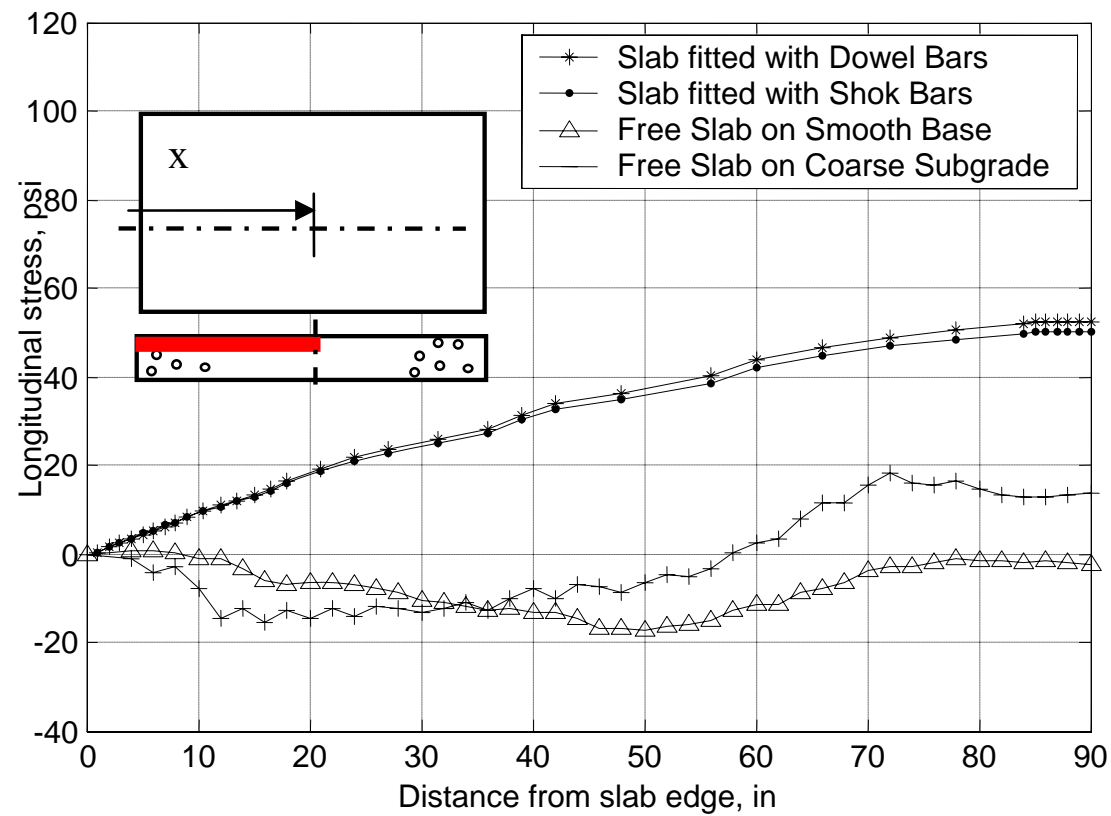

(a): Slab Top

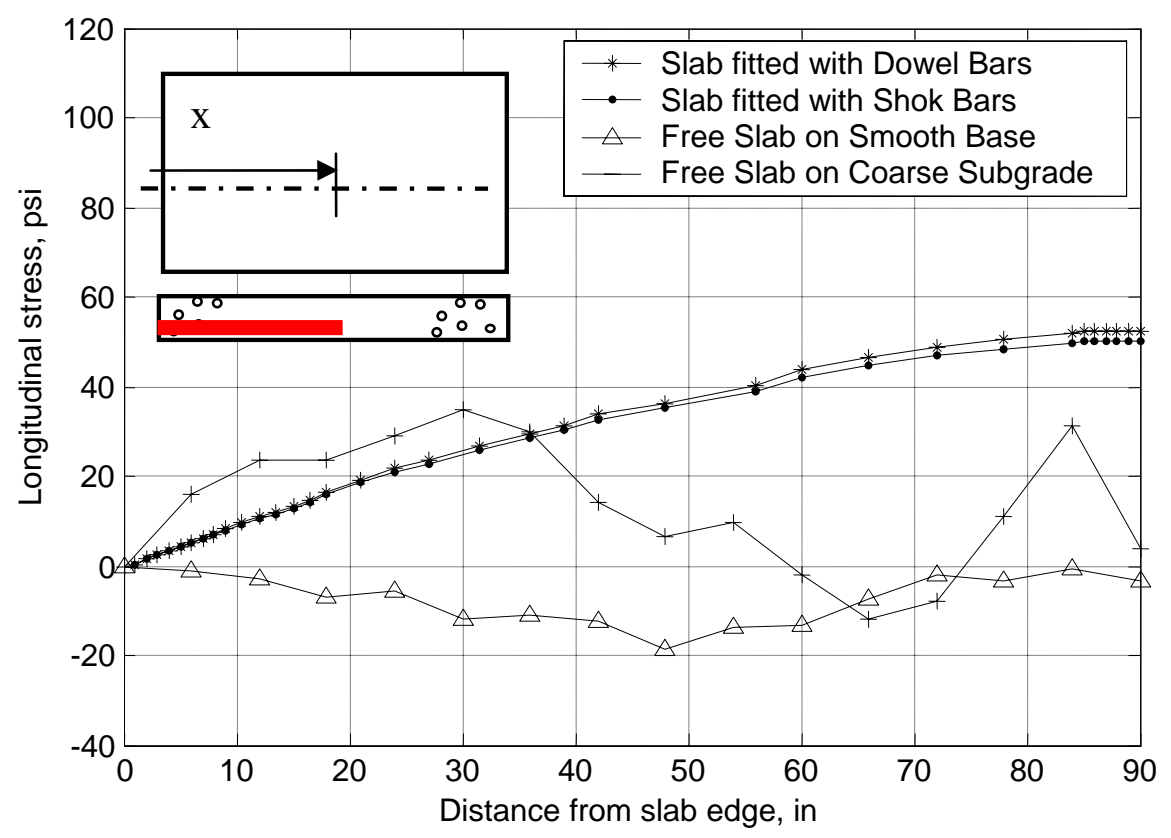

(b): Slab bottom

Figure 5.19: Longitudinal Stress along slab centerline - Temperature Drop of $-10{ }^{\circ} \mathrm{C}$ 


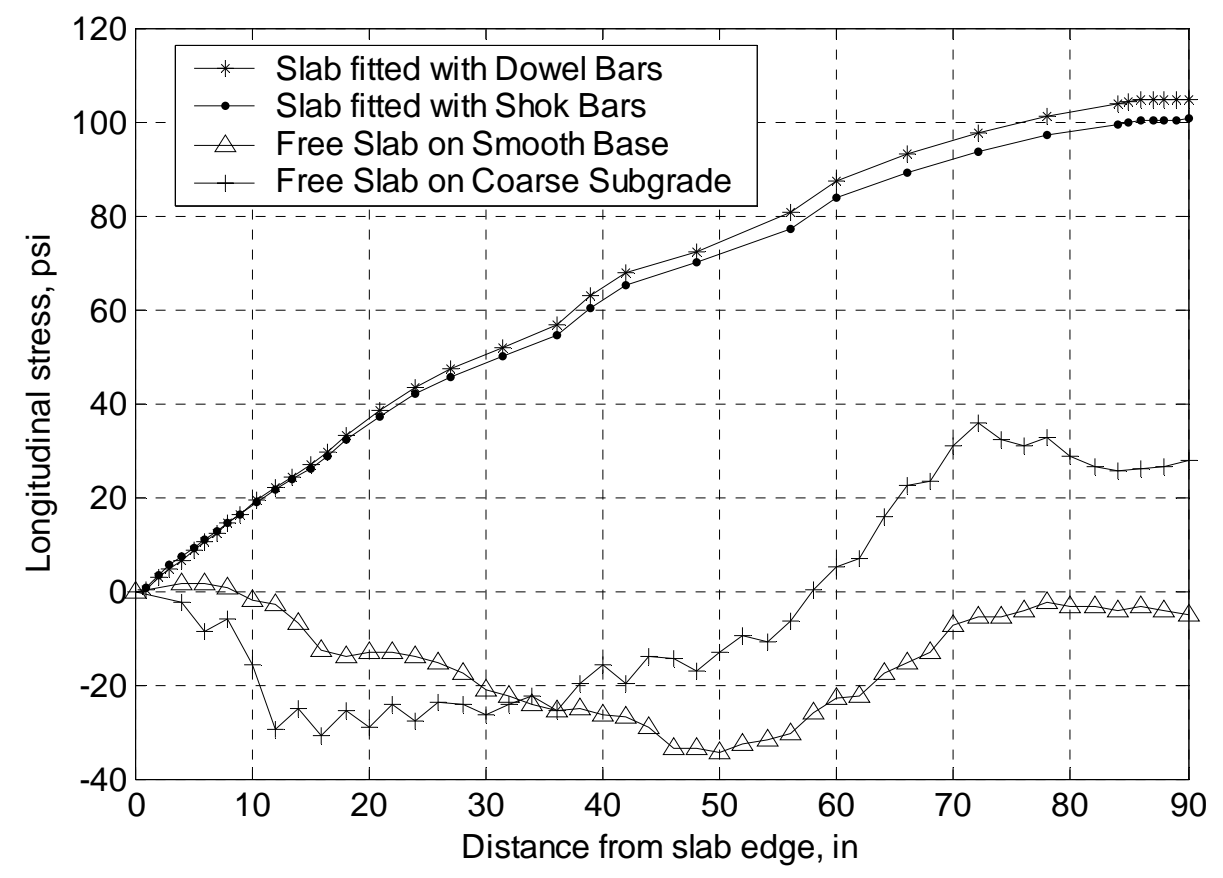

(a): Slab top

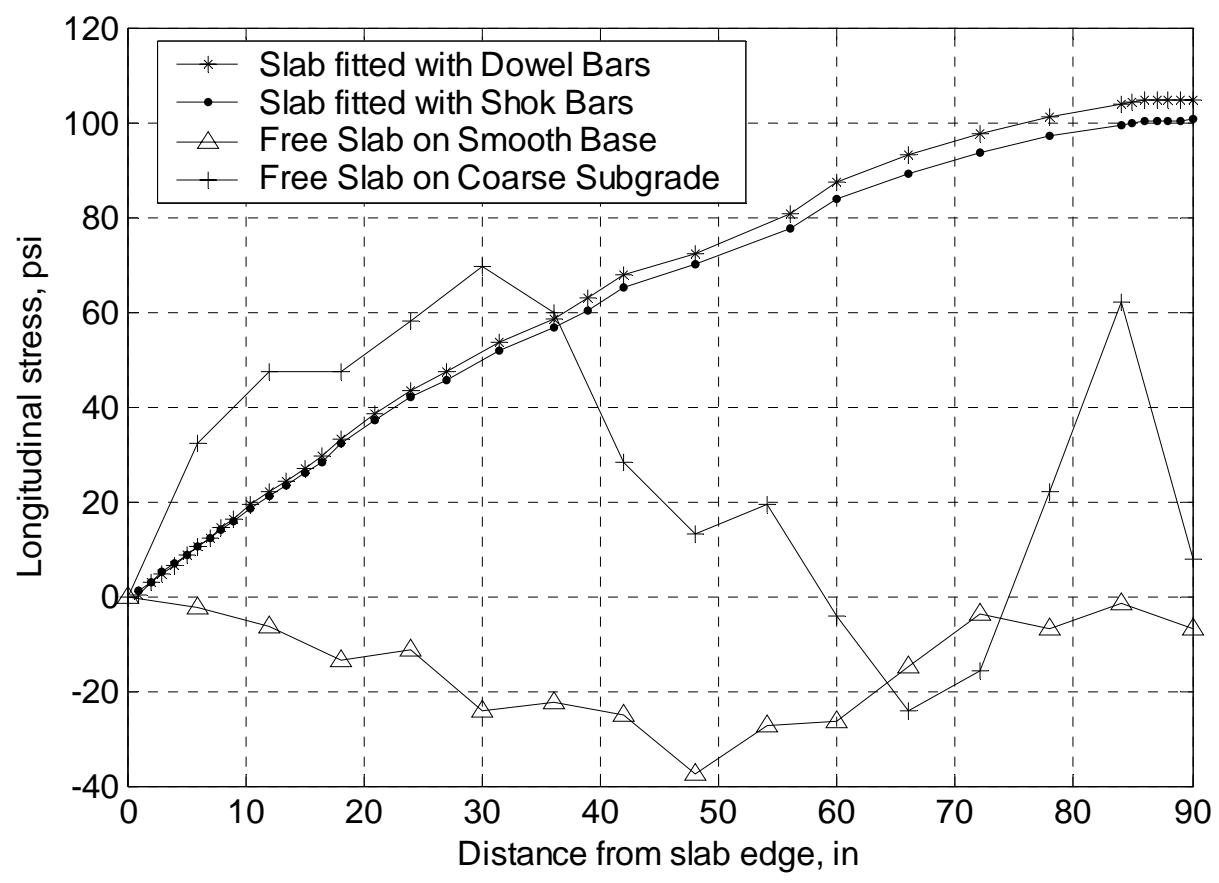

(b): Slab bottom

Figure 5.20: Longitudinal Stress along slab centerline - Temperature Drop of $-20^{\circ} \mathrm{C}$ 


\subsection{SUMMARY}

A method has been developed to validate the thermo elastic response of 3DFE models of concrete slabs to temperature variations. Although the measured strains include the effect of construction curling, shrinkage, and moisture changes that are not accounted for in the 3DFE model, their influence can be significantly reduced by considering the change in the strain that occurs over a short period of time. Comparison between the 3DFE-computed and the measured changes in strains indicate acceptable agreement. Comparing measured and 3DFE-calculated bending moments in dowel bars or shokbars provides a good means to validate the model response to slab curling. Bending of dowel bars and shokbars due to slab curling and/or due to slab contraction constitute the main constraint to slab movement. 


\section{CHAPTER SIX}

\section{PREDICTION OF SLAB TEMPERATURES AND STRAINS FROM ENVIRONMENTAL CONDITIONS}

\subsection{INTRODUCTION}

The design of concrete pavements requires the knowledge of weather conditions in the region. Pavement thickness depends on the maximum temperature gradient that might occur through the slab; the type of drainage required depends on the amount of rainfall that the region may receive; the amount of snowfall in the region and so on. Hence the data available with the local weather station can be used to predetermine the temperature gradient and stress levels in the pavements. It might also be important to continuously monitor the stress levels and overall performance of certain structures such as bridges and pavements subjected to the environment and traffic loads. This would involve expensive instrumentation of the structure. Instead it is economical if the temperature and strains values are directly correlated to the environmental conditions. This would help in damage control in terms of pavement or bridge repair by determining the regions of high distress in the pavements and attending to it immediately. Numerous efforts have been made to understand and quantify the relationships between the various environmental parameters and the performance of concrete pavements.

Figure 6.1 indicates the common input parameters that control the slab performance in terms of temperature variations, strains and stresses in the slab. The input parameters can be divided into two groups: Environment conditions which are not in human control and pavement properties which can be changed depending on the location and traffic requirements. The transfer function formulated should be capable of taking in these inputs and calculate or predict the output parameters i.e. slab temperature and strains. The transfer function can be any feasible method like equations based on thermal mechanics or approximation and prediction techniques like neural networks. 


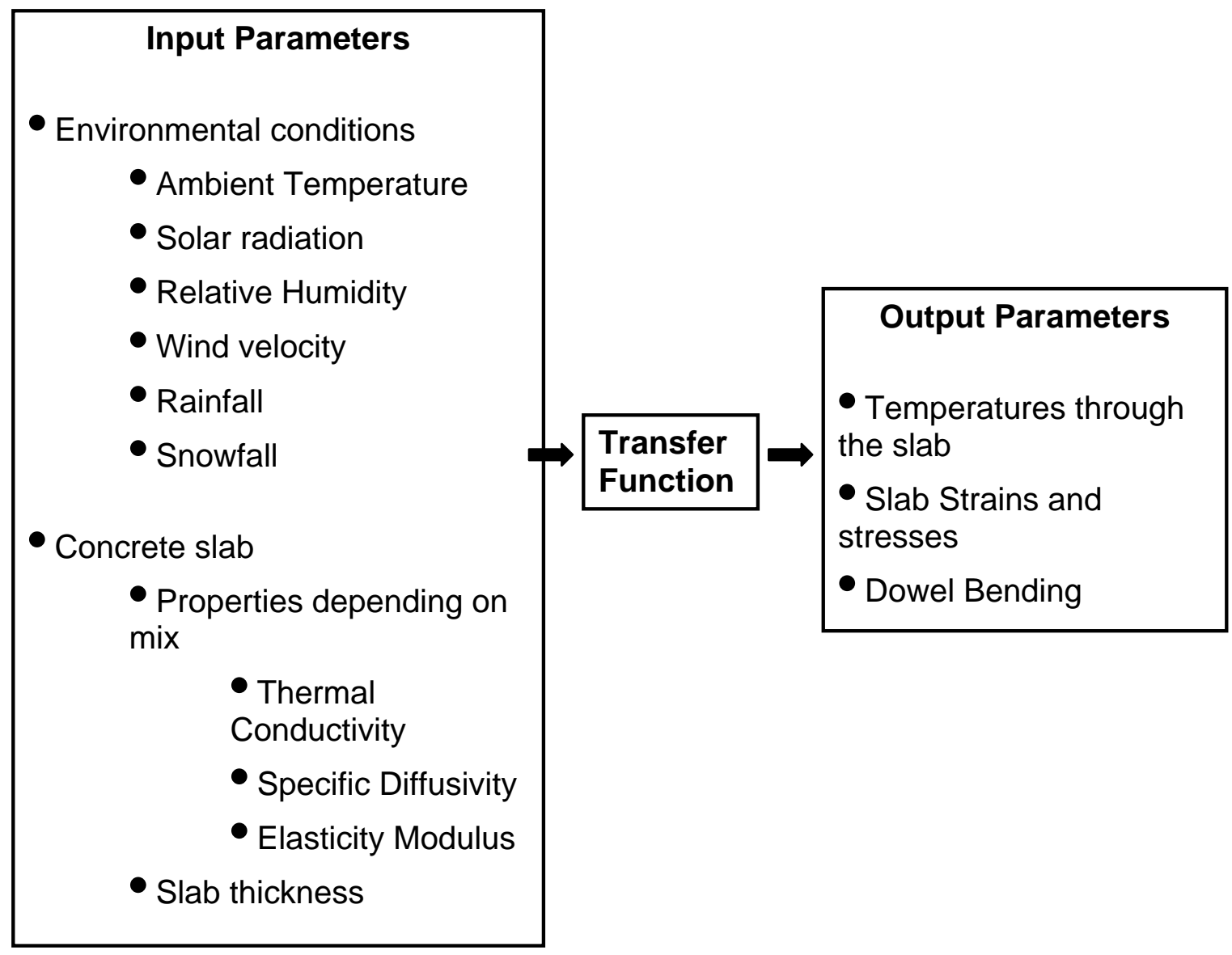

Figure 6.1: Parameters affecting slab performance

In this present effort local weather conditions are used to determine the temperature and in turn thermal strain values through the slab. The parameters measured by the weather station were air temperature, solar radiation, relative humidity, rainfall and wind velocity and direction.

\subsection{CERTAIN OBSERVATIONS MADE RELATING WEATHER CONDITIONS AND SLAB RESPONSE}

During the course of data analysis certain observations were made on the behavior of the concrete pavements based on the weather variables. 


\subsubsection{Accumulation of snow on pavement}

The variations in slab surface temperature usually follow the daily rise and fall in the air temperature. But as shown in Figure 6.2, on some days this trend is absent. This deviation from the usual was attributed to the presence of snow on the pavement. The temperature on the slab surface does not change in accordance with the changes in the air temperature because the snow present on the surface acts as a heat insulator. It was also noticed that the temperature gradient through the slab on such days was linear with a negative gradient of around $-2{ }^{\circ} \mathrm{C}$.

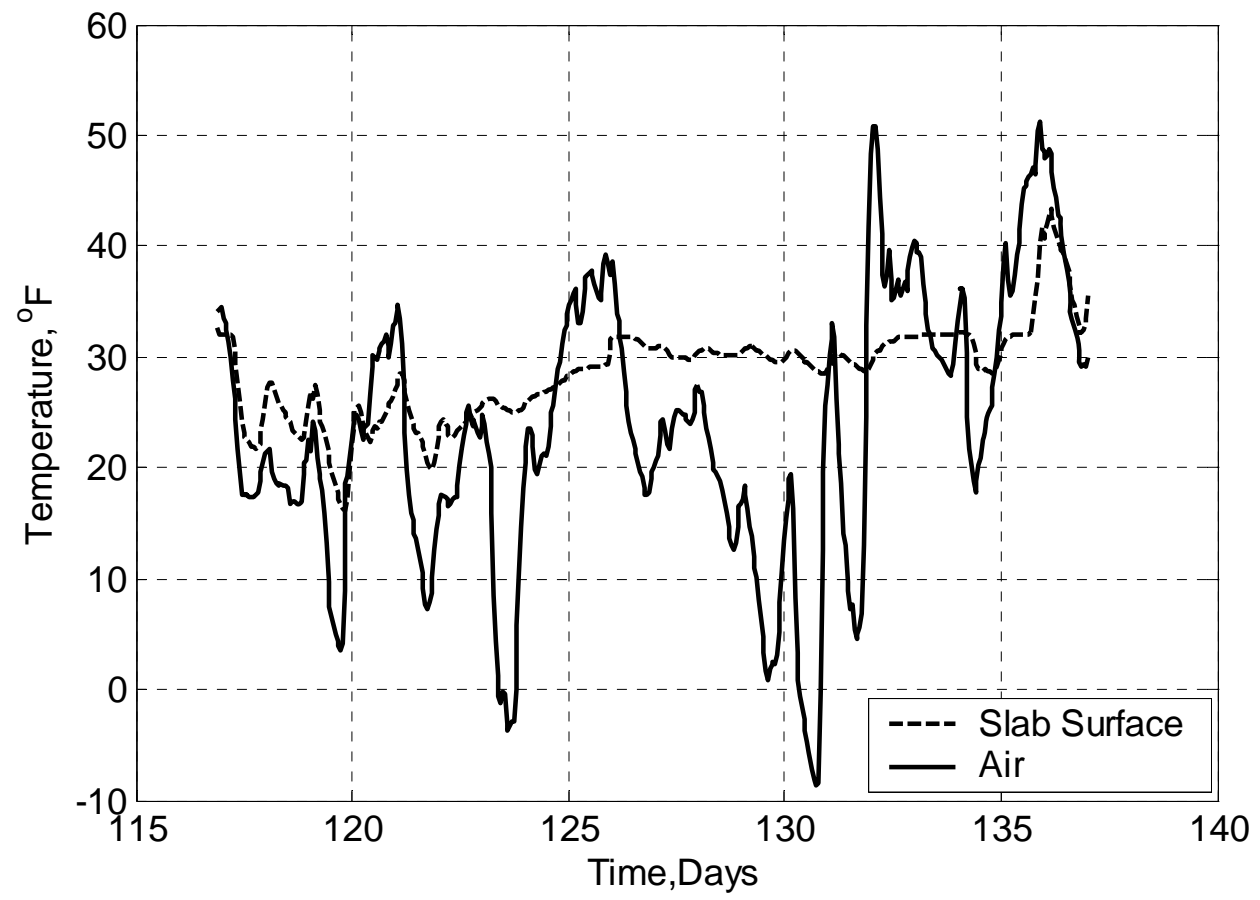

Figure 6.2: Variation of Slab surface and air temperature during snow accumulation

\subsubsection{Occurrence of non-linear temperature gradients through the slab}

The presence of non-linear temperature gradients through the thickness of the slab have been observed and reported by many researchers as to be either quadratic (Shoukry 2004) or cubic (Zollinger 2005). But this nonlinearity is not present throughout the day; in fact during most parts of the day a linear gradient exists. Figure 6.3a plots the air and slab surface temperature changes over two days. 


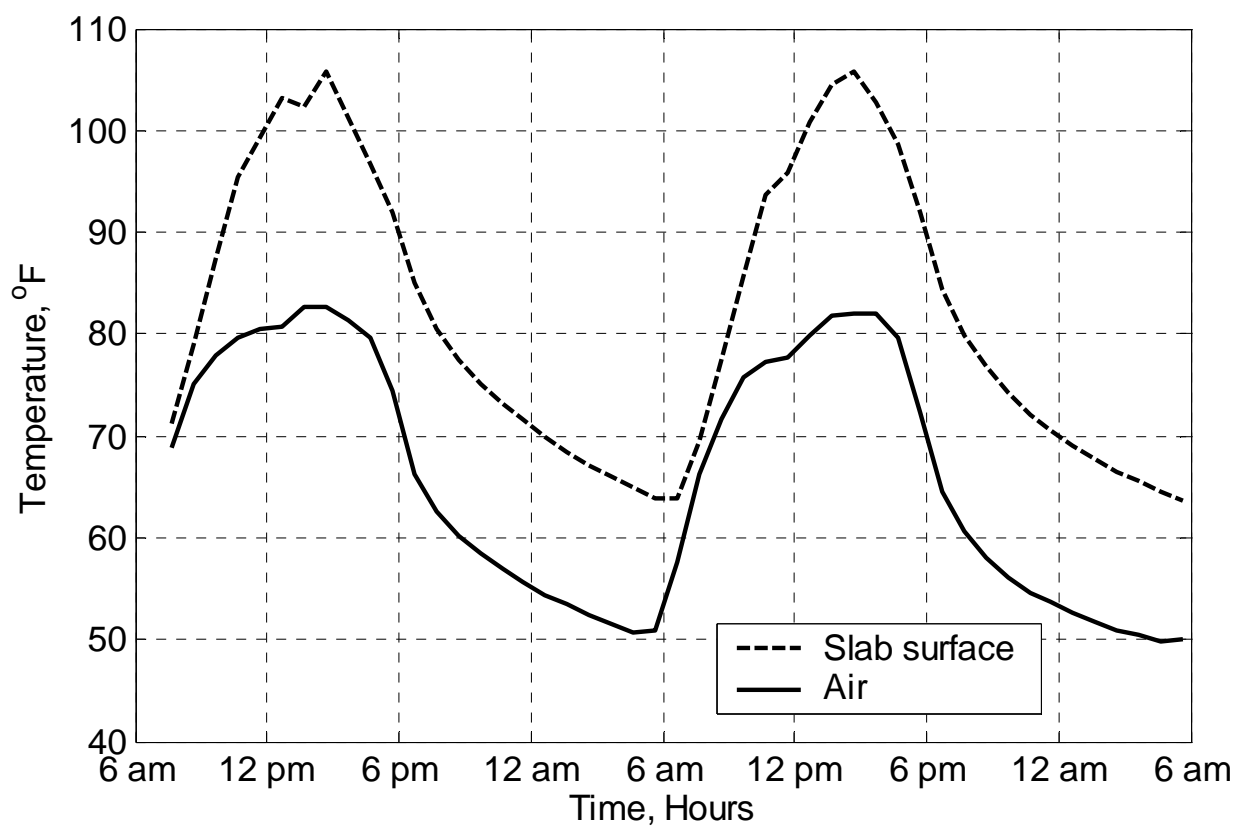

(a) Slab surface and air temperature variations through days 710 - 711

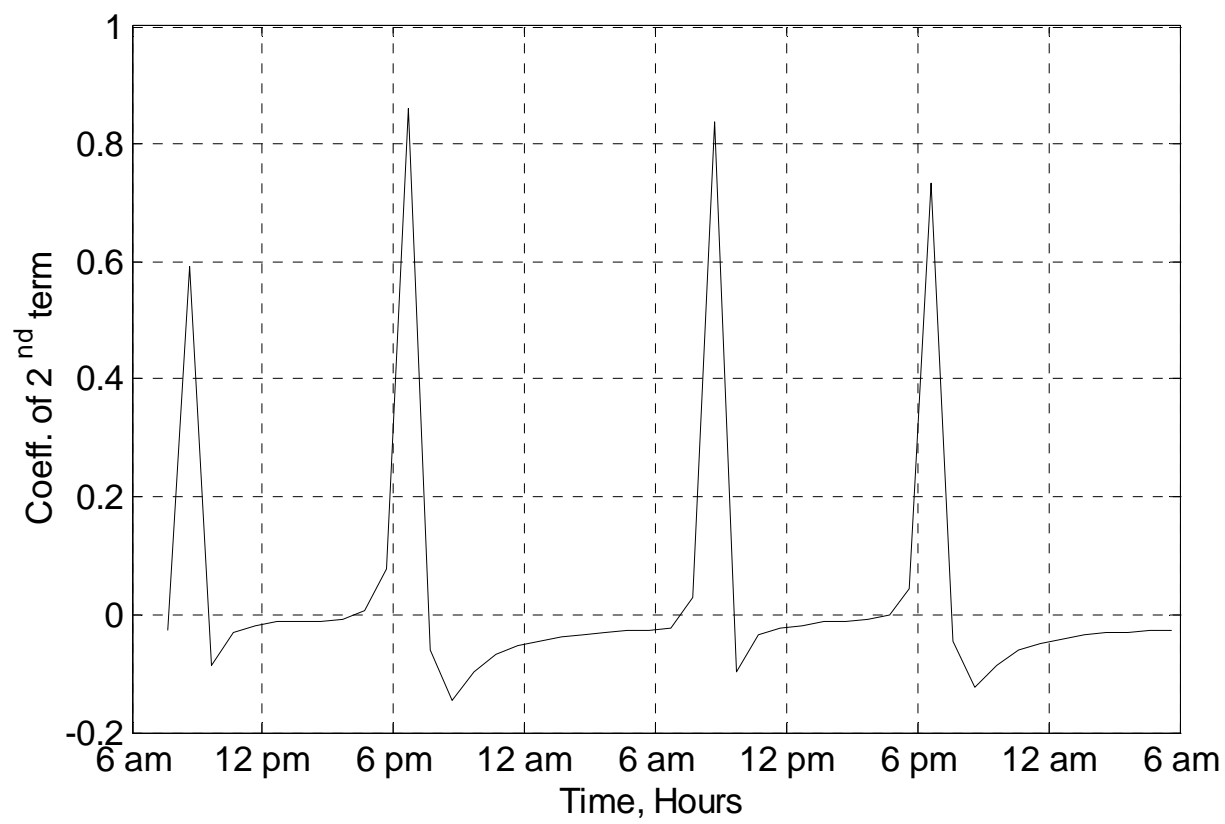

(b) Magnitude of the coefficient of $2^{\text {nd }}$ term plotted over days 710 - 711

Figure 6.3: Occurrence of nonlinearity through the day

From the data available, it was noticed that the gradient in a quadratic form occurs more often than a cubic gradient. Hence, the temperature profile through the thickness of the 
slab was fit to a quadratic equation $\left(a_{2} x^{2}+a_{1} x+a_{0}\right)$ and the coefficient of the square term "a2" is plotted in Figure 6.3b. The presence of a value other than zero indicates that the profile is non linear. As can be seen from the plot, nonlinear temperature profile exists when the surface temperature increases just after sunrise around $8 \mathrm{AM}$ and decreases around $7 \mathrm{PM}$ after sun down on a clear day with no rainfall. The remaining periods of the day have relatively very low values of the coefficient which implies that the temperature gradient is generally linear. A nonlinear gradient occurs when there is a steep increase or decrease in the slab temperature. Figure 6.4 plots the values of rain, slab surface and air temperature along with the magnitude a2.
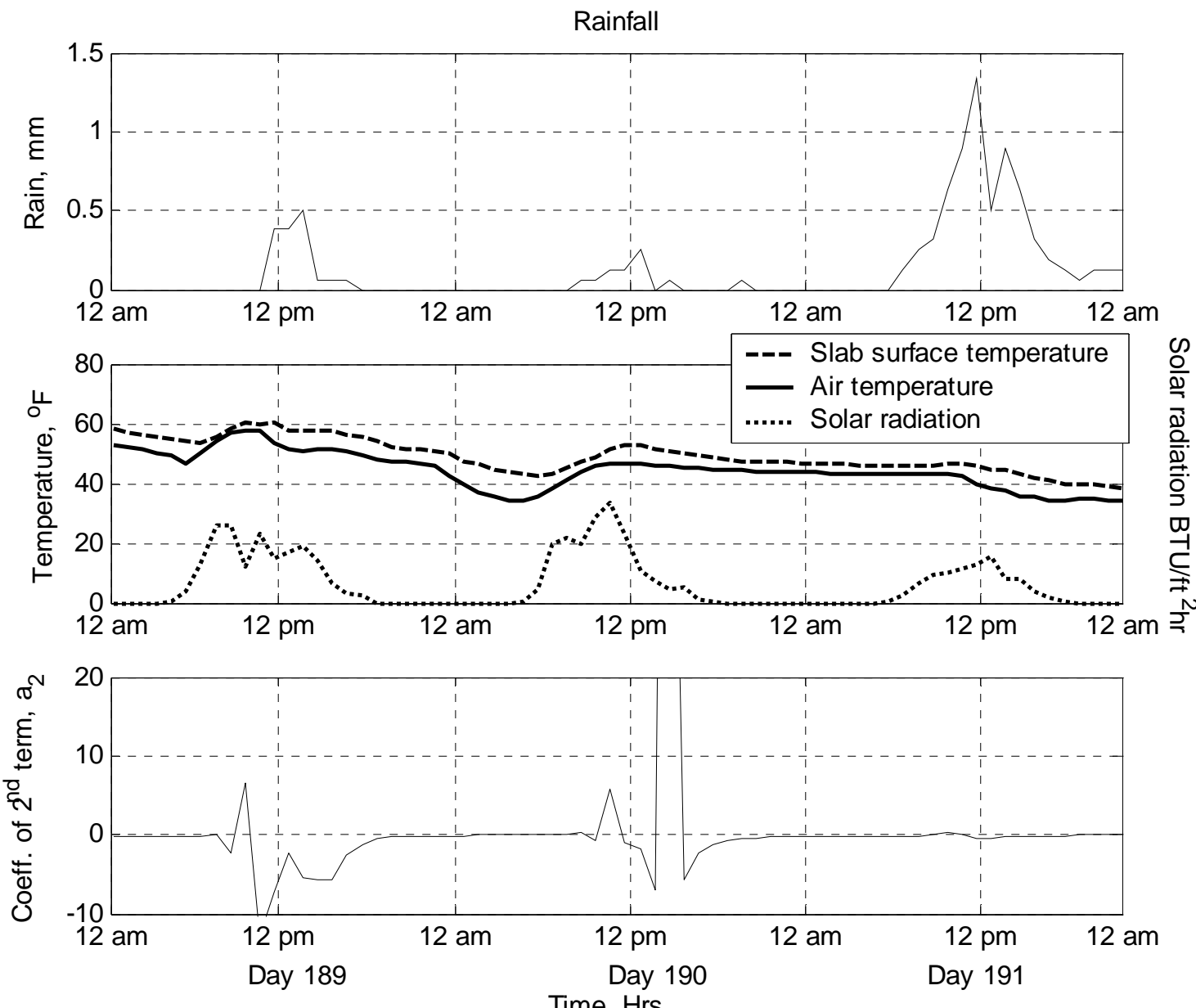

Figure 6.4: Magnitude of $2^{\text {nd }}$ Coefficient during rainy days

As seen in Figure 6.4, nonlinearities in the temperature gradient usually occur 
- when the rain begins after some sunshine has heated up the slab resulting in cooling of the slab surface as is the case on day 189

- when there was rain and cloud cover through the day and then the clouds clear up during late afternoon, the water on the surface evaporates due to heating by the sun resulting in rapid cooling of the top surface as is the case on day 190

On day 191, rain and cloud cover throughout the day did not result in large nonlinear gradients through the slab thickness.

\subsubsection{Solar radiation through the year}

The solar radiation (including direct and diffused radiation) received at the site on a typical day of the month is plotted in Figure 6.5. As expected the total amount of radiation received is higher as well as for a longer duration during the summer months than during winter. This results in higher slab temperatures during summer than in winter.

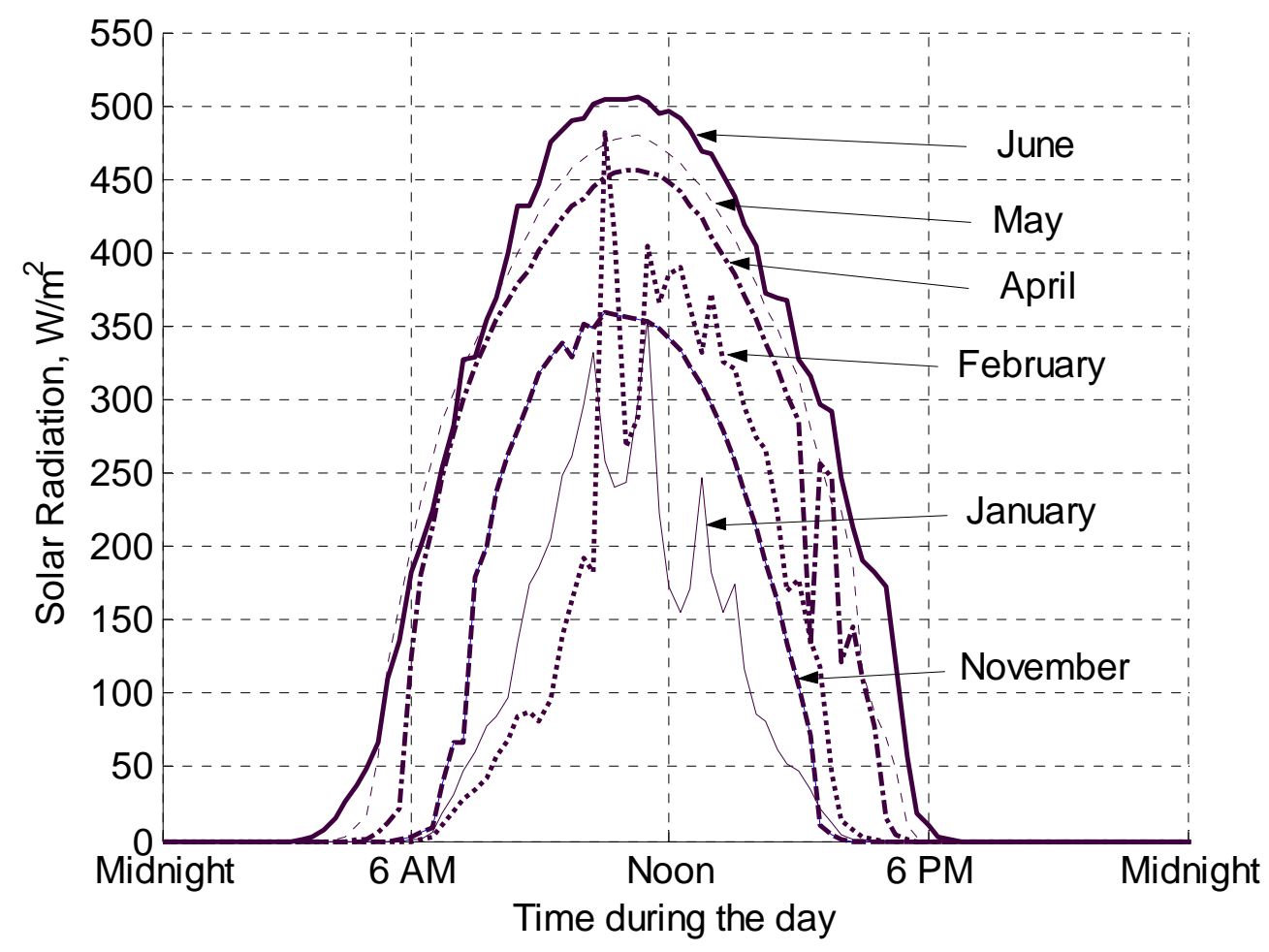

Figure 6.5: Solar radiation received during a typical day of the month 


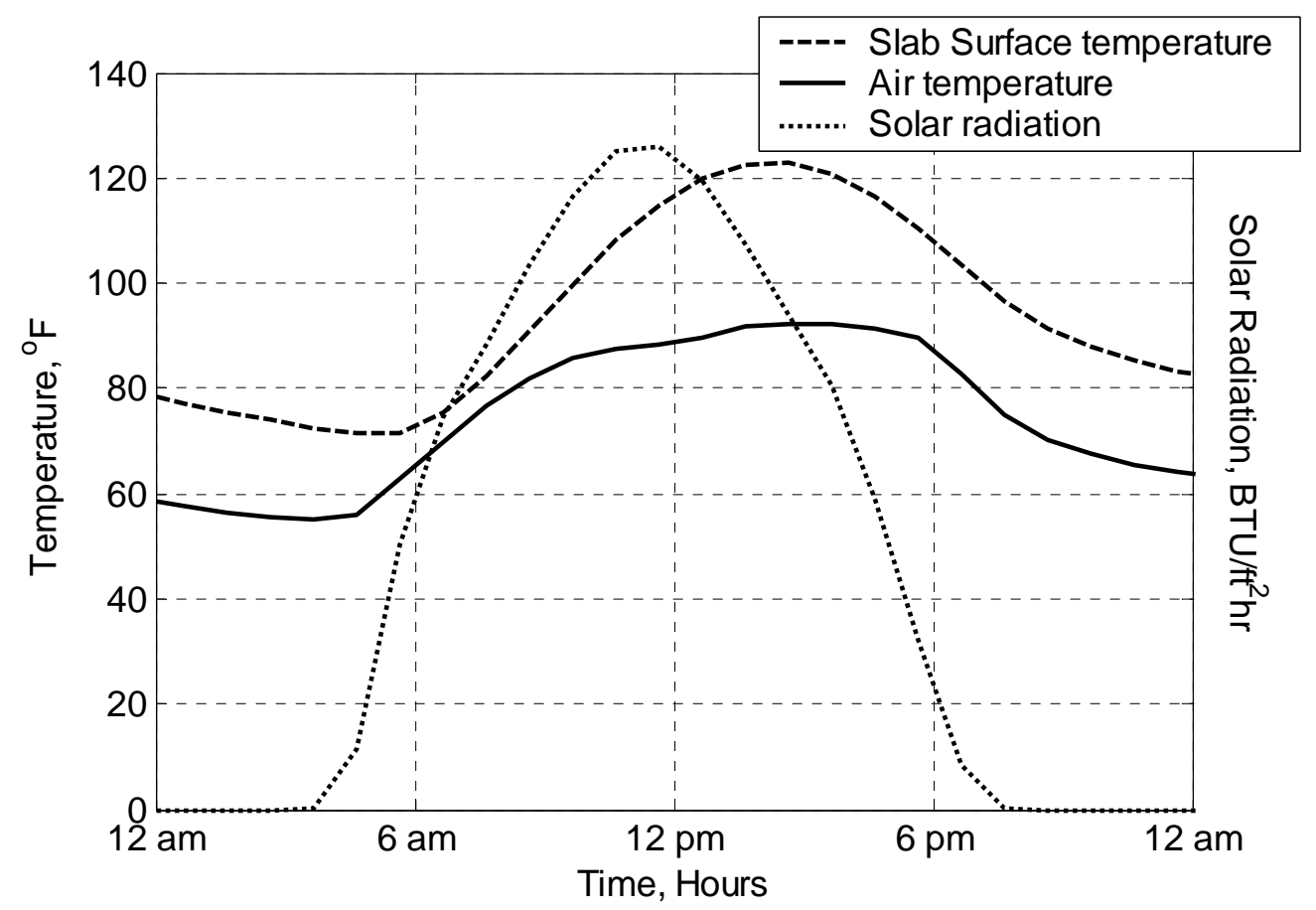

Figure 6.6: Temperature and Solar radiation during a day

Figure 6.6 plots the slab and air temperature along with the solar radiation received during a sunny day. The solar radiation reaches its maximum just before noon and the air and slab surface temperatures reach their respective peaks around $1 \mathrm{pm}$ and $2 \mathrm{pm}$.

\subsection{PAVEMENT TEMPERATURE CALCULATIONS}

\subsubsection{Heat Transfer Model}

The following is a brief description of the heat transfer model proposed by Dempsey et al (1970). They developed a climatic-materials-structural model for slab temperature prediction which describes that the meteorological parameters that affect the temperature of the slab surface are net solar radiation heat transfer and heat loss by convection heat transfer. The net solar radiation heat transfer includes heat absorbed or diffused due to direct solar radiation, diffused radiation and conductive heat transfer. 
The net rate of heat flow across the slab surface can be calculated from the equation as described by Solaimanian and Kennedy (1993) who based their calculations on the heat transfer model

$$
q_{\text {net }}=q_{s}+q_{a}-q_{c}-q_{k}-q_{r}
$$

where $\mathbf{q}_{\mathbf{s}}=$ energy absorbed from direct solar radiation

$$
=\alpha * \mathrm{R}
$$

$\mathrm{a}=$ surface absorptivity

$\mathrm{R}=$ solar radiation $\left(\mathrm{BTU} / \mathrm{hr}^{-\mathrm{ft}^{2}}\right)$

$$
\begin{aligned}
\mathbf{q}_{\mathbf{a}} & =\text { energy absorbed from diffused radiation } \\
& =\varepsilon_{\mathrm{a}}{ }^{*} \sigma^{*} \mathrm{~T}_{\mathrm{air}}{ }^{4}
\end{aligned}
$$

$\varepsilon_{\mathrm{a}}=0.77-0.28 *\left(10^{-\mathrm{p}^{*} 0.074}\right)$

$\sigma=$ Stefan - Boltzman constant

$\mathrm{T}_{\text {air }}=$ air temperature, $\mathrm{K}$

$\rho=$ vapor pressure (related to the relative humidity) in mm of mercury

$$
\begin{aligned}
\mathbf{q}_{\mathbf{k}} & =\text { energy conducted to and from the body } \\
& =-k \frac{T_{d}-T_{s}}{d}
\end{aligned}
$$

$\mathrm{k}=$ thermal conductivity, BTU/ft ${ }^{2}-\mathrm{hr}$

$\mathrm{T}_{\mathrm{s}}=$ surface temperature, $\mathrm{F}$

$\mathrm{d}=$ depth below surface, feet

$T_{d}=$ temperature at depth $\mathrm{d}, \mathrm{F}$

$$
\begin{aligned}
\mathbf{q}_{\mathbf{c}} & =\text { energy lost due to convection } \\
& =\mathrm{h}_{\mathrm{c}}{ }^{*}\left(\mathrm{~T}_{\mathrm{S}}-\mathrm{T}_{\text {air }}\right)
\end{aligned}
$$

$h_{c}=$ surface coefficient of heat transfer 


$$
=122.93\left\{0.00144 V_{m}^{0.3} U^{0.7}+0.00097\left(V_{1}-V_{\text {air }}\right)^{0.3}\right\}
$$

where $\mathrm{V}_{\mathrm{m}}=$ average of air temperature and pavement surface temperature in Kelvin $\mathrm{V}_{1}$ and $\mathrm{V}_{\text {air }}$ slab surface and air temperatures in ${ }^{\circ} \mathrm{C}$

$$
\begin{aligned}
& \mathbf{q}_{\mathbf{r}}=\text { radiation emitted from surface } \\
& =\varepsilon * \sigma^{*} \mathrm{~T}_{\mathrm{s}}{ }^{4} \\
& \varepsilon=\text { emissivity }
\end{aligned}
$$

It is assumed that thermal equilibrium is achieved at the slab surface i.e. the neat heat transfer at the surface is zero. Using the equations 6.2 to 6.6 given above which are in terms of the surface temperature, the $4^{\text {th }}$ order polynomial equation 6.1, $q_{s}+q_{a}-q_{c}-q_{k}-q_{r}=0$ is solved to obtain the surface temperature. The heat conducted through the slab can be represented by a one dimensional heat transfer partial differential equation. Dempsey et al used the finite difference method to solve the heat transfer equation and obtain the temperatures through the slab thickness.

\subsubsection{Thermal diffusion theory: Barber (1957)}

Barber (1957) presented a relation between pavement temperatures and the parameters of weather condition including wind velocity, air temperature and solar radiation. Consider a 24 hour periodic temperature variation of $T_{m}+T_{v} \sin (0.262 t)$ in contact with a semi-infinite slab. The surface temperature by the modified equations was then given by

$$
T_{S}=T_{M}+T_{V} \frac{H e^{-x C}}{\sqrt{(H+C)^{2}+C^{2}}} \sin \left(0.262 t-x C-\tan ^{-1} \frac{C}{H+C}\right)
$$

in which

$\mathrm{T}_{\mathrm{S}}=$ temperature of slab, $\mathrm{F}$

$\mathrm{T}_{\mathrm{M}}=$ mean effective air temperature, $\mathrm{F}$

$\mathrm{T}_{\mathrm{V}}=$ maximum variation in temperature from mean $\mathrm{T}_{\mathrm{M}}, \mathrm{F}$

$\mathrm{t}=$ time from beginning of cycle, hours

$\mathrm{x}=$ depth below surface, feet 
$\mathrm{H}=\mathrm{h} / \mathrm{k}$

$\mathrm{h}=$ surface coefficient, BTU $/ \mathrm{ft}^{2}-\mathrm{hr}-\mathrm{F}$

$\mathrm{k}=$ thermal conductivity, BTU- $\mathrm{ft} / \mathrm{ft}^{2}-\mathrm{hr}-\mathrm{F}$

$\mathrm{C}=\sqrt{0.131 / c}$

$\mathrm{c}=$ diffusivity, $\mathrm{ft}^{2} / \mathrm{hr}=\frac{k}{s w}$

$\mathrm{s}=$ specific heat, $\mathrm{BTU} / \mathrm{lb}-\mathrm{F}$

$\mathrm{w}=$ density, $\mathrm{lb} / \mathrm{ft}^{3}$

For forced convection including average re-radiation

$$
h=1.3+0.62 v^{3 / 4}
$$

where $\mathrm{v}=$ wind velocity, miles/hr

The effective air temperature to include solar radiation was taken as

$$
T_{E}=T a+\frac{b I}{h}
$$

where $\mathrm{T}_{\mathrm{E}}=$ effective air temperature, $\mathrm{F}$

$\mathrm{Ta}$ = air temperature, $\mathrm{F}$

$\mathrm{b}=$ absorptivity of surface to solar radiation

$\mathrm{I}=$ solar radiation, $\mathrm{BTU} / \mathrm{ft}^{2}-\mathrm{hr}$

The average contribution of solar radiation in one day to effective air temperature considering that $1 / 3^{\text {rd }}$ of the average is lost by long wave re-radiation,

$\mathrm{R}=0.67 * \mathrm{~b} * \mathrm{~h} * \mathrm{I}_{\mathrm{ave}}$

The maximum temperature of the pavement was then calculated from equation 6.7 using $\mathrm{T}_{\mathrm{M}}=\mathrm{T}_{\mathrm{E}}+\mathrm{R}$

where $\mathrm{T}_{\mathrm{E}}=$ effective air temperature, $\mathrm{F}$ and $\mathrm{T}_{\mathrm{V}}=0.5 * \mathrm{~T}_{\mathrm{R}}+3 \mathrm{R}$

where $\mathrm{T}_{\mathrm{R}}=$ daily range in air temperature

\subsubsection{Thermal diffusion theory: Modified Barber's equations}

In the present study, Barber's equation based on the thermal diffusion theory was modified to calculate the pavement surface temperature for the entire day and also for a sequence of days and not only the daily maximum slab temperature. In addition to the 
variables in the form of hourly data required for Barber's equations, the present modified equations use hourly relative humidity values.

Consider a 24 hour periodic temperature variation of $T_{m}+T_{v} \sin (0.262 t)$ in contact with a semi-infinite slab. The surface temperature by the modified equations was then given by

$$
T_{S}=T_{M}+T_{V} \frac{H}{\sqrt{(H+C)^{2}+C^{2}}} \sin \left(0.262 t-\tan ^{-1} \frac{C}{H+C}+\frac{4 \pi}{3}\right)+R h_{f} *\left(\frac{R H}{100}\right)
$$

with the same terminology as mentioned used for Barber's equation.

In addition,

$\mathrm{RH}=$ Relative Humidity in \%

$\mathrm{Rh}_{\mathrm{f}}=$ multiplication factor for relative humidity

The effective air temperature to include solar radiation is given by equation 6.9 $T_{E}=T_{A}+\frac{b I}{h}$

Where $\mathrm{T}_{\mathrm{E}}=$ effective air temperature, $\mathrm{F}$

$\mathrm{T}_{\mathrm{A}}=$ hourly air temperature measured by the weather station, $\mathrm{F}$

$\mathrm{b}=$ absorptivity of surface to solar radiation

$\mathrm{I}=$ solar radiation, $\mathrm{BTU} / \mathrm{ft}^{2} \mathrm{hr}$

The average contribution of solar radiation to air temperature considering 1/3 loss due to long wave re-radiation is given by equation 6.10 . The value $T_{M}$ is given by a new equation which takes into account the hourly changes in air temperature.

$$
\mathrm{T}_{\mathrm{M}}=\mathrm{T}_{\mathrm{fac}} \mathrm{T}_{\mathrm{E}}+\frac{\mathrm{T}_{\mathrm{fac}}}{4} \mathrm{R}
$$

where $\mathrm{T}_{\mathrm{fac}}$ is a parameter multiplier for effective temperature.

The time lag between the solar radiation (I) and surface temperature $\left(\mathrm{T}_{\mathrm{S}}\right)$ of 2 hours and the lag between the air temperature and surface temperature of 1 hour was taken into consideration in the equation for the top surface temperature calculation. 


\subsubsection{Parametric multipliers}

The parametric multipliers $\mathrm{Rh}_{\mathrm{fac}}$ and $\mathrm{T}_{\mathrm{fac}}$ are obtained from the daily values of solar radiations and mean air temperatures

$$
T_{\text {fac }}=0.42\left(\left\{\sum I_{d}\right\} * \text { mean } T_{\text {air }}\right)^{p}
$$

where $\Sigma \mathrm{I}_{\mathrm{d}}=$ total solar radiation received on that day

mean $\mathrm{T}_{\text {air }}=$ mean air temperature for that day

$p$ varies between 0.04 and 0.072 with the month of the year as given in the Table 6.1.

Table 6.1: Values of parameter $p$ for each month

\begin{tabular}{|c|c|}
\hline Month of year & p \\
\hline January & 0.040 \\
\hline February & 0.045 \\
\hline March & 0.055 \\
\hline April & 0.056 \\
\hline May & 0.056 \\
\hline June & 0.060 \\
\hline July & 0.060 \\
\hline August & 0.065 \\
\hline September & 0.072 \\
\hline October & 0.058 \\
\hline November & 0.050 \\
\hline December & 0.045 \\
\hline
\end{tabular}

The factor for relative humidity is given by

$$
R h_{f a c}=\left[7 e-5\left(\left\{\sum I_{d}\right\} * m e a n T_{a i r}\right)+9.3\right] / T_{f a c}
$$

Since the calculation of the slab temperatures depend on the total solar radiation and mean air temperature of a day, it is possible to calculate these slab temperatures with a 
delay of one day. This results in a near real time prediction of pavement temperatures and not true real time calculations.

\subsubsection{Temperature below slab surface}

The temperatures below the surface are functions of the surface temperature. The heat conducted into the slab can be represented by the one dimensional heat equation $\frac{\partial^{2} T}{\partial x^{2}}=\frac{1}{c} \frac{\partial T}{\partial t}$

where $\mathrm{c}=$ diffusivity.

As in the case with Dempsey's model the forward finite difference method was used to calculate the slab temperatures through the slab thickness. The method described here was used by Dickinson (1978).

The slab is divided into $n$ number of layers of equal thickness $\Delta x$ and the temperatures within the pavement at time $t$ at the interface of the layers are $T_{1}, T_{2}, T_{3} \ldots T_{i}$. Given values of temperature at these interfaces the new temperatures at $t+\Delta t$ know as $\mathrm{T}^{\prime}{ }_{1}, \mathrm{~T}_{2}{ }_{2}$, $\mathrm{T}_{3}{ }_{3} \ldots \mathrm{T}_{\mathrm{I}}$ are obtained by the finite difference method.

The new temperatures $T^{\prime}$ at the interfaces are calculated by the following series of equations where $\mathrm{T}_{0}$ is the calculated surface temperature and

$$
F=\frac{c \Delta t}{(\Delta x)^{2}}
$$

$\mathrm{T}_{1}=\mathrm{T}_{1}+\mathrm{F}\left(\mathrm{T}_{2}+\mathrm{T}_{0}-2 \mathrm{~T}_{1}\right)$

$\mathrm{T}_{2}^{\prime}=\mathrm{T}_{2}+\mathrm{F}\left(\mathrm{T}_{3}+\mathrm{T}_{1}-2 \mathrm{~T}_{2}\right)$

$\mathrm{T}^{\prime}{ }_{\mathrm{i}}=\mathrm{T}_{\mathrm{i}}+\mathrm{F}\left(\mathrm{T}_{\mathrm{i}+1}+\mathrm{T}_{\mathrm{i}-1}-2 \mathrm{~T}_{\mathrm{i}}\right)$

An adiabatic boundary was assumed at a certain depth in the slab beyond which there is no heat transfer. This is done to provide the terminating equation for the series of equations. Hence the terminating equation becomes

$$
\mathrm{T}_{\mathrm{n}}^{\prime}=\mathrm{T}_{\mathrm{n}}+2 \mathrm{~F}\left(\mathrm{~T}_{\mathrm{n}-1}-\mathrm{T}_{\mathrm{n}}\right)
$$




\section{Calculation Start Temperature (CST)}

To begin the series of calculations of temperature gradients a time was selected where the gradient through the slab thickness was close to zero. This time was observed to be approximately 3 hrs after sun rise when the slab surface begins to heat up and temperatures through the thickness of the slab are approximately at the same temperature. This concept of finding the right time and temperature (CST) for starting the calculation was proposed by Dickinson (1978). The selection of the CST is important to predict the temperatures close to the start point. The error in the predicted temperature values can be reduced by choosing CST to be 3 hours after sun rise on a clear sky day. Once the calculation process has stabilized say after 1 day of the start time the predicted temperatures will be accurate. This time and temperature could vary with the location of the pavement hence more information is required to generalize this method.

Hence it can be safely considered that at this time all the temperatures in the slab have the same value as the calculated surface temperature i.e. $T_{1}=T_{2}=T_{3}=\ldots T_{i}=T_{0}$ (surface temperature) $=$ CST .

The value of $\mathrm{F}$ should lie below 0.5 beyond which the calculation procedure becomes unstable. It was found that $\Delta t=0.05 \mathrm{hr}$ and $\Delta x=1$ inch were good values for $\mathrm{k}=1.25$ resulting in $F=0.3$. For the best match between calculated and observed temperature gradients $n$ was found to be 40 which results in placing the adiabatic boundary at 40 in. below the slab surface.

The available data from the site was re-sampled to obtain hourly values of the weather conditions and slab temperatures. Hence the predicted surface temperature values were interpolated to obtain incremental values for every time step of $\Delta t=0.05 \mathrm{hrs}$. 


\subsection{RESULTS AND DISCUSSION}

In order to obtain the closest agreement between the predicted and measured gradients the correct choice of thermal and concrete properties is very essential. The following material properties for the concrete slabs were used as given by a research conducted by US Army (TM5-852-6 1988)

Thermal Conductivity, $\mathrm{k}=1.00 \mathrm{BTU}-\mathrm{ft} / \mathrm{ft}^{2}-\mathrm{hr}-\mathrm{F}$, (at $75^{\circ} \mathrm{F}$ for concrete with sand and gravel with aggregate (not dried))

Absorptivity, $\mathrm{b}=0.7$,

Specific heat, $\mathrm{s}=0.2 \mathrm{BTU} / \mathrm{lbs}-\mathrm{F}$,

Density, $\mathrm{w}=150 \mathrm{lb} / \mathrm{ft}^{3}$

Due to some unavoidable circumstances there are a few gaps in the data collected from the weather station. From the data that was collected a complete set of weather variables for one year was available except for the months November and December at the time of writing. The value of the factor 'p' used in equation 6.15 and mentioned in Table 1 for the calculation of the temperature factor $\mathrm{T}_{\mathrm{fac}}$ was extrapolated from the data available for November and December.

\subsubsection{Comparison among the three models}

The slab top surface temperature predicted by the three models mentioned in the previous section is plotted in Figure 6.7. 


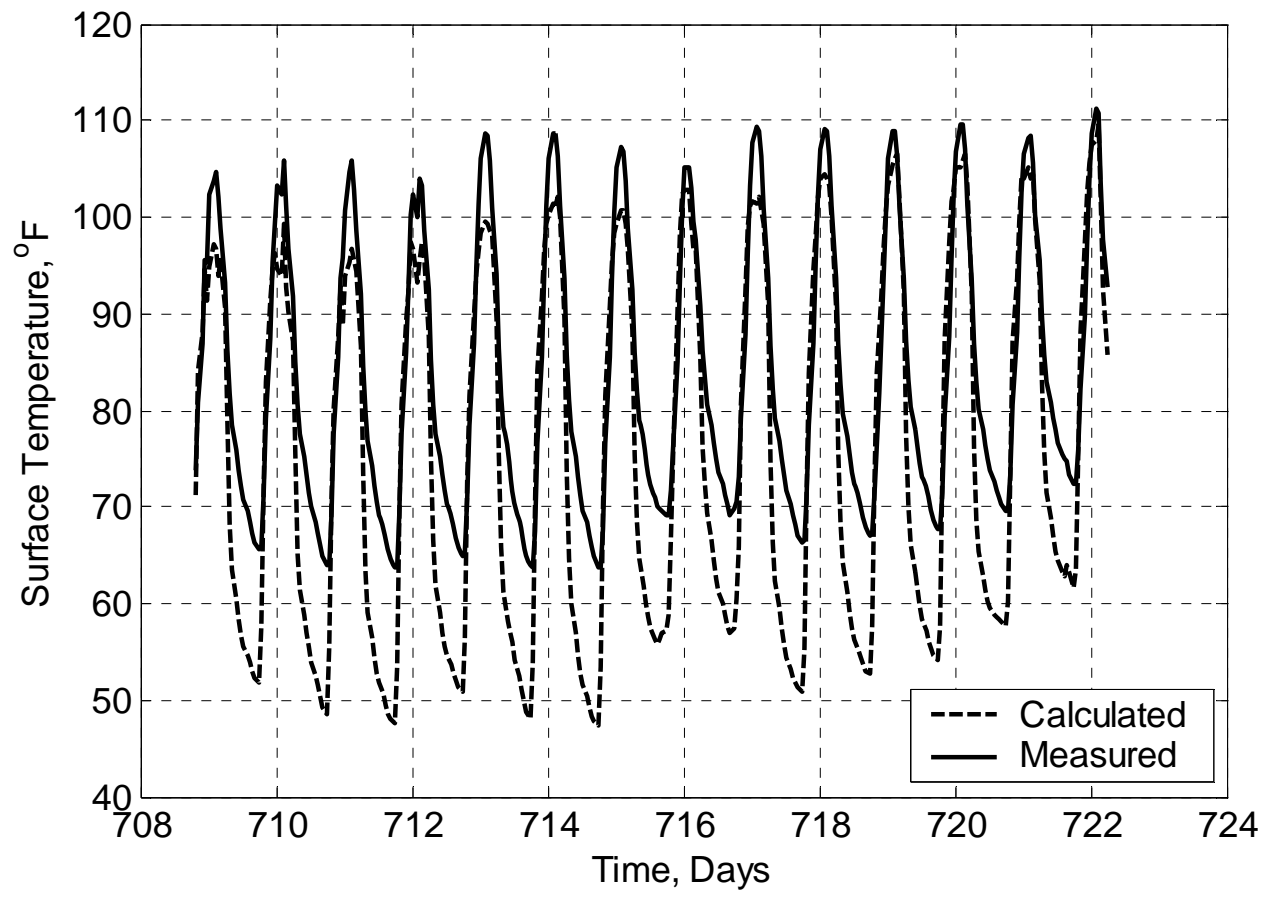

Figure 6.7 a: Heat transfer model

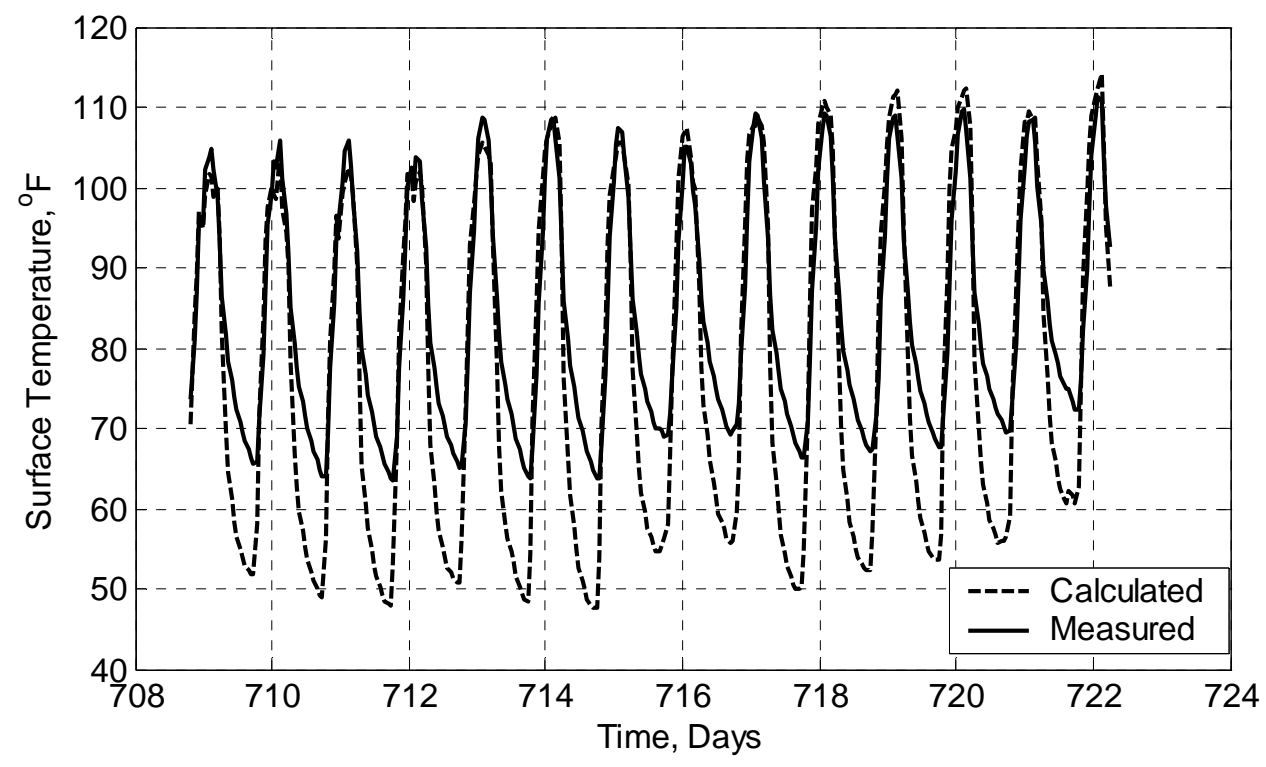

Figure 6.7 b: Barber's original equation 


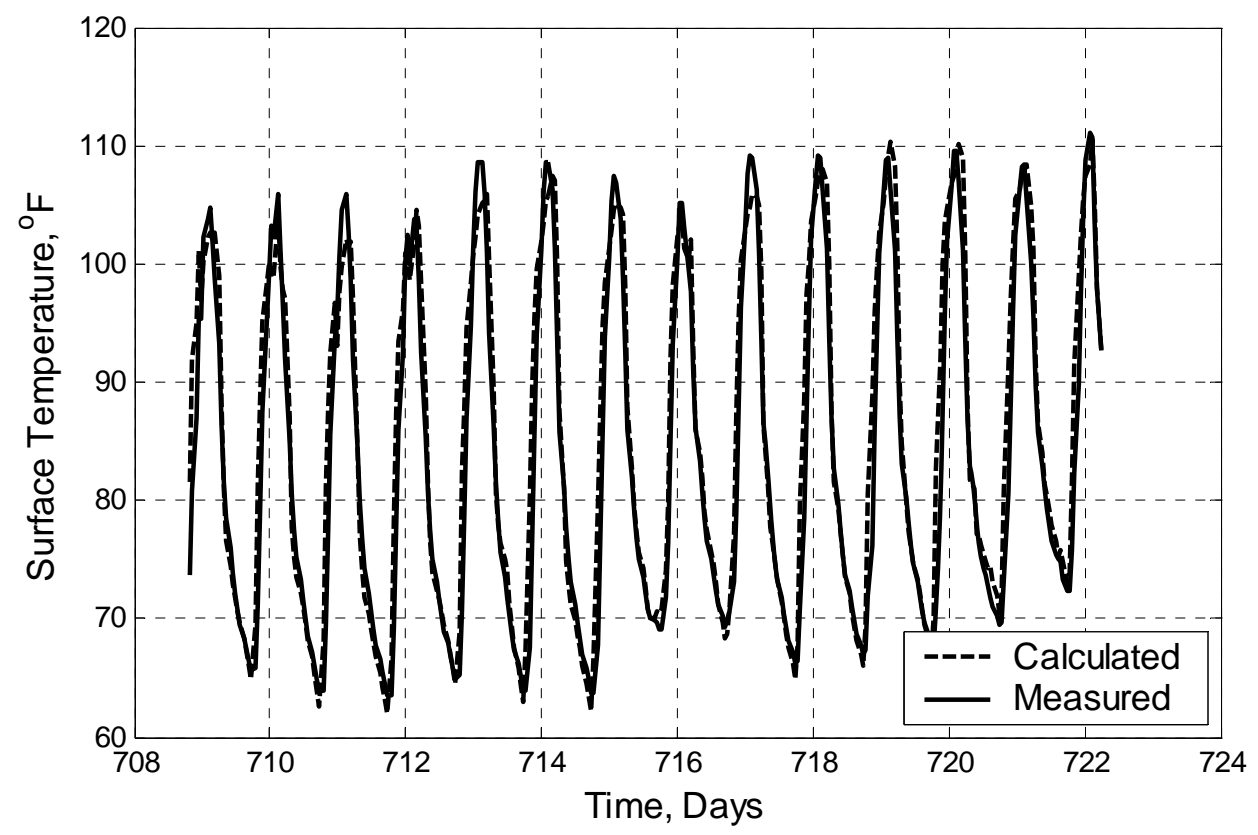

Figure 6.7 c: Modified Barber's equation

From Figures 6.7 a-b it can be noticed that the heat transfer method and Barber's original equations were able to predict the maximum surface temperatures up to an accuracy of $+/ 3{ }^{\circ} \mathrm{C}$. But in both cases when the major contributor to the slab temperature, the solar radiation was absent i.e. during the night times the models fails to correctly predict the slab temperature. In the case of the heat transfer model, the constant term in the 4th order equation to calculate the surface temperature of the slab includes the solar radiation values. In the absence of a large constant value in the equation the calculated temperatures are lower than expected. The minimum surface temperatures during the nights were off by 7 to $9{ }^{\circ} \mathrm{C}$. As the temperature below the surface depend on the surface temperature, a mismatch in the predicted surface temperature results in differences in the calculated temperatures within the slab.

This drawback in the original equation proposed by Barber was answered in the modified Barber's equation as presented in the current study. The long wave radiation from the slab is absorbed by the water vapor in the surrounding air and is re-radiated back to the surface. This re-radiation delays the cooling of the concrete pavement. It was found that this effect was well captured by changes in the relative humidity during the day and night 
cycles. This was incorporated into Barber's equation to get a good agreement with the measured temperature history. As seen in Figure 6.7c, the modified equations were able to predict the temperatures for the entire day and for a sequence of days. The maximum deviation from the measured values for the entire data available was within $+/-4{ }^{\circ} \mathrm{C}$ at the slab top and $+/-2{ }^{\circ} \mathrm{C}$ at the slab bottom during sunny, cold, and days with light rain. The days with heavy rain experience larger errors the reasons for which are discussed later in the report.

A number of researchers have used the heat transfer models and obtained good results for the maximum temperature reached by the slab with an error of $+/-3{ }^{\circ} \mathrm{C}$ between the measured and calculated temperature. Most of the research work was concentrated on the prediction of the maximum temperature reached in the slab for design purposes. Dempsey used the theory to calculate temperatures for a sequence of days and reported good match in temperatures recorded at 6am and 3 pm. In a paper, Hermansson (2001) has printed plots for calculated slab temperature for asphalt concrete using the heat transfer model and has obtained good results with the measured values. Though the author claims to have obtained a good match for hourly temperatures for a sequence of 30 days for concrete pavements, it has not been supported with any plot or table, except for a mention that the temperature values were within error limit of $+/-2{ }^{\circ} \mathrm{C}$.

\subsubsection{Examples using Modified Barber's equation}

Figures 6.8 to 6.11 are a few examples of the calculated and measured temperature values during different months of the year using the modified Barber's equation. Each plot is followed by a comment on the nature of temperature calculation and reasons for deviations from the measured. 

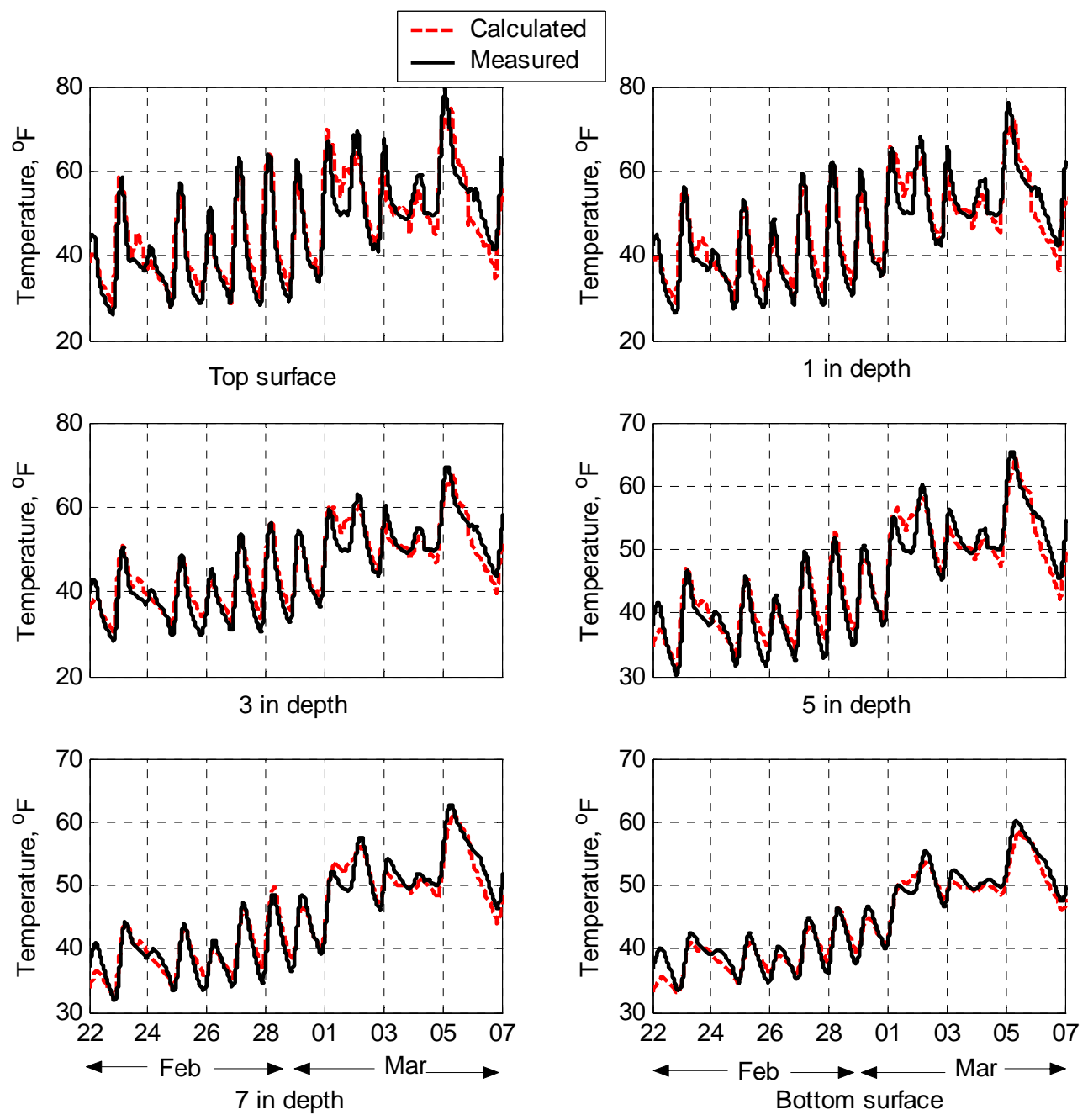

Figure 6.8: Measured and calculated temperatures at different depths (Feb/Mar 2004)

The mismatch between calculated and measured temperatures on March $6^{\text {th }}$ and $7^{\text {th }}$ is due to heavy rains during those days. The deviation on March $2^{\text {nd }}$ is discussed later in this chapter. 

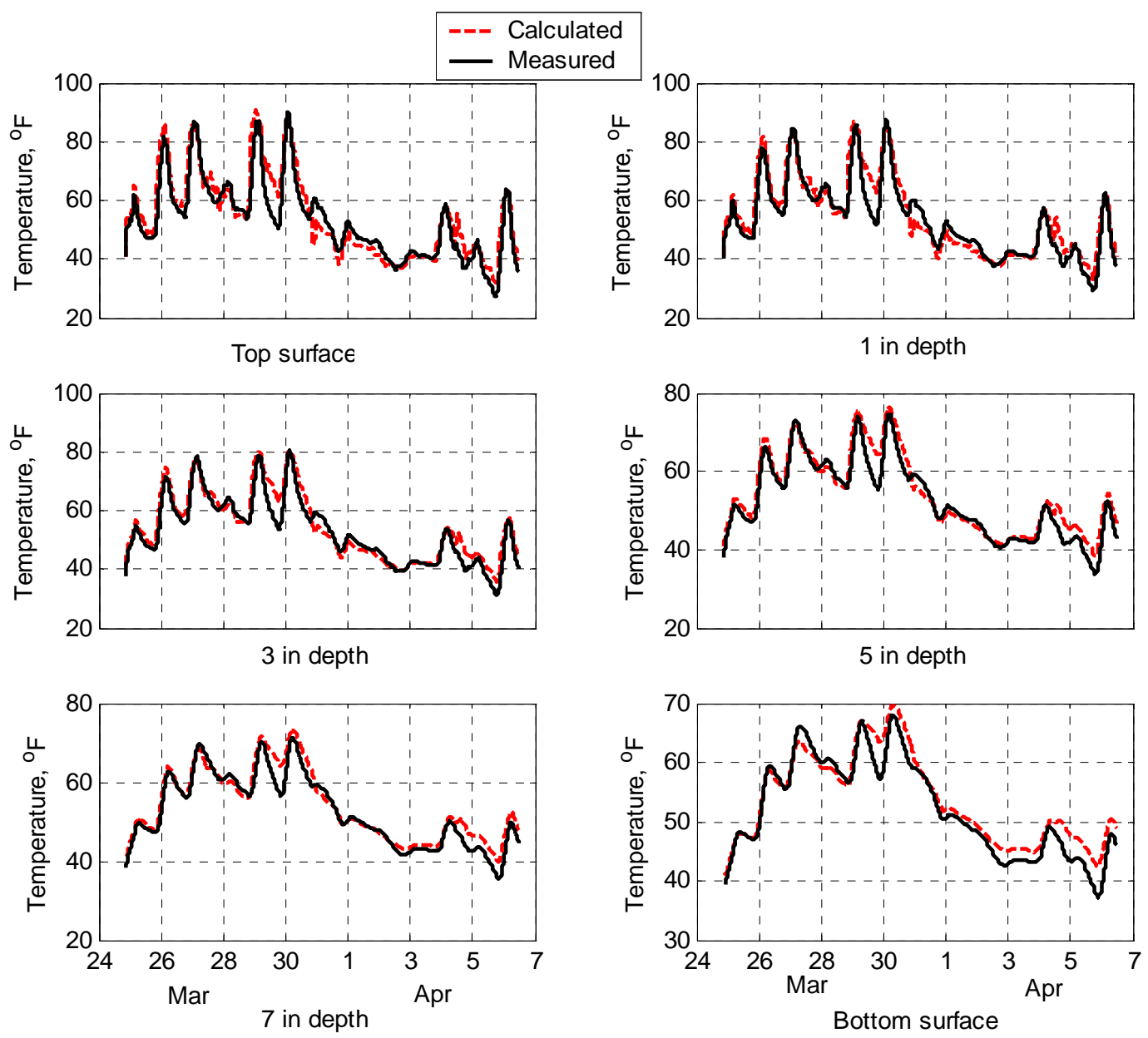

Figure 6.9: Measured and calculated temperatures at different depths (Mar/Apr 2004) 

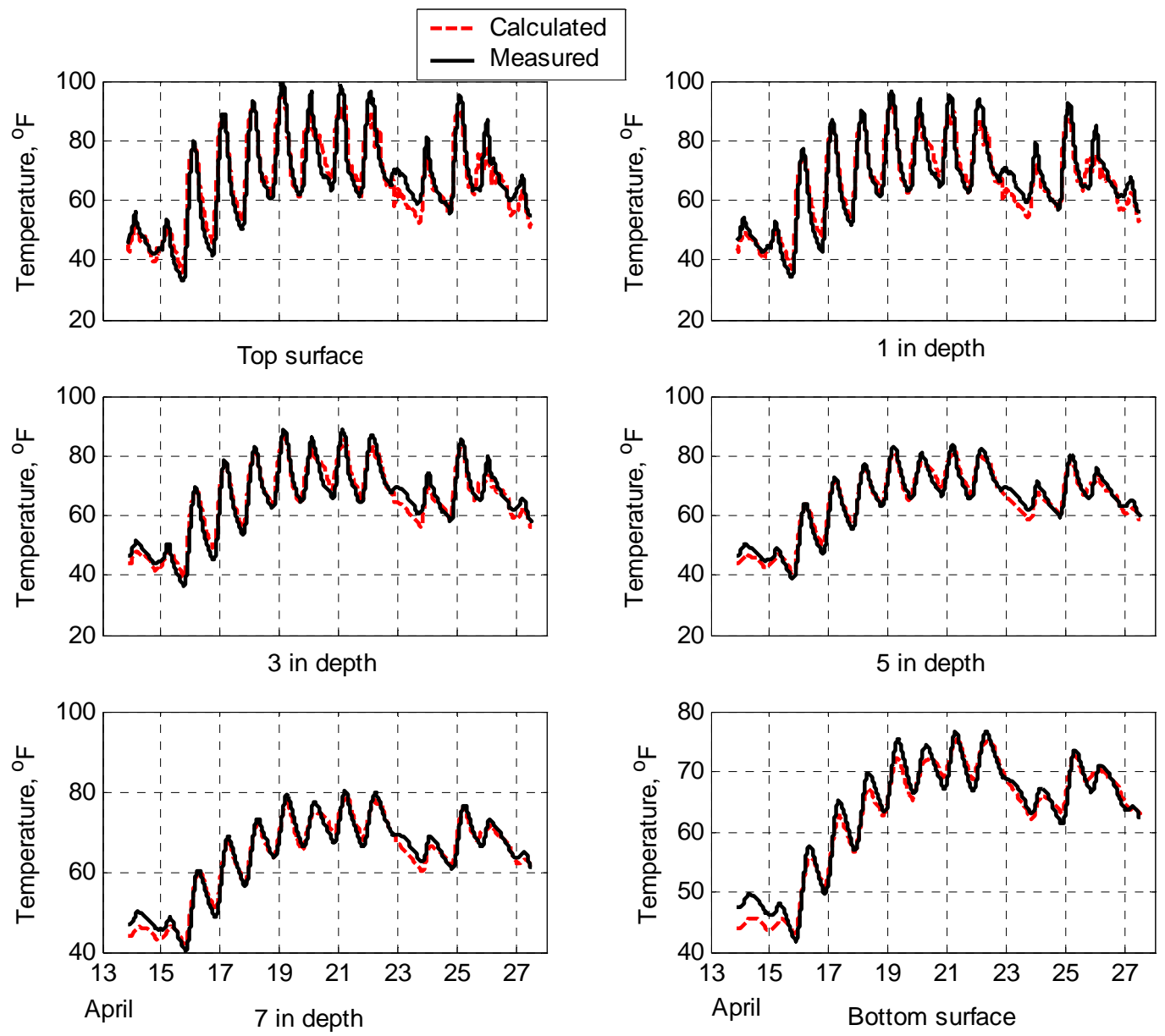

Figure 6.10: Measured and calculated temperatures at different depths (Apr 2004)

As can be seen in Figure 6.10, the error in calculated temperatures in the initial day is due to the value of calculation start temperature, CST. At the time of start of calculations for this data set the gradient was not zero. The slab bottom is at a lower temperature than the slab top at the start time. But after the initial difference in calculations the procedure stabilized and the error reduces for the remaining days. This example was included to stress the importance of the CST. A similar case can be seen in Figure 6.8. 

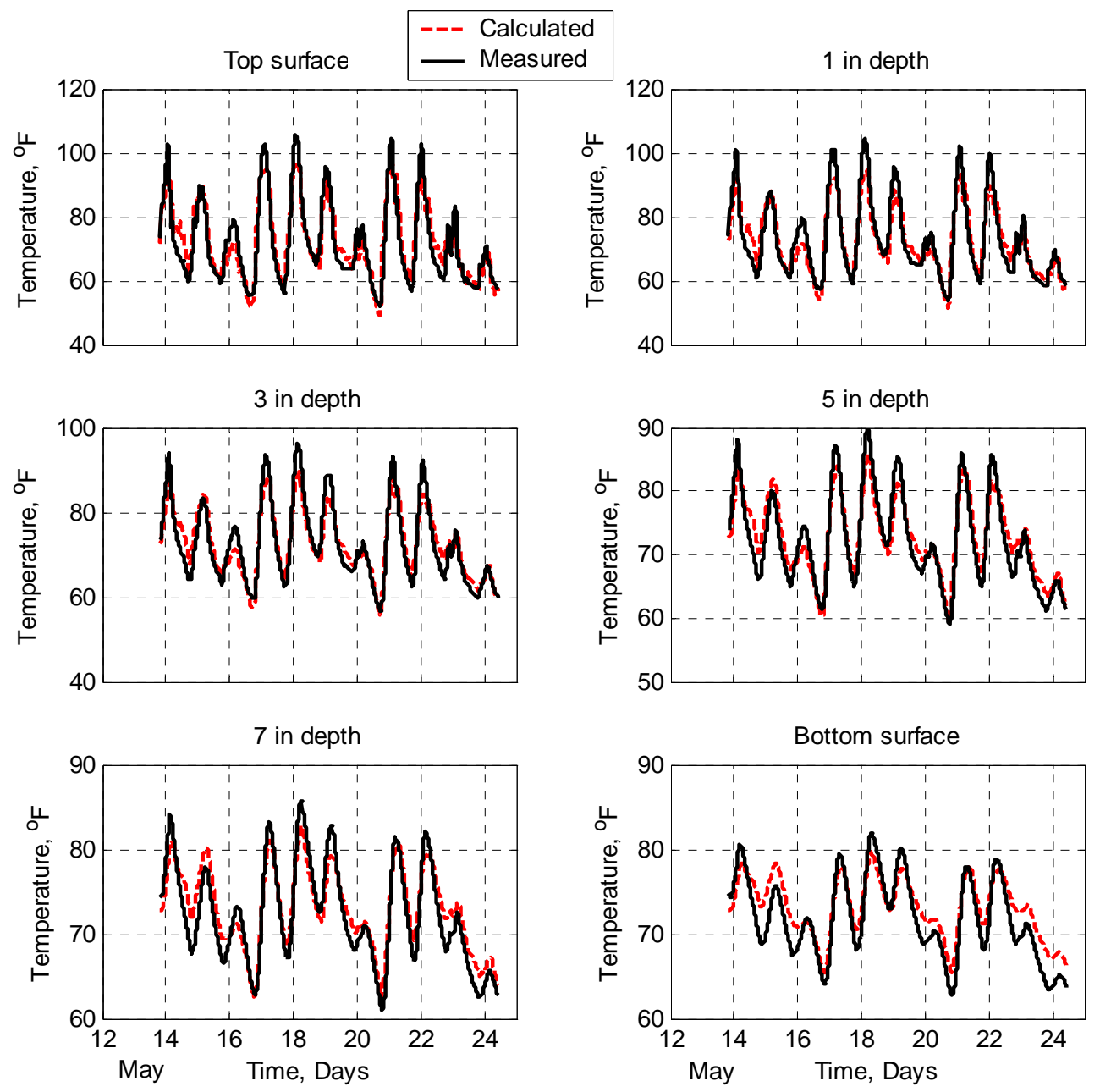

Figure 6.11: Measured and calculated temperatures at different depths (May 2005) 

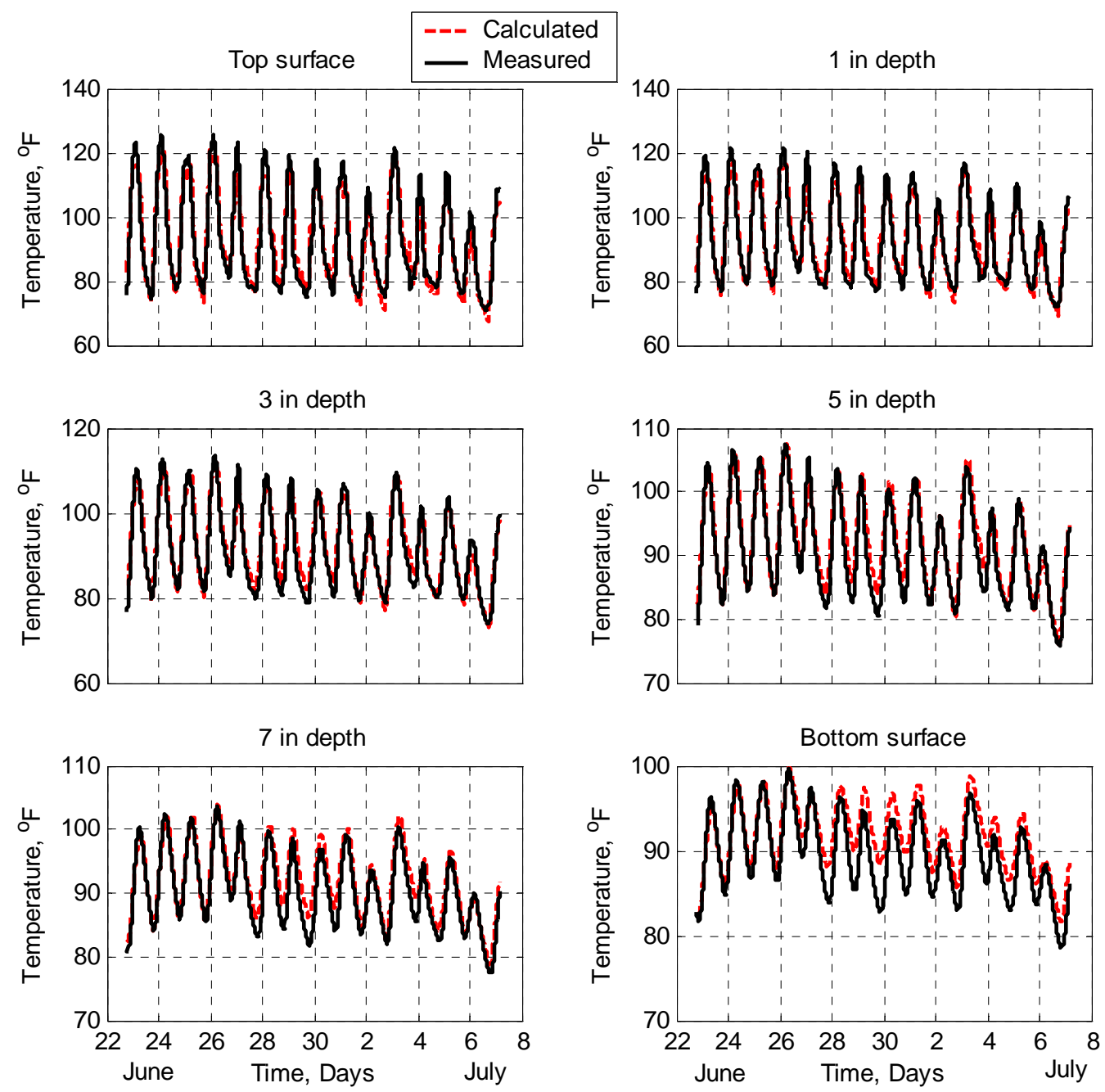

Figure 6.12: Measured and calculated temperatures at different depths (June/July 2005)

The error in the slab bottom between days June 28 to July $2^{\text {nd }}$ can be attributed to the possibility of presence of drained water on the fabric sheet between the slab and the subgrade due to the continued rain during those mentioned days. The rain water might not have drained off completely producing the lower slab bottom temperatures. 

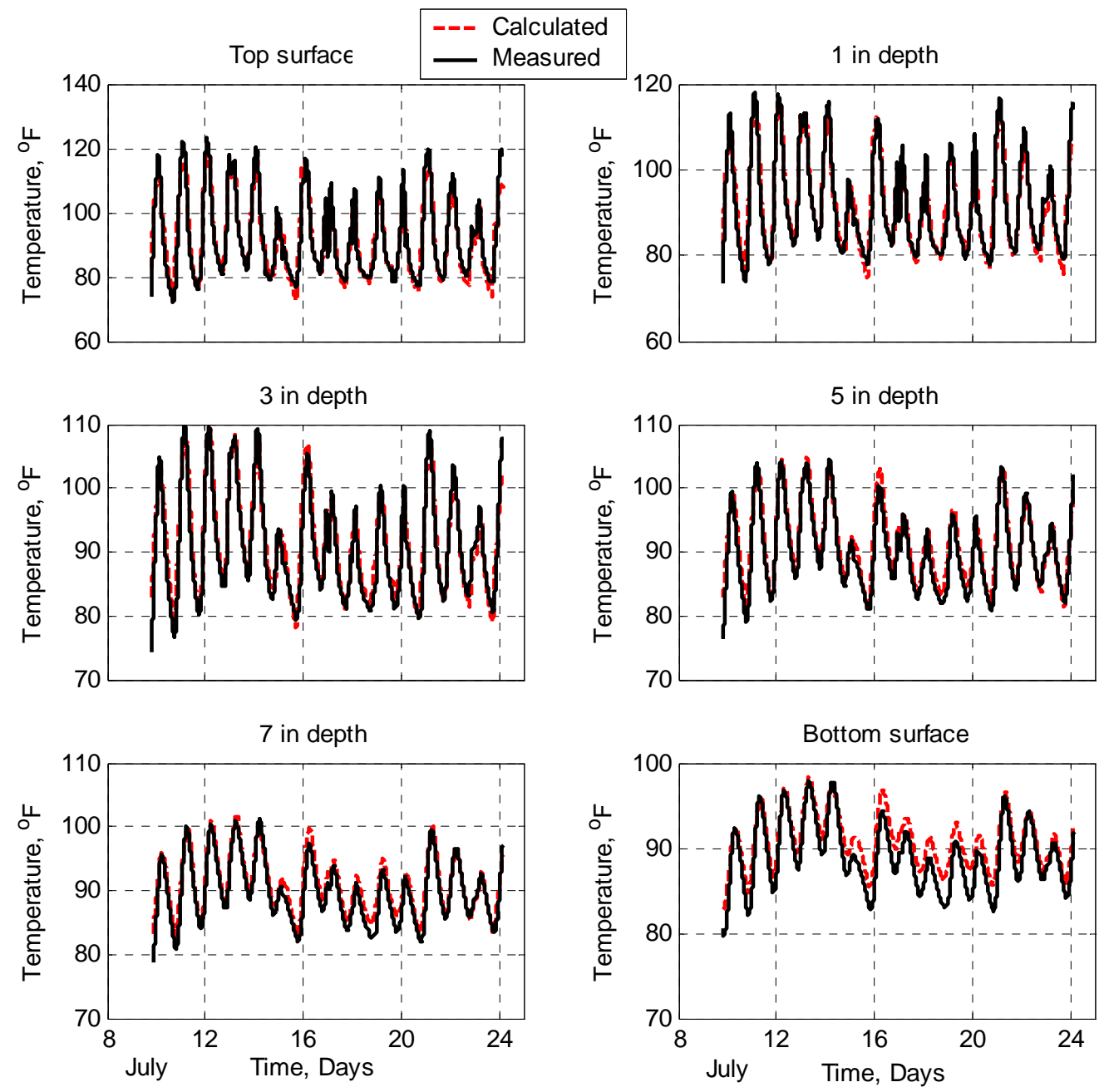

Figure 6.13: Measured and calculated temperatures at different depths (July 2005) 

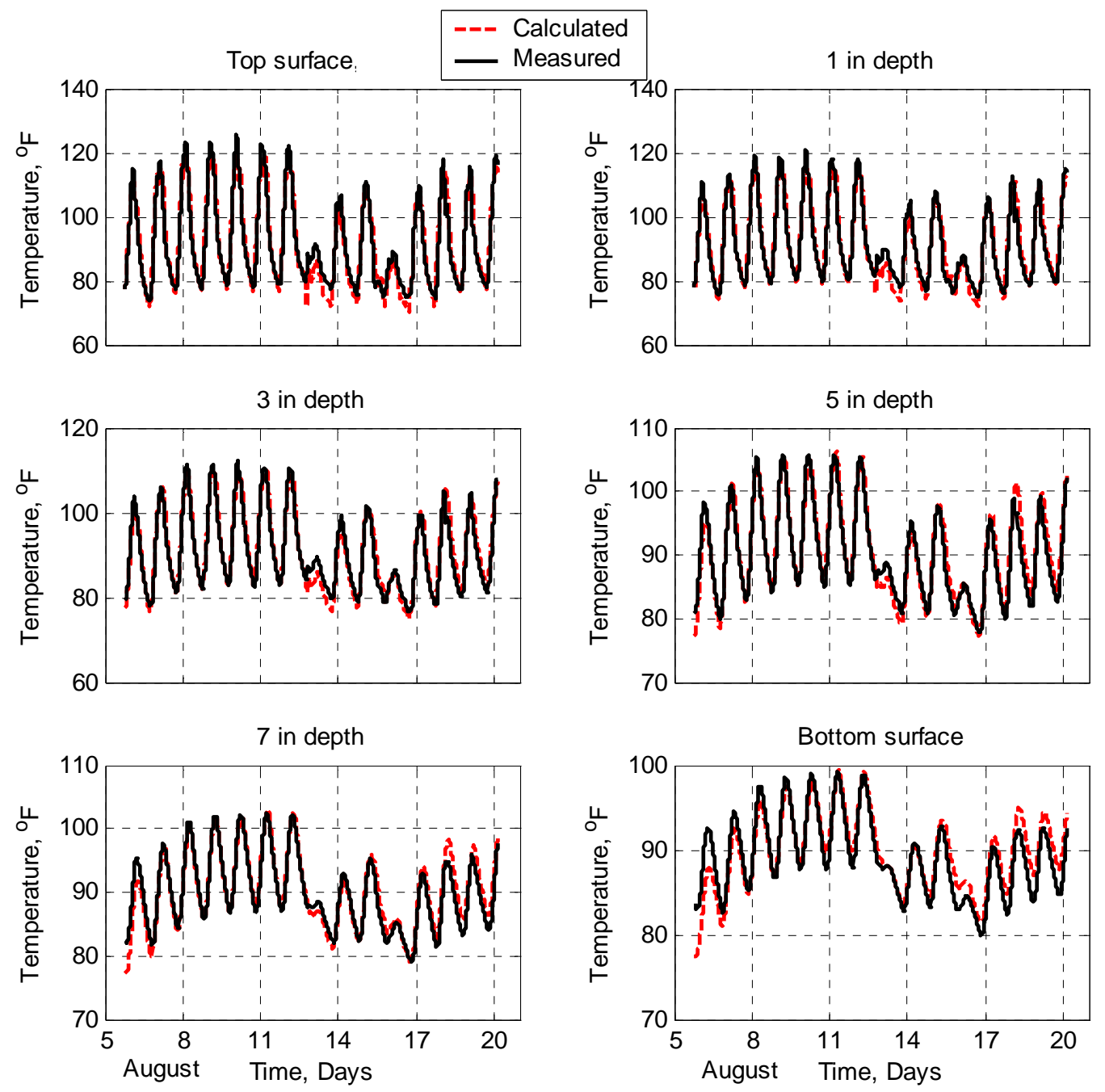

Figure 6.14: Measured and calculated temperatures at different depths (August 2005)

On August $13^{\text {th }}$ though there was no rain, the entire day was very cloudy. Hence there is an error in prediction of temperature at the top surface of the pavement. 

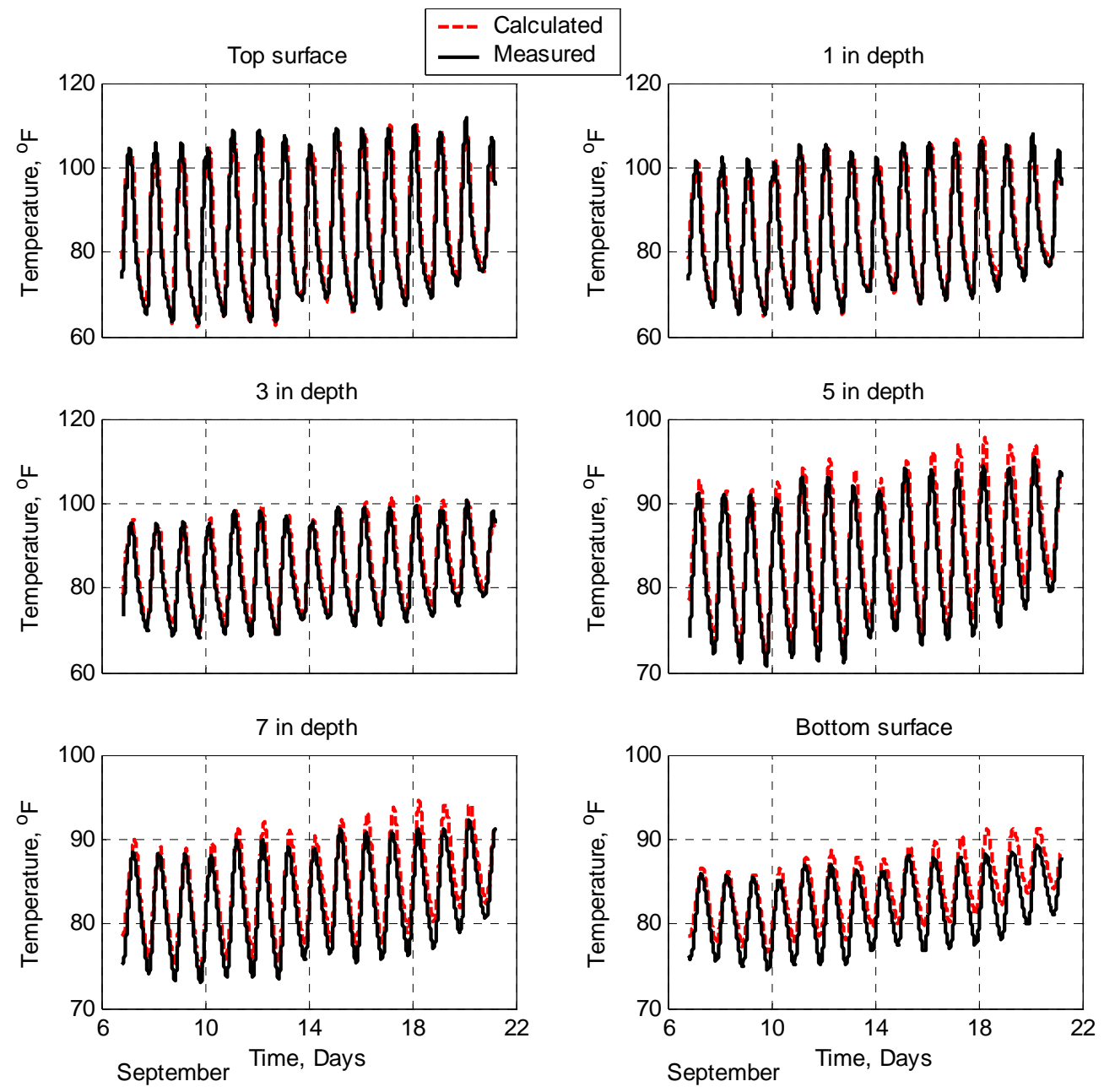

Figure 6.15: Measured and calculated temperatures at different depths (Sep 2005) 

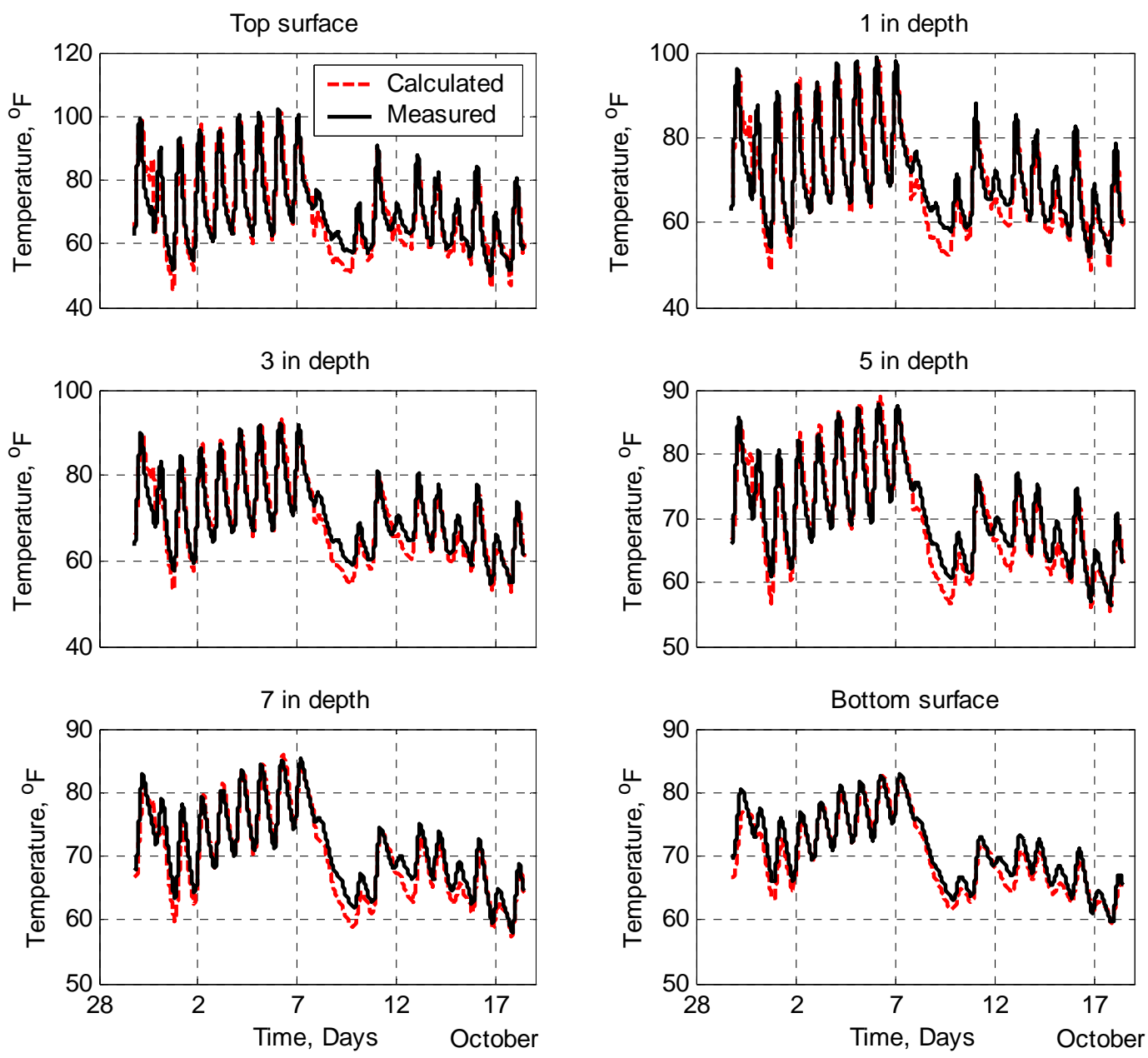

Figure 6.16: Measured and calculated temperatures at different depths (October 2005)

As seen in Figure 6.15, the effect of rain can be observed at the slab top surface by the lower slab temperatures predicted by the equation. The error decreases with increase in depth.

\subsubsection{Prediction of slab temperature during extreme weather conditions}

The inaccuracy of the equations presented in this paper increases when there is a sudden drop in slab temperature usually due to sudden rainfall. Since the calculation 
procedure depends on the relative humidity, the higher humidity during a rainfall increases the calculated slab surface temperature. The temperature of the pavement surface usually falls by around $5{ }^{\circ} \mathrm{C}$ due to heavy rainfall, but the changes in the temperature towards the slab bottom in more gradual. As seen in figures during the days of rain, the error in prediction is higher in the temperature calculations on the surface compared to the slab bottom. The inaccuracies are less during days when the rain is preceded by cloud cover and the ambient temperature decreases along with the slab temperature.
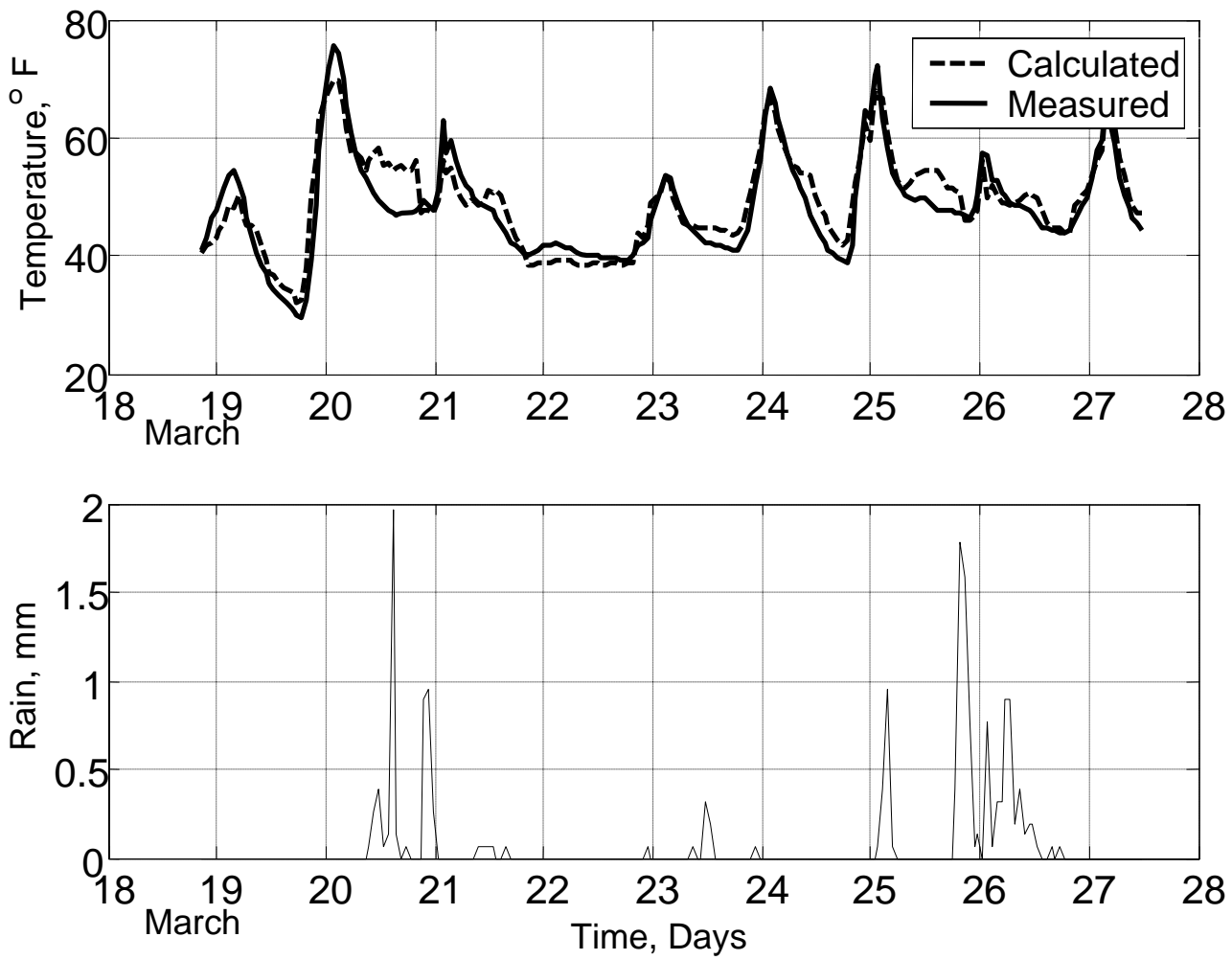

Figure 6.17: Over prediction of slab temperature during heavy rains

In Figure 6.17, notice the over prediction of surface temperature on the night of March 20 and March 25. Relatively high radiation was received during the day with a maximum of around $100 \mathrm{BTU} / \mathrm{ft}^{2}$-hr. This heated up the slab during the daytime. It rained heavily in the late afternoon till the early hours of the next day. The calculated temperature of the slab surface was higher than the measured temperature since the cooling of the slab by heavy rains was not included in the calculations. In Figure 6.18, 
the opposite effect was noticed. The rain started early in the morning of September 2, and the solar radiation low in the range of $25 \mathrm{BTU} / \mathrm{ft}^{2}-\mathrm{hr}$ due to the presence of clouds. The factors $\mathrm{T}_{\text {fac }}$ and $\mathrm{RH}_{\text {fac }}$ depend on the total solar radiation and mean air temperature of the day as given by equations 6.15 and 6.16 respectively. Hence the low solar radiation received results in low values of the 2 multipliers which consequently leads to the under prediction of the surface temperature in this case by the equation 6.13. Since both types of cases of over prediction and under prediction were seen, more work is needed to include the effect of rain in the equations.
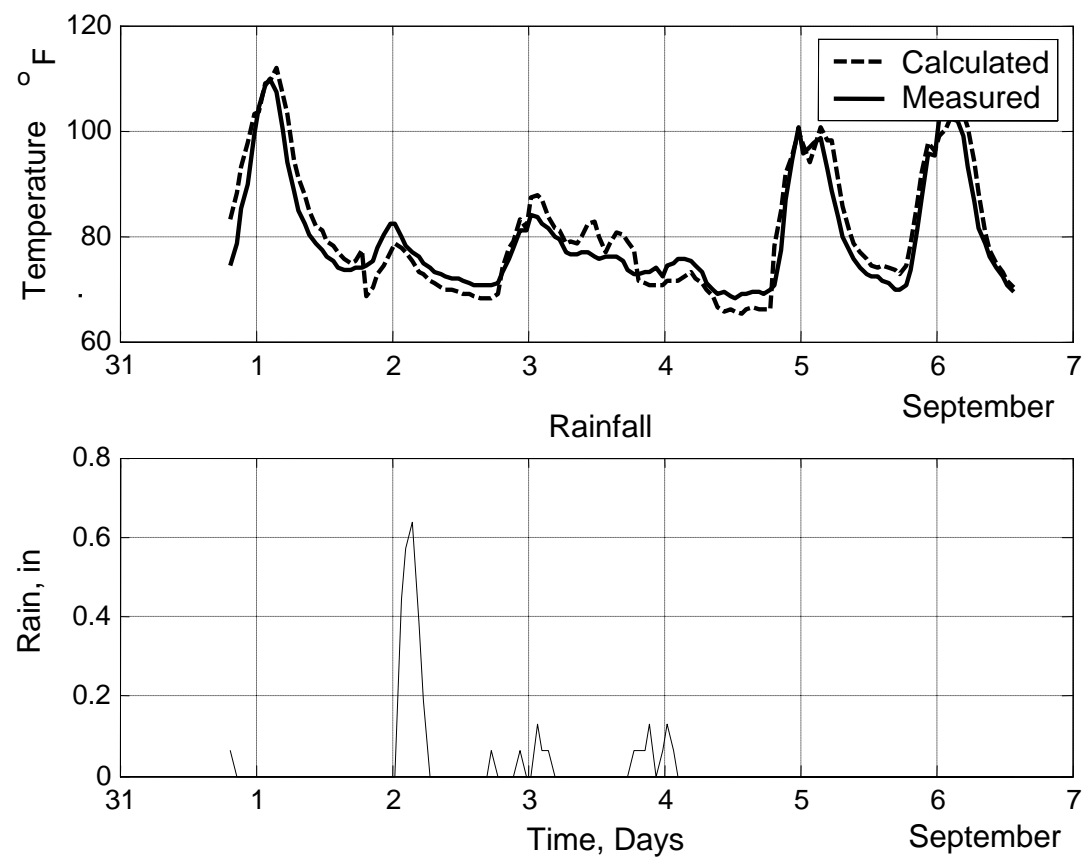

Figure 6.18: Under prediction of slab temperature during rains 

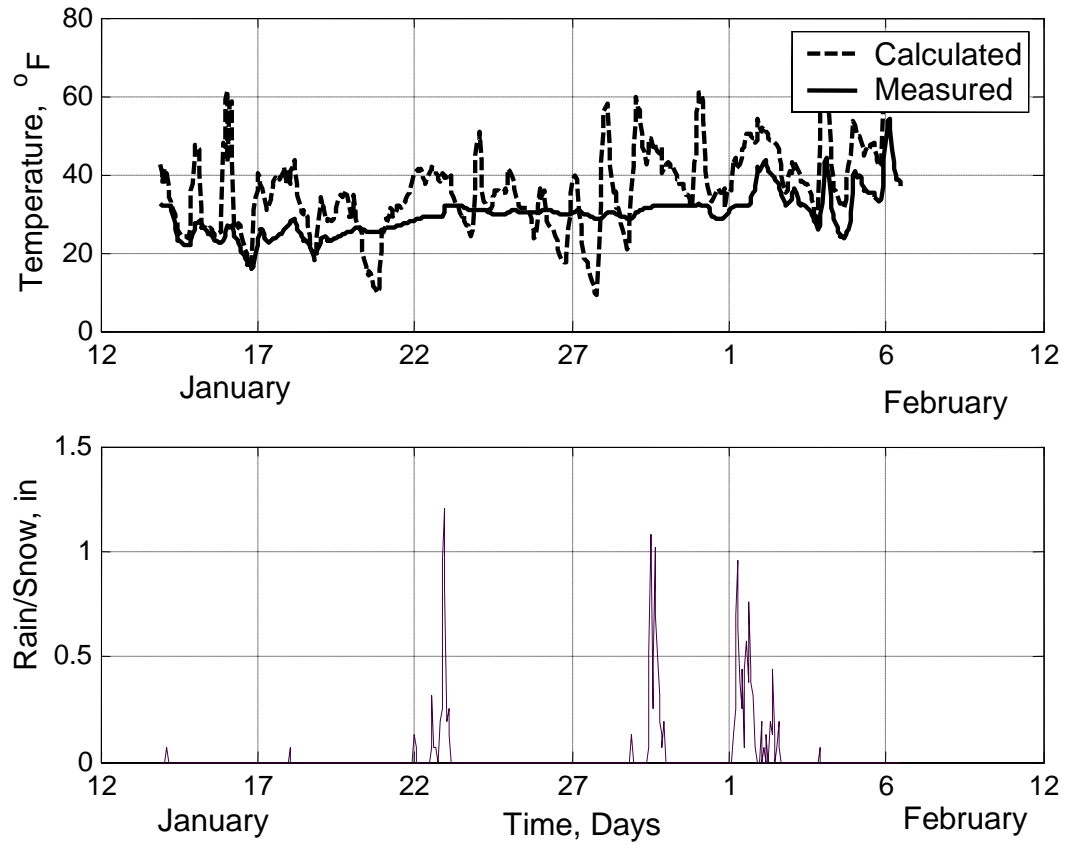

Figure 6.19: Error in prediction during snowfall

As mentioned earlier with reference to Figure 6.2, during the days when the slab is covered with snow, the snow acts as an insulator and the variations in air temperature does not affect the slab temperatures. As the equations presented here depend in the air temperature and do not include the effects of snow on the slab, they are not able to predict the slab temperatures correctly.

During heavy rains the calculated negative gradient is higher than the measured temperature gradient by up to $4{ }^{\circ} \mathrm{C}$. Figure 6.20 presents an example. 


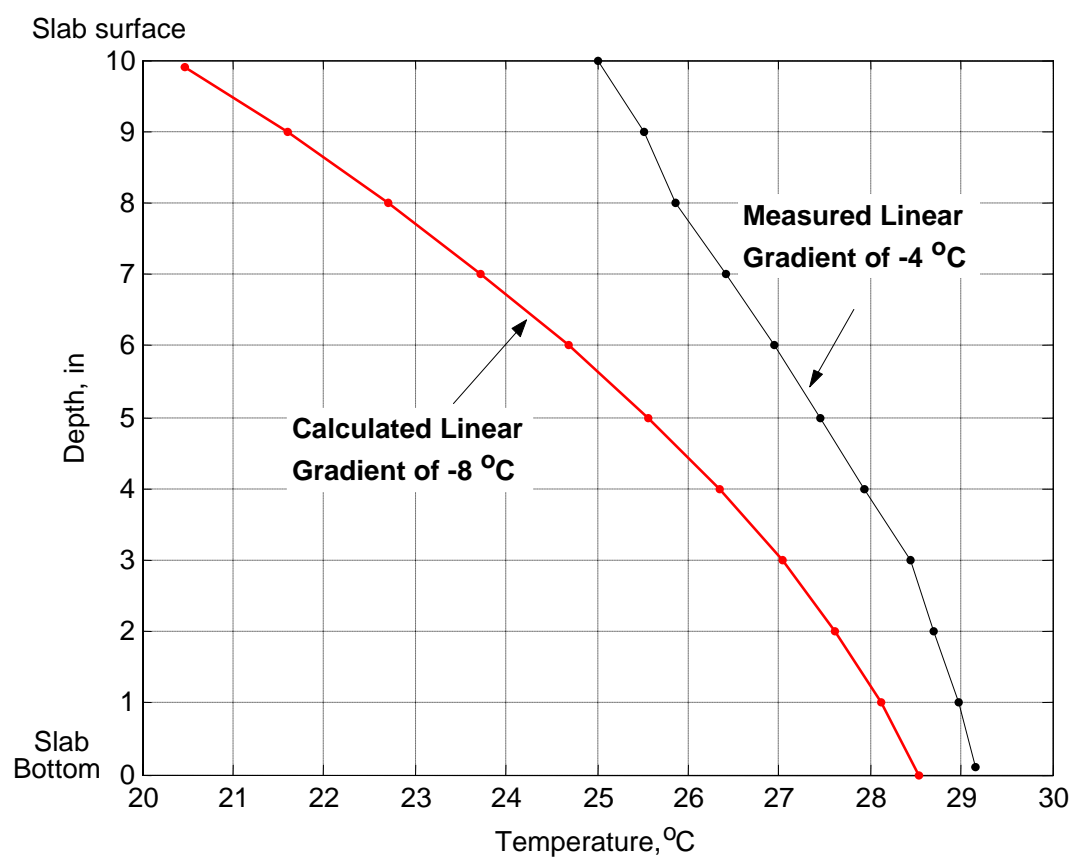

Figure 6.20: Gradient difference during rains

There are a few situations when the weather conditions measured at the site could not be related to the slab temperature, i.e. the proposed equations failed to predict the slab temperatures. An example of this is illustrated below. Figure 6.21 a-e plot the slab and air temperatures, rainfall received, relative humidity, wind speed and solar radiation on days March 2 and 3. 

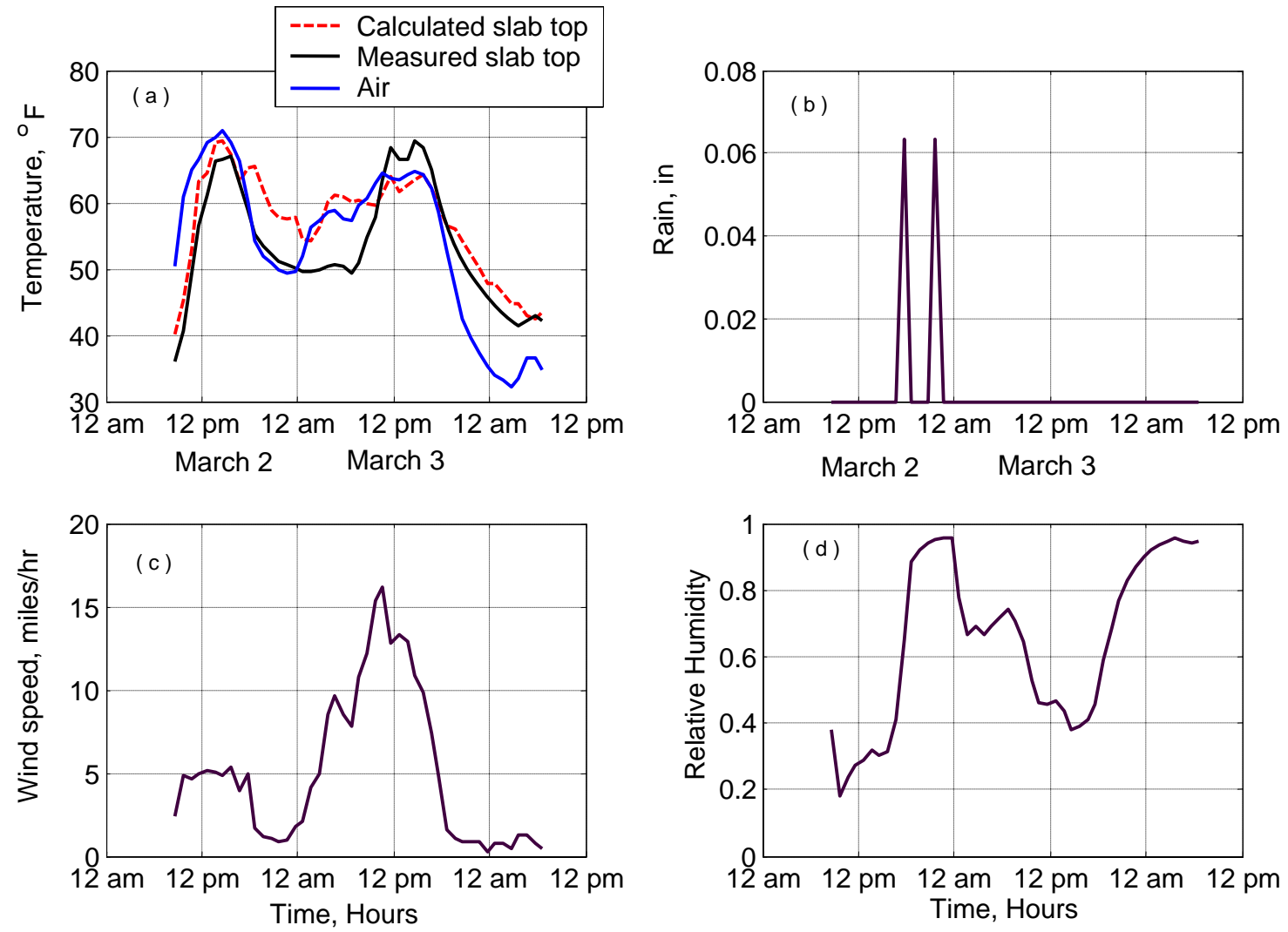

Figure 6.21 a-d: Conditions on March 2 and 3

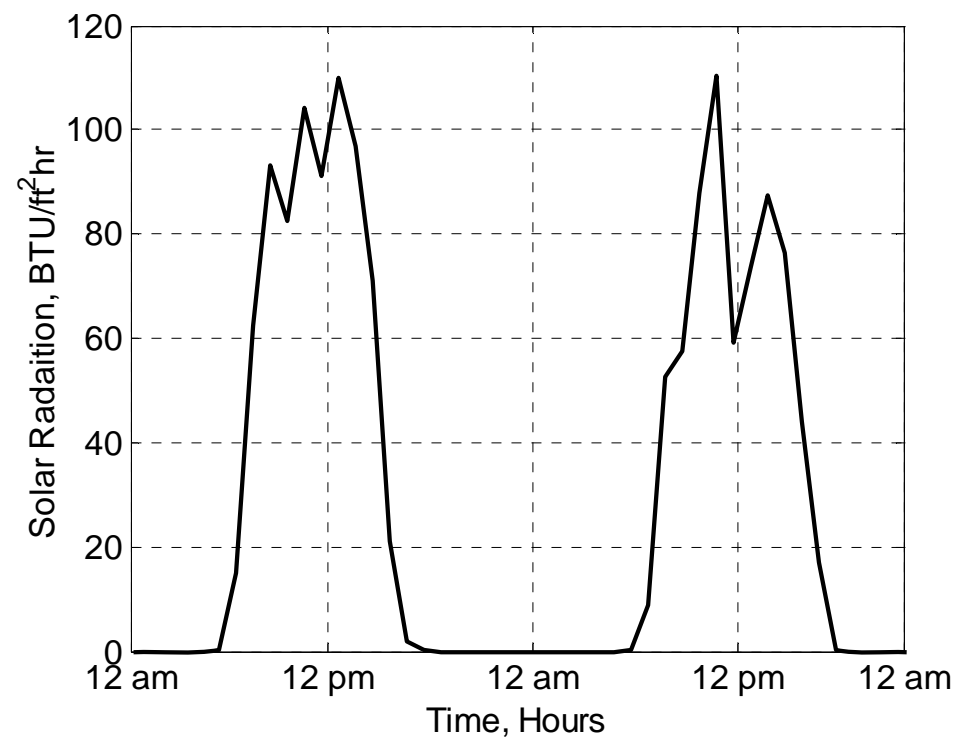

Figure 6.21 e: Solar radiation on March 2 and 3 
Rain in the late afternoon, cools the slab surface and the high relative humidity during the period results in the higher calculated slab temperatures due to the nature of the equations. The inability of the equations to predict correctly during rains has been discussed earlier. But as an exception, during the early hours of March $3^{\text {rd }}$, the air temperature increased by almost $10{ }^{\circ} \mathrm{F}$. In the absence of solar radiation during the night this abnormal increase in air temperature did not increase the slab surface temperature. Since the equation takes the air temperature into consideration the predicted slab temperature is higher than the measured temperature. On such occasions too the calculated temperatures differ from the measured temperatures.

\subsubsection{Effect of fabric sheet between slab and subgrade}

The thermistor trees are placed in the slabs jointed with dowel bars and Shokbars. These slabs have a fabric sheet between the bottom of the slab and the smooth subgrade. This sheet might act as an insulator for the transfer of heat to and from the subgrade. As the fabric sheet is absent in the free slab on high friction subgrade, the possibility of differing temperature values was verified from the thermistors attached to the three strain gages at the slab mid section. The temperatures from the thermistor tree at the corresponding depths of 9 in, 5 in and 1 inch in the dowelled slab were compared. It was found that on an average the temperatures in the high friction slab differ from the thermistor readings by $+/-2{ }^{\circ} \mathrm{C}$. In fact a difference of $+/-2^{\circ} \mathrm{C}$ was observed even between the temperature readings at the mid sections between all the slabs. This indicates that the presence of the fabric sheet does not significantly affect the heat flow between the slab and subgrade. On the other hand, as mentioned with reference with Figure 11, the sheet might retain rain water during continuous rainfall and lower the slab bottom temperature. But since the differences in calculated temperatures are within the acceptable limits of $+/-3^{\circ} \mathrm{C}$ the effect of the fabric sheet can be overlooked. 


\subsubsection{Error analysis of calculated temperatures}

A statistical analysis of the error between the calculated and measured temperature values was performed. Table 6.2 lists the mean, standard deviation and $\mathrm{r}^{2}$ values of the error at three locations through the pavement thickness. The error values at other depths lie between these numbers.

Error $=$ Measured temperature - Calculated Temperature $=\mathrm{T}_{\mathrm{i}}^{\text {meas }}-\mathrm{T}_{\mathrm{i}}^{\text {calc }}$.

Table 6.2: Statistical analysis

\begin{tabular}{|c|c|c|c|}
\hline Location & Mean, $\left.\boldsymbol{\mu} \mathbf{(}^{\mathbf{0}} \mathbf{C}\right)$ & Standard Deviation, $\boldsymbol{\sigma}\left({ }^{\mathbf{0}} \mathbf{C}\right)$ & $\mathbf{r}^{\mathbf{2}}$ \\
\hline Slab top surface & $\mu_{\text {top }}=-0.395$ & $\sigma_{\text {top }}=2.376$ & 0.957 \\
\hline 5 in below surface & $\mu_{\text {mid }}=-0.665$ & $\sigma_{\text {mid }}=1.352$ & 0.983 \\
\hline Slab bottom surface & $\mu_{\text {bot }}=-0.885$ & $\sigma_{\text {bot }}=1.268$ & 0.982 \\
\hline
\end{tabular}

The $\mathrm{r}^{2}$ value was calculated using the following equations.

$$
\begin{aligned}
& S S E=\sum_{i=1}^{n}\left[T_{i}^{\text {meas }}-T_{i}^{\text {calc }}\right]^{2} \\
& S S T=\sum_{i=1}^{n}\left[\left(T_{i}^{\text {meas }}-\operatorname{mean}\left(T^{\text {meas }}\right)\right]^{2}\right. \\
& r^{2}=1-S S E / S S T
\end{aligned}
$$

where $\mathrm{n}=$ total number of data points

$$
\begin{aligned}
& \mathrm{T}_{\mathrm{i}}^{\text {meas }}=\text { measured values of temperature, } \mathrm{F} \\
& \mathrm{T}_{\mathrm{i}}^{\text {calc }}=\text { calculated values of temperature, } \mathrm{F}
\end{aligned}
$$

Figure 22 plots the Probability Distribution Functions of the error in temperatures at the slab surface, at a depth of 5 in from top surface and at the slab bottom. The probability distribution function is given by the expression:

$$
f(x)=\frac{1}{\sigma \sqrt{2 \pi}} e^{-(x-\mu)^{2} /\left(2 \sigma^{2}\right)}
$$

where $\mathrm{f}(\mathrm{x})=$ probability distribution function 
$\mathrm{x}=$ error, measured - calculated temperatures at a time point

$\mu=$ mean of the entire error set

$\sigma=$ standard deviation of the error set

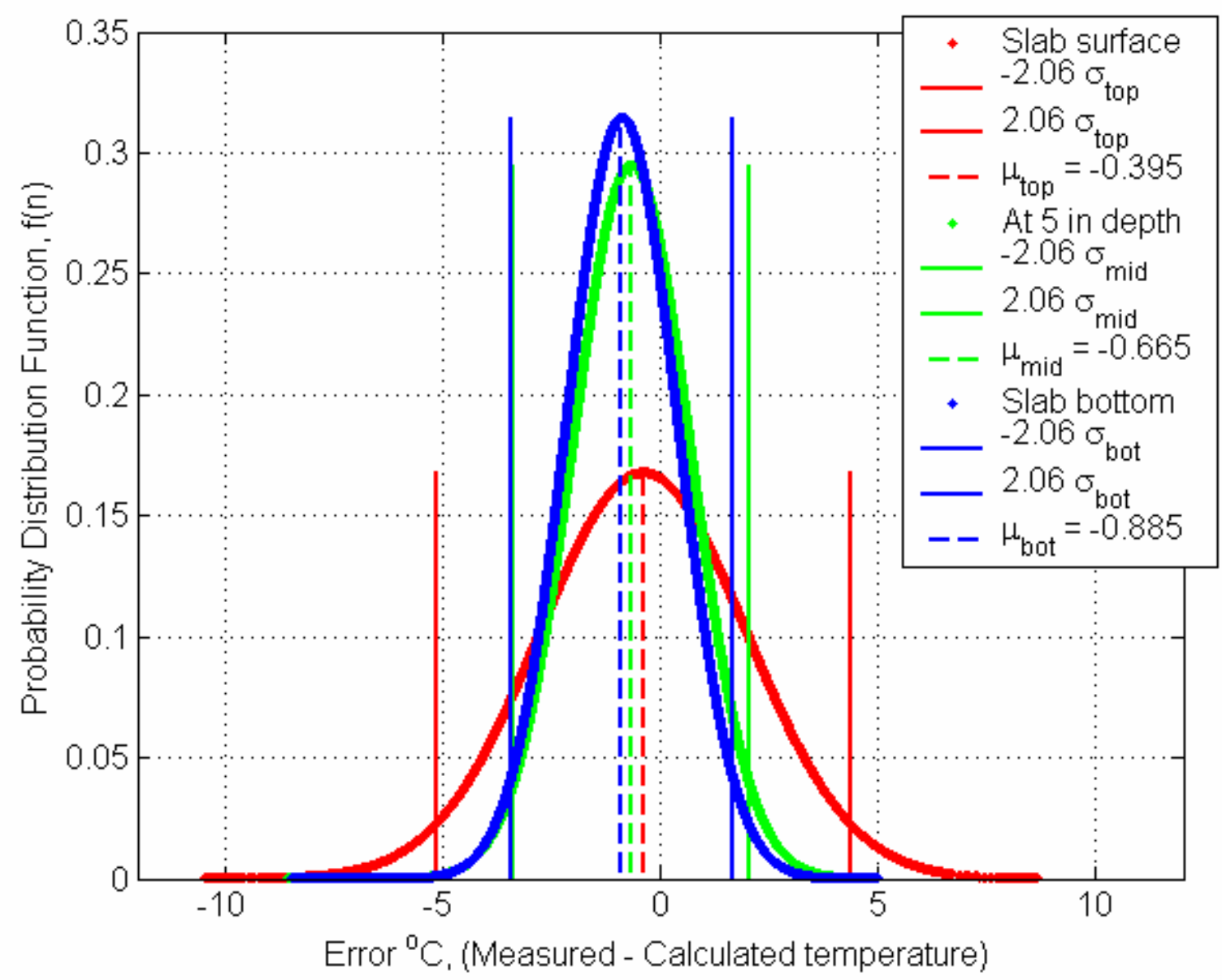

Figure 6.22: Probability distribution function (PDF) of error

The solid vertical lines in Figure 6.22 correspond to error ranges which allow the prediction of temperatures with a 95\% confidence level. The narrowness of the PDF plots shows that the variation of the calculated temperatures with the measured values is lesser at the bottom than at the slab top. This is also confirmed by the standard deviation and $\mathrm{r}^{2}$ values listed in Table 6.2. By observation it was noticed that the largest variations in calculated temperature values at the slab surface were during heavy rains of approx. $+/-5$ ${ }^{\circ} \mathrm{C}$ and due to presence of snow up to a value of $+/-10{ }^{\circ} \mathrm{C}$. 


\subsubsection{Calculation of strains}

The strains in the slab are related to the temperature values and moisture content in the pavement. The total strains can be given by the algebraic summation of the thermal strains and the moisture strains (Jeong and Zollinger 2005). In their paper, Jeong et al (2005) calculate the total strains given by the following equation.

$$
\varepsilon_{\text {tot }}=\varepsilon_{T}+\varepsilon_{M}=\alpha_{T} \Delta T_{e q}+\varepsilon_{x} \Delta R H_{e q}
$$

where $\varepsilon$ tot $=$ total strains; $\quad \varepsilon_{\mathrm{T}}=$ thermal strains $; \quad \varepsilon_{\mathrm{M}}=$ moisture strains

$\alpha_{\mathrm{T}}=$ coefficient of thermal expansion

$\Delta \mathrm{T}_{\mathrm{eq}}=$ Equivalent linear thermal gradient

$\varepsilon_{\mathrm{x}}=$ ultimate shrinkage strain (compressive strain)

$\Delta \mathrm{RH}_{\mathrm{eq}}=$ equivalent linear moisture gradient

The calculated pavement temperature values from the equations discussed in the previous sections can be used to determine the overall strains in the slab. The experimental set up does not facilitate the measurement of moisture through the slab thickness hence the total strains were calculated as the summation of the thermal strains and a residual strain. This residual strain has the effects of strains due to concrete shrinkage, creep and daily changes in moisture content. Additional instrumentation to measure the moisture changes in the concrete could be used to isolate the strains due to moisture and include its effects in the equation for total strains. Since continuous data was not available from the weather station, the temperature values from the thermistors attached to the strain gages were used to formulate equation 6.24 which calculates the total longitudinal strains measured by the strain gages at the mid section of the concrete pavements.

$$
\varepsilon_{\text {cal }}{ }^{d}=\alpha_{\text {eff }} T_{d}+\varepsilon_{\text {eff }}
$$

where $\varepsilon_{\text {cal }}^{\mathrm{d}}=$ total strain at depth $\mathrm{d}$

$\alpha_{\mathrm{eff}}=\alpha_{\mathrm{exp}}+0.2 * \sin (0.0172 t)$

where $\alpha_{\exp }=$ experimental coefficient of thermal expansion

$T_{d}=$ temperature of concrete at depth $d$

eeff $=\varepsilon_{r}+\varepsilon_{v}^{*} \cos (0.0172 t)$ 


$$
\begin{aligned}
& \text { where } \varepsilon_{\mathrm{r}}=\text { residual strain found experimentally } \\
& \qquad \begin{aligned}
\varepsilon_{\mathrm{V}} & =\text { amplitude variation in residual strains } \\
\mathrm{t} & =\text { time }
\end{aligned}
\end{aligned}
$$

$\alpha_{\text {exp }}$ is obtained from the measured strain and temperature values from the strain gages at the top and bottom in the mid section of the slabs. The term $0.2 \sin (0.0172 \mathrm{t})$ was included in the Equation 6.25 since the value of strains/ ${ }^{\circ} \mathrm{C}$ varies in phase with time and temperature over one year with an amplitude value of $+/-0.2$. The $\alpha_{\exp }$ values were higher during summer months and lower during the winter months. Similarly, the residual strains varied about the mean value $\varepsilon_{\mathrm{r}}$ with a magnitude of $\varepsilon_{\mathrm{v}} \mu$ strains but out of phase with time and temperature over one year i.e. the values were lower during summer months and higher during the winter months.

The average values of $\alpha_{\text {exp }}, \varepsilon_{\mathrm{r}}$ and $\varepsilon_{\mathrm{v}}$ are tabulated for four slabs with different end constraints at the slab top and bottom in Table 3a and 3b.

Table 6.3: Factors $\alpha_{\exp }, \varepsilon_{\mathrm{r}}$ and $\varepsilon_{\mathrm{v}}$ for different slabs

(a) Slab top

\begin{tabular}{|c|c|c|c|}
\hline Location & $\alpha_{\exp }\left(\mu\right.$ strains $\left./{ }^{\circ} \mathrm{C}\right)$ & $\varepsilon_{\mathbf{r}}(\mu$ strains $)$ & $\varepsilon_{\mathbf{v}}(\mu$ strains $)$ \\
\hline Slab with Dowel bars & 8.5 & -310 & 5 \\
\hline Slab with Shokbars & 8.6 & -300 & 5 \\
\hline Free slab on smooth subgrade & 8.8 & -260 & 10 \\
\hline Free slab on coarse subgrade & 8.7 & -240 & 10 \\
\hline
\end{tabular}

(b) Slab bottom

\begin{tabular}{|c|c|c|c|}
\hline Location & $\alpha_{\exp }\left(\mu\right.$ strains $\left./{ }^{\circ} \mathrm{C}\right)$ & $\varepsilon_{\mathbf{r}}(\mu$ strains $)$ & $\varepsilon_{\mathbf{v}}(\mu$ strains $)$ \\
\hline Slab with Dowel bars & 8.5 & -250 & 5 \\
\hline Slab with Shokbars & 8.6 & -240 & 5 \\
\hline Free slab on smooth subgrade & 8.8 & -235 & 5 \\
\hline Free slab on coarse subgrade & 8.7 & -255 & 5 \\
\hline
\end{tabular}


The values of $\alpha_{\text {exp }}$ reflect the freedom of the slabs for expansion and compression. As mentioned in Chapter 4: Experimental Data Analysis and from the values in Table 6.3 and as expected the free slabs experience higher fluctuations in thermal strains than the jointed slabs. From the values of $\varepsilon_{\mathrm{r}}$, it is seen that the slab jointed with dowel bars has the highest residual strain values followed by the slab with Shokbars and then the free slabs. This reiterates the strain relieving advantages of the Shokbars over the dowel bars discussed in Chapter 4. The compressive residual strains are higher at the slab top than at the slab bottom because the slab top is more sensitive to environmental changes. The values listed in Table 6.3 are specific to the current experimental test setup of concrete mixtures and end constraints on slabs. Further experiments on different test setups need to be done to get a more generalized form of the strain equations.

Examples of the calculated longitudinal strains at the top and bottom at mid slab plotted along with the measured strain values are given in Figure 6.23 a to d. Assuming that the error from the calculations of slab temperatures are zero, the temperatures measured by the thermistors attached to the strain gages were used for the calculations of strain values are plotted in the following figures. 


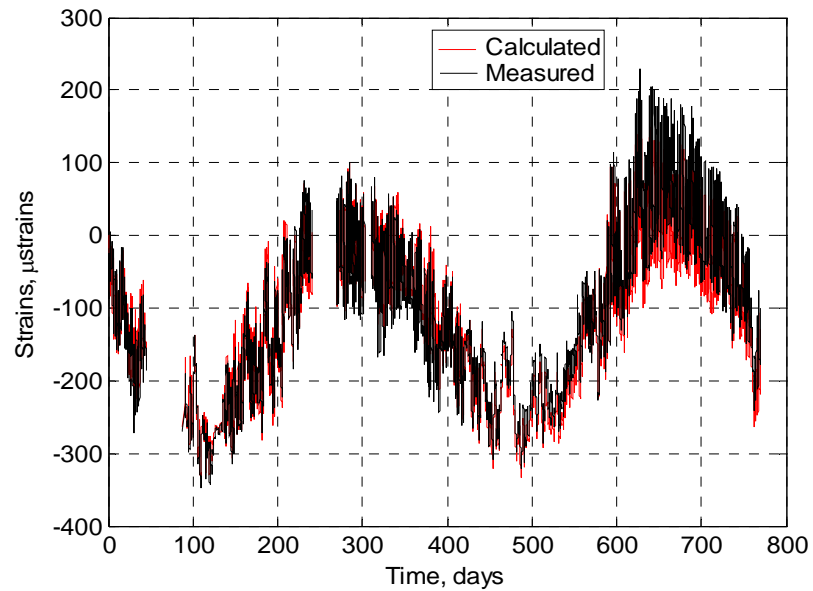

(a) Free slab on low friction base (Slab top)

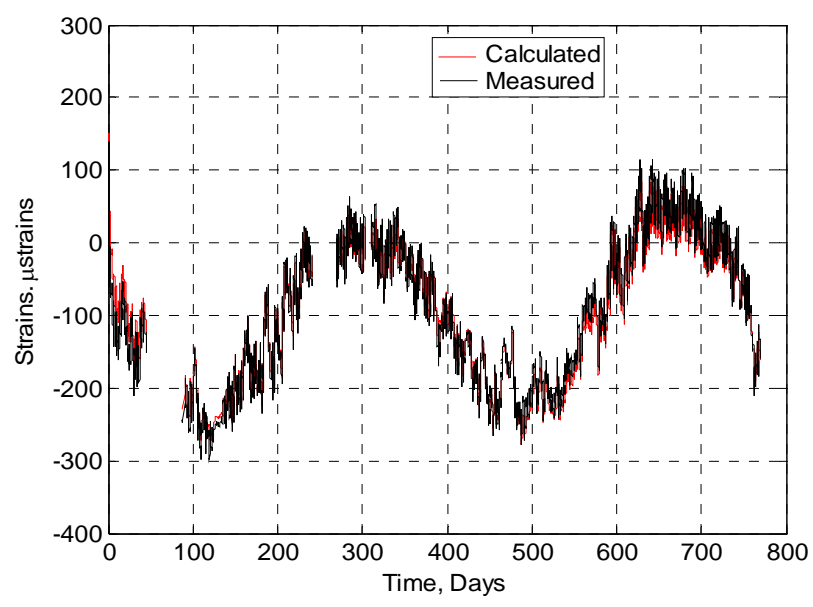

(b) Free slab on low friction base (Bottom)

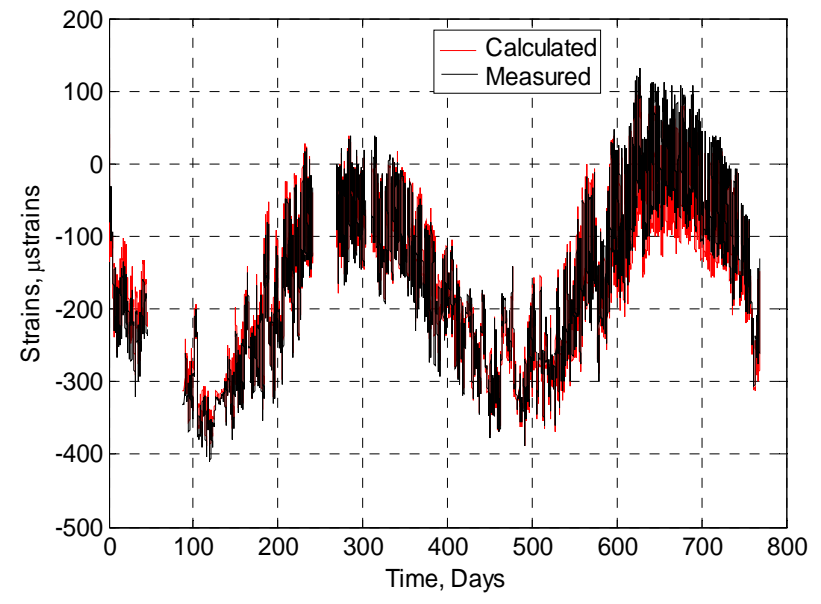

(c) Slab jointed with regular dowels (Top)

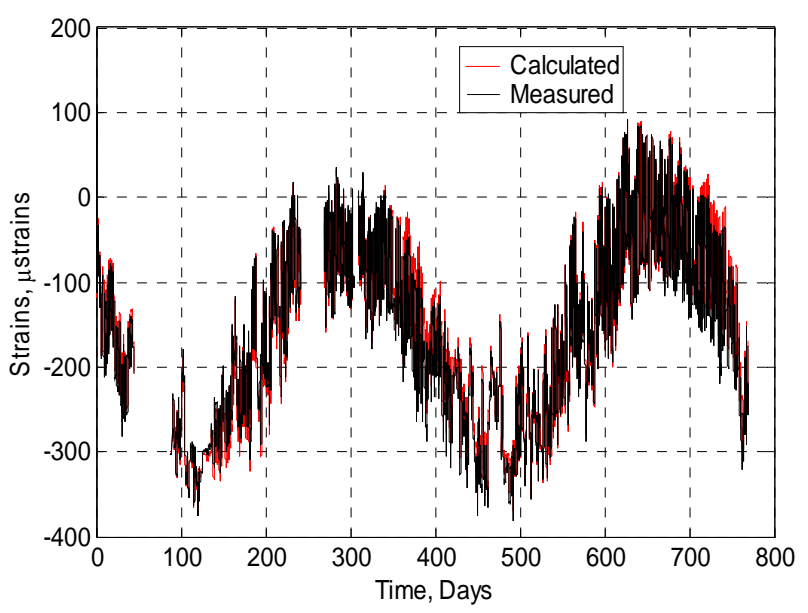

(d) Slab jointed with Shokbars (Top)

Figure 6.23: Examples of calculated and measured longitudinal strains

The plots for the other locations in the various slabs are given in Appendix A. As seen in the plots in Figure 6.23 the deviation in calculated strains is during the summer of the second year i.e. around the 650 day mark. It was noticed that the year 2005 experienced higher temperatures during summer than the previous year. The increase in temperature induces tensile strains which reduces the overall compressive strains. It was noticed that the compressive strains reduced by almost $30 \mu$ strains. The highest error occurs during this period as the effect of increase in temperature was not incorporated into the equations. 


\subsubsection{Error analysis}

Statistical analysis of the error between the calculated and measured values of the strains was done and the results tabulated in Table 6.4.

Table 6.4: Statistical analysis of error between calculated and measured strains

\begin{tabular}{|c|c|c|c|c|c|c|}
\hline \multirow[t]{2}{*}{ Location } & \multicolumn{2}{|c|}{ Mean, $\mu$ ( $\mu$ strains) } & \multicolumn{2}{|c|}{$\begin{array}{c}\text { Standard deviation. } \\
\sigma(\mu \text { strains) }\end{array}$} & \multicolumn{2}{|c|}{$\mathbf{r}^{2}$} \\
\hline & Top & Bottom & Top & Bottom & Top & Bottom \\
\hline Dowel jointed slab & 5.88 & -9.86 & 19.37 & 16.59 & 0.966 & 0.964 \\
\hline Shokbar jointed slab & -2.66 & -1.86 & 21.71 & 12.46 & 0.954 & 0.983 \\
\hline $\begin{array}{l}\text { Free slab on low } \\
\text { friction subgrade }\end{array}$ & 10.17 & 2.55 & 21.65 & 14.53 & 0.951 & 0.976 \\
\hline $\begin{array}{l}\text { Free slab on high } \\
\text { friction subgrade }\end{array}$ & 13.39 & 3.00 & 19.41 & 13.33 & 0.951 & 0.978 \\
\hline
\end{tabular}

The comparisons discussed here include data collected over two years with slab temperatures ranging from $-15{ }^{\circ} \mathrm{C}$ in winter up to $50{ }^{\circ} \mathrm{C}$ during summer and the slab strains ranging from low compressive strains of $400 \mu$ strains to high tensile strains of around $200 \mu$ strains.

As indicated by the standard deviations and $r^{2}$ values, the error is higher at the slab top than at the bottom as it is exposed to larger fluctuations in environmental conditions. As mentioned earlier the equation was arrived at by considering the temperatures from the thermistors attached to the strain gages and not the slab temperatures calculated from the weather data. This was unavoidable because continuous data was not available from the weather station. Hence if the calculated temperatures are used for the strain calculations then the inaccuracies from the temperature prediction will add on to the error of strain calculation. The maximum deviation in calculated temperatures is $4{ }^{\circ} \mathrm{C}$ which translates to an error of around 35 microstrains $\left(4 \times 8.8 \mu\right.$ strains $\left./{ }^{\circ} \mathrm{C}\right)$ in the strain calculation. 


\section{CHAPTER SEVEN \\ CONCLUSIONS AND RECOMMENDATIONS}

\subsection{CONCLUSIONS}

\subsubsection{Thermal analysis}

The major portion of the study focuses on examining the state of stress developed in concrete slabs due to shrinkage; under subsequent environmental conditions; under the effect of different constraints. Four individual full-scale concrete slabs were tested: 1) Free slab on a smooth base; 2) Free slab constructed on a rough base coarse; 3) dowel jointed concrete slab; and 4) Slab fitted with shokbars. The study also aims at establishing experimental data base for validation of the results obtained from the $3 \mathrm{D}$ finite element models. The study included the development of a methodology to validate the thermo-elastic response of the 3DFE model of concrete pavements to temperature variations. Based on the theoretical and experimental results presented in this study, the following conclusions could be withdrawn:

1. The presence of dowel bars at transverse joints results in a high magnitude of permanent strain at the early age. The magnitude of this strain is 4.6 times of that developed in a similar slab constructed without dowel bars.

2. Replacing the traditional dowel bars with shokbars reduces the magnitude of the permanent strain developed at the early age by 30 percent.

3. The constraint due to the rough surface of the base coarse layer resulted in 8 percent increase in the permanent strain developed in the slab when compared with that developed in the slab on the smooth base surface.

4. Within the temperature range experienced by the slabs constructed in this project, linear strain-temperature relationships were observed for slabs with different constraints. However, the slope of such a linear relationship depends on the degree of edge constraint as well as the location of the measuring point within the slab; meaning the relationship for point on the slab edge differs from that at the slab center. 
5. The longitudinal stresses developed in the slab fitted with shokbars were found to be closer to those developed in the free slab base than the stresses developed in the slab fitted with traditional dowel bars.

6. Slab fitted with Shokbars had more freedom to curl at the early age, developing higher bending moments in the dowels, and relieving curling stresses in the concrete slabs than the slab fitted with dowels.

7. Shokbar design reduced the axial forces recorded in the dowel bars by approximately 80 percent.

8. Shokbar design offered a more uniform distribution of the axial forces and bending moments along the joint.

9. The joints fitted with dowel bars showed approximately 85 percent difference in their average openings, meanwhile 20 percent difference was observed between joints fitted with Shok bars.

10. Bending of the dowel bars or Shok bars at transverse joints due to slab curling is the main cause of restraint to slab contraction or expansions due to temperature variations.

11. Comparison between the 3DFE-computed and the measured changes in strains indicate acceptable agreement. Comparing measured and 3DFE-calculated bending moments in dowel bars or shokbars provides a good means to validate the model response to slab curling.

\subsubsection{Slab temperature and strain prediction}

The thermal diffusivity theory was used to formulate an equation which can calculate the slab surface temperatures for a 24 hour period and for sequence of days. A one dimensional heat equation was employed to calculate the temperatures interior to the slab. An equation to calculate the total longitudinal strains in the pavements was proposed and the effective coefficient of thermal expansion and residual strains for slab with different end constraints were identified. Based on the study of the effect of environmental conditions on pavements and the comparison between calculated and measured parameters of the pavement the following conclusions were made: 
1. The fluctuations in the temperature and strains were higher in the slab surface compared to inside the slab as it was the most exposed to the environmental conditions and hence the most sensitive.

2. The snow cover on the slabs insulate the slab from the changes the air temperature.

3. The error between the calculated and measured temperature values were within the acceptable limits of $+/-4{ }^{\circ} \mathrm{C}$ at the top surface and $+/-2{ }^{\circ} \mathrm{C}$ at the slab bottom during most days of the year which includes days with light rain and cloud cover. For sunny days the error was within $+/-2{ }^{\circ} \mathrm{C}$ at the top surface and $+/-1{ }^{\circ} \mathrm{C}$ at the slab bottom.

4. The increased error values during heavy rains were up to $5{ }^{\circ} \mathrm{C}$ and snow cover was up to $10{ }^{\circ} \mathrm{C}$.

5. The changes in thermal properties of the concrete such as thermal conductivity, thermal diffusivity due to high moisture content were not considered in the present study. The differences in values contribute to the error in temperature and strain values during heavy rains.

6. The higher value of the effective coefficient of thermal expansion in the slabs fitted with Shok bars show that they allow for more freedom in expansion and contraction than the dowel bars.

\subsection{RECOMMENDATIONS FOR FUTURE WORK}

1. The value of coefficient of friction between the slab and the subgrade (smooth and coarse subgrade) is debatable. Simple techniques should be developed to experimentally measure the actual coefficient of friction between the slab and subgrade.

2. With the availability of larger sets of weather and strain data from concrete slabs from the present site and any other site the temperature and strain prediction equations can be further generalized. The value of 'p' for each month of the year used in the calculation of the multiplier $\mathrm{T}_{\mathrm{fac}}$ can be generalized to suit a larger set of locations.

3. The application of Neural Networks to predict the parameters can be explored with the larger sets of data. Variables such as concrete composition, latitude of the location, thickness of concrete slab can be included in future research work. 
4. The equation used to predict slab temperatures needs to be modified to include the effects of sudden heavy rainfall which cool the slab rapidly and also the presence of snow on concrete. The changes in thermal properties of the concrete have to be considered during the times of heavy rains. The steps provided in the Appendix can be used to calculate thermal conductivity and thermal diffusivity of concrete with changes in moisture content in the slab.

5. The temperature and strains calculation equations can be extended to bridge decks where continuous monitoring of strains and is more important. 


\section{REFERENCES}

1. Balbo, J.T and Severi, A., Thermal gradients in concrete pavements in tropical environment: Experimental appraisal, Transportation Research Record, n 1809, 2002, 02-2560, p 12-22

2. Barber, E.S. Calculation of maximum pavement temperatures from weather reports. Bulletin 168, HRB, National Research Council, Washington, D.C, 1957, pp 1-8.

3. Beegle, D.J., and Sargand S.M (1995). Three-Dimensional Finite Element Modeling of Rigid Pavement. Final Report No. ST/SS/95-002, Ohio Department of Transportation, Federal Highway Administration, Columbus, Ohio.

4. Bradbury, R.D (1938). Reinforced Concrete Pavements. Wire Reinforcement Institute, Washington, D.C.

5. Boley, B.A, and Jerome H. Weiner, Theory of Thermal Stresses, Dover Publications Inc, New York.

6. Channakeshava, C and F.Barzegar, and G.Z. Voyiajis (1993). Nonlinear FE Analysis of Plain Concrete Pavemnts with Doweled Joints. Journal of Transportation Engineering, ASCE, Vol. 119, No.5, pp. 763-781.

7. Choubane Bouzid, and Mang Tia (1995), Analysis and Verification of ThermalGradient Effects on Concrete Pavement. Journal of Transportation Engineering, Vol. 121, No. 1, pp. 75-81.

8. Dempsey, B.J. A heat transfer model for evaluating frost action and temperature related effects in multilayered pavement systems, Highway Research Record 342, HRB, National Research Council, Washington, D. C, 1970, pp. 39-56

9. Dickinson, E.J., A method for calculating the temperature gradients in asphaltic concrete pavement structures based on climatic data, Australian Road Research, Vol. 8, No. 4, Dec 1978, pp. 16-34

10. Friberg, B.F (1938), Load and Deflection Characteristics of Dowels in Transverse Joints of Concrete Pavements. Proceedings of Highways Research Board No.18, National Research Council, Washington, D.C, pp. 140-154. 
11. Harik, I.E, P. Jianping, H. Southgate, and D. Allen (1994), Temperature Effects on Rigid Pavements. Journal of Transportation Engineering,Vol.120,p127-143.

12. Hermansson, A. Mathematical model for calculation of pavement temperatures: Comparison of calculated and measured temperatures, Transportation Research Record 1764, TRB, National Research Council, Washington D.C. 2001, p180-188

13. Huang, Y.H. (1993). “Pavement Analysis and Design”, Prentice Hall, Englewood.

14. Jeong, J. H and Zollinger, D. G., Environmental effects on the behavior of jointed plain concrete pavements, Journal of Transportation Engineering, v 131, n 2, February, 2005, p 140-148

15. Larsen, G and Dempsey, B.J, Enhanced integrated climatic model Version 2.0, Minnesota Department of Transportation, October 1997.

16. Lytton, R.L, Pufahl, D.E, Michalak, C.H, Liang, H.S and Dempsey, B.J, An integrated model of the climatic effects on pavements, FHWA-RD-90-033, Federal Highway Administration, November 1993.

17. Mahboub Kamyar C., Yinhui Liu, and David L. Allen (2004), Evaluation of Temperature Responses in Concrete Pavement. Journal of Transportation Engineering, Vol. 130, No. 3, pp. 395-401.

18. Masad, E, R. Taha and B. Muhunthan (1996). Finite Element Analysis of Temperature Effects on Plain-Jointed Concrete Pavements. Journal of transportation Engineering, ASCE, Vol. 122, No.5, pp.338-398.

19. McCullough, B.F and Rasmussen, R.O, Fast Track Paving: Concrete temperature control and traffic opening criteria for bonded concrete overlays: Final Report, FHWA-RD-98-167, Federal Highway Administration, October 1999

20. Ramsamooj, D.V (1999), Stresses in Jointed Rigid Pavements, Journal of Transportation Engineering, Vol. 125 No 2, pp. 101-107.

21. Rumney, T. N and Jimenez, R.A., Pavement temperatures in the southwest, Highway Research Record 361, HRB, National Research Council, Washington D.C. 1971, pp. 1-13

22. Shoukry, S.N, G.W. William and M. Riad (2001). Finite Element Modeling of Rigid Pavements, CD Proceedings of the Second International Symposium on 
Maintenance and Rehabilitation of Pavements and Technological Control, Auburn, Alabama, Paper Number 01-120.

23. Shoukry S.N., G.W. William, and M. Riad (2002). Characteristics of Concrete Stresses in Doweled Transverse Joints. International Journal of Pavement Engineering. Vol. 3 (2), pp. 117-129.

24. Shoukry S.N, G.W. William, S. Srinivasan (2002), Analysis of Mid-slab Transverse Cracking in Jointed Concrete Pavements. International Journal of Pavements, Vol.1 No.3, pp. 81-94.

25. Shoukry, S.N, and G.W William, and M. Riad. (2003), Nonlinear Temperature Gradient Effects in Dowel Jointed Concrete Slabs. International Journal of Pavement Engineering. Vol. 4 (3), pp. 131-142.

26. Shoukry, S.N, G.W William and M Riad (2003), Performance Evaluation of Shok Bar, West Virginia Department of Transportation, Division of Highway.

27. Shoukry, S.N, G.W William and M Riad (2004), Field testing of Shok Bar, RP\# 170, West Virginia Department of Transportation, Division of Highway.

28. Shoukry S.N, G.W William, M. Riad, D. Rao-Hejamadi (2005), Effect of Temperature Shrinkage and Moisture on Slab Stresses, RP 172, West Virginia Department of Transportation, Division of Highways.

29. Solaimanian ,M. and Kennedy, T.W., Predicting maximum pavement surface temperature using maximum air temperature and hourly solar radiation., Transportation Research Record 1417, TRB, National Research Council, Washington D.C., 1993, pp 1-11

30. US Army, Artic and Sub artic Construction- Calculations methods for determination of depths of freeze and thaw in soils, US Army TM5-852-6, Jan 1988, http://www.wbdg.org/ccb/DOD/UFC/ufc_3_130_06.pdf , (last visited Dec 2005).

31. Westergaard H.M (1926). Stresses in Concrete pavements computed by Theoretical Analysis. Public Roads, Vol.7, No 2, pp-25-35

32. Westergaard H.M (1927). Analysis of stresses in concrete due to variations of Temperature, Proceedings of the $6^{\text {th }}$ Annual. Meeting Highway Research Board, National Research Council, Vol. 6, pp 201-215. 
33. Westergaard H.M (1929). Spacing of Dowels. Proceedings of Highway Research Board No.8, National Research Council, Washington, D.C, pp. 154-158.

34. William Gergis. W and Samir Shoukry (2001). 3D Finite Element Analysis of Temperature-Induced Stresses in Dowel jointed Concrete Pavements. International Journal of Geomechanics, Volume 1, No. 3, pp. 291-307. 


\section{APPENDIX}

(Issued 1 June 1963)

CRD-C 44-63

METHOD FOR CALCULATION OF THERMAL CONDUCTIVITY OF CONCRETE

Scope

1. This method is suitable for calculating the thermal conductivity of concrete from results of tests for diffusivity and specific heat.

Calculation

2. (a) The thermal conductivity of concrete shall be calculated from the following equation:

$$
k=\alpha s W
$$

where:

$\mathrm{k}=$ thermal conductivity, Btu/ft-hrdeg $F$, $\alpha=$ thermal diffusivity, $\mathrm{ft}^{2} / \mathrm{hr}$, $s=$ specific heat, Btulb-deg $F$, $\mathrm{W}=$ actual unit weight, $1 \mathrm{~b} / \mathrm{ft}^{\prime}$.

The thermal diffusivity of concrete shall be determined using either Method CRD-C 36 or CRD-C 37. The specific heat of the concrete shall be determined according to the procedure of Method CRD-C 124. The unit weight of concrete shall be determined using the procedures of Method CRD-C 7.

(b) The themal conductivity of lightweight concrete and similar materials at various moisture contents shall be calculated from the following equation:"

IProcedure based on paper: "Torts for Thermal Diffusivity of Gramala Matarials" by William L. Shannon and Wintarop A. Wolls, poblisked in Proceedings of the and Winthrop A. Wolls, poblisied in Proceedings of the
American Sociaty for Tosties Matorials, Vol 47, 1947.

$$
\mathrm{k}=\alpha \mathrm{C}
$$

where:

$\mathbf{k}=$ thermal conductivity, Btu/ft-hr-

$$
\operatorname{deg} F \text {, }
$$

$\alpha=$ thermal diffusivity, $\mathrm{ft} / \mathrm{hr}$

$C=$ volumetric heat capacity, Btu/fe$\operatorname{deg} F$.

The thermal diffusivity shall be determined using method of test for themal diffusivity of lightweight concrete and similar materials. A curve shall be made of diffusivity versus moisture content for the range used. The volumetric heat capacity shall be calculated from the following equation:

$$
C=\gamma\left(c_{1} \div \frac{w}{100}\right)
$$

where:

$C=$ volumetric heat capacity, Btu/fe. $\operatorname{deg} \mathrm{F}$,

$\gamma=$ dry unit weight, $\mathrm{lb} / \mathrm{ft}^{3}$, $c_{1}=$ specific heat of dry sample,

$w=$ moisture content, percent dry weight.

The specific heat of material removed from diffusivity specimen shall be determined according to the procedure of Method CRD-C 242.

\section{Report}

3. The calculated value for thermal conductivity shall be reported to two decimal places, e.g., $k=1.35$ Btu/ft-hr-deg F. 